\author{
UNIVERSIDADE DE SÃO PAULO \\ ESCOLA DE ENGENHARIA DE SÃO CARLOS \\ DEPARTAMENTO DE ENGENHARIA DE ESTRUTURAS
}

RODRIGO MAZIA ENAMI

Reforço de pilares curtos de concreto armado por encamisamento com concreto de ultra-alto desempenho 

RODRIGO MAZIA ENAMI

\title{
Reforço de pilares curtos de concreto armado por encamisamento com concreto de ultra-alto desempenho
}

\author{
VERSÃO CORRIGIDA
}

A versão original encontra-se na Escola de Engenharia de São Carlos

Tese apresentada à Escola de Engenharia de São Carlos, da Universidade de São Paulo, como parte dos requisitos para obtenção do título de Doutor em Engenharia Civil.

Área de concentração: Engenharia de Estruturas.

Orientador: Prof. Dr. Ricardo Carrazedo 
AUTORIZO A REPRODUÇÃO TOTAL OU PARCIAL DESTE TRABALHO, POR QUALQUER MEIO ÇONVENCIONAL OU ELETRÔNICO, PARA FINS DE ESTUDO E PESQUISA, DESDE QUE CITADA A FONTE.

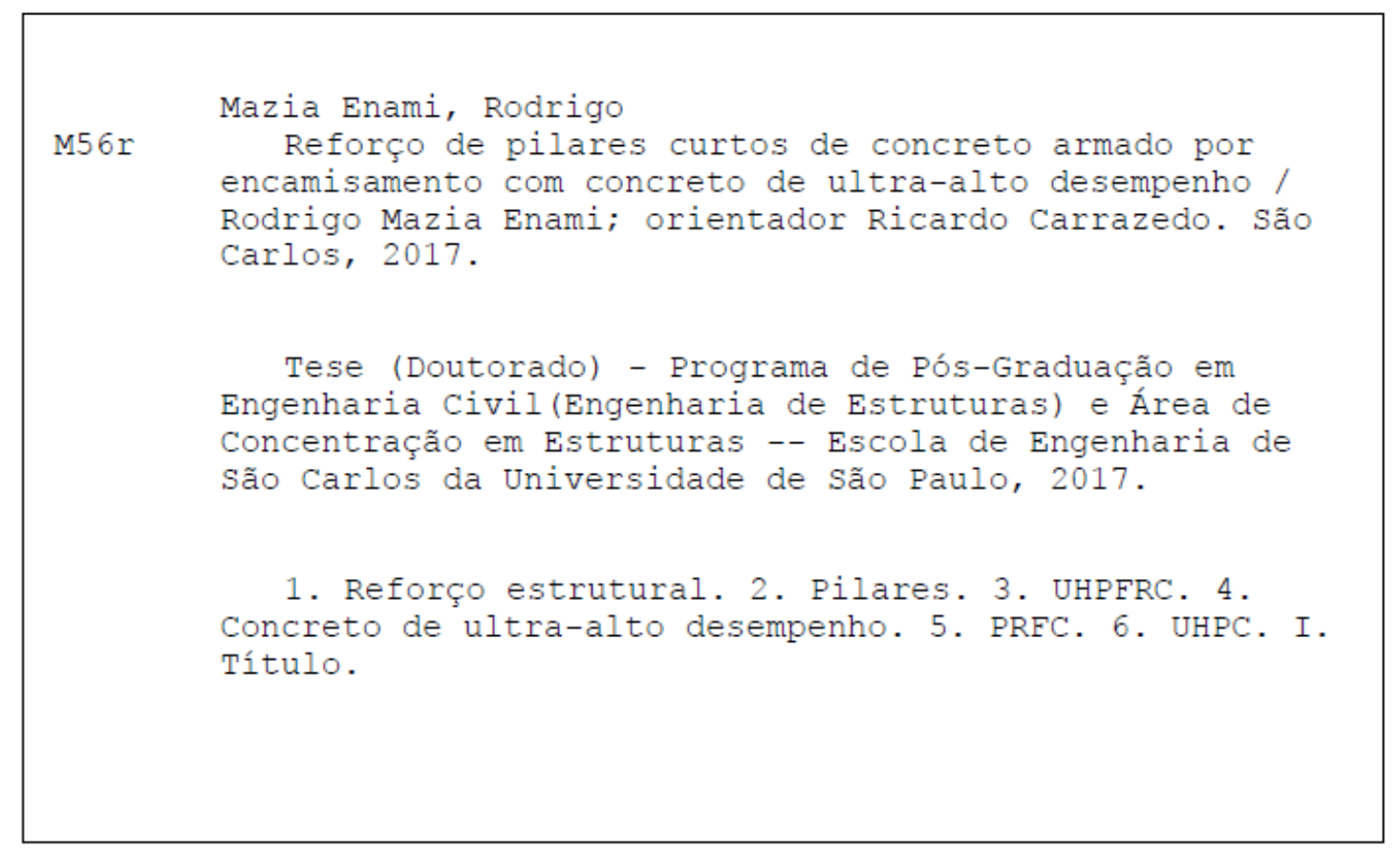




\section{FOLHA DE JULGAMENTO}

Candidato: Engenheiro RODRIGO MAZIA ENAMI.

Título da tese: "Reforço de pilares curtos de concreto armado por encamisamento com concreto de ultra-alto desempenho".

Data da defesa: 16/10/2017.

Comissão Julgadora:

Resultado:

Prof. Dr. Ricardo Carrazedo

APROVADO

(Orientador)

(Escola de Engenharia de São Carlos/EESC)

Prof. Dr. José Samuel Giongo

(Escola de Engenharia de São Carlos/EESC)

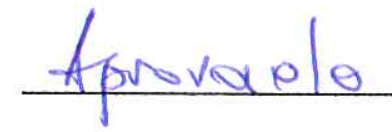

Prof. Dr. Romel Dias Vanderlei

APROVADO

(Universidade Estadual de Maringá/UEM)

Prof. Dr. Armando Lopes Moreno Junior

APROVADO

(Universidade Estadual de Campinas/UNICAMP)

Profa. Dra. Gláucia Maria Dalfré

(Universidade Federal de São Carlos/UFSCar)

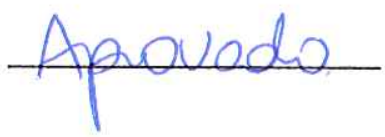

Coordenador do Programa de Pós-Graduação em Engenheira Civil (Engenharia de Estruturas):

Prof. Titular Humberło Breves Coda

Presidente da Comissão de Pós-Graduação:

Prof. Associado Luís Fernando Cosła Alberio 

Dedico este trabalho à minha esposa e eterna companheira Elicimara Beltran Martins Enami. 



\section{AGRADECIMENTOS}

Primeiramente a Deus, doador da vida, criador e mantenedor do universo.

À minha esposa, Elicimara e às minhas filhas Elise e Lauren por me acompanharem e apoiarem em todos os momentos da minha vida.

Aos meus pais Wanderlei e Cida e aos meus irmãos, Marcelo e Lorena pelo apoio durante a realização da pesquisa.

Aos meus primos, tios e avós, em especial ao meu primo Fábio Cesar pelo apoio.

Aos funcionários e docentes da Universidade Estadual de Maringá, em especial ao Prof. Tamanini, ao Sr. Edson e ao Sr. Adenilson.

Aos professores Samuel, Romel, Gláucia e Armando pela participação na banca e por ajudarem com seus conhecimentos.

Ao meu orientador, Professor Ricardo Carrazedo por me guiar em cada etapa desse trabalho com paciência e sabedoria.

À toda equipe do Departamento de Estruturas (SET-USP) em especial do Laboratório de Estruturas de Concreto pela atenção e colaboração durante estes anos de trabalho.

A todos os amigos que fiz durante o período de doutorado, tanto em São Carlos, como em Umuarama e Maringá. O apoio de vocês foi imprescindível.

Ao Conselho Nacional de Desenvolvimento Científico e Tecnológico (CNPq), pelo apoio financeiro. 



\section{RESUMO}

\section{ENAMI, R. M. Reforço de pilares curtos de concreto armado por}

encamisamento com concreto de ultra-alto desempenho. 2017. 136 p. Tese (Doutorado) - Escola de Engenharia de São Carlos, Universidade de São Paulo, São Carlos, 2017.

O presente trabalho avaliou a influência dos concretos de ultra-alto desempenho com fibras (UHPFRC) e sem fibras (UHPC) no reforço de pilares curtos de concreto armado de seção transversal circular e quadrada. Avaliou-se também a adição de armaduras adicionais de reforço e de polímeros reforçados com fibras de carbono (PRFC) em alguns pilares reforçados. Para a avaliação deste novo sistema de reforço optou-se pela realização de um programa experimental e simulações numéricas. É importante ressaltar que no programa experimental, nenhum pilar reforçado possuía seção transversal maior que a seção do pilar de referência. Foi verificado por meio do programa experimental, que as camisas de UHPC apresentaram ruína de natureza frágil e não se recomenda a sua utilização a menos que acompanhada de mecanismos que garantam adequado confinamento do pilar reforçado. Nos pilares circulares e quadrados reforçados com UHPFRC foram verificados, respectivamente, incrementos de resistência de $106,4 \%$ e $83,6 \%$ onde o concreto do cobrimento foi substituído por UHPFRC, 154,3\% e 111,7\% onde além da substituição do cobrimento foram inseridas armaduras adicionais e $160 \%$ e $85,6 \%$ onde houve a colocação de PRFC após a substituição do cobrimento. Todos os pilares reforçados com UHPFRC não apresentaram destacamento da camisa de reforço. Foram realizadas simulações numéricas variando a espessura da camisa de UHPFRC e do número de camadas de PRFC tanto nos pilares de seção circular como nos pilares de seção quadrada. Por meio destas simulações, notou-se que a adição de pequenos incrementos de espessura da camisa de UHPFRC, proporciona elevados incrementos de resistência ao pilar reforçado, ao passo que o aumento do número de camadas de PRFC não influenciaria significantemente no incremento de resistência e sim na ductilidade do conjunto.

Palavras-chave: Reforço de pilares. Concreto de ultra-alto desempenho. PRFC. UHPFRC. UHPC. 



\begin{abstract}
ENAMI, R. M. Strengthening of short columns with jacketing for ultra-high performance concrete. 2017. 136 p. Thesis (Ph.D. in Civil Engineering (Structures)) - São Carlos School of Engineering, University of São Paulo, São Carlos, 2017.

The present work evaluated the influence of ultra-high performance concrete with fibers (UHPFRC) and without fibers (UHPC) on the strengthening of short columns of reinforced concrete of circular and square cross section. It was also evaluated the addition of additional reinforcement and carbon fiber reinforced polymers (PRFC) on some strengthened columns. For the evaluation of this new system of strengthening we opted for the realization of an experimental program and numerical simulations. It is important to note that in the experimental program, no strengthened columns had a larger cross section than the reference column section. It was verified through the experimental program that the UHPC shirts presented ruin of a fragile nature and their use is not recommended unless accompanied by mechanisms that guarantee adequate confinement to the strengthened columns. In the circular and square columns strengthened with UHPFRC, respectively, resistance increments of $106.4 \%$ and $83.6 \%$ were verified, where the cover concrete was replaced by UHPFRC, $154.3 \%$ and $111.7 \%$, in addition to the substitution of additional reinforcement were inserted and $160 \%$ and $85.6 \%$ where PRFC placement was performed after the replacement of the cover. All strengthened columns with UHPFRC did not present detachment of the strengthening jacket. Numerical simulations were performed by varying the thickness of the UHPFRC jacket and the number of PRFC layers on both the circular section columns and the square section columns. Through these simulations, it was noted that the addition of small thickness increments of the UHPFRC jacket would provide high increments of strength to the strengthened columns, while increasing the number of PRFC layers would not significantly influence the increase in strength but rather ductility of the assembly.
\end{abstract}

Palavras-chave: Strengthening of columns. Ultra-high Performance Concrete. CFRP. UHPFRC. UHPC. 



\section{SUMÁRIO}

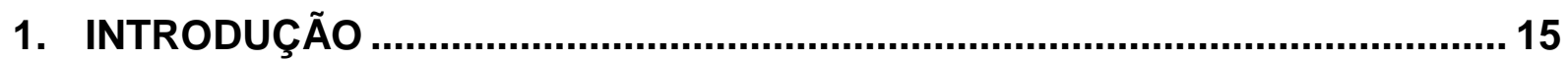

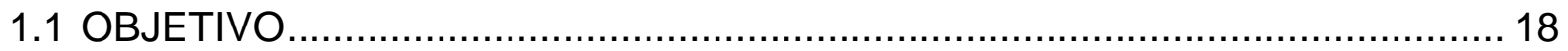

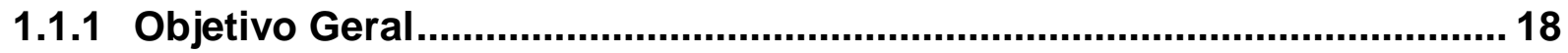

1.1.2 Objetivos Específicos .................................................................... 18

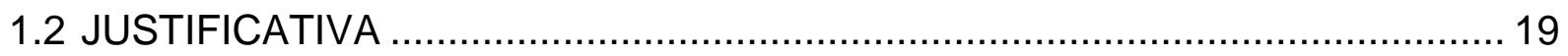

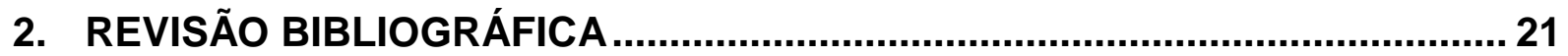

2.1 CONCRETO DE ULTRA-ALTO DESEMPENHO …....................................... 21

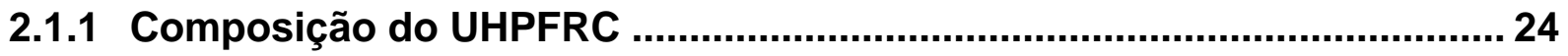

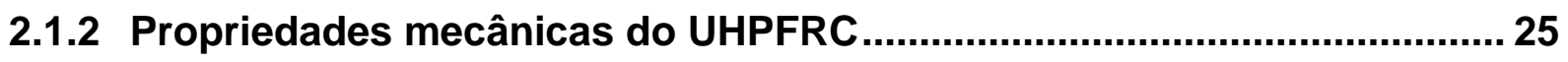

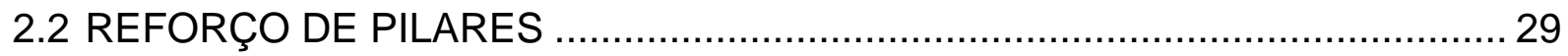

2.2.1 Principais técnicas de reforço de pilares................................................. 29

2.2.2 Pesquisas sobre novas técnicas de reforço de pilares ............................ 33

2.2.3 Polímeros reforçados com fibras (PRF).................................................. 37

3. MÉTODO

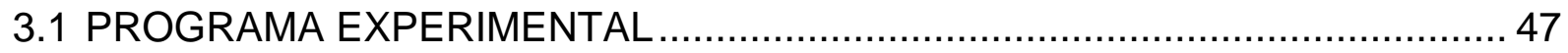

3.1.1 propriedades dos Materiais............................................................... 47

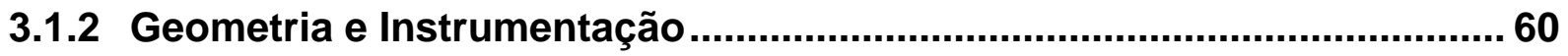

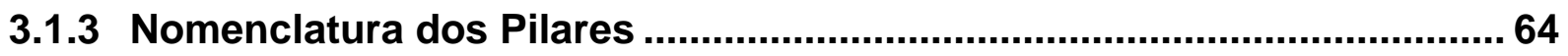

3.1.4 Descrição do processo de fabricação dos pilares ....................................... 65

3.1.5 Descrição dos ensaios dos pilares..........................................................68

3.1.6 ELABORAÇÃO dos diagramas força-deslocamento ...............................69

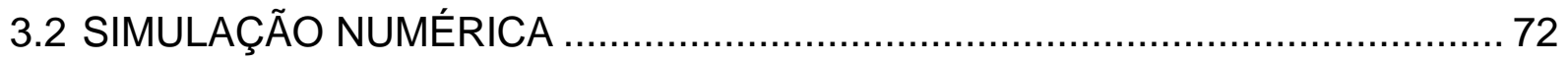

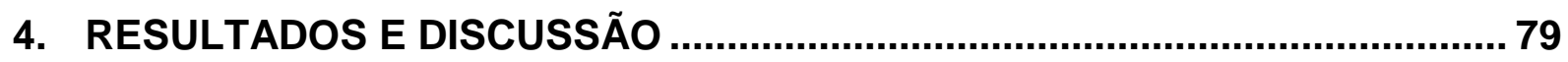

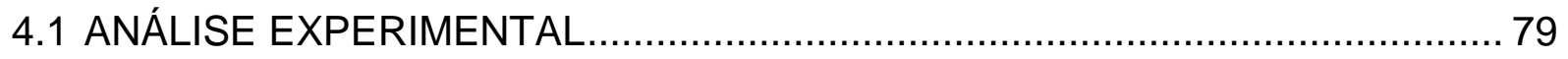

4.1.1 Comportamento dos pilares circulares ................................................... 79

4.1.2 Comportamento dos pilares quadrados ................................................ 86

4.2 SIMULAÇÕES NUMÉRICAS COM O PROGRAMA ABAQUS......................... 91

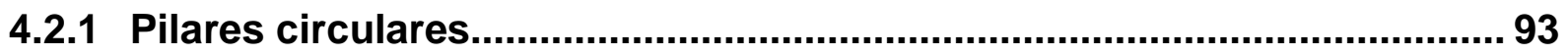

4.2.2 Comportamento dos pilares quadrados ........................................... 109 


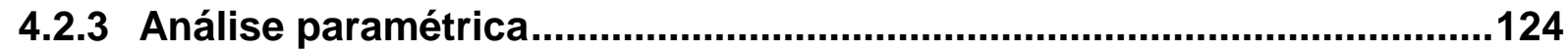

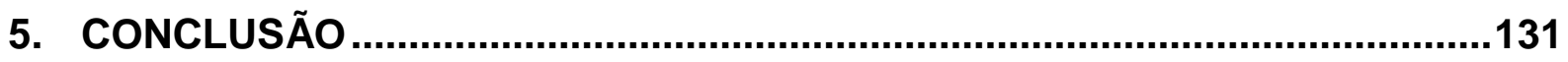

REFERÊNCIAS BIBLIOGRÁFICAS ..............................................................133 


\section{INTRODUÇÃO}

Durante a vida útil das edificações, problemas patológicos podem ocorrer pelos mais variados motivos, dentre os quais se destacam a falta de manutenção, erros de projeto, mudança da finalidade dos espaços projetados e fenômenos naturais não previstos.

Estas manifestações patológicas reduzem a vida útil da edificação quando não reparadas oportunamente e em alguns casos comprometem significativamente a capacidade resistente das estruturas.

A fim de restaurar a capacidade resistente, ou, ampliá-la, processos de reparo e reforço de fundações, vigas, lajes e pilares são constantemente estudados para melhorar o comportamento das estruturas.

No caso de pilares, algumas opções de reforço são utilizadas com maior frequência, como o aumento da seção transversal com concreto armado, a utilização de chapas de aço e em casos mais específicos, a utilização de fibras de carbono para o encamisamento dos pilares.

Os reforços citados são bem conhecidos, bem como o comportamento dos mesmos na maioria das situações de carregamento. No entanto, novas tecnologias de reforço devem ser estudadas, para atenderem de forma cada vez mais satisfatória a gama de problemas encontrados nas edificações.

Muitas vezes a utilização de alguns desses tipos de reforços são inviabilizados pela característica do problema. Por exemplo, o reforço com aumento de seção é inapropriado para locais onde não é possível a redução do espaço interno, o reforço com fibras de carbono não é recomendado para locais onde não se pode ter elevada deformação do elemento reforçado e o reforço com chapas de aço demanda mão-deobra especializada e cuidados para que não haja a corrosão do aço.

No uso de Polímeros Reforçado com Fibras (PRF), Ribeiro (2010) afirma que a deformação máxima que um pilar pode alcançar segundo as normas vigentes para garantir a segurança local e global da estrutura é de 0,2\%, colocando em dúvida o uso de PRF para reforço de pilares, já que a deformação correspondente à força última neste tipo de reforço pode superar dez vezes este valor.

O código normativo ACl 440.2R (2008) coloca um limite para deformação em pilares reforçados com PRF de 1\%, considerando que acima deste valor não há 
garantia da integridade do concreto. Porém o código não aborda o fato das deformações excessivas causarem problemas na estrutura como um todo, fazendo com que haja certa ressalva em considerar deformações elevadas para esse tipo de sistema de reforço.

Por esse motivo, o uso de PRF, principalmente em pilares, pode não ser a melhor alternativa em casos onde não são admitidas grandes deformações, e o uso de concretos de resistência normal não é interessante em casos onde não se deseja um aumento significativo da seção transversal.

Assim, algumas pesquisas sobre o uso de concretos de elevada resistência para o reforço de pilares vêm sendo desenvolvidas para suprir certas carências dos sistemas de reforço atualmente utilizados.

Com o surgimento de concretos especiais (que possuem excelentes propriedades mecânicas), existe elevado potencial para proporcionar às estruturas reforçadas características que superem em muito a capacidade resistente da estrutura original sem, no entanto, necessitar de grandes deformações e grande aumento na espessura do sistema de reforço.

Para entender o reforço de estruturas com aplicação de concretos especiais e PRF muitas pesquisas foram realizadas no Departamento de Estruturas da Escola de Engenharia de São Carlos e em outras localidades do mundo.

Estas pesquisas nortearam o presente trabalho visto que houve importantes constatações em relação ao uso de concretos de alto desempenho e polímeros reforçados com fibras para o reforço de pilares. As constatações mais relevantes são mencionadas a seguir.

Por meio das pesquisas realizadas por Takeuti $(1999,2003)$, foi possível constatar que o reforço de pilares de concreto armado por encamisamento com Concreto de Alto Desempenho (CAD) obtém significativo acréscimo de resistência com pequeno aumento de espessura, como também, ao se aplicar adequado nível de confinamento no reforço é possível contar com a contribuição do pilar original.

Sudano $(2010)$ corrobora com a afirmação de Takeuti $(1999,2003)$ quando observa que no caso de aumento da seção transversal do pilar com CAD sem confinamento, a contribuição do pilar original deve ser desprezada. Porém, notou que houve a mobilização de efeitos de confinamento com o uso de fibras metálicas no concreto da camisa de reforço ( $1 \%$ em volume). 
$\mathrm{Na}$ busca pelo estudo de alternativas de reforço de pilares sem aumento da seção transversal foi desenvolvido um programa experimental por Sudano (2005) para avaliar o uso de PRF. Foi constatado, então, que a forma da seção transversal tem uma influência significativa sobre os efeitos de confinamento.

Na mesma linha de pesquisa, Carrazedo $(2002,2005)$ avaliou os efeitos de confinamento obtidos em pilares de concreto encamisados com Polímeros Reforçados com Fibras de Carbono (PRFC). Baseando-se nos estudos, observou importantes ganhos de resistência e ductilidade dos elementos reforçados de seções circulares, quadradas e retangulares sob compressão centrada e com pequenas excentricidades.

Um material semelhante ao concreto de ultra-alto desempenho utilizado na presente pesquisa foi estudado para possível utilização em reforço de pilares. Este concreto, de nome "Slurry Infiltrated Fiber Concrete" ou SIFCON (concreto cujas fibras são orientadas anteriormente à injeção do concreto) foi estudado por Abdollahi et al. (2012) em um programa experimental para encamisar modelos com formato de corpos-de-prova de concreto convencional, onde se constatou significativos ganhos de resistência devido à resistência elevada do revestimento, como também pelo aparecimento de pressões laterais (confinamento).

A técnica de encamisamento com SIFCON mostrou-se potencialmente eficiente para o uso em reforço de pilares, porém, notou-se que esta técnica não é de fácil execução para casos em escala real.

Já o UHPFRC, além de apresentar resistência à tração semelhante ao SIFCON, e resistência à compressão superior, apresenta também propriedades extremamente interessantes para um material de reforço, como os citados no trabalho de Tayeh et al. (2013), onde concluíram que o mesmo apresenta baixa permeabilidade, resistência muito elevada, excelentes propriedades mecânicas, resistência a ambientes severos, alta durabilidade e forte aderência com o concreto convencional.

Por meio dos estudos ora citados e com a evolução dos concretos de alto desempenho, houve o interesse de desenvolver esta pesquisa para analisar o uso do concreto de ultra-alto desempenho, bem como a utilização de PRFC e armaduras adicionais em conjunto com este concreto a fim de criar novas técnicas de reforço de pilares. 
A técnica proposta é muito interessante por não aumentar a seção transversal do pilar reforçado, garantir um aspecto semelhante ao do pilar original e aumentar significativamente a resistência.

\subsection{OBJETIVO}

\subsubsection{OBJETIVO GERAL}

Avaliar o comportamento de pilares curtos de concreto armado de seções circulares e quadradas, reforçados com concreto de ultra-alto desempenho, armaduras adicionais e PRFC's, submetidos à compressão centrada.

\subsubsection{OBJETIVOS ESPECÍFICOS}

Os objetivos específicos deste trabalho são:

a) Desenvolver um UHPC/UHPFRC fluido o suficiente para a concretagem.

b) Avaliar a interação do concreto original com o UHPC e com o UHPFRC;

c) Verificar a possibilidade de ruína prematura do reforço com UHPC e com o UHPFRC devido ao destacamento do reforço;

d) Avaliar o ganho de resistência provocado pela adição de mantas de PRFC nos pilares reforçados com UHPC e com o UHPFRC;

e) Avaliar se a adição da manta de PRFC contribui significativamente para o aumento de ductilidade da peça e da solidez do conjunto;

f) Avaliar os níveis de deformação axial do conjunto;

g) Verificar se a resistência do pilar original pode ser considerada integralmente nos vários tipos de reforço;

h) Avaliar o mecanismo de ruína da camisa de reforço por meio de simulações numéricas.

i) Avaliar a influência do aumento da espessura da camisa de UHPFRC para a resistência do pilar reforçado através de simulações numéricas.

j) Avaliar a influência do aumento do número de camadas de PRFC para a resistência do pilar reforçado através de simulações numéricas. 


\subsection{JUSTIFICATIVA}

O reforço estrutural é necessário quando se deseja aumentar a capacidade resistente da estrutura em face a fatores que a levaram à perda de parte de sua resistência ou que geraram solicitações de maior intensidade do que foi projetada inicialmente.

Para garantir este acréscimo de resistência aos elementos reforçados, diversas técnicas foram desenvolvidas ao longo da história. Para o reforço de pilares, as técnicas mais utilizadas são o aumento da seção transversal com concreto armado e a fixação de perfis metálicos.

Porém, estas técnicas têm suas limitações. Por isso, novas técnicas foram surgindo para preencher certas lacunas. Deste modo, por exemplo, foram desenvolvidas técnicas de reforço com Polímeros Reforçados com Fibras (PRF), cujo aumento na seção do elemento reforçado é praticamente nulo, são de fácil aplicação e proporcionam rapidez na entrada em serviço da estrutura reforçada.

O reforço de pilar com PRF, apesar de aumentar a resistência, é acompanhado de elevada deformação. Elevadas deformações axiais limitam a utilização deste tipo de reforço em muitos casos em face do risco de ruína de elementos estruturais adjacentes.

A fim de tentar amenizar o problema das deformações acentuadas geradas pelo reforço com PRF, sem aumentar a seção do pilar, novas alternativas de reforço são propostas.

Essas novas alternativas consistem na substituição do cobrimento do pilar por uma camada de concreto de ultra-alto desempenho, reforçada ou não por armaduras adicionais e por PRF.

A utilização de concretos de ultra-alto desempenho pode contribuir para a durabilidade da estrutura reforçada uma vez que este material pode ser enquadrado na classificação de altíssima durabilidade. Ele também apresenta excelentes propriedades mecânicas, principalmente com a adição de fibras metálicas, o que pode contribuir significativamente para o acréscimo de resistência do pilar reforçado.

Pretende-se, portanto, desenvolver um reforço de pilar que não altere as características do pilar original, não apresente deformações excessivas, gere um incremento acentuado de resistência e seja de fácil execução. 
Caso estas características sejam alcançadas com o uso do concreto de ultraalto desempenho, esta pode vir a ser a técnica mais interessante para reforço de pilares.

Neste âmbito, esta pesquisa pretende dar continuidade aos trabalhos realizados no Departamento de Estruturas (SET) da Escola de Engenharia de São Carlos da Universidade de São Paulo, em que novas técnicas de reforço de estruturas têm sido desenvolvidas. 


\section{REVISÃO BIBLIOGRÁFICA}

Inicialmente são apresentadas a origem, a composição, as propriedades e a utilização do concreto de ultra-alto desempenho.

Posteriormente são apresentados os tipos mais comuns de reforço de pilares, além de novos estudos que utilizaram concretos especiais e polímeros reforçados com fibras. Por meio desta apresentação são mostrados novos desafios a serem alcançados no âmbito de reforço de pilares.

\subsection{CONCRETO DE ULTRA-ALTO DESEMPENHO}

Durante as últimas quatro décadas, pesquisadores de todo o mundo têm tentado desenvolver concretos de alto desempenho (SHI et al., 2015). Em 1990, Metha e Aitcin sugeriram este termo para concretos que possuíam alta trabalhabilidade, alta resistência e alta durabilidade (METHA e MONTEIRO, 2008).

Apesar do termo alto desempenho remeter a produtos que possuem maior durabilidade (no caso do concreto, isso pode ser relacionado com a pequena permeabilidade). Em 1998, o ACl Technical Activities Committee aprovou uma definição para o concreto de alto desempenho em que não necessariamente incluía a durabilidade, mas sim, certas características para aplicações em ambientes específicos como, por exemplo, facilidade de aplicação, adensamento sem segregação, resistência nas primeiras idades e a longo-prazo, propriedades mecânicas, permeabilidade, densidade, calor de hidratação, tenacidade, estabilidade de volume e longa vida útil em ambientes agressivos (METHA e MONTEIRO, 2008).

Embora o $\mathrm{ACl}$ tenha este conceito de alto desempenho, há pesquisadores que relacionam o alto desempenho à trabalhabilidade, resistência e durabilidade.

Em 1993, Richard e Cheyrezy utilizaram componentes com maior finura e reatividade para desenvolver o Concreto de Pós Reativos (CPR). O CPR foi caracterizado pelo alto teor de aglutinantes, pequena relação água/cimento, uso de sílica ativa, pó de quartzo fino, superplastificantes e fibras. Frequentemente sua produção utiliza cura térmica. Este concreto apresentou propriedades mecânicas elevadas, como resistência à compressão superior a $150 \mathrm{MPa}$, alta ductilidade, alta 
tenacidade e excelente durabilidade, e mais tarde passou a ser denominado UHPC Ultra High Performance Concrete (SHI et al., 2015).

Atualmente, o UHPC que contém fibras é denominado UHPFRC - Ultra High Performance Fiber Reinforced Concrete.

O UHPFRC, portanto, é um material composto de elevada resistência, trabalhabilidade, ductilidade e durabilidade em comparação ao concreto convencional (BRÜHWILER e DENARIÉ, 2013; TAYEH et al., 2013).

Há um consenso que este concreto apresenta resistência à compressão superior a 150 MPa. Porém, Graybeal (2007) considerou como UHPFRC os concretos sem cura térmica, ensaiados aos 28 dias, com resistência média à compressão de 119 MPa. Hassan et al. (2012) consideraram como UHPC concretos que obtiveram a máxima tensão aos 28 dias de 121,32 MPa. Assim, percebe-se que a classificação como UHPC ou UHPFRC não depende somente da resistência à compressão, mas também de outros fatores que garantem propriedades superiores às dos concretos de alta resistência.

A propriedade do UHPFRC que vai de encontro com a sustentabilidade, é a durabilidade. De acordo com Wang et al. (2014), o UHPFRC se enquadra na classificação de altíssima durabilidade (very high durable) em virtude, principalmente, da pequena porosidade e tamanho dos poros, em que $74 \%$ dos vazios se encontram no interior do C-S-H (inferiores a $4 \mathrm{~nm}$ ).

Segundo Tayeh et al. (2012), o UHPFRC (chamado de UHPFC pelos autores) apresenta boa ligação com o concreto antigo em idades precoces do compósito, proporcionando a rápida entrada em serviço de estruturas reparadas com este concreto. A preparação adequada da superfície é recomendada para garantir uma boa ligação entre o substrato e o UHPFRC.

A Figura 2.1-a mostra o ensaio de cisalhamento para a verificação da união entre o concreto convencional e o UHPFRC realizado por Tayeh et al. (2012). Este ensaio foi realizado preparando-se a superfície de contato com jato de areia e verificou-se que a ruína não ocorreu na interface entre os dois concretos (Figura 2.1b), mostrando mais uma vantagem em se utilizar este material para o reforço de estruturas.

Tayeh et al. (2012) concluíram que o desempenho da ligação mecânica superior e a impermeabilidade podem ser traduzidos por um reparo de concreto 
eficiente e durável, o que pode resultar em redução do número de intervenções durante a vida útil da estrutura.

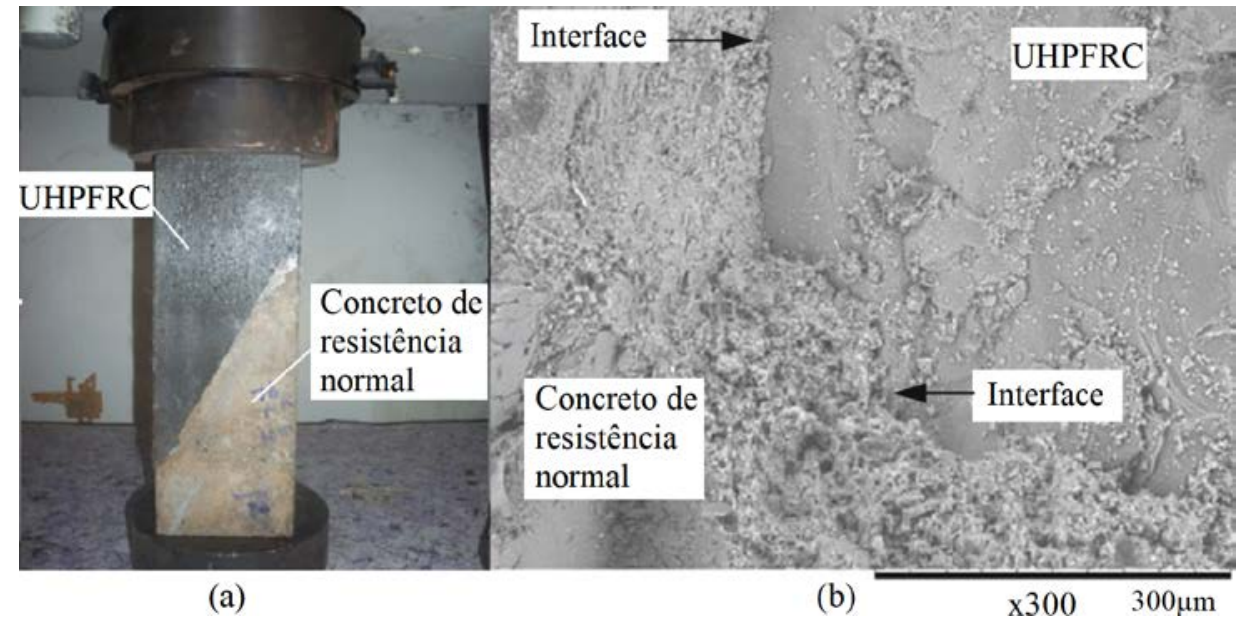

Figura 2.1 - (a) Ensaio para a verificação da ligação entre o concreto antigo e o UHPFRC e (b) zona de transição após o ensaio.

Fonte: Tayeh et al. (2012)

Comercialmente, o concreto de ultra-alto desempenho mais popular mundialmente é o Ductal ${ }^{\circledR}$, cuja utilização vem se expandindo, como pode ser observado nas obras apresentadas na Figura 2.2, e cujas propriedades mecânicas vêm sendo estudadas por diversos pesquisadores.

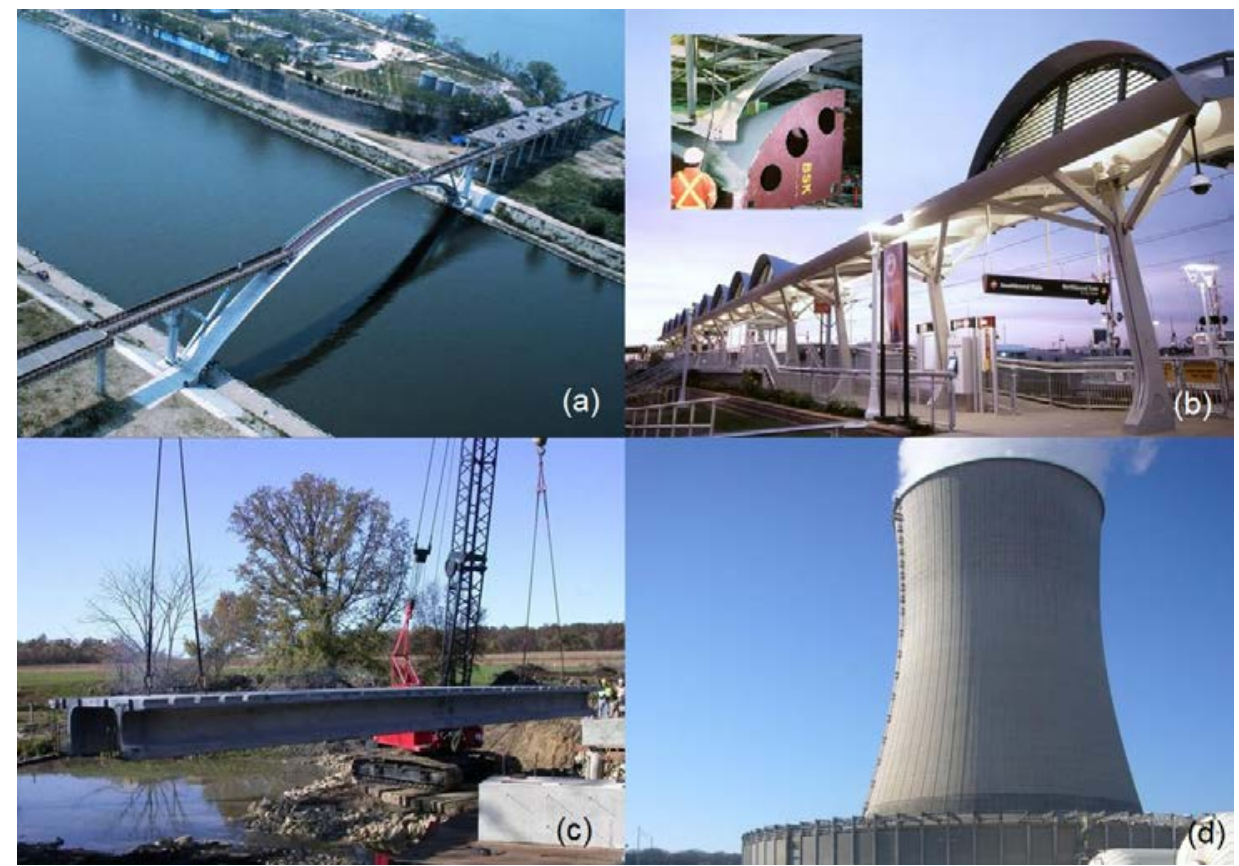

Figura 2.2 - Obras internacionais que utilizaram UHPFRC: (a) Passarela Seonyu, Seul, Coréia; (b) A Estação de Metro Shawnessy, Calgary, Canadá; (c) Ponte do Parque Jakway, Iowa USA; (d) Vigas e longarinas na estação de energia elétrica de Cattenom, lowa, EUA 
Outra forma de utilização do UHPFRC é para fins arquitetônicos. Pela sua elevada resistência à tração e à compressão e por ser um concreto fluido, seu emprego em formas variadas de pequenas espessuras é possível formando, assim, elementos muito interessantes, como mostra a Figura 2.3.

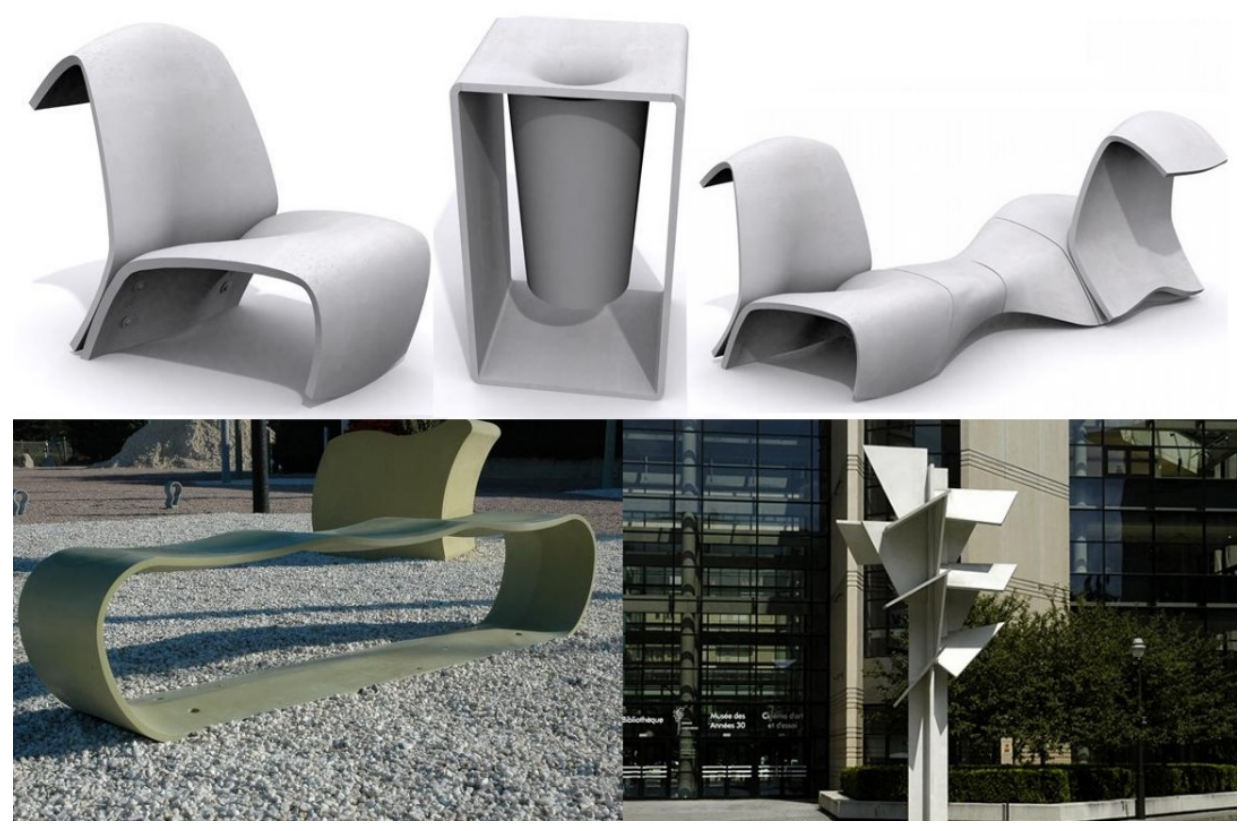

Figura 2.3 - Obras arquitetônicas feitas de UHPFRC (DUCTAL, 2014)

\subsubsection{COMPOSIÇÃO DO UHPFRC}

De acordo com Graybeal (2005) ${ }^{1}$ apud Tayeh et al. (2013), as propriedades do UHPFRC são obtidas principalmente pela melhor homogeneidade da mistura, comparada ao concreto normal, por causa da eliminação de todos os agregados graúdos. A areia fina com um tamanho que varia de $150 \mu \mathrm{m}$ a $600 \mu \mathrm{m}$, é dimensionalmente o maior material granular na mistura. A segunda maior partícula é o cimento, com um diâmetro médio de $15 \mu \mathrm{m}$. A sílica ativa é a menor partícula utilizada no UHPFRC, a qual possui aproximadamente um centésimo do tamanho de uma partícula de cimento. Outra partícula fina é o pó de quartzo, com diâmetro médio de $10 \mu \mathrm{m}$ (material não utilizado nesta pesquisa). As fibras de aço são dimensionalmente os maiores componentes da mistura.

${ }^{1}$ Graybeal, Benjamin A. Characterization of the behavior of ultra-high performance concrete. Tese de Doutorado, Universidade de Maryland, 2005. 
Uma dosagem típica de UHPFRC que contém areia fina, cimento Portland, sílica ativa, pó de quartzo, fibras metálicas, superplastificante e água é apresentada na Tabela 2.1.

Tabela 2.1 - Dosagem típica do UHPFRC

\begin{tabular}{cc}
\hline Componentes & $\begin{array}{c}\text { Mistura típica por peso } \\
\left(\mathbf{k g} / \mathbf{m}^{\mathbf{3}} \mathbf{)}\right.\end{array}$ \\
\hline Areia & $490-1390$ \\
Cimento & $610-1081$ \\
Sílica Ativa & $50-334$ \\
Pó de Quartzo & $0-410$ \\
Fibras & $40-250$ \\
Superplastificante & $9-71$ \\
Água & $126-261$ \\
\hline
\end{tabular}

Fonte: Voort (2008) ${ }^{2}$ apud Tayeh et al. (2013)

Uma composição típica de UHPFRC necessita de uma elevada energia de mistura, fazendo com que equipamentos não convencionais em nossos canteiros de obras sejam utilizados como, por exemplo, um misturador ciclópico. Por este motivo, Sobuz et al. (2016) desenvolveram um concreto de ultra-alto desempenho capaz de ser misturado em qualquer canteiro de obras sem a necessidade de equipamentos especiais. Os autores conseguiram fabricar um UHPC fluido com betoneira comum utilizando o traço 1:1:0,266:0,233 (cimento, areia, sílica ativa e fibras metálicas).

Como a proposta do presente trabalho é desenvolver um sistema de reforço aplicável sem maiores problemas em canteiros de obras convencionais, a proporção entre cimento, sílica ativa, areia e fibras metálicas proposta por Sobuz et al. (2016) é utilizada na pesquisa com sucesso.

\subsubsection{PROPRIEDADES MECÂNICAS DO UHPFRC}

Como citado anteriormente, o UHPFRC possui excelentes propriedades mecânicas.

${ }^{2}$ Voort, V. Design and field testing of tapered H-shaped Ultra High Performance Concrete piles. lowa State University, 2008. 
De acordo com Makita e Brühwiler (2014) a resistência do UHPFRC é acima de 180 MPa na compressão e de 10 MPa na tração. Guo e Wang (2011) afirmam que as resistências típicas à compressão do UHPFRC variam de $150 \mathrm{MPa}$ a $220 \mathrm{MPa}$ e à tração de $7 \mathrm{MPa}$ a $15 \mathrm{MPa}$, sem cura térmica. Brühwiler e Denarié (2013) apontam resistências à tração do UHPFRC entre 9 MPa e 15 MPa. Habel e Gauvreau (2008) consideram a resistência à compressão acima de $130 \mathrm{MPa}$ e à tração acima de 8 MPa. Em uma investigação experimental, Máca et al. (2013) apontaram valores acima de 150 MPa para compressão e 10 MPa para tração. Kang et al. (2010) por meio da análise de vários trabalhos, constataram também uma resistência à compressão superior a 150 MPa e à tração superior a 10 MPa.

Pode-se observar o comportamento deste material na tração e na compressão por meio de ensaios experimentais encontrados na literatura, tal como apresentado nas Figuras 2.4 e 2.5 .

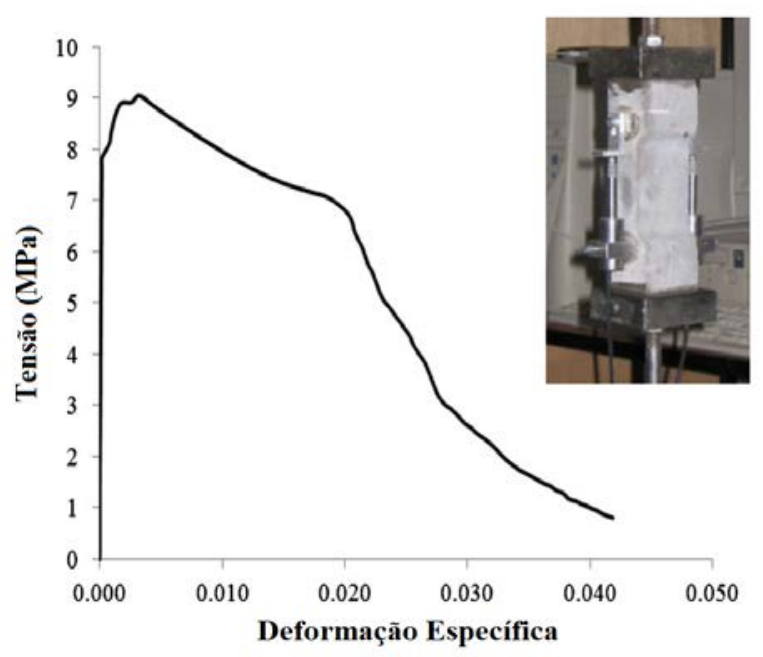

(a)

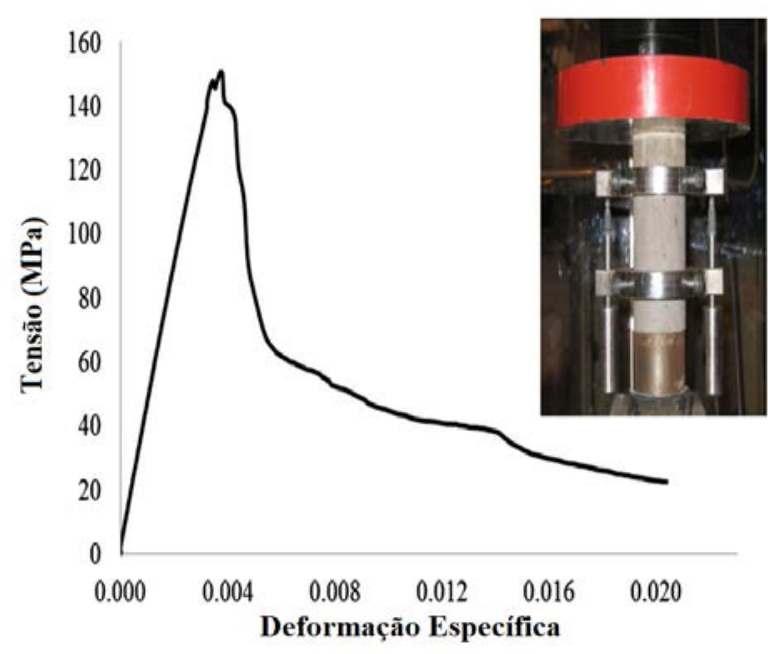

(b)

Figura 2.4 - Curvas tensão-deformação na tração (a) e compressão (b) do UHPFRC provenientes dos ensaios de Mahmud et al. (2013). 


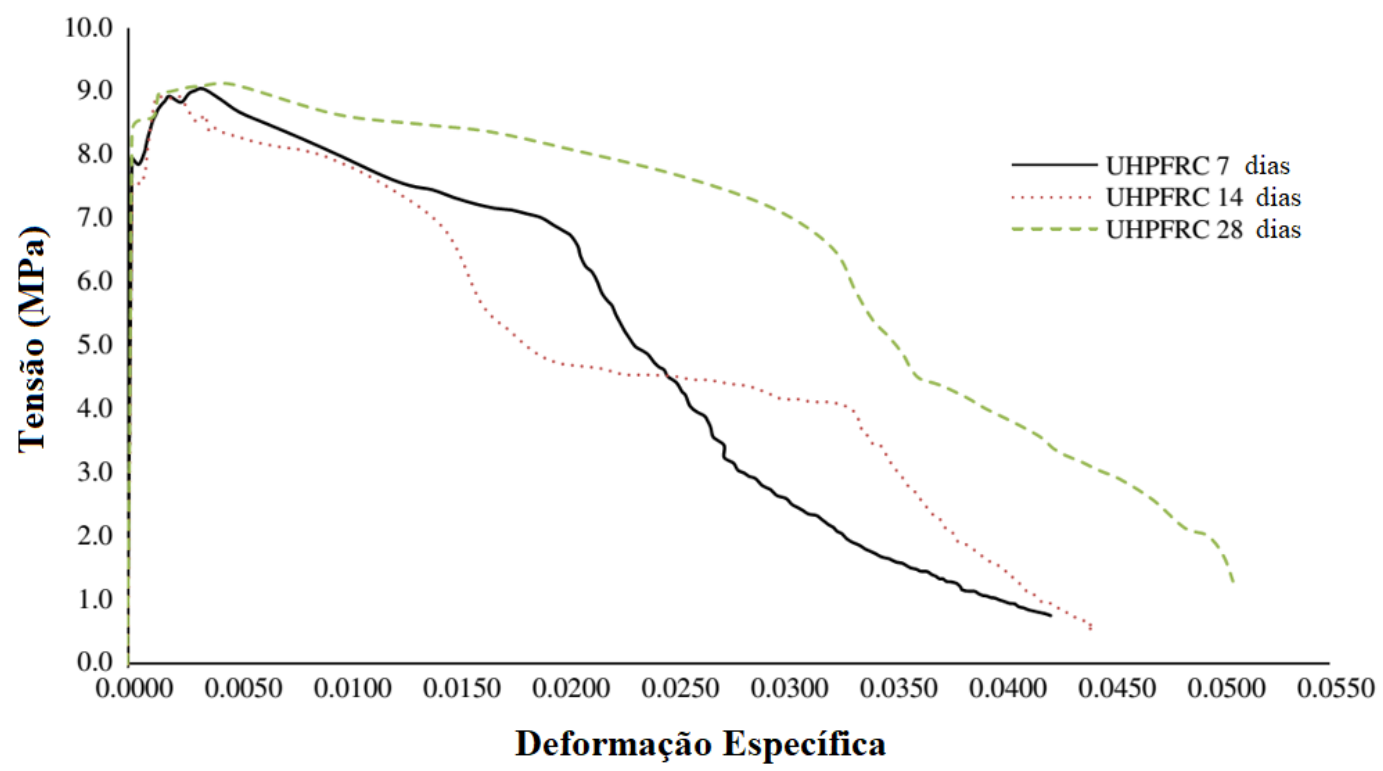

(a)

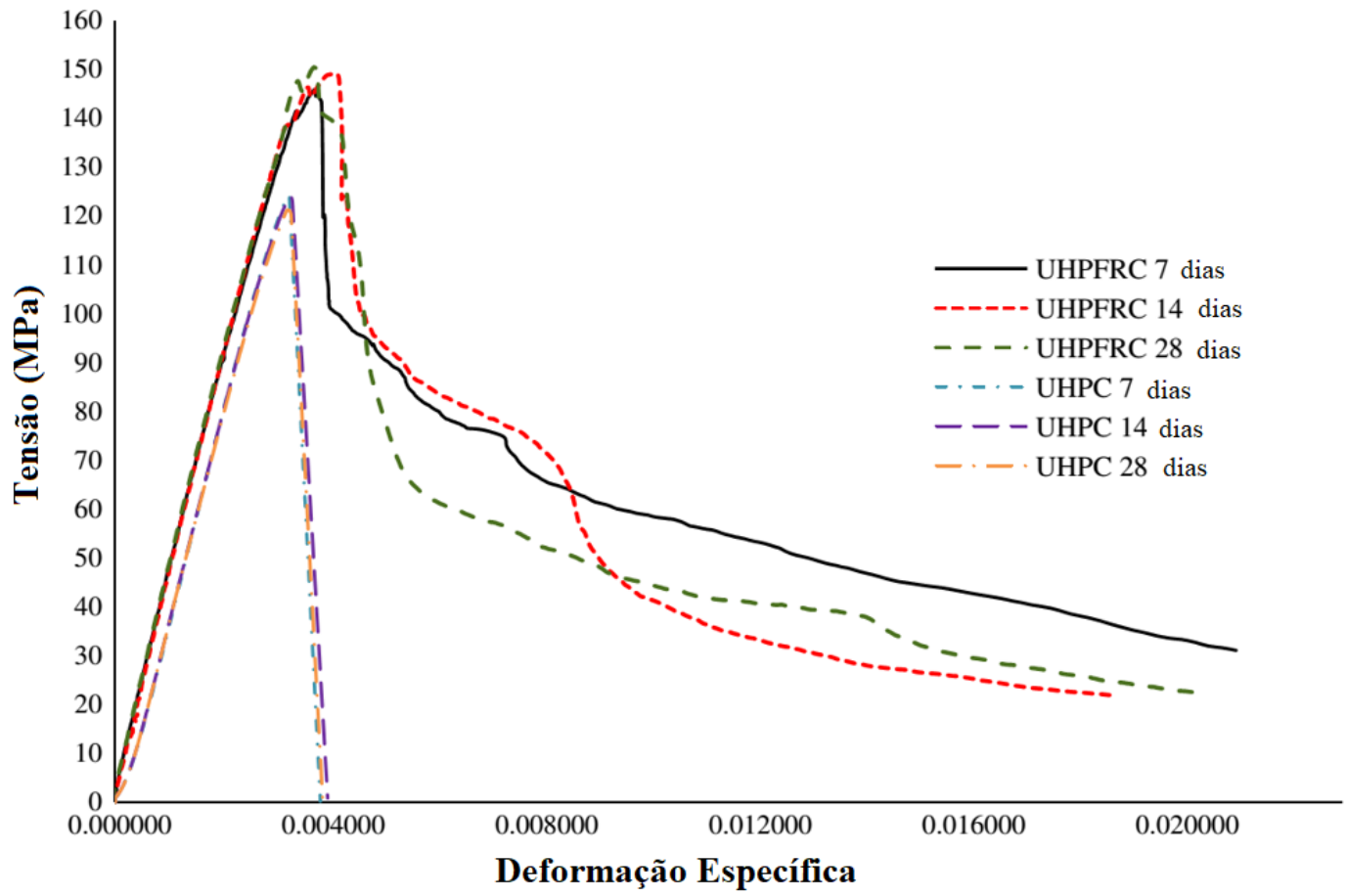

(b)

Figura 2.5 - Curvas tensão-deformação na tração (a) e compressão (b) do UHPFRC provenientes dos ensaios de Hassan et al. (2012).

A curva tensão-deformação na compressão do UHPFRC pode ser construída aproximadamente, com base na resistência à compressão, na deformação última e no módulo de elasticidade. Muitas curvas foram propostas para descrever o trecho ascendente deste material, cujo comportamento praticamente independe do volume de fibras. 
O comportamento do concreto com fibras e sem fibras no trecho ascendente do diagrama são similares pois a contribuição das fibras se dá principalmente após a fissuração do concreto, em que as fibras atuam costurando a fissura, conferindo maior ductilidade ao concreto.

A fib (2012) e Graybeal (2007) propuseram curvas tensão-deformação para o UHPFRC do trecho ascendente. Porém, Empelmann et al. (2008) propuseram uma curva com trecho descendente baseado no volume, diâmetro e comprimento das fibras (Tabela 2.2). Como todas as curvas citadas apresentam comportamentos muito similares no trecho ascendente, a curva de Empelmann et al. (2008) torna-se muito interessante para fins de simulação numérica pois também apresenta o trecho descendente.

Tabela 2.2 - Construção do diagrama tensão-deformação na compressão para o UHPFRC

\begin{tabular}{|c|c|c|}
\hline Ponto i & $\varepsilon_{\mathrm{ci}}$ & $f_{c i}$ \\
\hline 1 & 0 & 0 \\
\hline 2 & $\left(2 \alpha_{\text {in }}-1\right) \cdot f_{c} / E_{c m}$ & $\left(2 \alpha_{\text {in }}-1\right) \cdot f_{c}$ \\
\hline 3 & $\varepsilon_{\mathrm{cu}}$ & $f_{c}$ \\
\hline 4 & $1,25 \cdot \varepsilon_{\mathrm{cu}}$ & $0,35 \cdot\left(\sum v_{f} \cdot l_{f} / d_{f}\right) \cdot f_{c}$ \\
\hline 5 & $5 \cdot \varepsilon_{\mathrm{cu}}$ & $0,1 \cdot\left(\sum v_{f} \cdot I_{f} / d_{f}\right) \cdot f_{c}$ \\
\hline
\end{tabular}

Fonte: Adaptação de Empelmann et al. (2008)

Para a determinação dos parâmetros para a construção das curvas tensãodeformação, Graybeal (2007) sugere que a deformação correspondente à tensão máxima na compressão uniaxial pode ser estimada em 3,7\% e o módulo de elasticidade pode ser calculado em função da resistência à compressão de acordo com a equação 1.

$$
E=3.840 \cdot \sqrt{\left(f_{c}\right)}
$$

Sendo que $f_{c}$ é a resistência à compressão do concreto.

O comportamento à tração do UHPFRC difere-se significativamente do comportamento do concreto de resistência normal e dos concretos de alta resistência 
sem fibras. Esta diferença se dá principalmente pelo grande aumento de ductilidade e pelo fato das fissuras se distribuírem ao longo da peça tracionada (Figura 2.6).

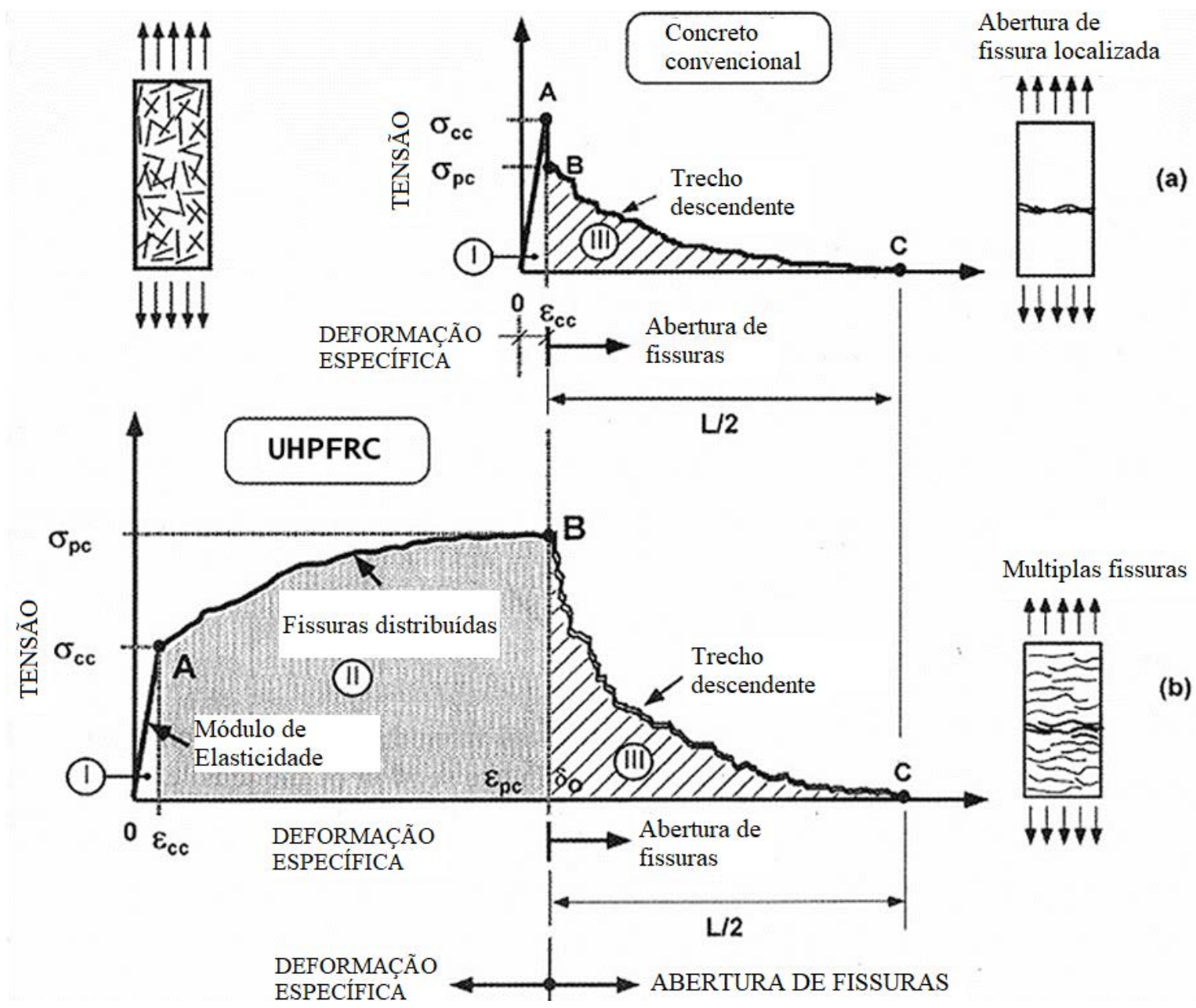

Figura 2.6 - Comparação entre o diagrama tensão-deformação de concretos com fibras (FRC) e de UHPFRCs.

Fonte: Naaman (2002)

O UHPFRC apresenta fissuração distribuída em todo seu comprimento antes da abertura de uma fissura principal quando tracionado.

\subsection{REFORÇO DE PILARES}

\subsubsection{PRINCIPAIS TÉCNICAS DE REFORÇO DE PILARES}

O reforço de pilares é realizado quando há a necessidade de aumentar a resistência da estrutura em virtude principalmente da correção de erros de projeto ou 
de execução, modificação do uso, perda de capacidade resistente por avarias no elemento estrutural (choques, incêndios, etc.), por desgaste, deterioração ou modificação da concepção estrutural (SOUZA e RIPPER, 1998).

As principais técnicas de reforço de estruturas são o aumento da seção transversal do pilar com o aumento da taxa de armadura, fixação de chapas metálicas e uso de PRF. A seguir são apresentadas cada uma das principais técnicas de reforço.

\subsubsection{Reforço por aumento da seção transversal e da taxa de armadura}

Esta técnica de reforço garante o aumento de resistência do pilar original pela adição de seção resistente de concreto e pela adição de armaduras (Figura 2.7). Os pormenores da execução deste reforço são descritos por Souza e Ripper (1998) e por Helene (2003).

Para a efetiva contribuição do pilar original na resistência do pilar reforçado, uma das alternativas é o descarregamento do pilar original, que garantirá uma maior solidez do conjunto quando atuarem as solicitações. Porém, o descarregamento de pilares muito solicitados, como o de edifícios altos é, muitas vezes inviável pela alta intensidade da solicitação.

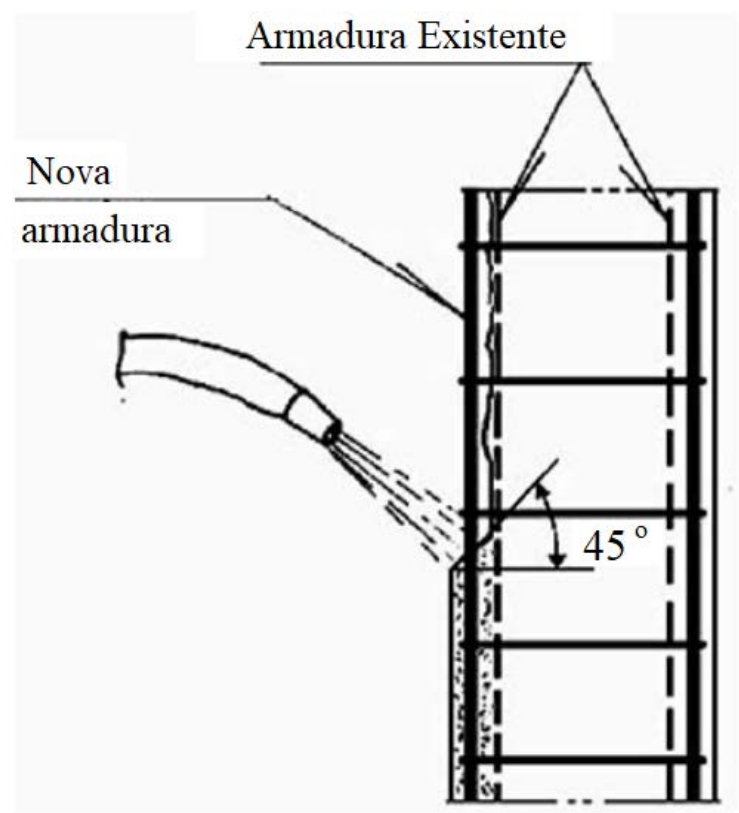

Figura 2.7- Esquema de reforço por aumento da seção e da taxa de armadura.

Fonte: Souza e Ripper (1998) 
Outra forma de garantir resistência ao conjunto é o uso do efeito de confinamento provocado pelo aumento da taxa de armadura transversal do reforço ou pela mudança da geometria da seção transversal, que garante também a contribuição do pilar original.

De acordo com Takeuti (2003), no reforço de pilares com encamisamento, desde que garantidas adequadas condições de confinamento, a contribuição do pilar original pode ser totalmente considerada. Porém, nos casos em que há descarregamento antes do reforço, as deformações axiais são menores.

Uma das principais desvantagens desta técnica de reforço é o grande aumento da seção transversal, que muitas vezes comprometem a estética e a funcionalidade da edificação. Assim, em locais onde as dimensões da seção transversal são um fato determinante, outras técnicas devem ser utilizadas.

\subsubsection{Reforço com utilização de chapas de aço}

Esta técnica consiste na fixação de chapas de aço no pilar original (Figura 2.8) com o uso de chumbadores ou colagem com resina epoxídica a fim de suportarem os esforços solicitantes, totalmente ou em conjunto com o pilar original.

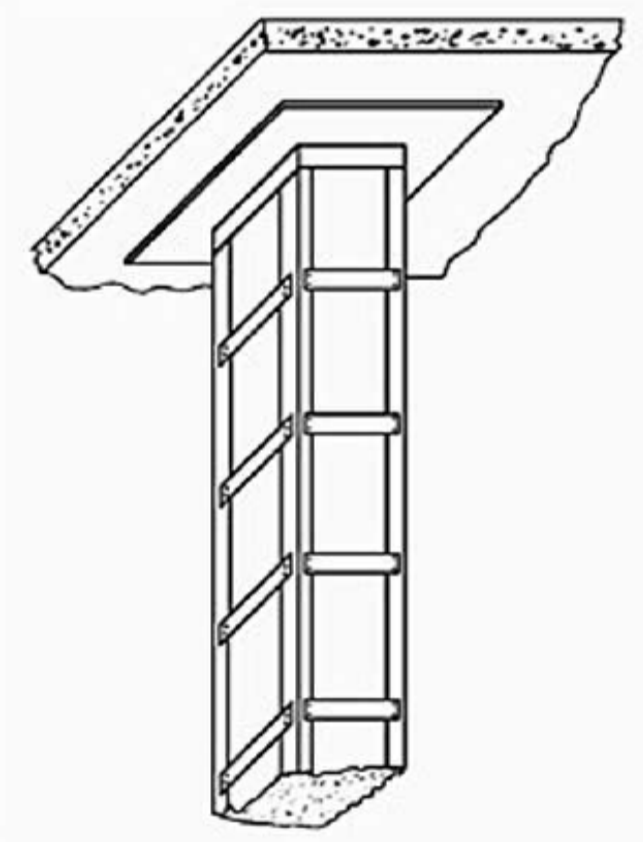

Figura 2.8- Esquema de reforço com perfis metálicos.

Fonte: Souza e Ripper (1998) 
Segundo Souza e Ripper (1998), o reforço com chapas metálicas deve ser dimensionado para suportar todas as solicitações quando o pilar original perde sua capacidade resistente ou quando está na iminência da ruína pois, no segundo caso, qualquer acréscimo de tensão levaria à perda de resistência do pilar original, transferindo todos os esforços solicitantes para o reforço.

Quando há descarregamento ou quando a solicitação não está muito próxima da resistência, ou seja, quando o pilar pode ser submetido a maiores deformações sem que ocorra a ruína, o pilar original pode ser considerado no cálculo da capacidade resistente do pilar reforçado (SOUZA e RIPPER, 1998).

Esta técnica possui a vantagem de a seção transversal ser praticamente inalterada. Em contrapartida, existe a desvantagem deste sistema demandar cuidados especiais quanto à corrosão do aço.

Algumas considerações adicionais sobre o dimensionamento e execução desta técnica de reforço podem ser encontradas em Souza e Ripper (1998) e Helene (2003).

\subsubsection{Reforço por encamisamento com PRF}

Esta técnica de reforço consiste principalmente na aplicação de manta de PRF envolvendo todo o pilar (Figura 2.9) para a mobilização de pressões laterais. Quanto maior o número de camadas de PRF, maiores pressões são mobilizadas e maior é a resistência do pilar reforçado. Neste tipo de reforço, o pilar reforçado pode obter resistências superiores ao dobro da capacidade do pilar original.

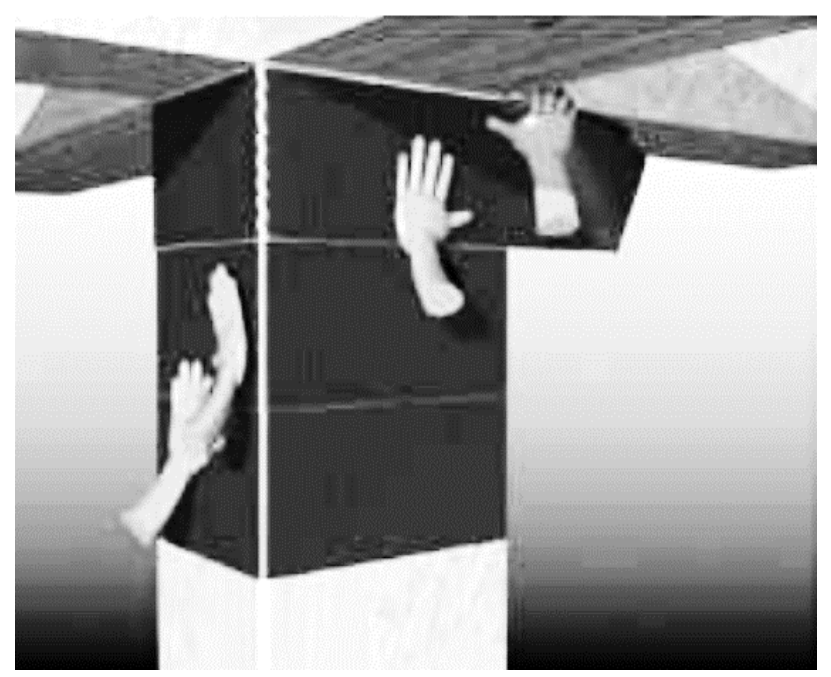

Figura 2.9 - Esquema de reforço de pilares com PRF.

Fonte: Machado (2010) 
É importante enfatizar que a geometria da seção que proporciona maior incremento de resistência para a mesma quantidade de camadas de reforço é a circular. A efetividade do reforço é minimizada quanto mais distante da seção circular for a seção do pilar.

Algumas vantagens deste sistema de reforço são o baixíssimo peso próprio (pode ser desprezado nos cálculos), o quase inexistente aumento da seção transversal e o elevado incremento de capacidade resistente do pilar.

Por outro lado, possui a desvantagem de mobilizar grandes deformações para atingir a resistência última. Elevadas deformações em pilares podem levar a estrutura ao colapso, pois os deslocamentos acentuados podem gerar esforços não previstos aos elementos estruturais adjacentes.

Mais informações sobre este tipo de reforço, a influência da seção e sobre o efeito de confinamento podem ser observadas no item 2.2.3 (Polímeros Reforçados com Fibras).

\subsubsection{PESQUISAS SOBRE NOVAS TÉCNICAS DE REFORÇO DE PILARES}

\subsubsection{Aumento da seção transversal com concreto de alto desempenho e PRF}

O estudo do comportamento de pilares reforçados com Concreto de Alta Resistência (CAR) com e sem fibras e com polímeros reforçados com fibras (PRF) foi realizado por Sudano (2010).

No trabalho de Sudano (2010), foram ensaiados pilares circulares, quadrados e retangulares reforçados com diferentes materiais de reforço, como concreto de alta resistência, concreto de alta resistência com fibras, Polímeros Reforçados com Fibras de Carbono (PRFC) e Polímeros Reforçados com Fibras de Vidro (PRFV), além da combinação destes materiais. Foram também abordados casos em que houve mudança da seção transversal.

Nos ensaios referentes aos pilares circulares, que em muito contribuem para embasar algumas hipóteses desta tese, foram levados à ruína, dois pilares de referência de concreto simples com dimensões de $15 \mathrm{~cm}$ x $60 \mathrm{~cm}$ (C 01 e C 02), dois pilares com dimensões de $15 \mathrm{~cm}$ x $60 \mathrm{~cm}$ encamisados com uma camada de fibra de carbono, dois pilares reforçados com camisa de concreto de alta resistência e armaduras com dimensões de $20 \mathrm{~cm}$ x $60 \mathrm{~cm}$ (C-CA 01 e C-CA 02), dois pilares 
encamisados com concreto de alta resistência com fibras com dimensões de $20 \mathrm{~cm} \mathrm{x}$ $60 \mathrm{~cm}$ (C-CF 01 e C-CF 02), dois pilares encamisados com concreto de alta resistência com fibras e uma camada de fibra de carbono com dimensões de $20 \mathrm{~cm}$ x $60 \mathrm{~cm}$ (CCF 11 e C-CF 12) e dois pilares reforçados com camisa de concreto de alta resistência, armaduras e uma camada de PRFC com dimensões de $20 \mathrm{~cm} \times 60 \mathrm{~cm}$ (C-CA 11 e C-CA 12).

Os diagramas tensão-deformação dos modelos apresentados acima podem ser observados na Figura 2.10.

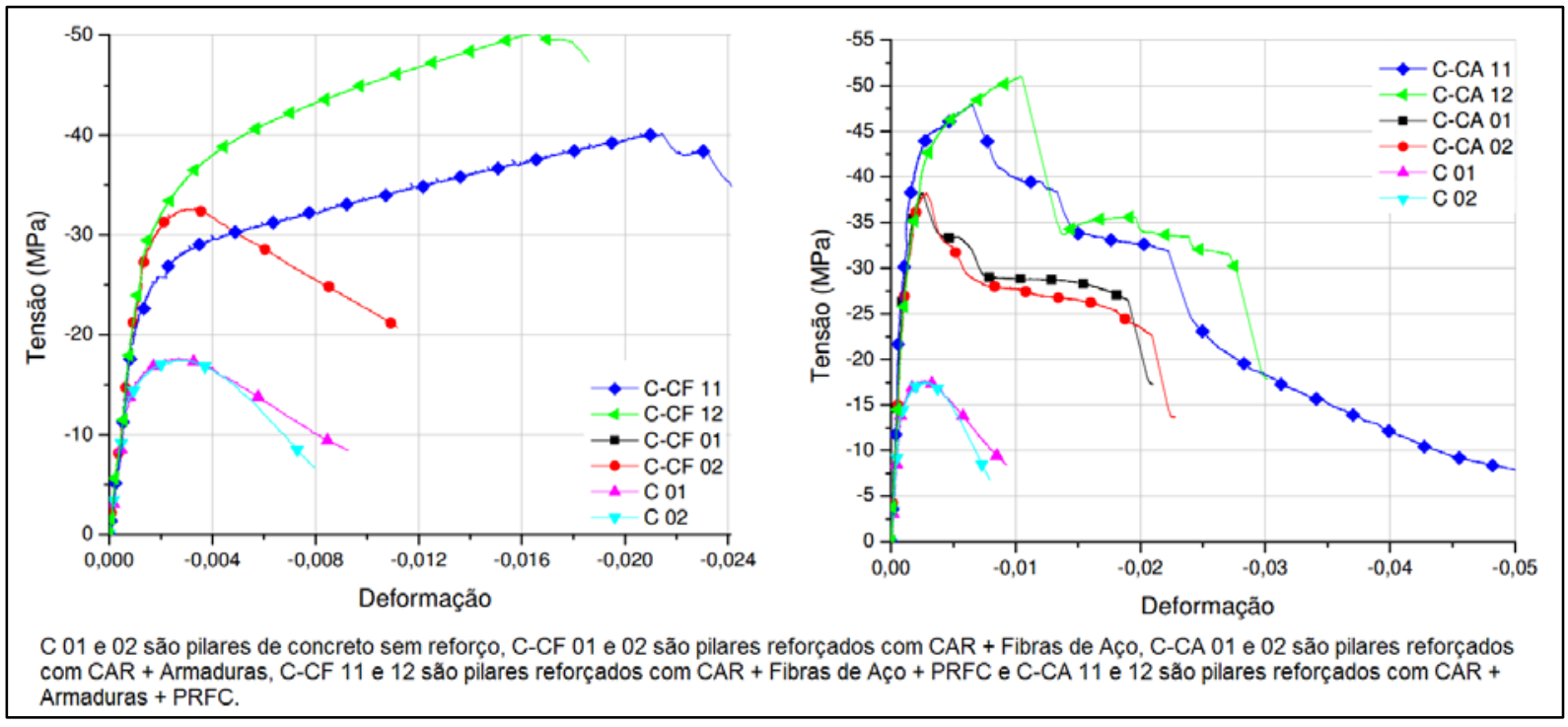

Figura 2.10 - Diagrama tensão-deformação dos pilares reforçados com CAR e PRF. Fonte: Sudano (2010)

A relação tensão-deformação dos pilares reforçados com CAR, armaduras e PRFC e dos pilares reforçados com CAR, fibras de aço e PRFC, podem ser observados na Figura 2.11.

Observando-se a Figura 2.11 nota-se que o uso de PRFC, além de contribuir para o aumento de resistência, também melhorou a ductilidade do pilar, evitando ruínas a pequenas deformações.

De acordo com Sudano (2010), a ruína prematura de modelos que continham armaduras de reforço foi causada pelo efeito "cover spalling" (desprendimento do cobrimento), pois neste caso há o surgimento do arqueamento das pressões de confinamento na direção longitudinal que causa este efeito. Com a utilização de fibras de aço em alternativa às armaduras de reforço, eliminou-se o arqueamento da direção longitudinal e assim, eliminou-se o problema. 
A Figura 2.11 mostra um acréscimo de resistência maior nos pilares que continham armaduras de reforço. Deve-se lembrar, que a resistência do aço é muito maior que a do CAR utilizado, portanto, boa parte deste acréscimo se deve ao acréscimo das armaduras longitudinais.

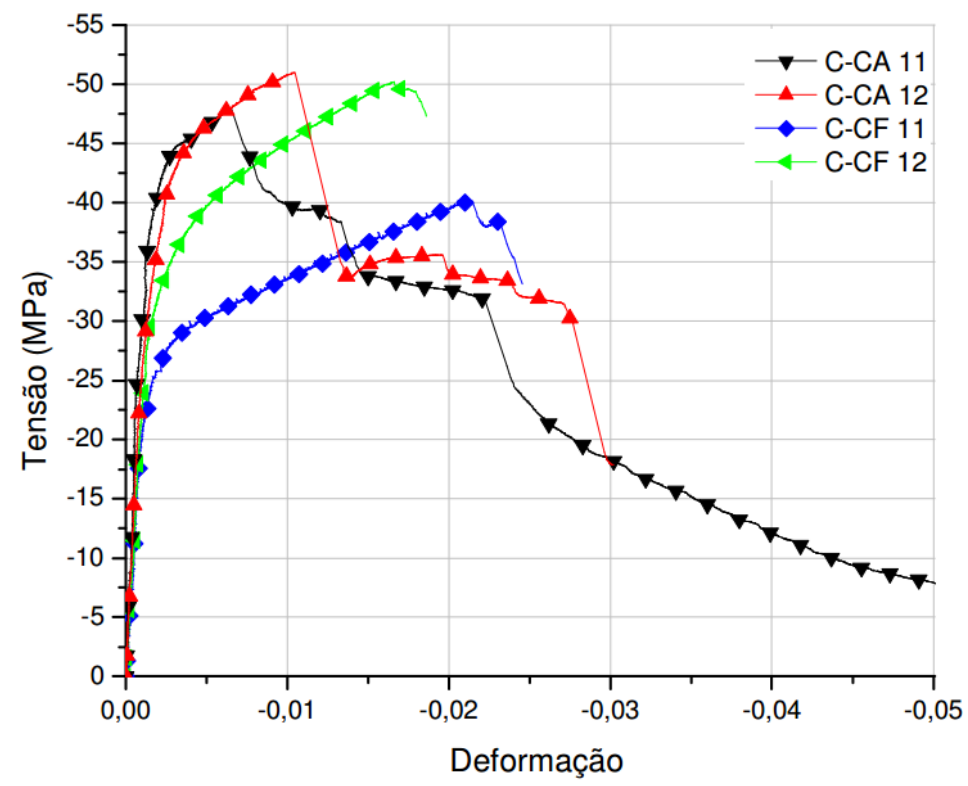

Figura 2.11 - Diagrama tensão-deformação dos pilares reforçados com CAR, armaduras e PRFC e dos pilares reforçados com CAR, fibras de aço e PRFC.

Fonte: Sudano (2010)

\subsubsection{Aumento da seção transversal com SIFCON}

Uma nova opção para reforço de pilares foi estudada por Abdollahi et al. (2012). Em um programa experimental, os autores propõem um novo método de confinamento de pilares utilizando SIFCON (Slurry Infiltrated Fiber Concrete, em língua inglesa).

O SIFCON é um concreto especial em que as fibras de aço são dispostas na posição desejada e posteriormente é injetado um concreto de alto desempenho fluído de agregados extremamente finos que preenche os vazios entre as fibras e a fôrma.

No programa experimental de Abdollahi et al. (2012) modelos com formato de corpos-de-prova circulares de concreto de resistência normal foram revestidos por SIFCON, sendo o núcleo de concreto convencional submetido a uma força axial, de modo a avaliar a contribuição do confinamento gerado pela camisa de reforço (Figura 2.12). 
Por exemplo, um modelo cilíndrico com dimensões de $15 \mathrm{~cm}$ de diâmetro por $30 \mathrm{~cm}$ de altura, com resistência de $40 \mathrm{MPa}$, revestido por uma camisa de SIFCON de espessura de $15 \mathrm{~mm}$ e resistência de aproximadamente $129 \mathrm{MPa}$, gerou um acréscimo de resistência de cerca de $54 \%$, provocado pelo confinamento gerado por uma pressão lateral de aproximadamente $5 \mathrm{MPa}$. É importante ressaltar que a aplicação da força foi apenas no núcleo, e não em toda a superfície do pilar pois, a intenção, foi avaliar a camisa de reforço submetida apenas a tensões de tração.
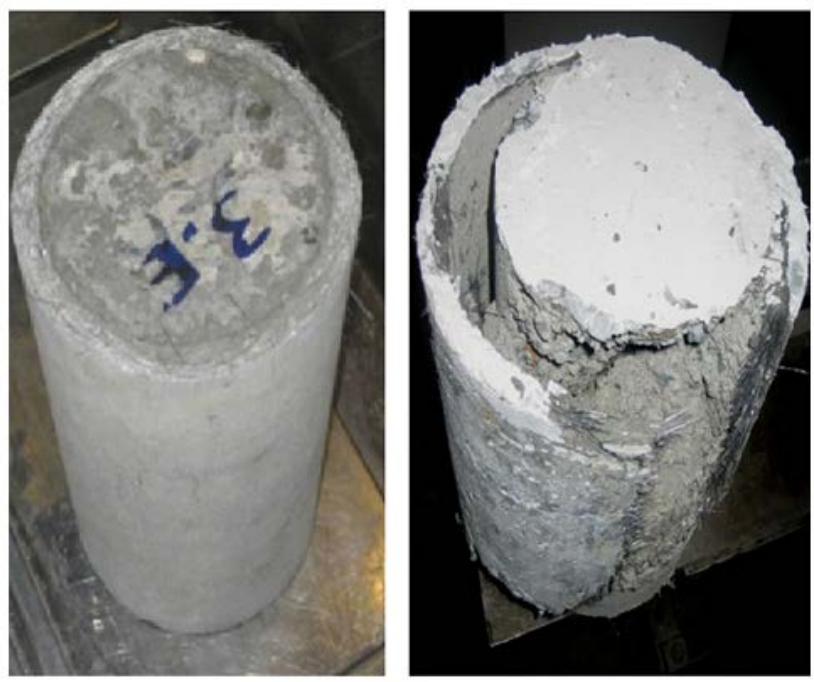

(a)

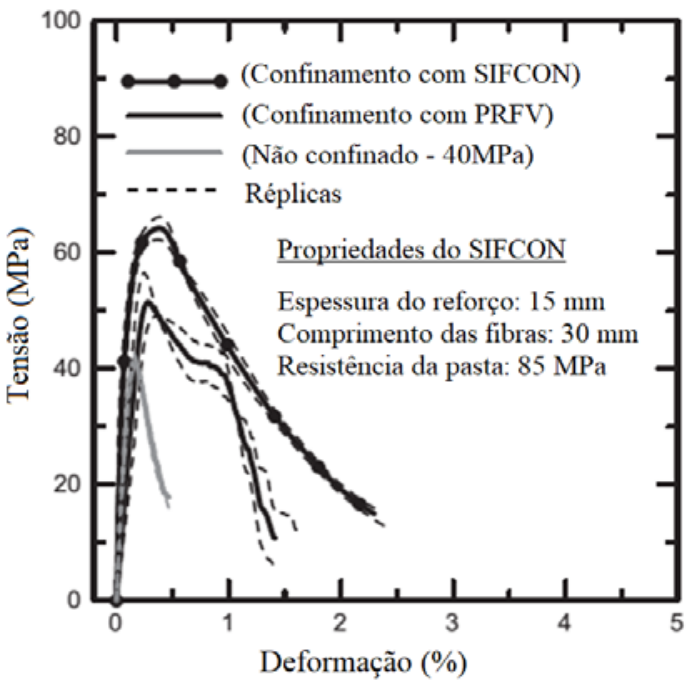

(b)

Figura 2.12- (a) Antes e depois do ensaio do modelo confinado com SIFCON e (b) curva tensão-deformação do concreto confinado e não-confinado.

Fonte: Abdollahi et al. (2012)

A pressão lateral foi mobilizada pela ação das fibras de aço que aumentaram de forma acentuada a ductilidade do concreto na tração.

A Figura 2.12 mostra um corpo-de-prova antes e depois do ensaio, bem como o diagrama tensão-deformação do concreto confinado e não-confinado.

Analisando os dados apresentados por Abdollahi et al. (2012), nota-se que os reforços de pilares circulares com SIFCON parecem muito promissores em termos de comportamento estrutural, porém, a execução desta técnica em situações reais de reforço parece muito complexa.

Para a determinação da pressão lateral desenvolvida pela camisa de SIFCON, Abdollahi et al. (2012) sugerem a Equação 2.

$$
f_{l}=\frac{f_{0 t} \cdot t_{\text {sifcon }}}{R}
$$


Sendo que $f_{l}$ é a pressão lateral, $f_{0 t}$ é a tensão de tração, $t_{s i f c o n}$ é a espessura da camisa de reforço e $R$ é o raio do pilar

Para a resistência do concreto convencional confinado, Abdollahi et al. (2012) propuseram a Equação 3.

$$
f_{c c}^{\prime}=f_{c o}^{\prime} \cdot\left[1+1,91 \cdot\left(\frac{f_{l}}{f_{c o}^{\prime}}\right)^{0,54}\right]
$$

Sendo que $f_{c c}^{\prime}$ é a resistência do concreto convencional confinado e $f_{c 0}^{\prime}$ é a resistência do concreto não confinado.

Como o concreto utilizado na presente pesquisa tem propriedades mecânicas semelhantes em relação à tração, estas equações foram utilizadas para a determinação das pressões laterais provocadas pelo UHPFRC e para a determinação da resistência do concreto confinado do núcleo.

\subsubsection{POLÍMEROS REFORÇADOS COM FIBRAS (PRF)}

Os polímeros reforçados com fibras são compósitos constituídos de fibras de alta-resistência com resinas poliméricas. São usualmente encontrados na forma de lâmina ou tecido (Figura 2.13). Segundo fib (2010), as principais vantagens da utilização dos PRF no reforço de estruturas de concreto são: imunidade à corrosão, pequeno peso próprio, facilidade de aplicação em lugares de difícil acesso, redução dos custos de mão-de-obra, resistência à tração consideravelmente alta, rigidez adaptável às necessidades de projeto, grande capacidade de deformação e grande disponibilidade em tamanhos e geometrias.

Parvin e Brighton (2014) complementam as vantagens da utilização de PRF para situações extremas na engenharia. Segundo os autores, a adição de PRF para restaurar ou reforçar estruturas pode salvar vidas, prevenindo a ruína e reduzindo os danos à infraestrutura, pois melhoram a capacidade resistente da peça tanto em situações de forças estáticas como principalmente em ações dinâmicas. 


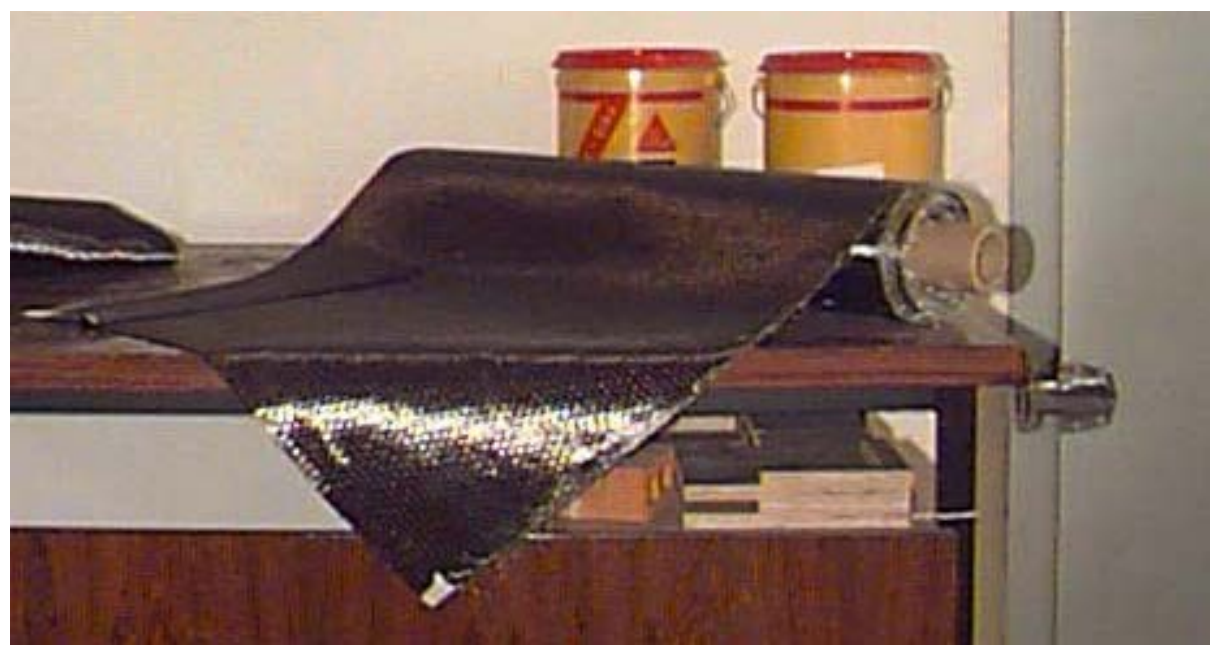

Figura 2.13 - Sistema de reforço estrutural SIKAWRAP® (tecido)

Fonte: Carrazedo (2002)

Dentre as fibras utilizadas para o reforço de estruturas as que mais se destacam são as de carbono e as de vidro. A preferência pelas fibras de carbono é justificada pelo alto módulo de elasticidade e elevada resistência, como demonstra a Tabela 2.3. No caso de reforço de pilares, principalmente de seções circulares, a fibra de carbono é ainda mais interessante que a fibra de vidro, pois seu elevado módulo de elasticidade proporciona maior confinamento e assim maior incremento de resistência.

Tabela 2.3 - Propriedades típicas das fibras (FELDMAN, 1989 e KIM, 1995)

\begin{tabular}{lccc}
\hline Material & $\begin{array}{c}\text { Módulo de } \\
\text { elasticidade (GPa) }\end{array}$ & $\begin{array}{c}\text { Resistência à } \\
\text { tração (MPa) }\end{array}$ & $\begin{array}{c}\text { Deformação } \\
\text { última de tração } \\
(\%)\end{array}$ \\
\hline $\begin{array}{l}\text { Carbono } \\
\text { Alta resistência }\end{array}$ & $215-235$ & $3500-4800$ & $1,4-2,0$ \\
$\quad \begin{array}{l}\text { Ultra-alta } \\
\text { resistência }\end{array}$ & $215-235$ & $3500-6000$ & $1,5-2,3$ \\
$\quad \begin{array}{l}\text { Alto módulo } \\
\text { Ultra-alto módulo }\end{array}$ & $350-500$ & $2500-3100$ & $0,5-0,9$ \\
\hline Vidro & $500-700$ & $2100-2400$ & $0,2-0,4$ \\
E & 70 & $1900-3000$ & $3,0-4,5$ \\
S & $85-90$ & $3500-4800$ & $4,5-5,5$ \\
\hline Aramida & & & \\
Baixo módulo & $70-80$ & $3500-4100$ & $4,3-5,0$ \\
Alto módulo & $115-130$ & $3500-4000$ & $2,5-3,5$ \\
\hline
\end{tabular}

Fonte: fib (2010)

A taxa de reforço é outro fator que influencia significativamente no diagrama tensão-deformação do elemento confinado. Quanto maior o número de camadas de reforço, maior a resistência e a deformação. Este fenômeno pode ser observado na Figura 2.14. 


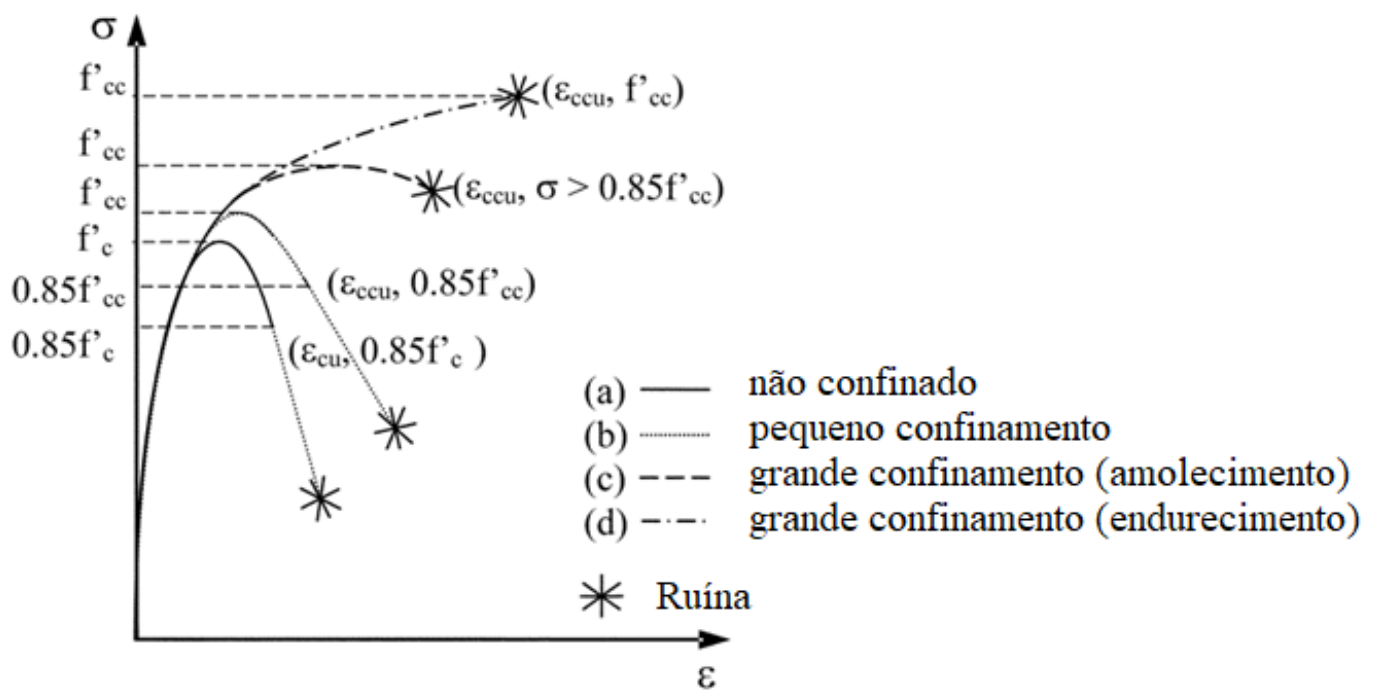

Figura 2.14- Tensão-Deformação de colunas com diferentes taxas de reforço Fonte: $\mathrm{ACl} 440.2 \mathrm{R}(2008)$

Quando pilares de seção retangular são encamisados por PRF, o efeito de confinamento diminui significativamente com o aumento da relação entre os lados, bem como com a diminuição do raio de arredondamento dos cantos. Uma forma aproximada de tratar o confinamento em pilares retangulares é a da área de confinamento efetivo que é ilustrada na Figura 2.15.

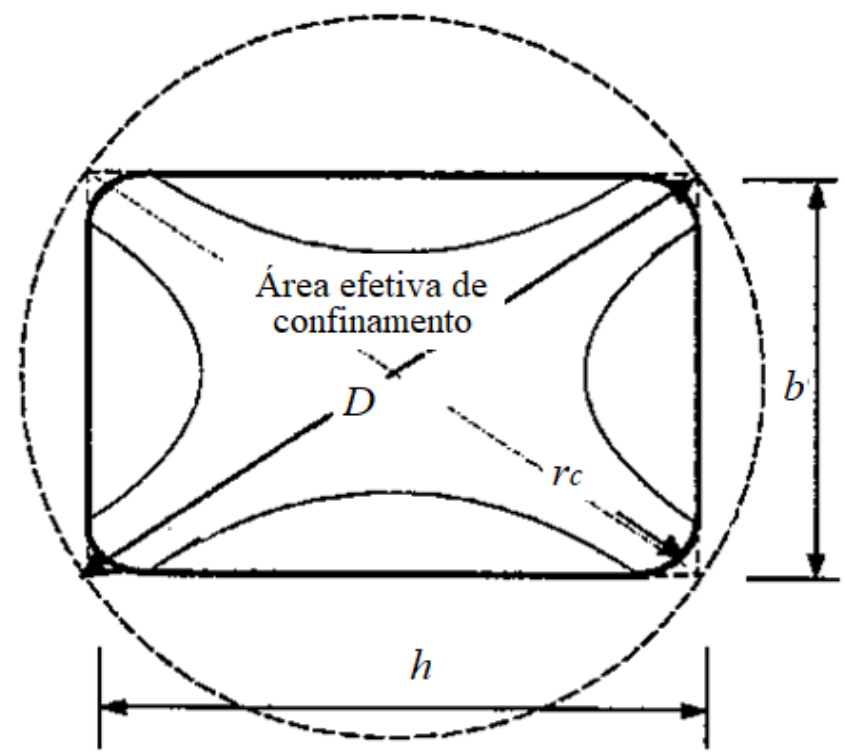

Figura 2.15- Área efetiva de confinamento em seções retangulares Fonte: $\mathrm{ACl} 440.2 \mathrm{R}(2008)$ 
Como a área de confinamento efetivo depende principalmente da relação entre os lados, pilares com relações muito altas não têm grande contribuição na resistência ou ductilidade pelo encamisamento com PRF, independente da taxa, módulo de elasticidade e resistência do reforço. Assim, quanto mais distante do círculo estiver a área da seção do pilar, menos efetivo é o sistema de reforço.

\subsubsection{Influência do efeito de confinamento}

O efeito de confinamento é o fenômeno que eleva a resistência à compressão do elemento por meio do surgimento de pressões laterais (ou de confinamento). Estas pressões são mobilizadas devido à inserção de elementos no material analisado, que dificultam a expansão lateral do mesmo, gerando assim, um estado triaxial de tensões.

No caso de pilares de concreto, existem diversas maneiras de provocar pressões laterais. Os estribos, os reforços com chapas metálicas e os reforços com PRF são os responsáveis mais comuns pela geração de pressões de confinamento. A técnica de encamisamento com concreto com fibras, como analisada por Sudano (2005), pode também mobilizar estes efeitos.

A Figura 2.16 mostra este fenômeno considerando o critério de Mohr, em que a superfície de ruína está representada em azul, e o semi-círculo destacado ilustra que quanto maior a pressão lateral (ponto d), maior pode ser a tensão axial aplicada (ponto g), a fim de que não haja ruína.

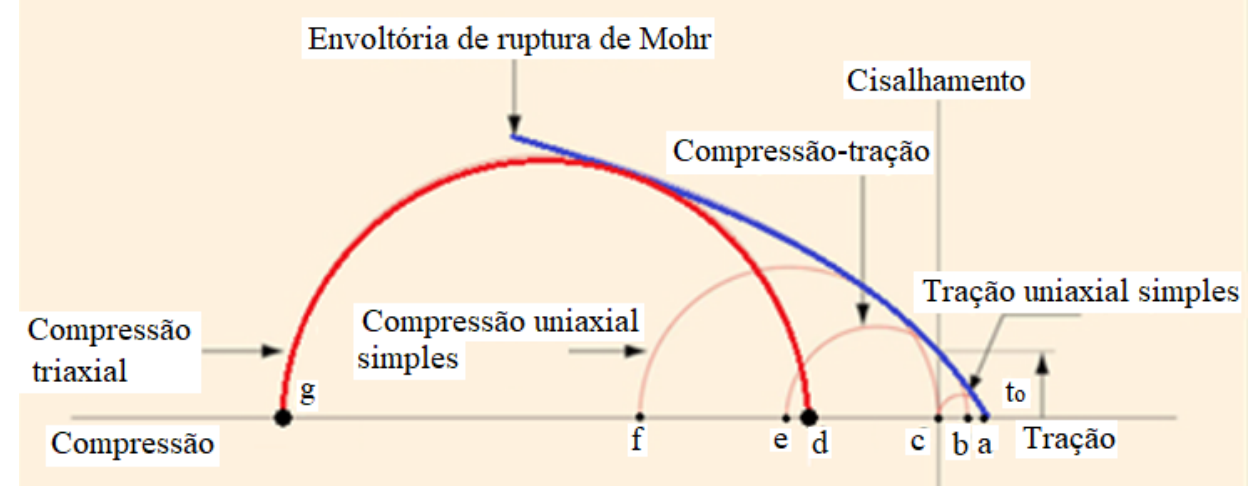

Figura 2.16 - Diagrama de ruína típico de Mohr para concreto (Mindess, S.; Young, J.F., Concrete, p. 401, 1981)

Fonte: Mehta e Monteiro (2008) 
Nota-se que o aumento de resistência em pilares circulares reforçados com PRFC é elevado. Carrazedo (2005), por exemplo, chegou a acréscimos de resistência de $129 \%$ utilizando mantas de PRFC para o confinamento de pilares circulares.

\subsubsection{Previsão do comportamento de pilares encamisados com PRF}

A previsão da resistência e deformação últimas de pilares reforçados são os principais aspectos para se determinar o tipo de reforço. Atualmente existem diversos modelos para a previsão do comportamento de pilares de concreto encamisados com PRF. Ozbakkaloglu et al. (2013) avaliaram 68 destes modelos, constatando que os modelos de Lam e Teng (2003) e Tamuzs et al. (2006) são os mais precisos para a previsão da resistência última e das deformações, respectivamente.

$\mathrm{O} \mathrm{ACl}$ 440.2R (2008) também fornece equações que descrevem 0 comportamento de pilares reforçados com PRF e usa como base os modelos propostos por Lam e Teng (2003). Como o ACl 440.2R (2008) é um código normativo respeitado internacionalmente, ele é recomendado para a previsão do comportamento do concreto de resistência normal.

Zohrevand e Mirmiran (2013) estudaram três modelos para descrever as curvas tensão-deformação de concretos de ultra-alto desempenho encamisados com PRF. Dentre os modelos de Lam e Teng (2003) recalibrado, Lam e Teng (2003) modificado e Samaan et al. (1998) recalibrado, constataram que o último mostrou-se mais preciso. Assim o modelo de Samaan et al. (1998) recalibrado por Zohrevand e Mirmiran (2013) é recomendado para prever o comportamento do UHPFRC confinado.

a) Modelo do ACI-440.2R (2008)

Este item apresenta os cálculos propostos pelo código normativo ACl 440.2R (2008) para previsão da resistência última, da deformação última e da curva tensãodeformação do concreto confinado (até $70 \mathrm{MPa}$ ).

A resistência última do concreto confinado por PRF pode ser determinada segundo a Equação 4.

$$
f_{c c^{\prime}}=f_{c}+\psi_{t} \cdot 3,3 \cdot k_{a} \cdot f_{l}
$$

Sendo que, $f_{c c}^{\prime}$ é a resistência à compressão do concreto confinado, $f_{c}$ é a resistência à compressão do concreto não-confinado, $\psi_{t}$ é um fator de redução $(0,95)$ 
determinado por meio da decisão do comitê, $k_{a}$ é um fator relacionado à geometria da seção transversal (no caso de seção circular $k_{a}=1$ ) para determinação de $f_{c c}^{\prime}$ e $f_{l}$ é a pressão de confinamento (pressão lateral).

A pressão de confinamento pode ser calculada segundo a Equação 5 .

$$
f_{l}=\frac{2 \cdot E_{f} \cdot n \cdot t_{f} \cdot \varepsilon_{f e}}{D}
$$

Sendo que $E_{f}$ é o módulo de elasticidade do PRF, $n$ é o número de camadas de PRF, $t_{f}$ é a espessura do PRF e $\varepsilon_{f e}$ é a deformação efetiva de ruína, dada na Equação 6.

$$
\varepsilon_{f e}=k_{\varepsilon} \cdot \varepsilon_{f u}
$$

Sendo que $\varepsilon_{f u}$ é a média da deformação de ruína do PRF baseado em 20 ou mais ensaios de tração e $k_{\varepsilon}$ é o fator de eficiência de deformação devido à ruptura prematura do sistema de reforço provocada pelo estado multiaxial de tensões que ocorre no PRF, diferente do estado uniaxial que ocorre no ensaio de caracterização. O ACl 440.2R (2008) propõe o valor de 0,55.

A deformação última para o concreto confinado não pode passar de $10 \%$ para prevenir fissurações excessivas e a perda da integridade do concreto. A deformação última do concreto confinado pode ser determinada por meio da Equação 7 .

$$
\varepsilon_{c c u}=\varepsilon_{c}^{\prime} \cdot\left(1,5+12 \cdot k_{b} \cdot \frac{f_{l}}{f_{c}^{\prime}} \cdot\left(\frac{\varepsilon_{f e}}{\varepsilon_{c}^{\prime}}\right)^{0,45}\right)
$$

Sendo que $k_{b}$ é o fator relacionado com a geometria da seção transversal para determinação de $\varepsilon_{c c u}$ (para seção circular, $k_{b}=1$ ) e $\varepsilon_{c}^{\prime}$ é a deformação última do concreto não-confinado correspondente à $f_{c}^{\prime}$ (pode ser tomado como $0,2 \%$ ).

A curva tensão-deformação do concreto confinado pode ser construída por meio da Equação 8.

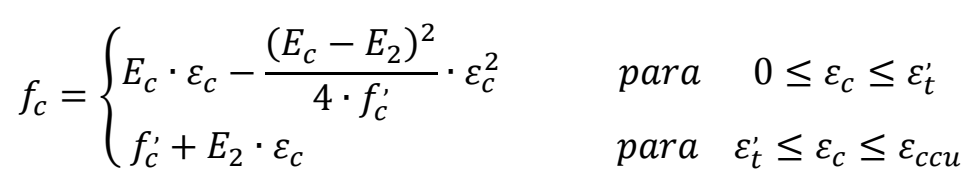

Sendo que, $E_{c}$ é o modulo de elasticidade do concreto não-confinado que pode ser calculado segundo as recomendações da fib (2012) para agregados quartzosos 
(Equação 9), $\varepsilon_{c}$ é a deformação correspondente à $f_{c}$, $\varepsilon_{t}^{\prime}$ é a deformação de transição e $E_{2}$ é o módulo de elasticidade do segundo trecho do diagrama tensão-deformação do concreto confinado, dado pela Equação 10.

$$
\begin{gathered}
E_{c}=21,5 \cdot 10^{3} \cdot\left(\frac{f_{c m}}{10}\right)^{1 / 3} \\
E_{2}=\frac{f_{c c}^{\prime}-f_{c}^{\prime}}{\varepsilon_{c c u}}
\end{gathered}
$$

A deformação de transição é calculada pela Equação 11.

$$
\varepsilon_{t}^{\prime}=\frac{2 \cdot f_{c}^{\prime}}{E_{c}-E_{2}}
$$

O comportamento da curva tensão-deformação do concreto confinado pode ser observado na Figura 2.17.

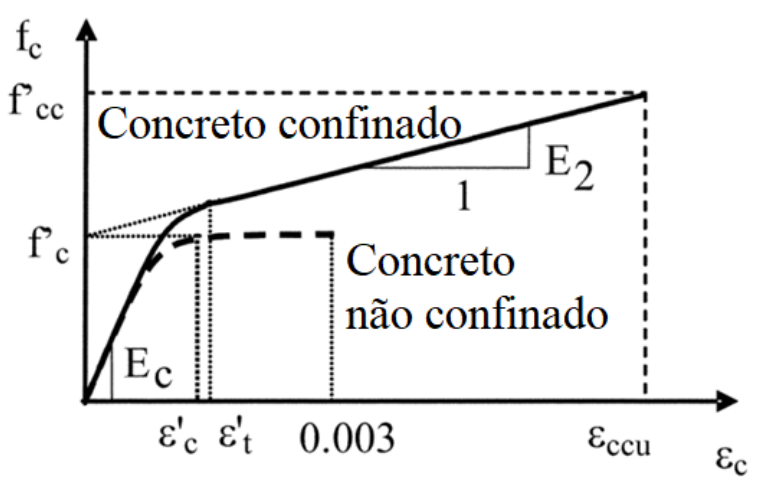

Figura 2.17- Modelo de Lan eTeng para o concreto confinado Fonte: $\mathrm{ACl} 440.2 \mathrm{R}(2008)$

b) Modelo de Samaan Recalibrado

Dentre os modelos propostos por Zohrevand e Mirmiran (2013), o de Samaan et al. (1998) recalibrado apresentou maior precisão em comparação com ensaios experimentais para a determinação do comportamento de concretos de ultra-alto desempenho confinados com PRF. 
Como o comportamento do UHPFRC é muito similar ao UHPC até o pico de tensão, este modelo pode ser utilizado para determinar seu comportamento até a ruína.

Neste item são apresentados os cálculos propostos por Zohrevand e Mirmiran (2013) para previsão da resistência última, da deformação última e da curva tensãodeformação do UHPC confinado.

A resistência última do UHPC confinado com PRF pode ser estimada segundo a Equação 12.

$$
f_{c u}^{\prime}=f_{c 0}^{\prime}+0,107 \cdot f_{r}^{2}
$$

Sendo que, $f_{c 0}^{\prime}$ é a resistência do UHPFRC não-confinado e $f_{r}$ é a pressão de confinamento.

A deformação última pode ser determinada por meio da Equação 13.

$$
\varepsilon_{c u}=\frac{f_{c u}^{\prime}-f_{0}}{E_{2}}
$$

Sendo que, $f_{0}$ é a tensão referente ao prolongamento do segundo trecho do diagrama tensão-deformação (Figura 2.18) e determinada conforme Equação 14.

$$
f_{0}=0,7862 \cdot f_{c 0}^{\prime}+0,455 \cdot f_{r}
$$

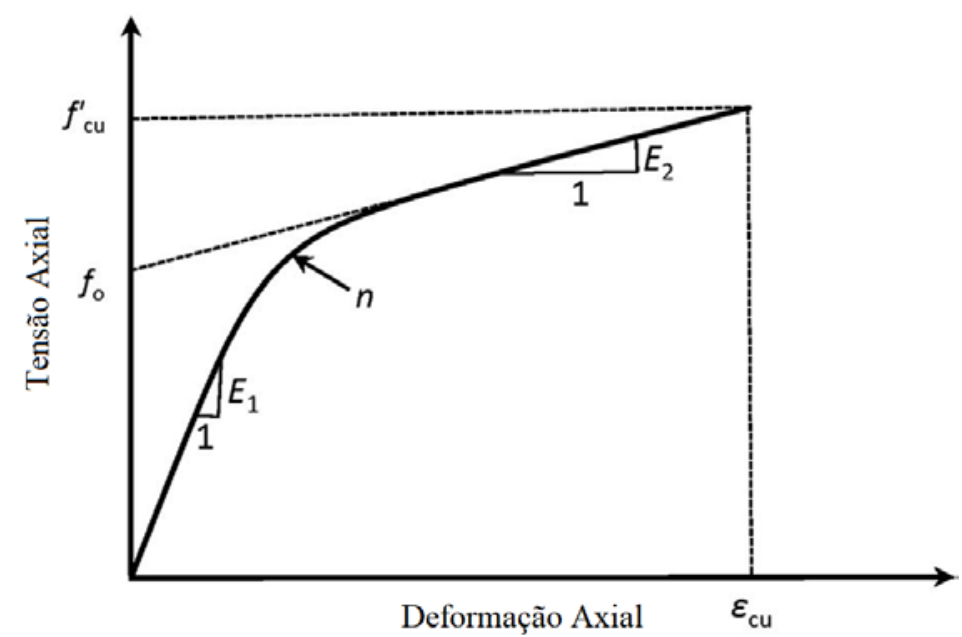

Figura 2.18- Esquema tensão-deformação proposto por Samaan et al. (1998) Fonte: Zohrevand e Mirmiran (2013)

Similar aos modelos bi-lineares, a curva utilizada para descrever o comportamento tensão-deformação pode ser determinada pela Equação 15. 


$$
f_{c}=\frac{\left(E_{1}-E_{2}\right) \cdot \varepsilon_{c}}{\left\{1+\left[\frac{\left(E_{1}-E_{2}\right) \cdot \varepsilon_{c}}{f_{0}}\right]^{1,5}\right\}^{1 / n}}
$$

Sendo que, $E_{1}$ é o módulo de elasticidade do primeiro trecho do diagrama tensão-deformação dado pela Equação 16, $E_{2}$ é o módulo de elasticidade do segundo trecho do diagrama tensão-deformação dado pela Equação 17, $\varepsilon_{c}$ é a deformação específica referente a $f_{c}$ e $n$ é o parâmetro de forma da curva, sugerido por Zohrevand e Mirmiran (2013) como sendo 12.

$$
\begin{gathered}
E_{1}=3840 \cdot \sqrt{f_{c 0}^{\prime}} \\
E_{2}=1350,76 \cdot\left[f_{c 0}^{\prime}\right]^{0,2}+5,675 \cdot \frac{E_{j} \cdot t_{j}}{D}
\end{gathered}
$$

Sendo que, $E_{j}$ é o módulo de elasticidade do PRF, $t_{j}$ é a espessura do PRF e $D$ é o diâmetro do pilar. 


\section{MÉTODO}

\subsection{PROGRAMA EXPERIMENTAL}

Neste item são abordados os ensaios para a determinação das propriedades dos materiais, incluindo seus respectivos resultados, todos os procedimentos adotados para a fabricação dos pilares, incluindo a montagem das fôrmas, a instrumentação e o processo de adensamento do concreto, principalmente do concreto de ultra-alto desempenho, cuja consistência é extremamente viscosa e a espessura extremamente fina (espessura máxima de 2,5 cm) para o uso de vibrador comercial.

\subsubsection{PROPRIEDADES DOS MATERIAIS}

\subsubsection{Concreto convencional}

O concreto convencional foi utilizado em todos os pilares desta pesquisa. Todos os pilares foram concretados em apenas uma etapa com a utilização do misturador planetário de concreto da marca CIBI, com capacidade de 250 litros de concreto pronto (Figura 3.1). O traço utilizado foi 1:2,7:3,7:0,6. O concreto apresentou "slump" de $14 \mathrm{~cm}$.

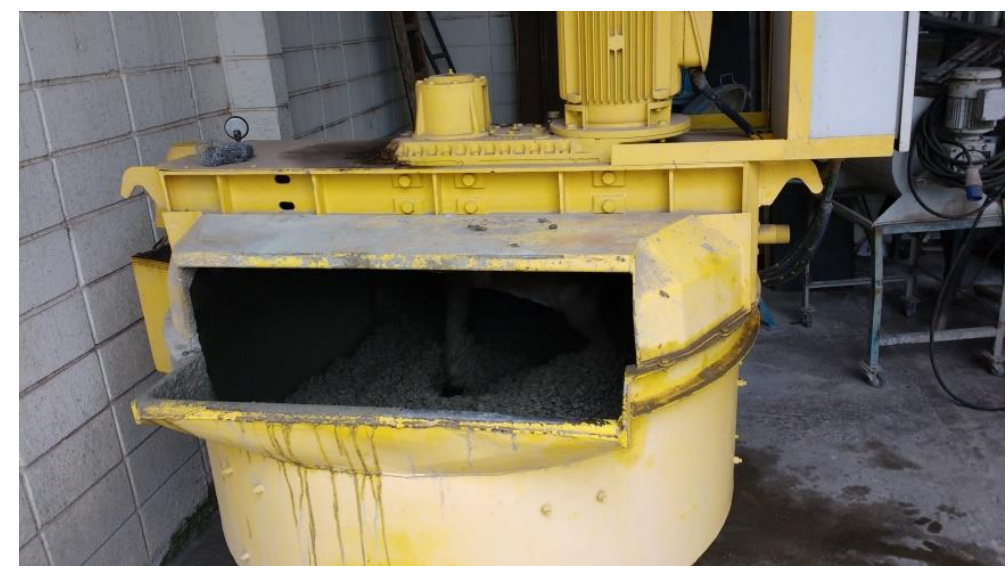

Figura 3.1 - Misturador planetário de concreto. 
Foram utilizados corpos-de-prova cilíndricos de $10 \mathrm{~cm}$ × $20 \mathrm{~cm}$ tanto para a determinação da resistência à compressão quanto para a determinação da resistência à tração pelo ensaio de compressão diametral.

A máquina de ensaio hidráulica, marca ELE, modelo Autotest 2000, com capacidade para 2.000 kN (Figura 3.2) foi utilizada para a determinação da resistência à compressão aos 32 dias e da resistência à tração (ensaio de compressão diametral). O ensaio foi realizado aos 32 dias pois foi a data mais próxima aos 28 dias disponível no laboratório.

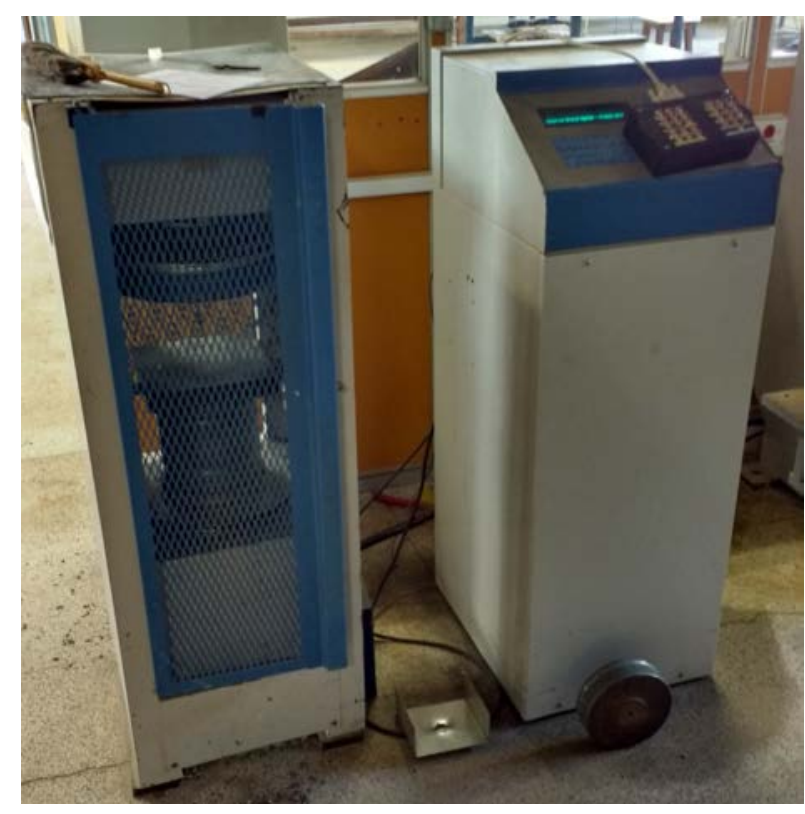

Figura 3.2 - Máquina hidráulica elétrica para ensaios à compressão, com capacidade para 2000 kN.

Para a realização dos ensaios à compressão do concreto aos 88 dias (próximo ao ensaio dos pilares) foi utilizada a máquina de ensaio da marca Instron, modelo 300 HVL, com capacidade para 1.500 kN e altura útil de ensaio de 1.500 mm (Figura 3.3), com a finalidade da obtenção da curva tensão-deformação do concreto. 


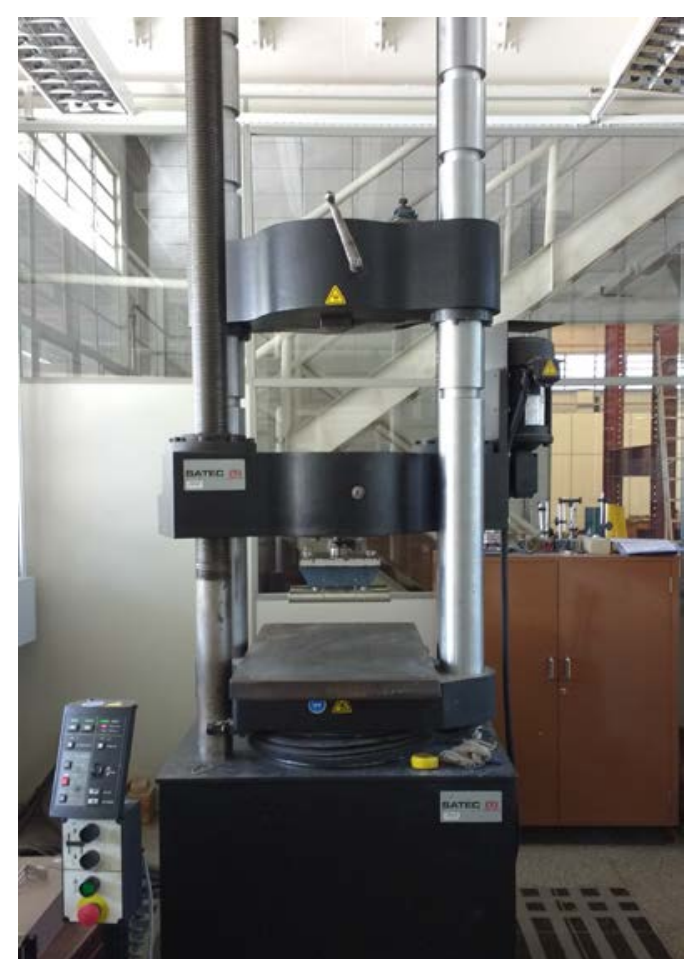

Figura 3.3 - Máquina de ensaio da marca Instron, modelo $300 \mathrm{HVL}$, com capacidade para $1.500 \mathrm{kN}$.

Para a determinação das curvas tensão-deformação dos corpos-de-prova cilíndricos com dimensões de $10 \mathrm{~cm}$ x $20 \mathrm{~cm}$, foram utilizados extensômetros removíveis da marca MSI, com curso de 1,5 mm (Figura 3.4).

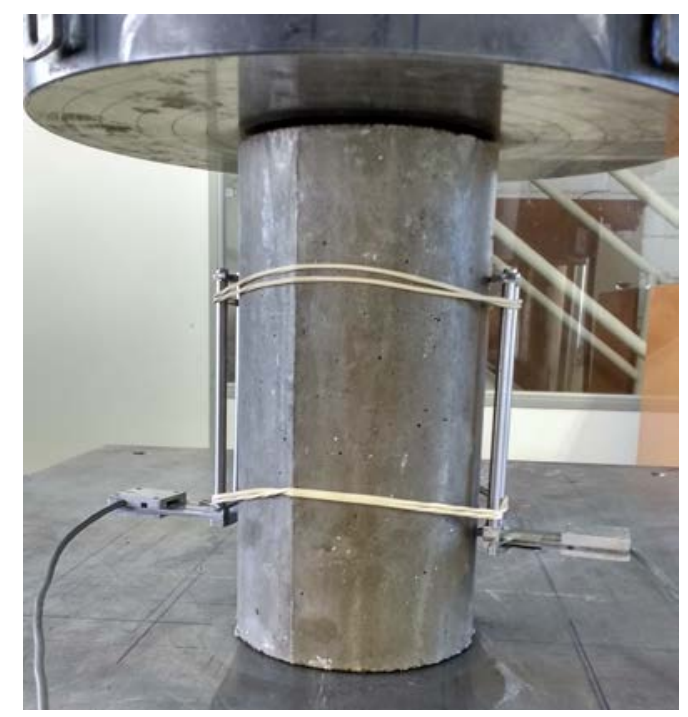

Figura 3.4 - Clip gages utilizados nos ensaios de caracterização.

As resistências alcançadas nos ensaios de compressão dos corpos-de-prova de concreto (utilizando velocidade de $0,05 \mathrm{~mm} / \mathrm{s}$ ) podem ser observadas na Tabela 
3.1 e as resistências referentes aos ensaios de compressão diametral são apresentadas na Tabela 3.2.

Tabela 3.1 - Resistência à compressão do concreto

\begin{tabular}{|c|c|c|}
\hline \multicolumn{3}{|c|}{ Resistência à Compressão do Concreto Convencional } \\
\hline $\mathrm{CPs}(10 \mathrm{~cm} \times 20 \mathrm{~cm})$ & 32 dias $(\mathrm{MPa})$ & 88 dias $(\mathrm{MPa})$ \\
\hline 1 & 27,32 & 29,13 \\
\hline 2 & 26,19 & 29,92 \\
\hline 3 & 28,04 & 29,94 \\
\hline 4 & 28,21 & 28,03 \\
\hline 5 & 26,10 & 29,50 \\
\hline Média & $\mathbf{2 7 , 1 7}$ & $\mathbf{2 9 , 3 1}$ \\
\hline
\end{tabular}

Os diagramas tensão-deformação dos corpos-de-prova cilíndricos $10 \mathrm{~cm}$ x 20 cm de concreto convencional ensaiados aos 88 dias, ou seja, próximo ao dia do ensaio dos pilares, são mostrados na Figura 3.5. A curva denominada "aproximada" foi a curva adotada para a realização das simulações numéricas dos pilares estudados.

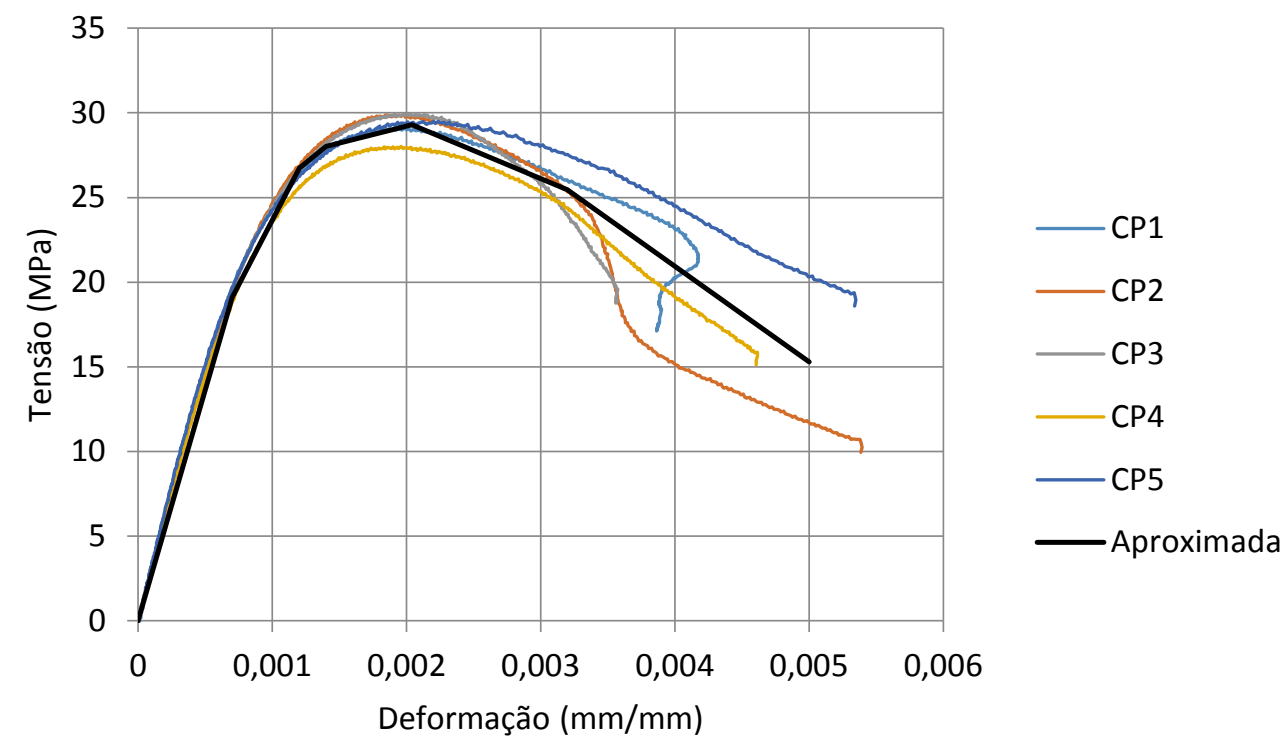

Figura 3.5 - Diagrama tensão-deformação dos corpos-de-prova de concreto convencional aos 88 dias.

Analisando-se a relação entre a resistência à compressão e a resistência à tração do concreto convencional, nota-se que a resistência à tração foi da ordem de 10\% da resistência à compressão. 
Tabela 3.2 - Resistência à tração do concreto convencional

\begin{tabular}{|c|c|c|}
\hline \multicolumn{3}{|c|}{ Resistência à Tração do Concreto Convencional por Compressão Diametral } \\
\hline \multicolumn{2}{|c|}{90 dias } \\
\hline CPs $(10 \mathrm{~cm} \times 20 \mathrm{~cm})$ & Força última $(\mathrm{kN})$ & Resistência à Tração $(\mathrm{MPa})$ \\
\hline 1 & 88,10 & 2,80 \\
\hline 2 & 103,20 & 3,28 \\
\hline 3 & 60,90 & 1,94 \\
\hline 4 & 110,50 & 3,52 \\
\hline 5 & 98,10 & 3,12 \\
\hline Média & $\mathbf{9 2 , 1 6}$ & $\mathbf{2 , 9 3}$ \\
\hline Desvio Padrão & $\mathbf{1 9 , 2 8}$ & $\mathbf{0 , 6 1}$ \\
\hline
\end{tabular}

\subsubsection{Concreto de Ultra-alto Desempenho}

Os materiais utilizados para a confecção dos concretos de ultra-alto desempenho desta pesquisa foram: cimento CP V - ARI da marca Holcim, areia industrial com as propriedades descritas na Tabela 3.3, sílica ativa da empresa Dow Corning, aditivo superplastificante ADVA CAST 585 e fibras metálicas da empresa Ganzhou Daye Metallic Fibers Co. Ltda., com comprimento de 13 mm, diâmetro de $0,2 \mathrm{~mm}$ e resistência à tração de $2.850 \mathrm{MPa}$.

Tabela 3.3 - Propriedades da areia industrial utilizada no UHPC

\begin{tabular}{|l|c|}
\hline Diâmetro médio dos grãos & $0,28 \mathrm{~mm}$ \\
\hline Diâmetro máximo & $0,6 \mathrm{~mm}$ \\
\hline Módulo de finura & 1,287 \\
\hline Massa específica & $2,64 \mathrm{~kg} / \mathrm{dm}^{3}$ \\
\hline Classificação (ABNT NBR 7211:1983) & Muito fina \\
\hline Composição Química & $99,42 \%$ de quartzo \\
\hline
\end{tabular}

Os materiais utilizados na confecção do concreto de ultra-alto desempenho com fibras (UHPFRC) podem ser observados na Figura 3.6. 


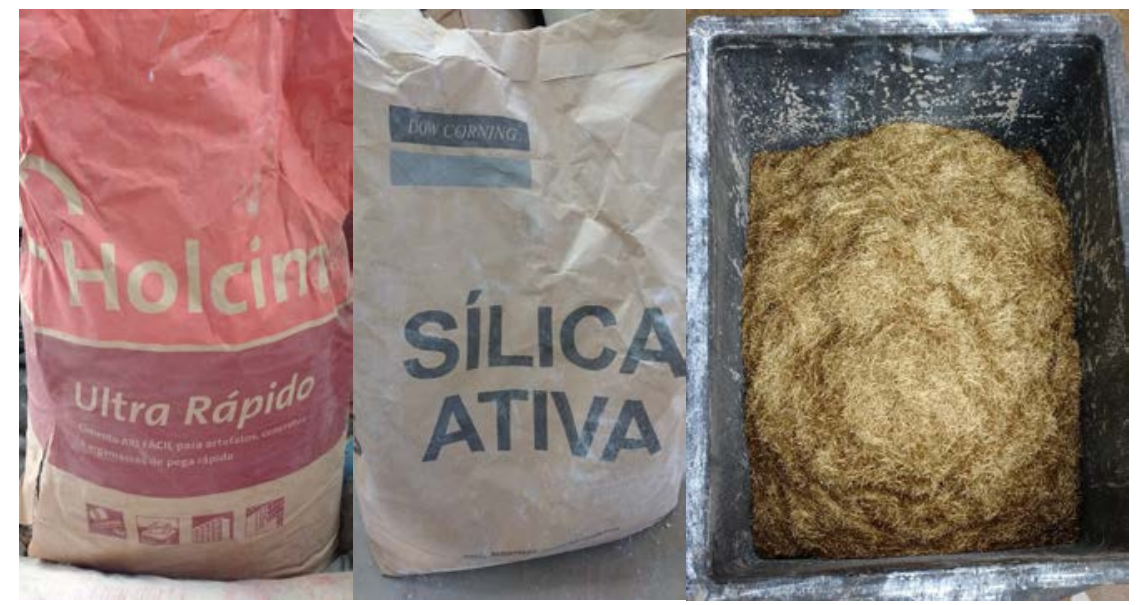

Figura 3.6 - Cimento, sílica ativa e fibra metálica utilizados na fabricação do UHPFRC

A composição do concreto de ultra-alto desempenho, com e sem fibras utilizado na pesquisa é mostrada na Tabela 3.4.

Tabela 3.4 - Composição do UHPC e do UHPFRC

\begin{tabular}{|l|c|c|}
\hline Materiais & UHPC & UHPFRC \\
\hline Cimento CP V - ARI & $40 \mathrm{~kg}$ & $40 \mathrm{~kg}$ \\
\hline Areia industrial & $40 \mathrm{~kg}$ & $40 \mathrm{~kg}$ \\
\hline Sílica ativa & $10,65 \mathrm{~kg}$ & $10,65 \mathrm{~kg}$ \\
\hline Superplastificante & $3,6 \mathrm{~kg}$ & $3,6 \mathrm{~kg}$ \\
\hline Água & $8 \mathrm{~kg}$ & $8 \mathrm{~kg}$ \\
\hline Fibras metálicas & - & $9,28 \mathrm{~kg}$ \\
\hline
\end{tabular}

A composição adotada tem como referência o traço 1:1:0,266:0,233 (cimento, areia, sílica ativa e fibras metálicas) utilizado por Sobuz et al. (2016). A relação água/cimento utilizada foi de 0,2 e a quantidade de superplastificante foi a máxima recomendada pelo fabricante, ou seja, $9 \%$ da massa de cimento.

Com esta proporção conseguiu-se um concreto fluído o suficiente para a concretagem dos pilares.

A mistura do concreto de ultra-alto desempenho foi feita por intermédio de betoneira convencional (Figura 3.7) na qual o cimento, a areia e a sílica ativa foram inseridos primeiramente, misturando-os por 5 minutos. É importante ressaltar a necessidade da vedação da betoneira a fim de que os materiais não sejam perdidos durante o processo. Na pesquisa, foi utilizada uma lona disponível no laboratório, juntamente com um elástico. Sugere-se alternativamente à lona, algum material transparente, como um plástico, por exemplo, para visualizar o aspecto da mistura, sem a necessidade de se parar o processo. 


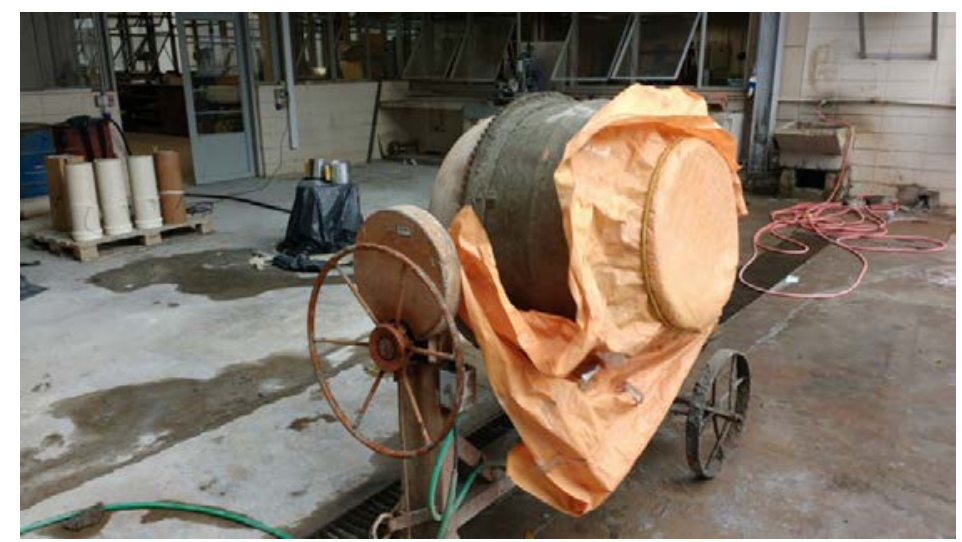

Figura 3.7 - Betoneira utilizada para confeccionar o concreto de ultra-alto desempenho

Após a mistura inicial foram inseridos a água juntamente com o aditivo superplastificante e misturados por cerca de 20 minutos, resultando em concreto extremamente fluído (Figura 3.8). As fibras metálicas foram adicionadas após os 20 minutos mencionados anteriormente e misturadas por cerca de 5 minutos, até se verificar a homogeneização da mistura.

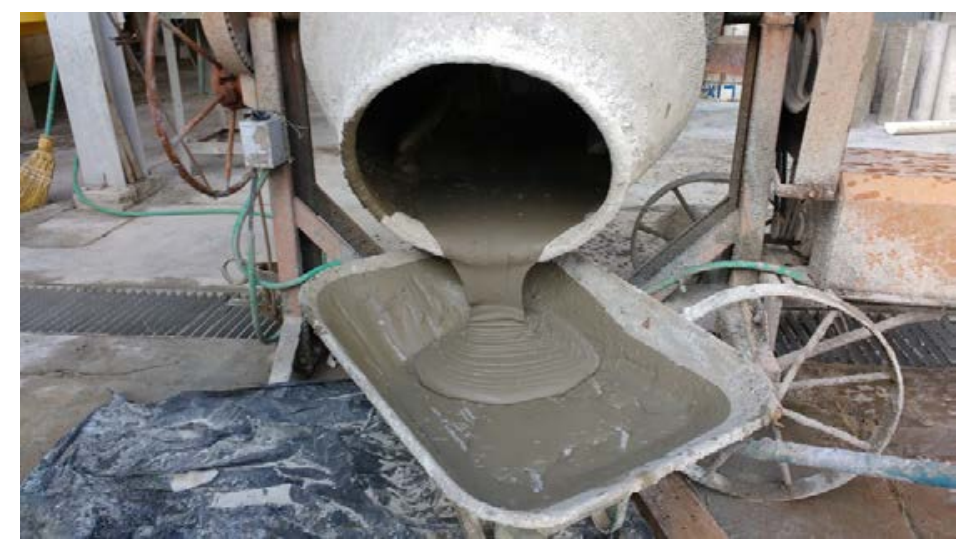

Figura 3.8 - Aspecto fluído do UHPC

Para a realização dos ensaios à compressão foi utilizada a máquina de ensaio da marca Instron, modelo $300 \mathrm{HVL}$, com capacidade para $1.500 \mathrm{kN}$ e altura útil de ensaio de $1.500 \mathrm{~mm}$ (Figura 3.3).

A Tabela 3.5 apresenta os resultados dos ensaios à compressão referentes ao concreto de ultra-alto desempenho sem fibras (UHPC) e a

Tabela 3.6 apresenta os resultados do concreto de ultra-alto desempenho com fibras (UHPFRC). Para a realização do ensaio à compressão do UHPC e do UHPFRC foram utilizados corpos-de-prova cilíndricos com dimensões de $5 \mathrm{~cm}$ de diâmetro por $10 \mathrm{~cm}$ de altura. 
Tabela 3.5 - Resistência à compressão do UHPC

\begin{tabular}{|c|c|c|c|}
\hline \multicolumn{4}{|c|}{ Resistência à Compressão do UHPC } \\
\hline \multicolumn{4}{|c|}{ Primeira Concretagem "ROD1" (Referente aos Pilares Circulares) } \\
\hline CPs & 28 dias (MPa) & 84 dias (MPa) & $\begin{array}{c}\text { Módulo de Elasticidade } \\
84 \text { dias (GPa) }\end{array}$ \\
\hline 1 & 102,41 & 118,22 & 39,61 \\
\hline 2 & 122,25 & 119,22 & 40,26 \\
\hline 3 & 119,05 & 123,20 & 41,17 \\
\hline 4 & 119,36 & 116,44 & 38,88 \\
\hline 5 & 117,35 & 115,72 & 39,19 \\
\hline Média & $\mathbf{1 1 6 , 0 8}$ & $\mathbf{1 1 8 , 5 6}$ & $\mathbf{3 9 , 8 2}$ \\
\hline \multicolumn{4}{|c|}{ Segunda Concretagem "ROD2" (Referente aos Pilares Quadrados) } \\
\hline CPs & 27 dias (MPa) & 84 dias (MPa) & Módulo de Elasticidade \\
\hline 1 & 97,65 & 125,42 & 34 dias (GPa) \\
\hline 2 & 106,02 & 119,61 & 39,98 \\
\hline 3 & 115,86 & 126,94 & 38,82 \\
\hline 4 & 113,48 & 114,58 & 37,24 \\
\hline 5 & 117,77 & 122,02 & 38,47 \\
\hline Média & $\mathbf{1 1 0 , 1 6}$ & $\mathbf{1 2 1 , 7 1}$ & $\mathbf{3 8 , 8 5}$ \\
\hline Média Geral & $\mathbf{1 1 3 , 1 2}$ & $\mathbf{1 2 0 , 1 4}$ & $\mathbf{3 9 , 3 4}$ \\
\hline Desvio Padrão & $\mathbf{8 , 2 3}$ & $\mathbf{4 , 1 6}$ & $\mathbf{1 , 0 8}$ \\
\hline
\end{tabular}

Tabela 3.6 - Resistência à compressão do UHPFRC

\begin{tabular}{|c|c|c|c|}
\hline \multicolumn{4}{|c|}{ Resistência à Compressão do UHPFRC } \\
\hline \multicolumn{4}{|c|}{ Primeira Concretagem (Referente aos Pilares Circulares) } \\
\hline CPs & 28 dias (MPa) & 80 dias (MPa) & $\begin{array}{c}\text { Módulo de Elasticidade } \\
80 \text { dias (GPa) }\end{array}$ \\
\hline 1 & 117,40 & 142,63 & 43,17 \\
\hline 2 & 112,15 & 130,97 & 41,59 \\
\hline 3 & 105,83 & 127,29 & 42,65 \\
\hline 4 & 111,36 & 133,32 & 42,14 \\
\hline 5 & 117,84 & 124,86 & 41,31 \\
\hline Média & $\mathbf{1 1 2 , 9 2}$ & $\mathbf{1 3 1 , 8 1}$ & $\mathbf{4 2 , 1 7}$ \\
\hline & Segunda Concretagem (Referente aos Pilares Quadrados) \\
\hline CPs & 28 dias (MPa) & 79 dias (MPa) & Módulo de Elasticidade \\
\hline 1 & 110,47 & 120,64 & 79 dias (GPa) \\
\hline 2 & 109,45 & 110,12 & 40,36 \\
\hline 3 & 107,12 & 126,52 & 42,91 \\
\hline 4 & 110,66 & 114,51 & 42,05 \\
\hline 5 & - & 128,24 & 39,44 \\
\hline Média & $\mathbf{1 0 9 , 4 2}$ & $\mathbf{1 2 0 , 0 1}$ & 41,33 \\
\hline Média Geral & $\mathbf{1 1 1 , 3 7}$ & $\mathbf{1 2 5 , 9 1}$ & $\mathbf{4 1 , 2 2}$ \\
\hline Desvio Padrão & $\mathbf{4 , 0 7}$ & $\mathbf{9 , 2 9}, \mathbf{6 9}$ \\
\hline
\end{tabular}


Todos os pilares foram simulados com as médias, tanto dos módulos de elasticidade, como das resistências à compressão e à tração referentes aos corposde-prova com idades próximas às dos ensaios dos pilares.

Os diagramas tensão-deformação dos corpos-de-prova $5 \mathrm{~cm}$ x10 cm de UHPC ensaiados aos 84 dias, ou seja, próximo ao dia do ensaio dos pilares, são mostrados na Figura 3.9. Como os transdutores de deslocamento foram retirados antes da ruína dos corpos-de-prova, foi determinado o módulo de elasticidade, e assim, considerouse comportamento elástico-linear até a ruína. As denominações ROD1 e ROD2, referem-se à primeira e à segunda concretagem com UHPC.
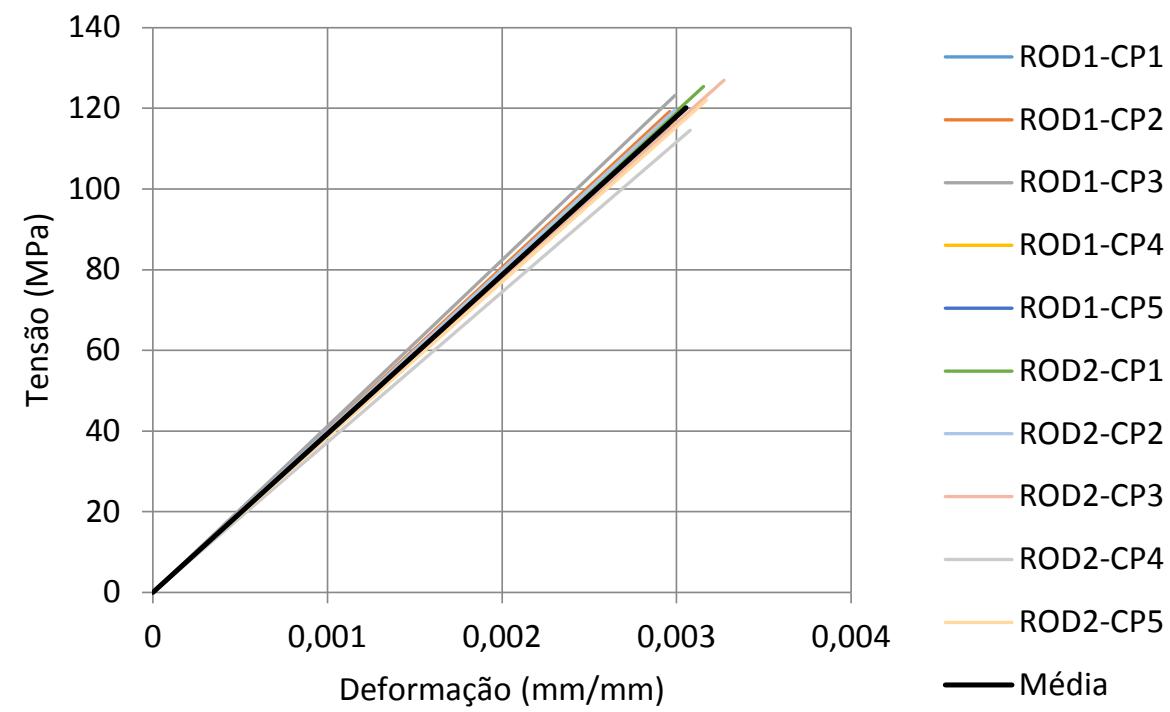

Figura 3.9 - Diagrama tensão-deformação dos corpos-de-prova de UHPC aos 84 dias.

Os diagramas força-deslocamento dos corpos-de-prova cilíndricos $5 \mathrm{~cm} \times 10$ cm de UHPFRC ensaiados aos 79 e 80 dias, são mostrados na Figura 3.10. A curva denominada "aproximada" foi a curva adotada na simulação dos pilares estudados. Esta curva foi criada com base na média dos módulos de elasticidade e na média das resistências.

Para a realização do ensaio de compressão diametral foi utilizada a máquina de ensaio hidráulica, marca ELE, modelo Autotest2000, capacidade para 2.000 kN (Figura 3.2).

A Tabela 3.7 apresenta os resultados dos ensaios de compressão diametral referentes ao concreto de ultra-alto desempenho sem fibras (UHPC) e a Tabela 3.8 apresenta os resultados do concreto de ultra-alto desempenho com fibras (UHPFRC). 


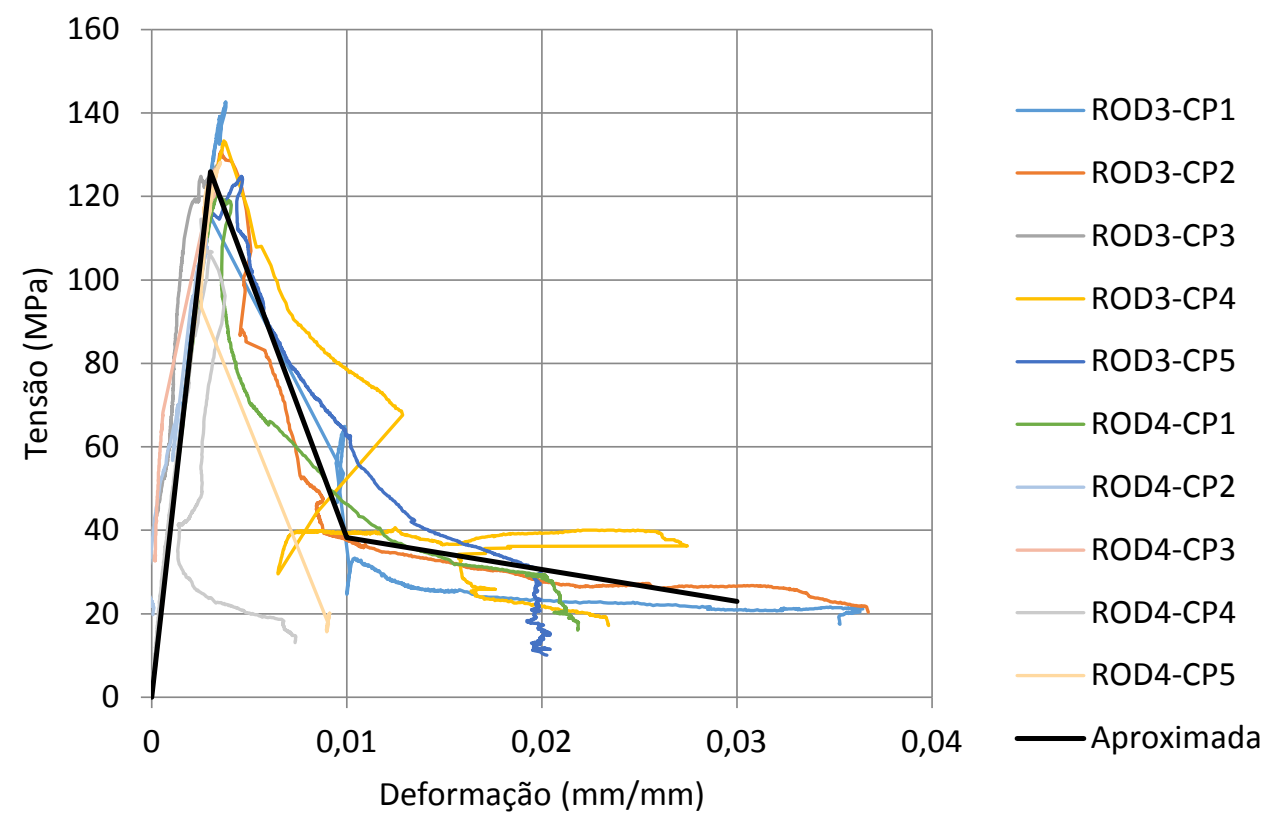

Figura 3.10 - Diagrama tensão-deformação dos corpos-de-prova de UHPFRC aos 79 e 80 dias.

Tabela 3.7 - Resistência à tração por compressão diametral do UHPC

\begin{tabular}{|c|c|c|}
\hline \multicolumn{3}{|c|}{ Resistência à Tração do UHPC por Compressão Diametral } \\
\hline \multicolumn{3}{|c|}{85 dias } \\
\hline \multicolumn{3}{|c|}{ Primeira Concretagem (Referente aos Pilares Circulares) } \\
\hline CPs & Força última (kN) & Resistência à Tração (MPa) \\
\hline 1 & 45,60 & 5,81 \\
\hline 2 & 53,50 & 6,81 \\
\hline 3 & 32,20 & 4,10 \\
\hline 4 & 42,50 & 5,41 \\
\hline 5 & 55,00 & 7,00 \\
\hline Média & $\mathbf{4 5 , 7 6}$ & $\mathbf{5 , 8 3}$ \\
\hline \multicolumn{2}{|c|}{ Segunda Concretagem (Referente aos Pilares Quadrados) } \\
\hline CPs & Força última (kN) & Resistência à Tração (MPa) \\
\hline 1 & 48,70 & 6,20 \\
\hline 2 & 41,40 & 5,27 \\
\hline 3 & 37,40 & 4,76 \\
\hline 4 & 39,10 & 4,98 \\
\hline 5 & 26,60 & 3,39 \\
\hline Média & $\mathbf{3 8 , 6 4}$ & $\mathbf{4 , 9 2}$ \\
\hline Média Geral & $\mathbf{4 2 , 2 0}$ & $\mathbf{5 , 3 7}$ \\
\hline Desvio Padrão & $\mathbf{8 , 9 6}$ & $\mathbf{1 , 1 4}$ \\
\hline
\end{tabular}


Observando-se a relação entre a resistência à compressão e a resistência à tração do UHPC e do UHPFRC, nota-se uma grande diferença de comportamento entre estes dois concretos. Analisando-se o UHPC, percebe-se que a relação entre a resistência à tração e à compressão foi muito menor que a do concreto convencional (abaixo de 5\%). Já no UHPFRC esta relação foi de aproximadamente 14\%, mostrando a vantagem da utilização das fibras metálicas.

Tabela 3.8 - Resistência à tração por compressão diametral do UHPFRC

\begin{tabular}{|c|c|c|}
\hline \multicolumn{3}{|c|}{ Resistência à Tração do UHPFRC por Compressão Diametral } \\
\hline \multicolumn{3}{|c|}{81 dias } \\
\hline \multicolumn{3}{|c|}{ Primeira Concretagem (Referente aos Pilares Circulares) } \\
\hline CPs & Força última (kN) & Resistência à Tração (MPa) \\
\hline 1 & 147,50 & 18,78 \\
\hline 2 & 147,20 & 18,74 \\
\hline 3 & 98,70 & 12,57 \\
\hline 4 & 152,90 & 19,47 \\
\hline 5 & 125,00 & 15,92 \\
\hline Média & $\mathbf{1 3 4 , 2 6}$ & $\mathbf{1 7 , 0 9}$ \\
\hline Desvio Padrão & $\mathbf{2 2 , 5 9}$ & $\mathbf{2 , 8 7}$ \\
\hline \multicolumn{3}{|c|}{ Segunda Concretagem (Referente aos Pilares Quadrados) } \\
\hline $\begin{array}{l}\text { Não foi possível a confecção dos corpos-de-prova para a realização do ensaio de compressão } \\
\text { diametral da segunda concretagem devido a uma falha humana. }\end{array}$ \\
\hline
\end{tabular}

\subsubsection{Armaduras}

Foram utilizadas barras de aço com diâmetro de $10 \mathrm{~mm}$ para as armaduras longitudinais, e de $5 \mathrm{~mm}$, para as armaduras transversais. Duas amostras de cada diâmetro foram utilizadas para o ensaio de tração uniaxial. Os corpos-de-prova foram instrumentados com clip gage (50 mm) e ensaiados na máquina de ensaio da marca Instron, modelo $300 \mathrm{HVL}$, com capacidade para $1.500 \mathrm{kN}$ e altura útil de ensaio de $1.500 \mathrm{~mm}$. Os ensaios de tração seguiram as recomendações da ABNT NBR 68921:2013.

As propriedades mecânicas dos aços utilizados nas armaduras transversais e longitudinais são apresentadas na Tabela 3.9. 
Tabela 3.9 - Propriedades mecânicas das armaduras transversais e longitudinais

\begin{tabular}{|c|c|c|c|c|}
\hline \multicolumn{5}{|c|}{ Propriedades das armaduras } \\
\hline \multirow{2}{*}{ Diâmetro } & \multicolumn{2}{|c|}{$5 \mathrm{~mm}(\mathrm{CA}-60)$} & \multicolumn{2}{c|}{$10 \mathrm{~mm}(\mathrm{CA}-50)$} \\
\cline { 2 - 5 } & Amostra 1 & Amostra 2 & Amostra 1 & Amostra 2 \\
\hline Módulo de Elasticidade (GPa) & 187,00 & 205,30 & 189,30 & 201,91 \\
\hline Resistência (MPa) & 818,39 & 820,73 & 647,03 & 644,70 \\
\hline
\end{tabular}

O diagrama tensão-deformação do aço utilizado nas armaduras transversais é apresentado na Figura 3.11 e do aço utilizado nas armaduras longitudinais na Figura 3.12. Alguns dos diagramas não são apresentados até a resistência indicada na Tabela 3.9, pelo motivo do clip gage ter sido retirado antes de atingida a referida tensão.

As curvas denominadas "Aproximada" são as utilizadas para a simulação numérica no programa de elementos finitos ABAQUS.

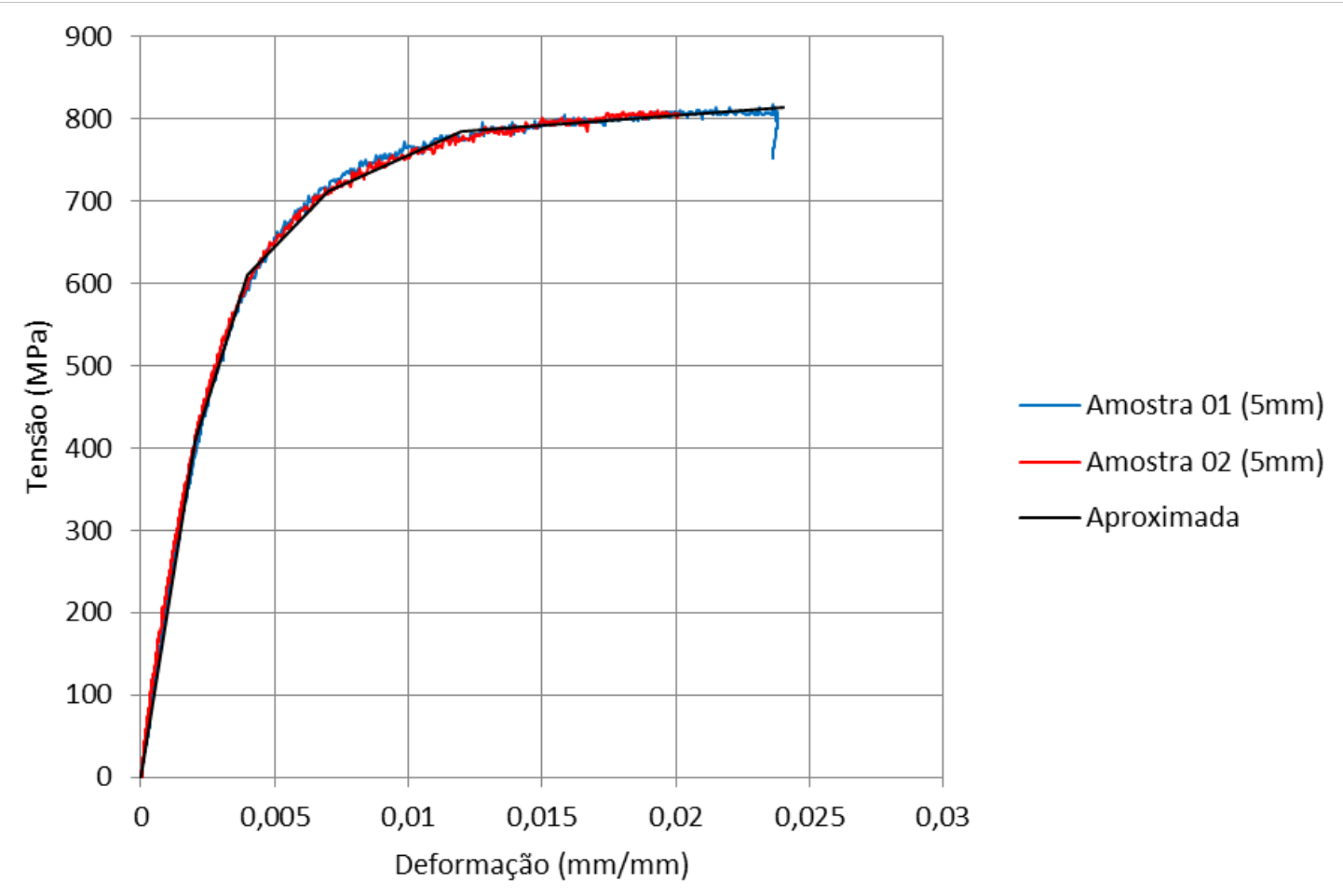

Figura 3.11 - Diagrama tensão-deformação das barras de aço das armaduras transversais. 


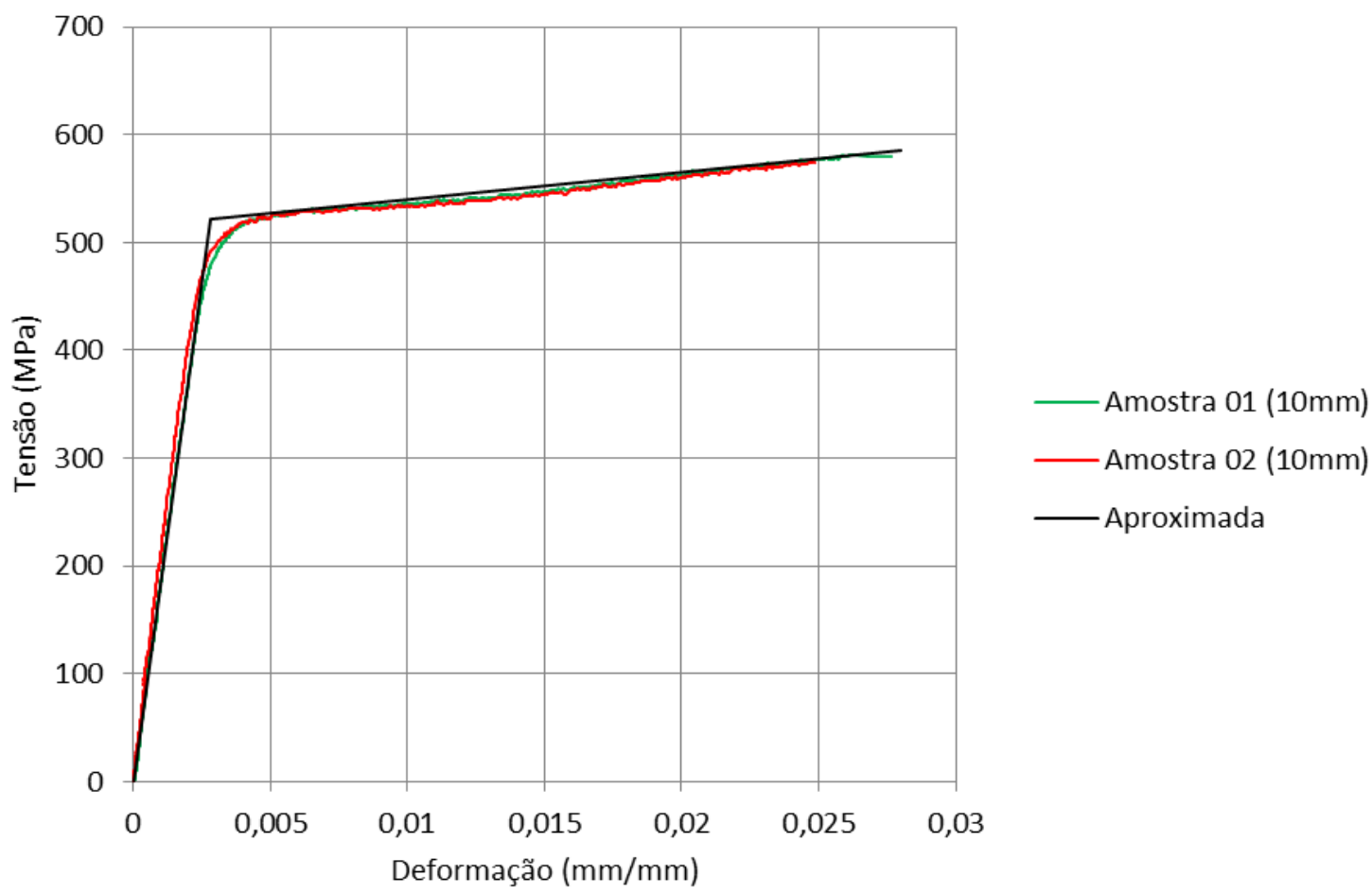

Figura 3.12 - Diagrama tensão-deformação das barras de aço das armaduras longitudinais.

\subsubsection{Polímero Reforçado com Fibra de Carbono (PRFC)}

O PRFC utilizado na pesquisa foi o SikaWrap 300 c/60 e a matriz foi a resina epóxi bicomponente Sikadur 330.

Os mesmos materiais foram utilizados por Oliveira (2017) em sua tese de doutorado e os resultados dos ensaios de caracterização obtidos em sua pesquisa podem ser observados na Tabela 3.10.

Tabela 3.10 - Propriedades do PRFC

\begin{tabular}{|c|c|c|c|c|c|c|}
\hline & $F(N)$ & $\varepsilon_{f}(\mathrm{~mm} / \mathrm{mm})$ & Largura $(\mathrm{mm})$ & Espessura $(\mathrm{mm})$ & $f_{\mathrm{f}}(\mathrm{MPa})$ & $\mathrm{E}_{\mathrm{f}}(\mathrm{MPa})$ \\
\hline $\mathrm{CP} 1$ & 17688,0 & 0,01444 & 17,25 & 0,16600 & 3089 & 213885 \\
\hline $\mathrm{CP} 2$ & 16571,0 & 0,01353 & 16,41 & 0,16600 & 3041 & 224788 \\
\hline $\mathrm{CP} 3$ & 15020,0 & 0,01226 & 16,61 & 0,16600 & 2724 & 222171 \\
\hline Média & & 0,01341 & & 0,16600 & 2951 & 220281 \\
\hline Fabricante & & 0,01500 & & 0,16600 & 3900 & 230000 \\
\hline
\end{tabular}

Fonte: Oliveira (2017)

De acordo com Oliveira (2017), a caracterização foi realizada por meio do ensaio de três corpos-de prova utilizando-se a máquina de ensaios EMIC com 
capacidade para $30 \mathrm{kN}$ seguindo as recomendações da ASTM D3039: 2014. Para a obtenção do módulo de elasticidade foram feitas leituras a $10 \%, 20$ \% e $30 \%$ da força última.

\subsubsection{GEOMETRIA E INSTRUMENTAÇÃO}

As dimensões adotadas para a moldagem dos pilares, foram pensadas a fim de se aproximar da área mínima proposta pela ABNT NBR 6118: 2014, de 360 cm², porém respeitando o limite da máquina de ensaio quanto à capacidade de força, que é de $2500 \mathrm{kN}$. A altura adotada dos pilares foi de $60 \mathrm{~cm}$, a fim de se ter um pilar curto e que não demandasse maiores equipamentos para seu manuseio.

Para facilitar a confecção de fôrmas para os pilares de seção circular, optou-se por utilizar tubos de PVC. Foram utilizados, portanto, tubos de PVC de $150 \mathrm{~mm}$ para a confecção dos pilares sem cobrimento de armadura, e depois foram utilizados tubos de PVC de $200 \mathrm{~mm}$ para a inserção dos cobrimentos de concreto de ultra-alto desempenho de $2,5 \mathrm{~cm}$ e tubos com diâmetro interno de $17,2 \mathrm{~cm}$, para a inserção dos cobrimentos de concreto de ultra-alto desempenho de $1,5 \mathrm{~cm}$.

As fôrmas dos pilares de seção quadrada foram feitas com chapas de MDF, parafusadas, descritas posteriormente com mais detalhes.

As composições de todos os pilares ensaiados, bem como a geometria dos mesmos, são apresentadas na Figura 3.13. 


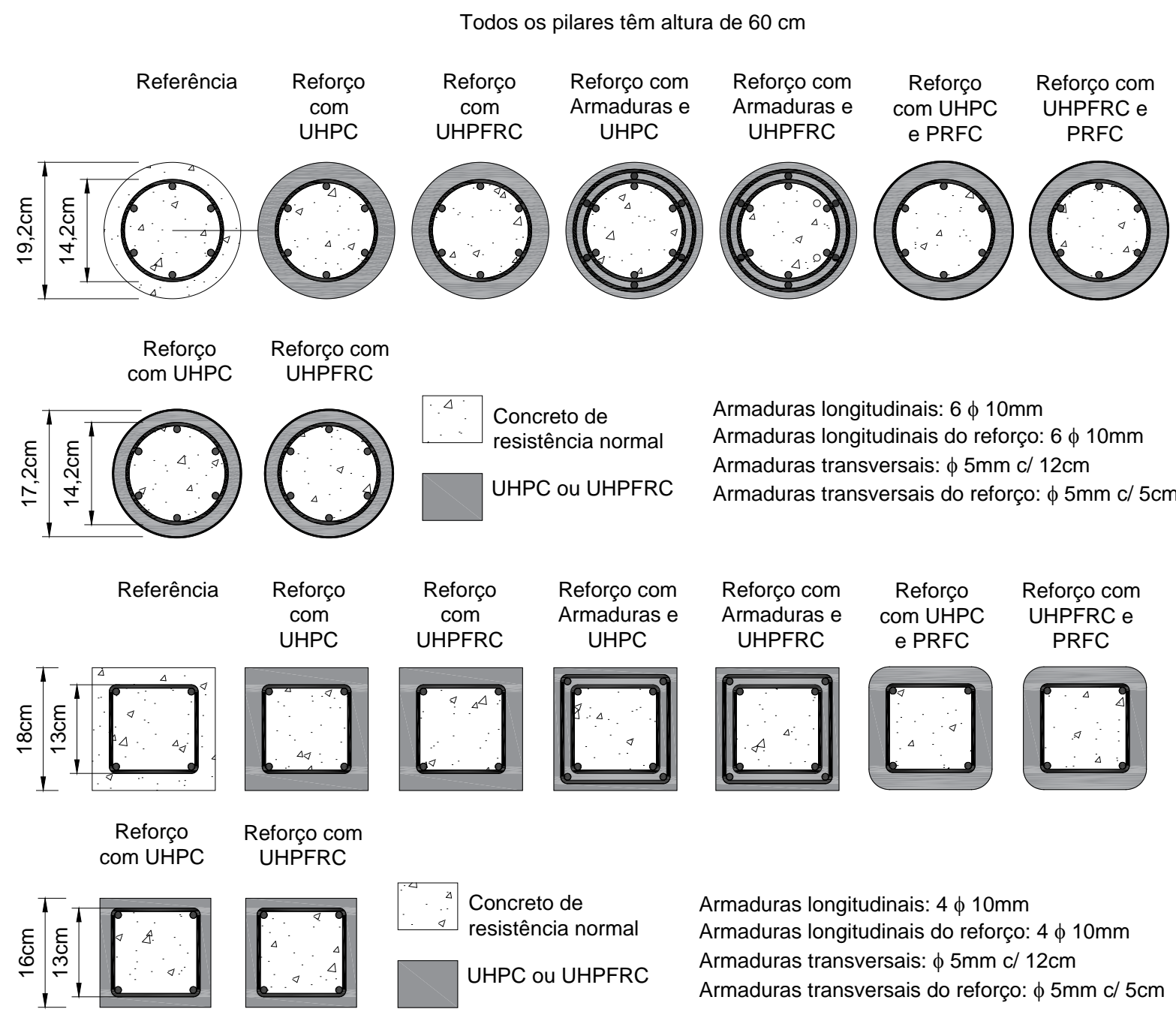

Figura 3.13 - Descrição da seção transversal dos pilares ensaiados.

Para a avaliar o comportamento dos pilares, os mesmos foram instrumentados com extensômetros e transdutores de deslocamentos instalados na metade da altura dos pilares. Foram instalados dois extensômetros em barras opostas, tanto nas armaduras longitudinais dos pilares originais (Figura 3.14), como nas armaduras longitudinais de reforço. Foram instalados também, extensômetros nos fios das armaduras transversais de reforço a fim de verificar os efeitos de confinamento, sendo que nos estribos circulares foram fixados diametralmente opostos e nos quadrados em lados opostos, como ilustra a Figura 3.15. 


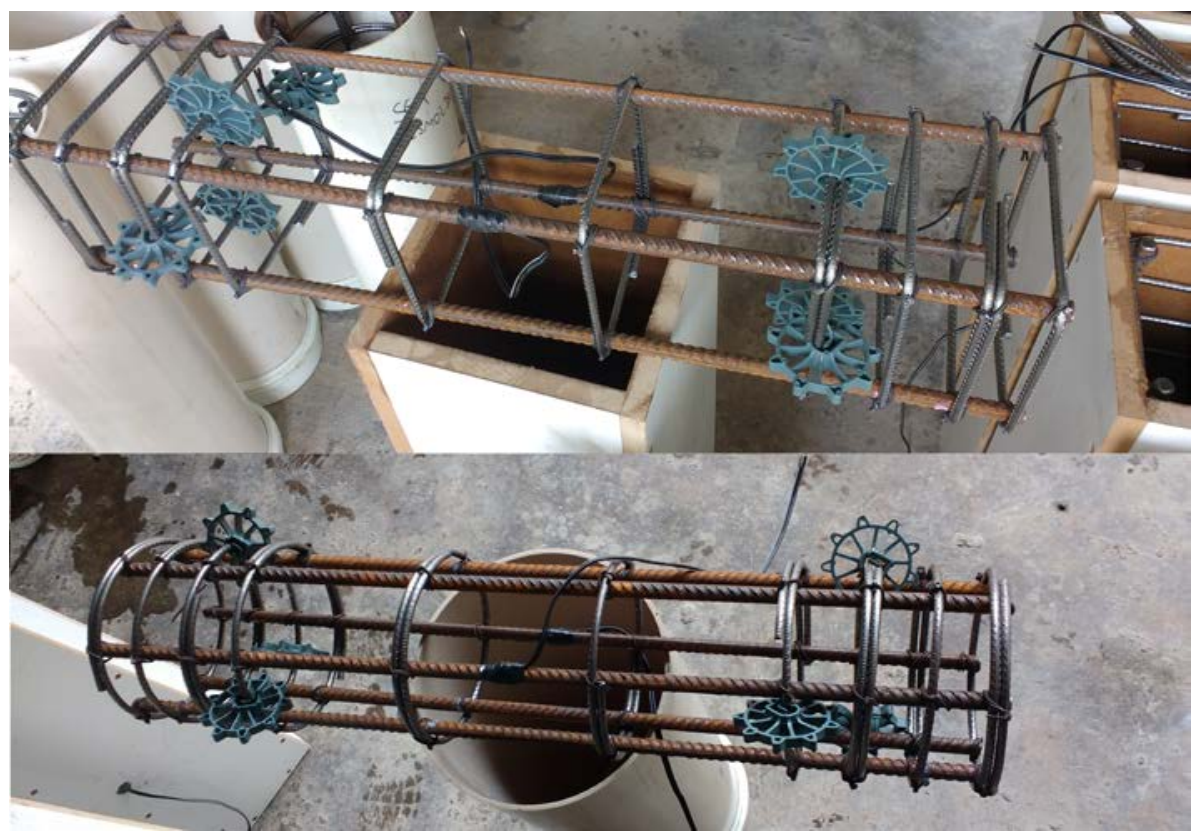

Figura 3.14 - Instrumentação das armaduras longitudinais dos pilares originais

Todos os extensômetros elétricos de resistência utilizados na pesquisa foram da marca KYOWA, modelo KFG-5-120-C1-11.

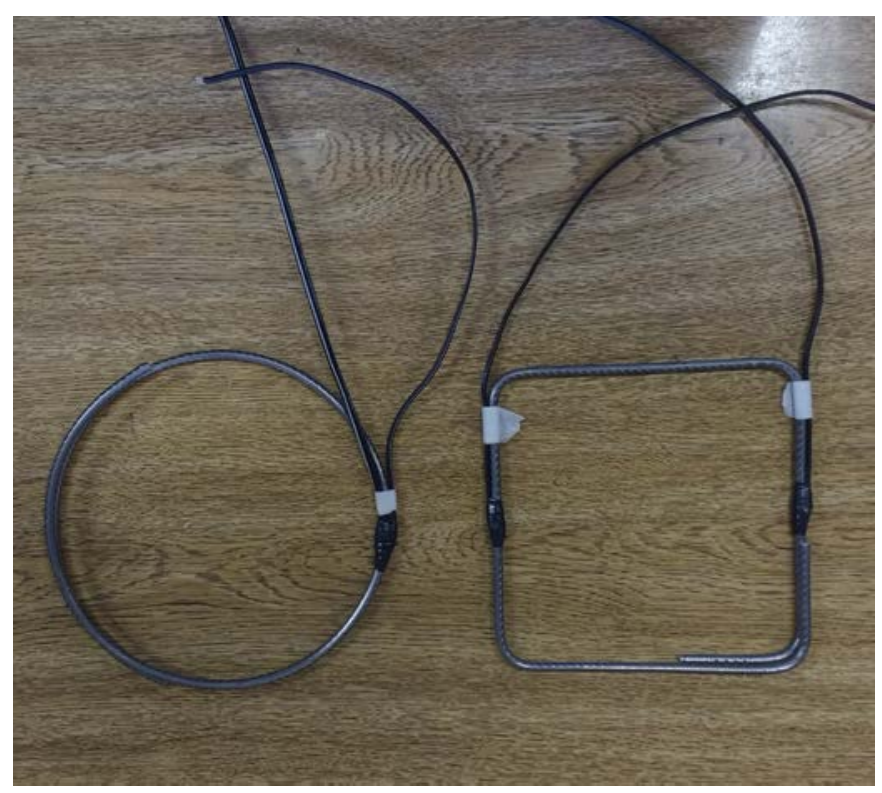

Figura 3.15 - Instrumentação dos estribos de reforço

Nos pilares quadrados, reforçados com UHPC ou UHPFRC e camada adicional de PRFC, foram colados seis extensômetros no PRFC, dispostos da seguinte maneira: um no centro, outro no início do arredondamento do canto e um no centro do canto arredondado (Figura 3.16a). Os outros três foram dispostos da mesma maneira, porém na face oposta. 
Nos pilares circulares, reforçados com UHPC ou UHPFRC e camada adicional de PRFC, foram colados dois extensômetros no PRFC, diametralmente opostos e na metade da altura (Figura 3.16b).

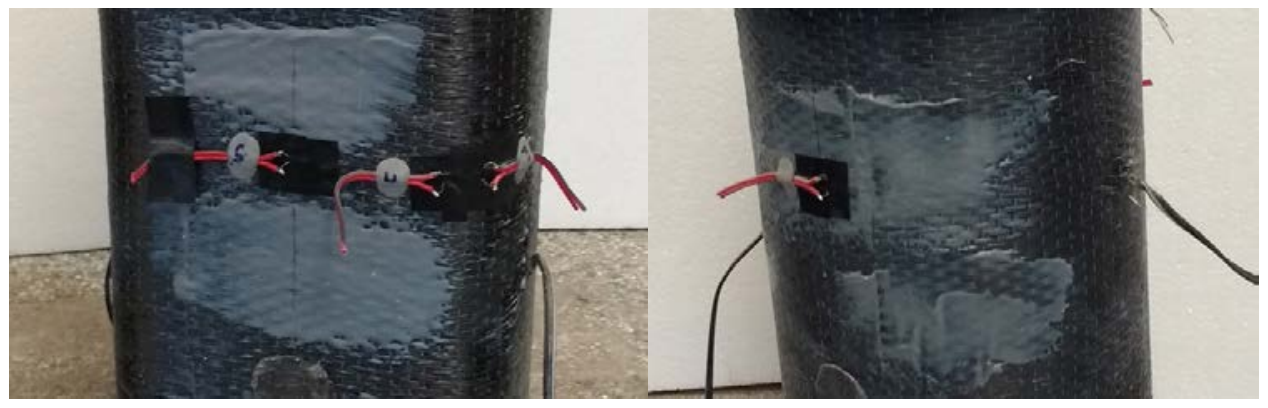

(a)

(b)

Figura 3.16 - Instrumentação de um dos lados dos pilares quadrados e circulares reforçados com PRFC

Para cada pilar ensaiado, foram utilizados quatro transdutores de deslocamento resistivo, marca Vishay, modelo HS25, com curso de $25 \mathrm{~mm}$. No caso foram instalados dois para a determinação da deformação total do pilar e dois para a determinação da deformação na porção média do mesmo (19 cm centrais), como mostra a Figura 3.17.

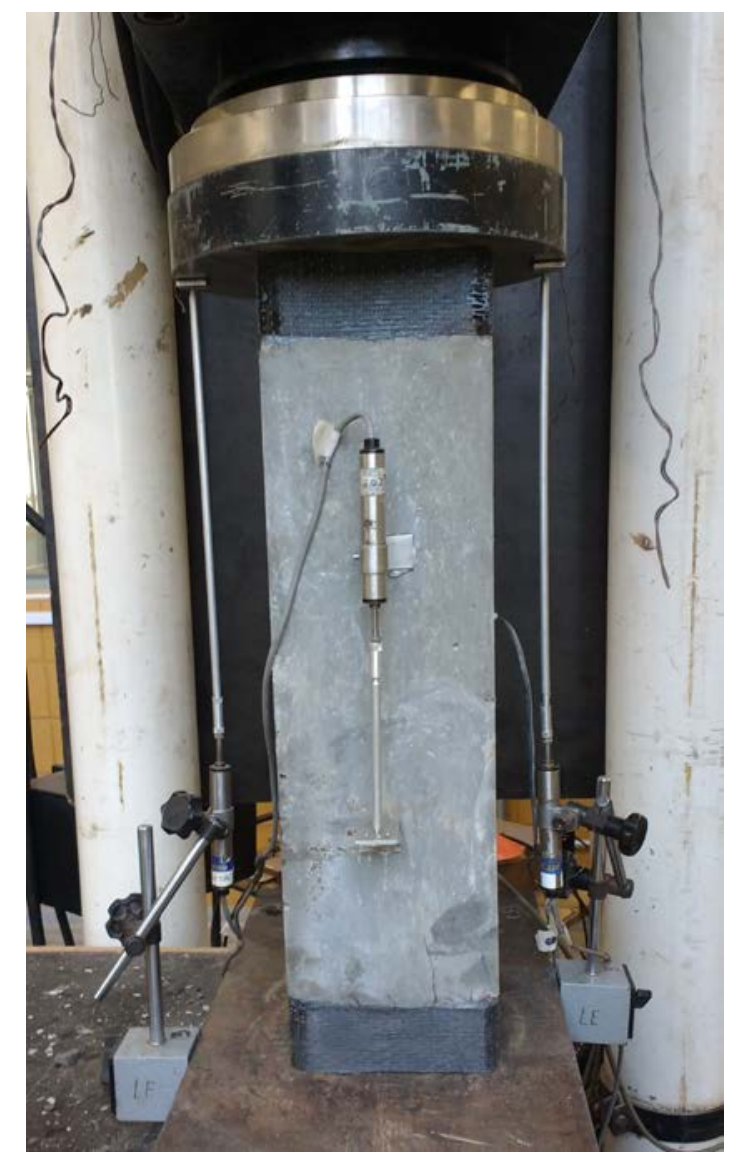

Figura 3.17 - Posição dos transdutores de deslocamento 


\subsubsection{NOMENCLATURA DOS PILARES}

Para facilitar a apresentação dos resultados, optou-se por adotar uma nomenclatura que levasse em consideração a geometria do pilar, a presença ou não de fibras metálicas no concreto de reforço e por fim algumas complementações com relação à camisa de reforço, como a redução da espessura padrão adotada $(2,5 \mathrm{~cm})$, a inserção de armadura de reforço ou o encamisamento com PRFC (polímero reforçado com fibra de carbono). O modo como foi definida a nomenclatura dos pilares pode ser melhor compreendida observando-se a Figura 3.18 e a nomenclatura dada a cada um dos pilares ensaiados é mostrada na Tabela 3.11

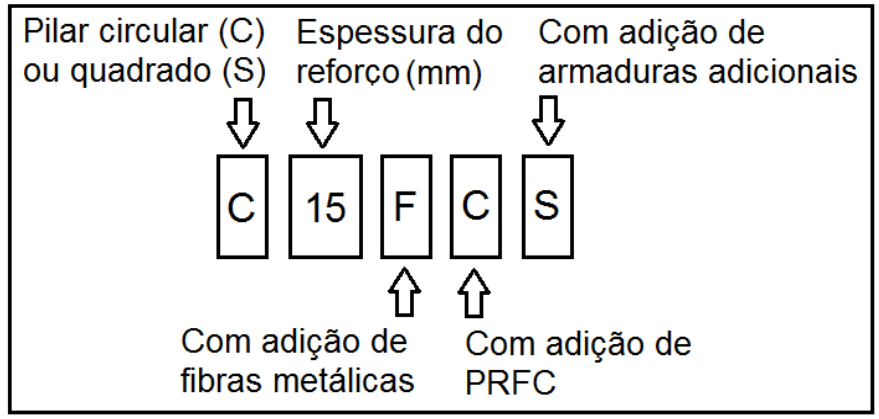

Figura 3.18 - Apresentação da nomenclatura dos pilares

Tabela 3.11 - Nomenclatura dos pilares ensaiados (sem repetição)

\begin{tabular}{|c|c|c|}
\hline & NOME & DESCRIÇÃO DOS PILARES \\
\hline \multirow{9}{*}{ 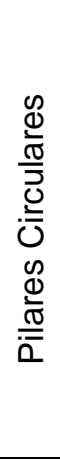 } & CREF & Pilar de seção circular de referência \\
\hline & $\mathrm{C} 25$ & Pilar de seção circular reforçado com UHPC \\
\hline & C15 & Pilar de seção circular reforçado com UHPC com espessura reduzida \\
\hline & C25C & Pilar de seção circular reforçado com UHPC e PRFC \\
\hline & C25S & Pilar de seção circular reforçado com UHPC e armadura adicional \\
\hline & $\mathrm{C} 25 \mathrm{~F}$ & Pilar de seção circular reforçado com UHPFRC \\
\hline & C15F & Pilar de seção circular reforçado com UHPFRC com espessura reduzida \\
\hline & C15FC & Pilar de seção circular reforçado com UHPFRC e PRFC \\
\hline & C15FS & Pilar de seção circular reforçado com UHPFRC e armadura adicional \\
\hline \multirow{9}{*}{ 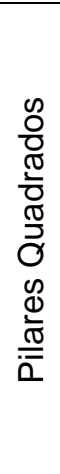 } & SREF & Pilar de seção quadrada de referência \\
\hline & S25 & Pilar de seção quadrada reforçado com UHPC \\
\hline & S15 & Pilar de seção quadrada reforçado com UHPC com espessura reduzida \\
\hline & $\mathrm{S} 25 \mathrm{C}$ & Pilar de seção quadrada reforçado com UHPC e PRFC \\
\hline & S25S & Pilar de seção quadrada reforçado com UHPC e armadura adicional \\
\hline & $\mathrm{S} 25 \mathrm{~F}$ & Pilar de seção quadrada reforçado com UHPFRC \\
\hline & S15F & Pilar de seção quadrada reforçado com UHPFRC com espessura reduzida \\
\hline & S15FC & Pilar de seção quadrada reforçado com UHPFRC e PRFC \\
\hline & S15FS & Pilar de seção quadrada reforçado com UHPFRC e armadura adicional \\
\hline
\end{tabular}




\subsubsection{DESCRIÇÃO DO PROCESSO DE FABRICAÇÃO DOS PILARES}

As fôrmas dos pilares quadrados foram executadas em MDF e as dos pilares circulares em PVC. Nas fôrmas dos pilares que receberam a camisa de reforço, foram inseridos parafusos na base (Figura 3.19), a fim de servirem de guia quando os mesmos recebessem o concreto de ultra-alto desempenho.

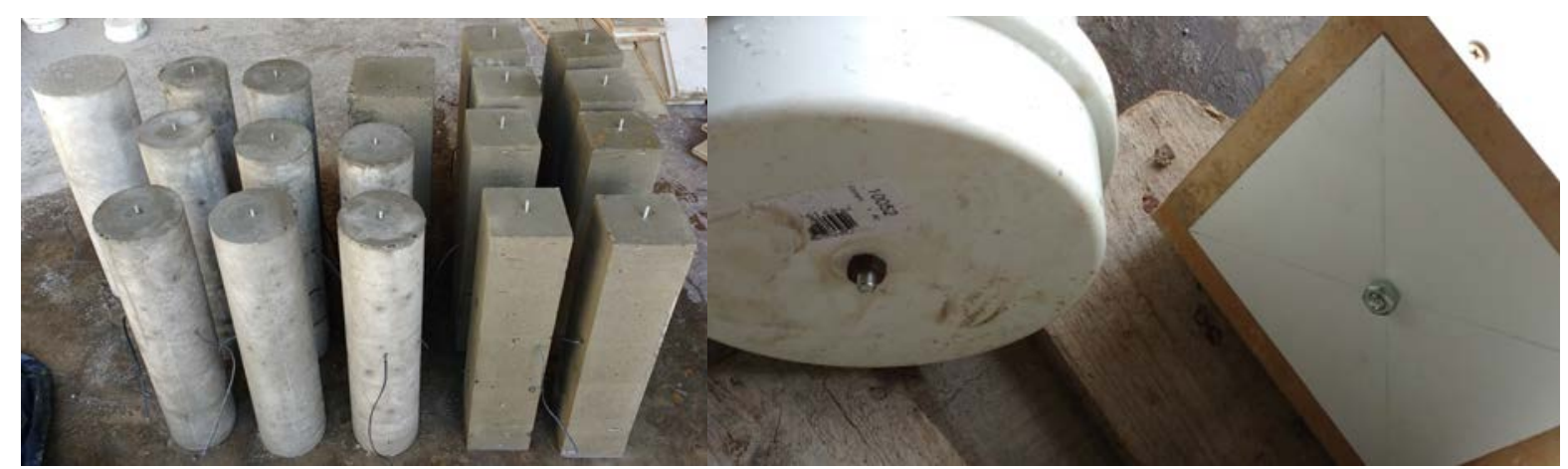

Figura 3.19 - Parafusos utilizados para centralizar os pilares originais

Todos os pilares foram concretados de uma única vez com concreto convencional, utilizando o misturador planetário de concreto, pois era o único que tinha capacidade de misturar o volume necessário para concretar todos os pilares. Para o adensamento destes pilares foi utilizado um vibrador com mangote de $25,4 \mathrm{~mm}$ (Figura 3.20).

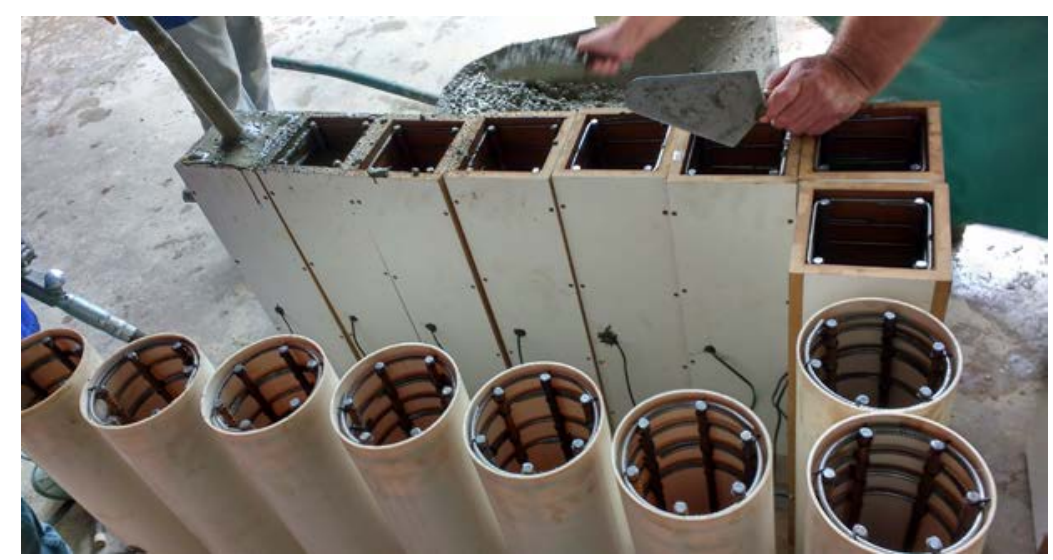

Figura 3.20 - Concretagem dos pilares com concreto convencional

Após a desforma dos pilares, com exceção dos pilares de referência, todos foram submetidos a um desgaste da superfície por uma esmerilhadeira angular com disco diamantado a fim de se obter uma superfície rugosa para receber a camisa de concreto de ultra-alto desempenho (Figura 3.21). 


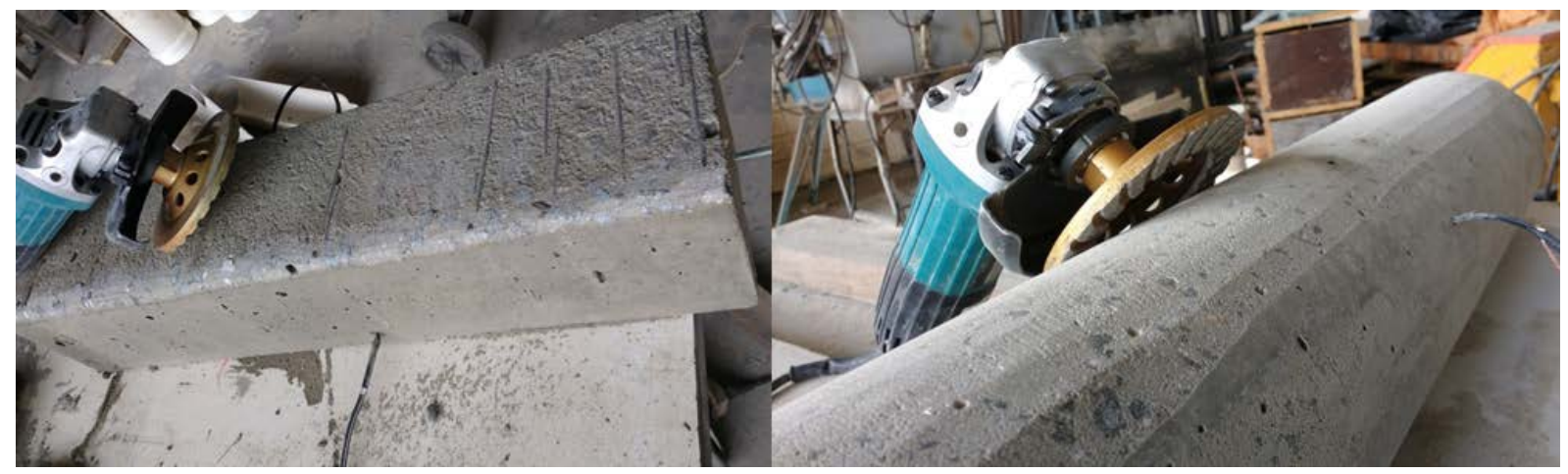

Figura 3.21 - Preparo da superfície para receber o UHPC e o UHPFRC

As fôrmas quadradas destinadas a receber o reforço com concreto de ultra-alto desempenho e PRFC, tiveram seus cantos arredondados com o uso de um quarto de tubo de PVC 60 mm colado com massa plástica (Figura 3.22).

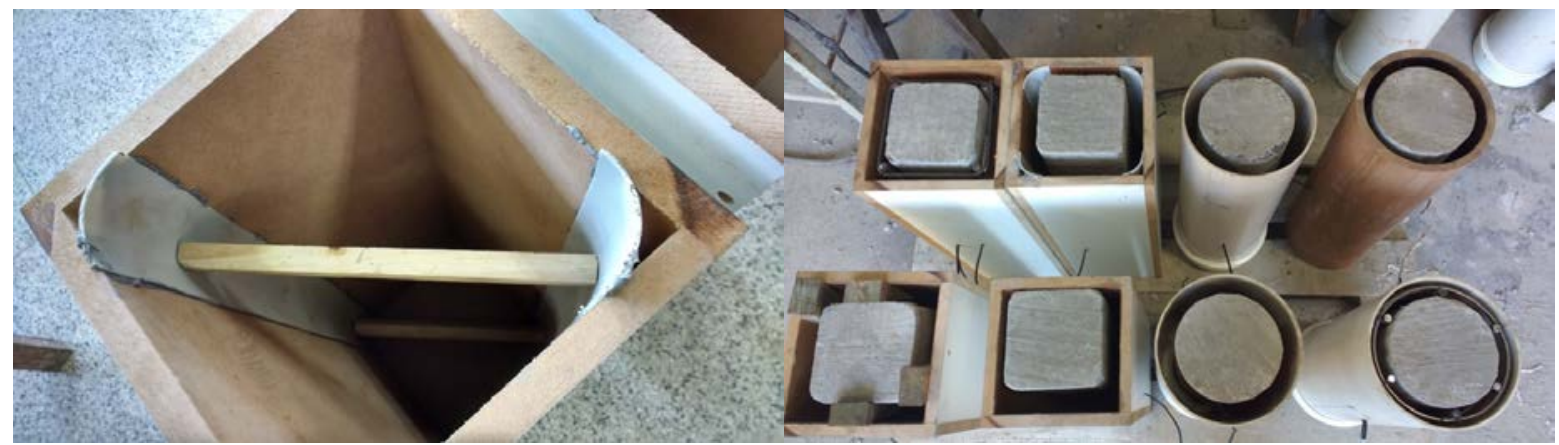

Figura 3.22 - Arredondamento dos cantos por meio de colagem de tiras de tubo de PVC

A centralização dos pilares nas fôrmas posteriores, foi feita por meio de cunhas de madeira, retiradas durante a concretagem e pelo parafuso de base.

A concretagem do reforço com concreto de ultra-alto desempenho se deu em quatro dias distintos. Primeiramente foram concretados com UHPC (concreto de ultraalto desempenho sem fibras metálicas) quatro pilares circulares, posteriormente, foram concretados também com UHPC, quatro pilares quadrados, depois, com UHPFRC (concreto de ultra-alto desempenho sem fibras metálicas), quatro pilares circulares e por fim com UHPRFC quatro pilares quadrados.

O adensamento do cobrimento de UHPC e de UHPFRC, foi feito por meio de haste metálica maciça fixada com o uso de abraçadeiras metálicas no mangote do vibrador (Figura 3.23). Esta técnica se mostrou muito simples e eficiente para a vibração do concreto em espaços estreitos. 


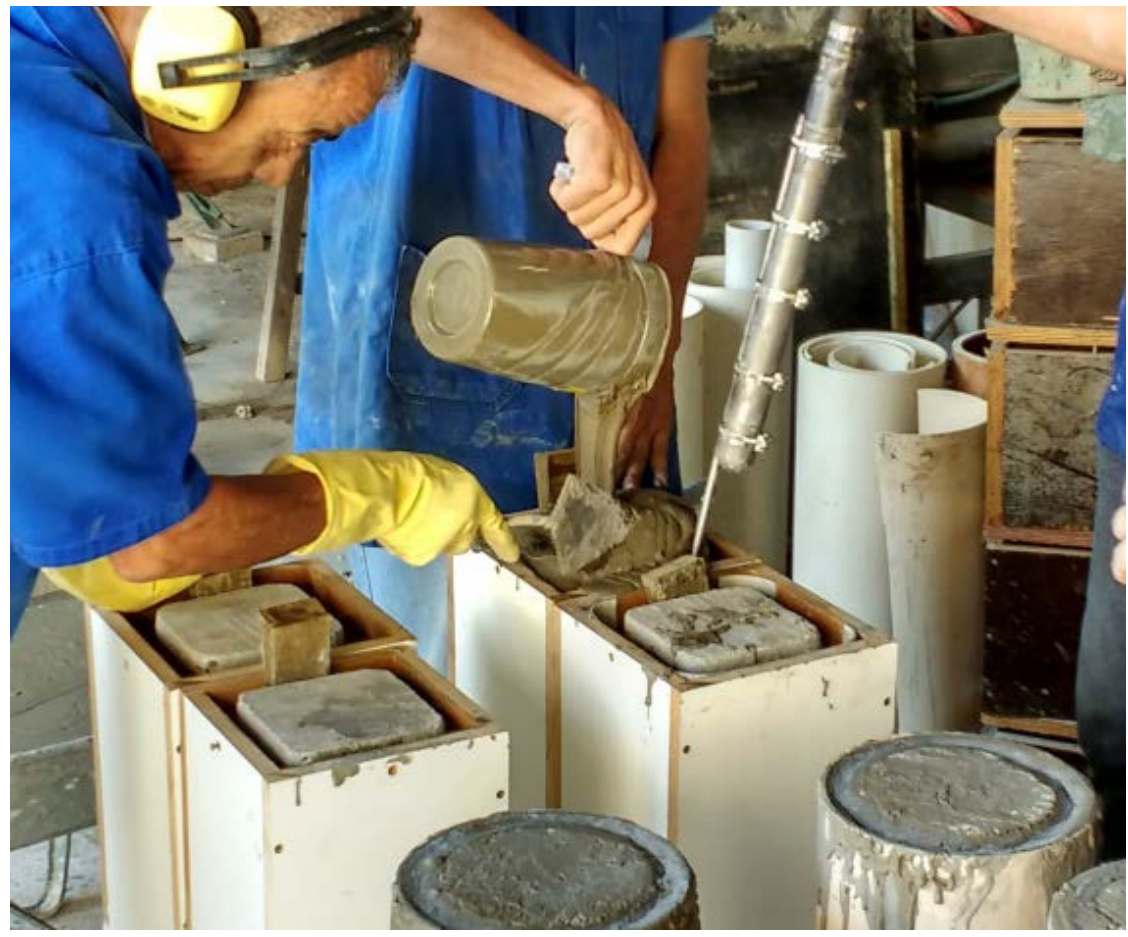

Figura 3.23 - Adensamento do concreto de ultra-alto desempenho

Após a desforma, as seções de topo dos pilares foram retificadas por uma esmerilhadeira com disco diamantado pois não havia retífica que comportasse os pilares moldados. As seções de topo dos pilares são apresentadas na Figura 3.24.

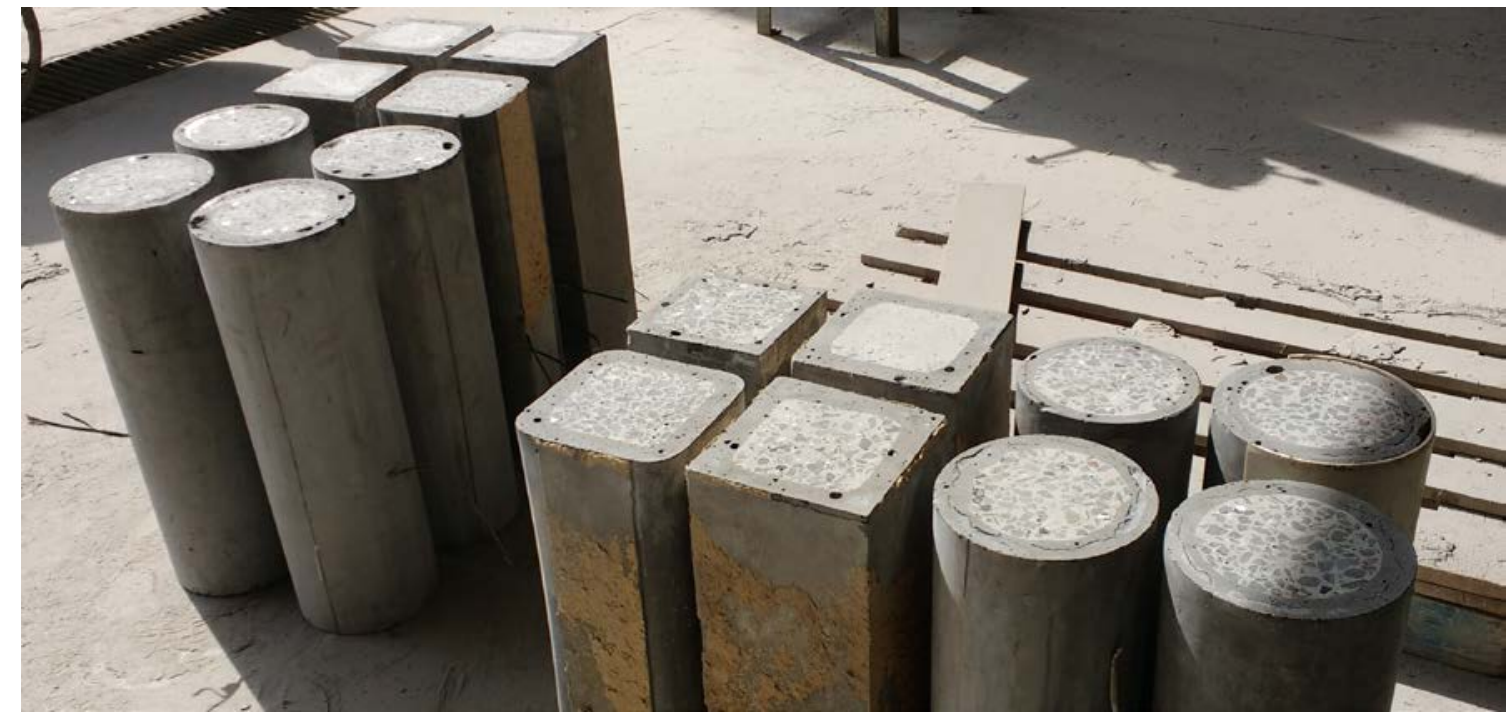

Figura 3.24 - Superfície dos pilares após a retifica da superfície com a esmerilhadeira

Para garantir que os pilares não rompessem nas extremidades, todos os pilares receberam duas camadas adicionais de PRFC, e para tanto, foi necessário arredondar os cantos dos pilares quadrados. O arredondamento foi realizado com a esmerilhadeira com disco diamantado como mostra a Figura 3.25. 


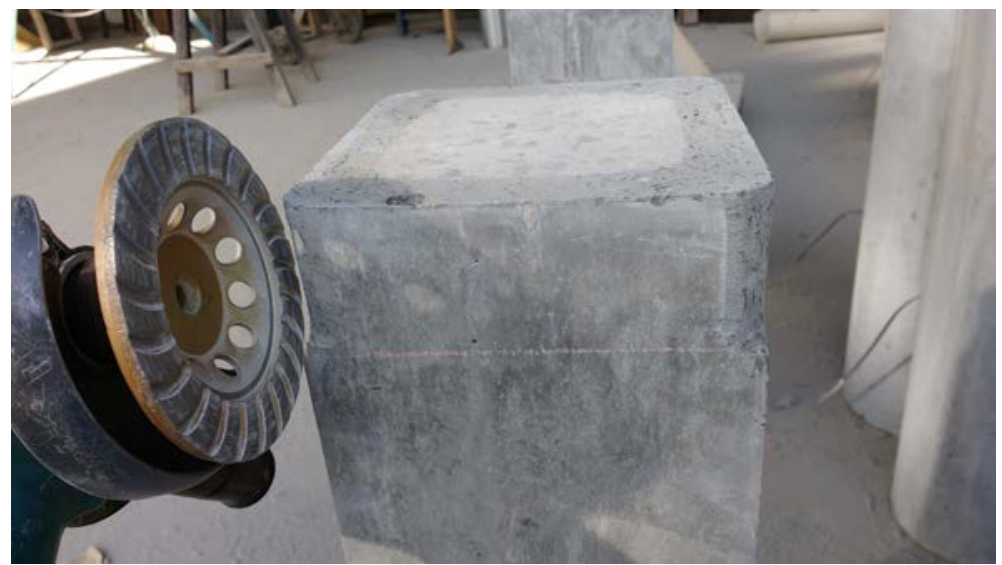

Figura 3.25 - Arredondamento dos cantos dos pilares quadrados com esmerilhadeira para receber o PRFC

Finalmente, alguns pilares foram reforçados com uma camada de PRFC, e outros apenas as extremidades, como mostra a Figura 3.26.

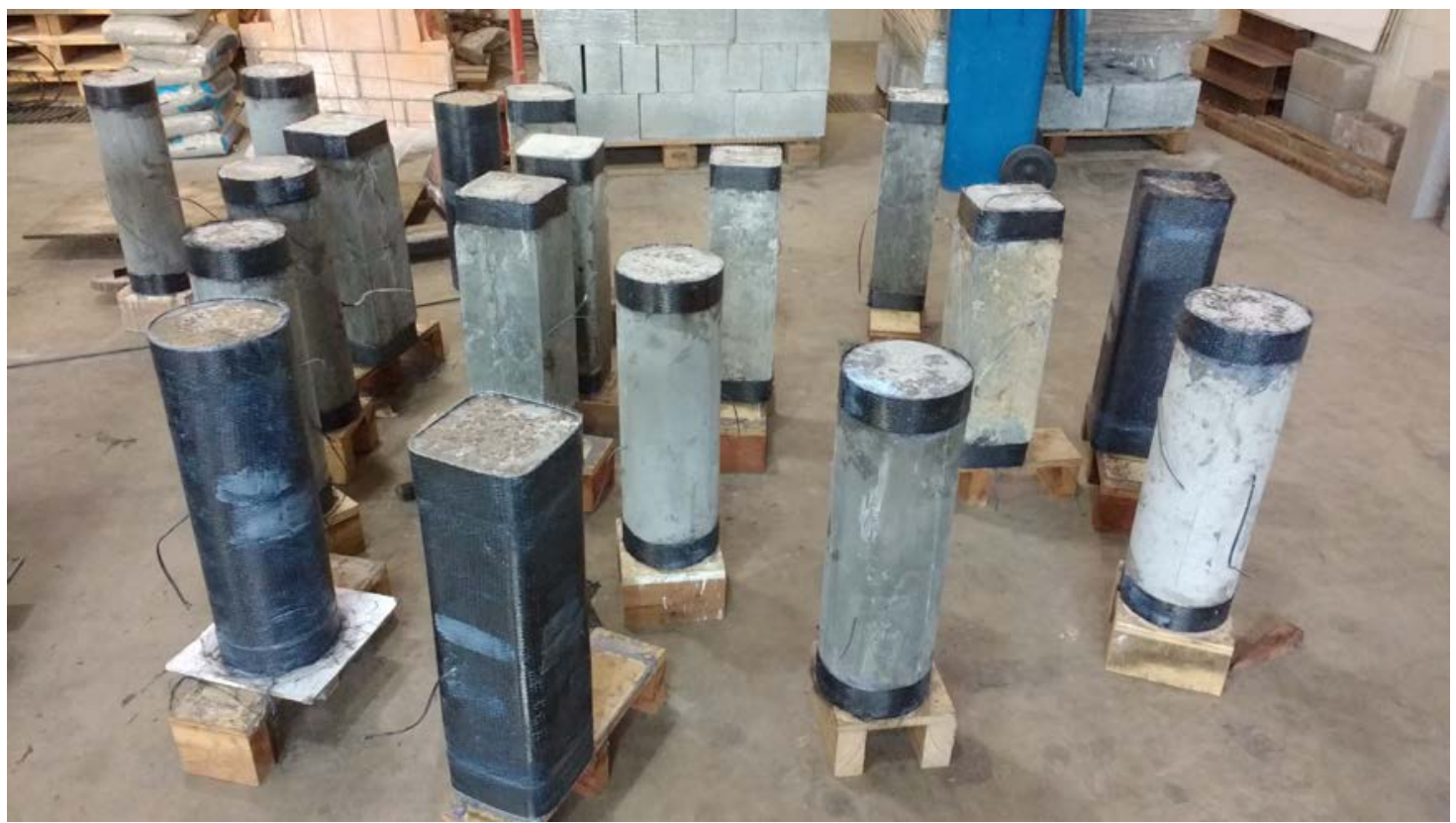

Figura 3.26 - Pilares preparados para o ensaio

\subsubsection{DESCRIÇÃO DOS ENSAIOS DOS PILARES}

Para o ensaio de compressão axial dos pilares, foi utilizada a máquina universal de ensaio, servo-hidráulica - Instron, modelo 8506A, com capacidade de 2.500 kN (Figura 3.27).

Os ensaios foram realizados com controle de deslocamento, com taxa de velocidade de $0,05 \mathrm{~mm} / \mathrm{s}$. O sistema de aquisição de dados utilizado foi o System 5000 da marca VISHAY. 
Os transdutores de deslocamento localizados na parte central dos pilares foram retirados antes da ruína para evitar o dano do equipamento. As leituras destes transdutores foram utilizadas para corrigir a rigidez inicial dos pilares.

Os transdutores utilizados nas medições de prato a prato da máquina de ensaio não foram retirados durante o ensaio. As curvas força-deslocamento dos pilares foram elaboradas considerando a média entre as medidas dos dois transdutores.

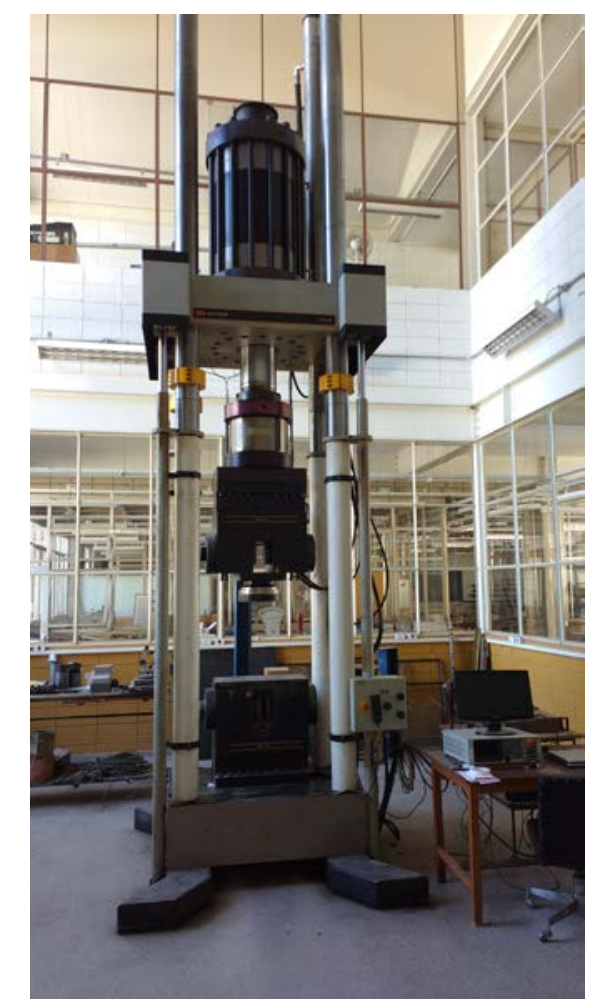

Figura 3.27 - Máquina universal de ensaio, servo-hidráulica - Instron, modelo 8506A, com capacidade de $3.000 \mathrm{kN}$.

\subsubsection{ELABORAÇÃO DOS DIAGRAMAS FORÇA-DESLOCAMENTO}

Este item aborda o procedimento adotado para a construção do diagrama forçadeslocamento dos pilares ensaiados.

Os pilares ensaiados apresentaram acomodações iniciais e rigidezes de interfaces observadas na construção da curva média entre os trandutores 01 e 02 (mediam os deslocamentos de prato a prato da máquina de ensaio), tais efeitos foram corrigidos conforme descrição a seguir.

Para melhor entendimento do processo de correção, a Figura 3.28 ilustra um caso típico, em que a área hachurada representa uma região com menor rigidez $\left(k_{a}\right)$, o pilar com rigidez $k_{p}$, e o conjunto com uma rigidez $k$. 

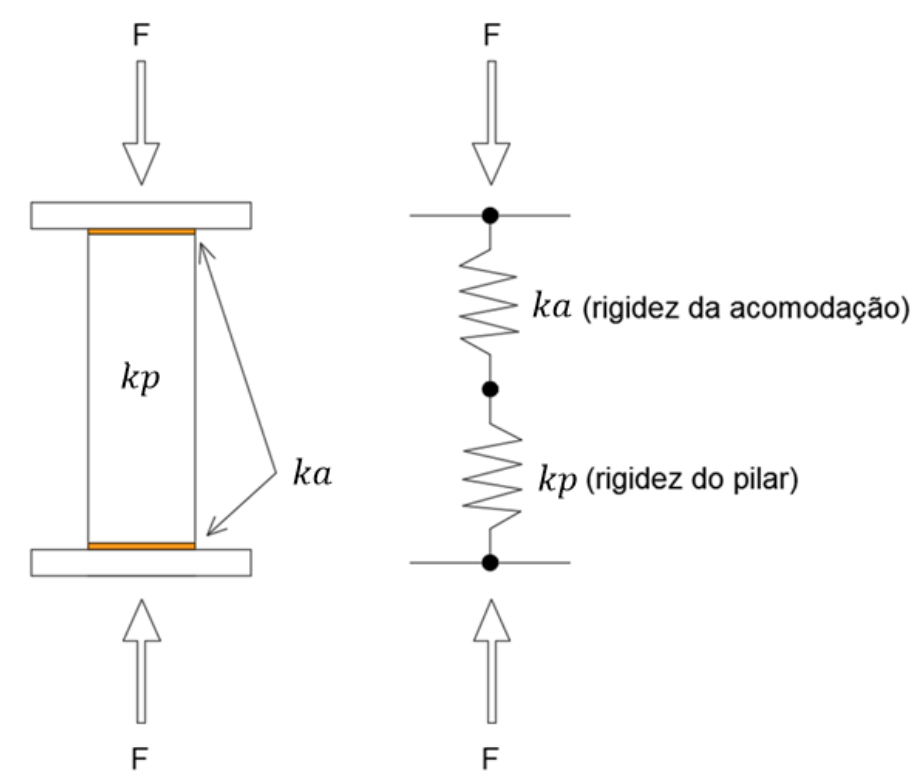

Figura 3.28 - Esquema representativo da rigidez dos pilares ensaiados.

A rigidez total, portanto, é dada pela equação 18.

$$
\frac{1}{k}=\frac{1}{k a}+\frac{1}{k p}
$$

A rigidez da região de acomodação pode ser escrita conforme a equação 19.

$$
k a=\frac{1}{\frac{1}{k}-\frac{1}{k p}}
$$

A rigidez $k$ (total) era conhecida a partir das leituras dos transdutores de prato a prato da máquina de ensaio. A rigidez $k_{p}$ pôde ser avaliada a partir das leituras dos transdutores na porção central dos pilares.

Assim, verificou-se nas leituras dos transdutores, a primeira região onde todos eles não apresentavam variações acentuadas na rigidez (Figura 3.29). Tomando-se o referido intervalo, escreveram-se as equações das retas, e, por conseguinte determinou-se a rigidez medida pelos transdutores de deslocamento.

Em virtude das diferenças de bases de medidas entre $k$ e $k_{p}$, foram multiplicados os deslocamentos referentes aos transdutores centrais pelo fator 60/19, já que os deslocamentos de prato a prato eram referentes ao tamanho do pilar (60 $\mathrm{cm}$ ) e os deslocamentos centrais eram referentes aos $19 \mathrm{~cm}$ centrais. 


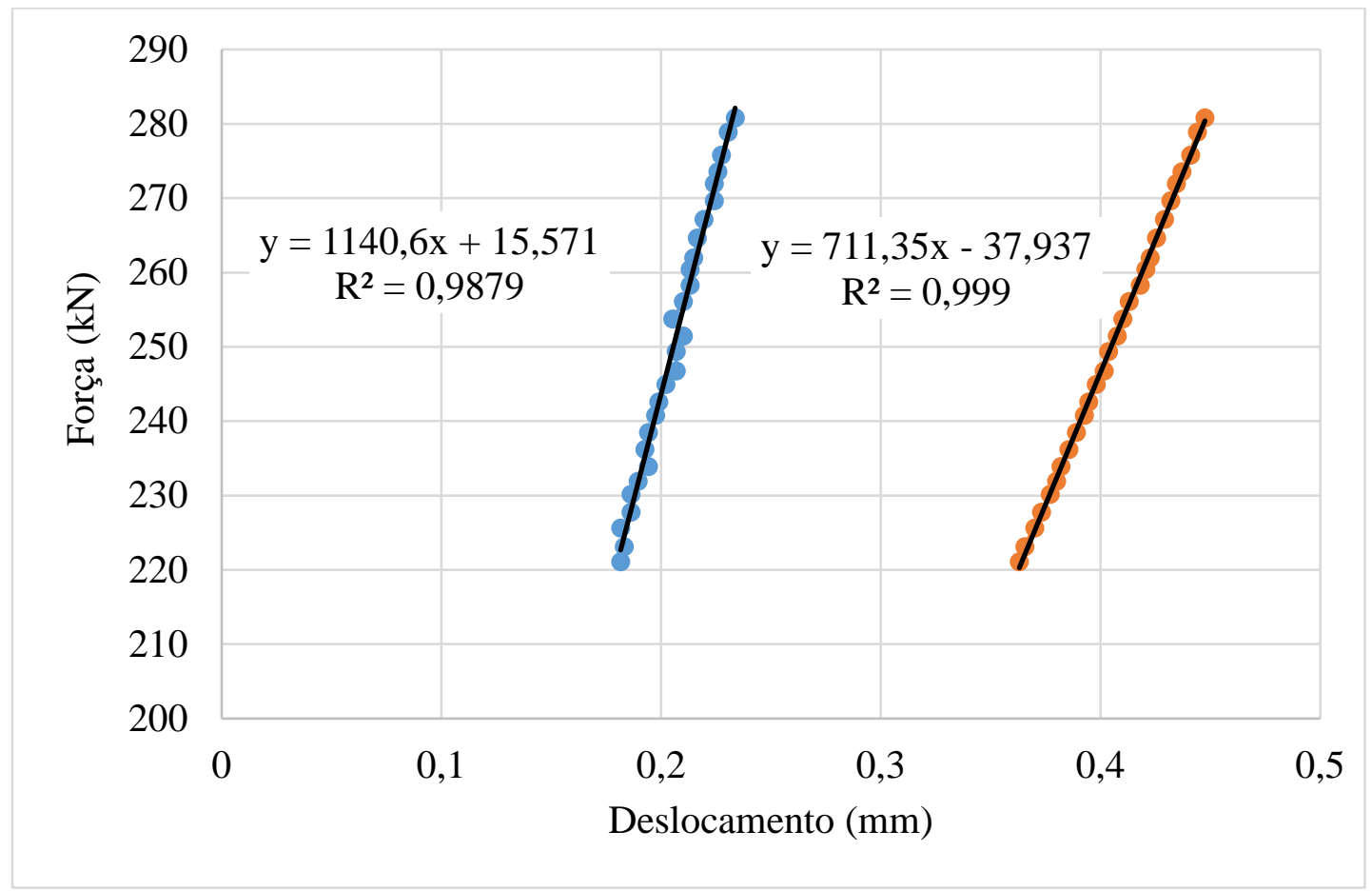

Figura 3.29 - Equações da primeira região onde todos os trandutores de deslocamento não apresentavam variações acentuadas na rigidez.

Substituiu-se então, a rigidez inicial até o intervalo escolhido (no caso, de $711,35)$ pela rigidez encontrada nos transdutores centrais $(1140,6)$.

Após este ponto, reduziu-se de cada incremento de deslocamento, a porção referente ao distanciamento da reta em relação ao eixo y, quando a mesma cruza o eixo x (no caso, 37,973 dividido por 711,35) e a parcela F/Ka.

Seguindo os procedimentos expostos, chega-se à curva corrigida, ilustrada na Figura 3.30 


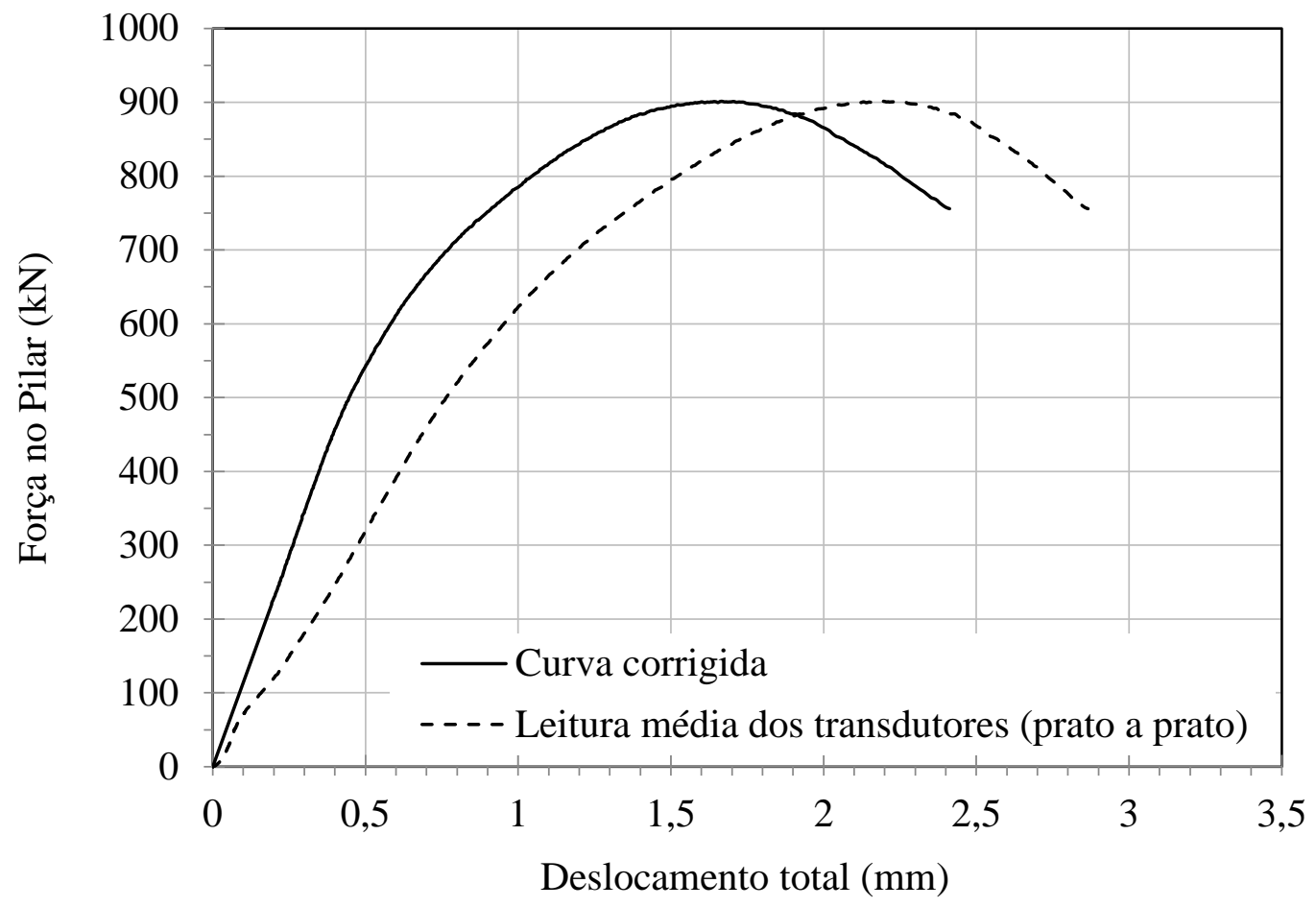

Figura 3.30 - Curvas força-deslocamento com e sem correção do pilar CREF.

As curvas força-deslocamento de todos os pilares foram corrigidas segundo 0 procedimento exposto.

\subsection{SIMULAÇÃO NUMÉRICA}

As simulações foram realizadas por meio do método dos elementos finitos utilizando o programa ABAQUS. O concreto, o UHPFRC e as armaduras foram modelados com elementos sólidos tridimensionais tipo C3D8R (Figura 3.31). Este elemento possui 8 nós, com três graus de liberdade por nó e integração reduzida.

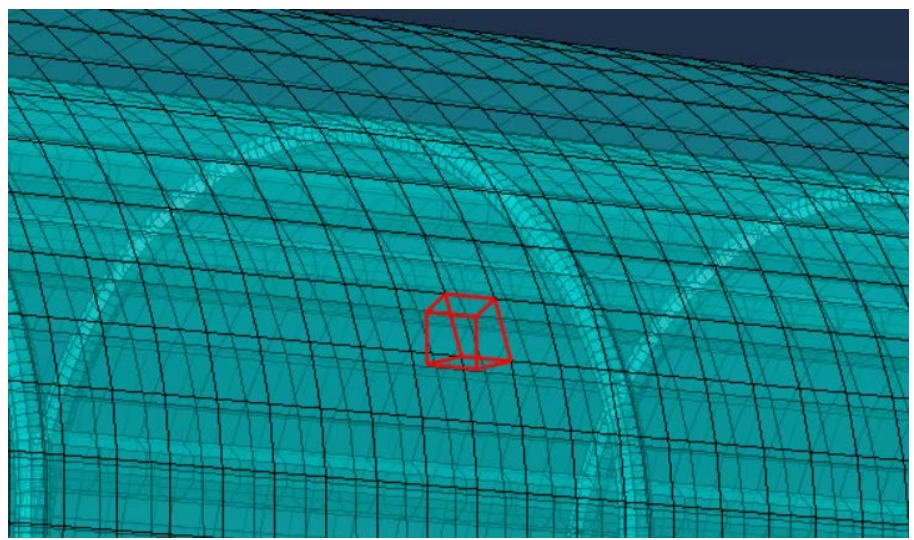

Figura 3.31 - Elemento sólido tridimensional C3D8R utilizado na simulação. 
A camisa de PRFC foi modelada com elementos de casca S4R. Os elementos tipo S4R possuem 4 nós, 6 graus de liberdade por nó e integração reduzida.

Foram utilizadas condições de plena aderência entre o concreto convencional e o UHPFRC e entre o UHPFRC e o PRFC por meio do comando "tie" e as barras de fios de aço foram consideradas imersas no concreto por meio do comando "embedded region".

Os dados relacionados às curvas tensão-deformação dos materiais foram baseados em curvas aproximadas referentes aos ensaios de caracterização. Optouse pela simplificação das curvas a fim de melhorar a convergência do modelo. As curvas representando a compressão axial no concreto convencional e do UHPFRC podem ser observadas na Figura 3.32 e na Figura 3.33, respectivamente, e as curvas pertinentes à tração dos aços utilizados nas armaduras longitudinais e nos estribos podem ser observadas na Figura 3.34 e na Figura 3.35, respectivamente.

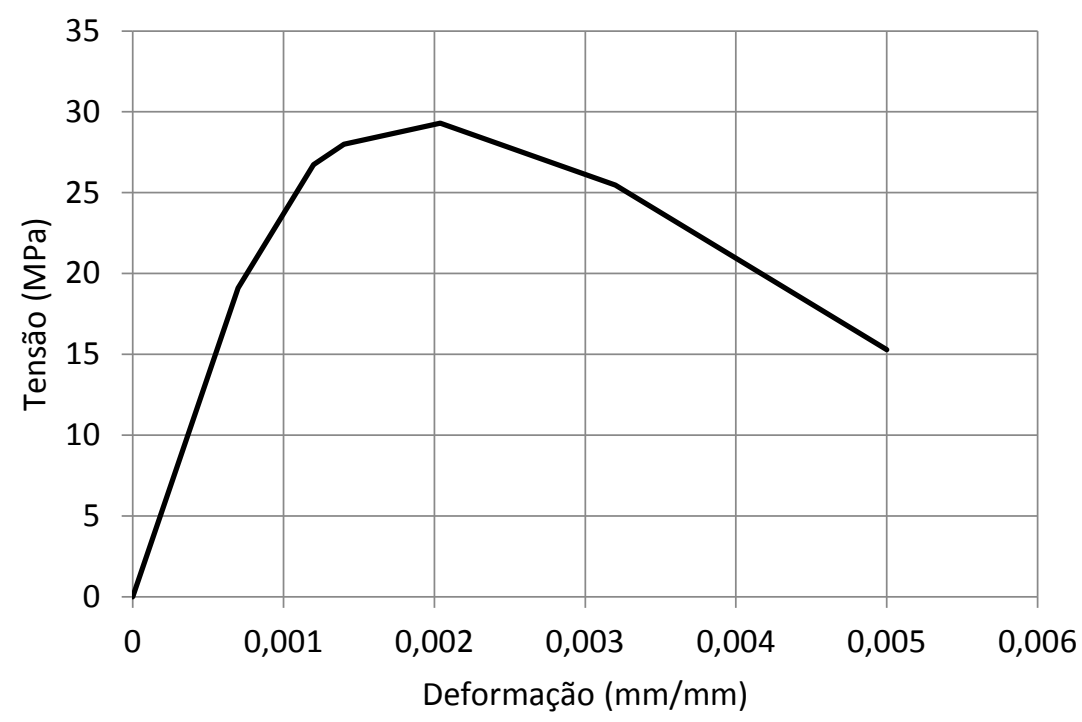

Figura 3.32 - Curva tensão-deformação do concreto convencional utilizada para a simulação numérica. 


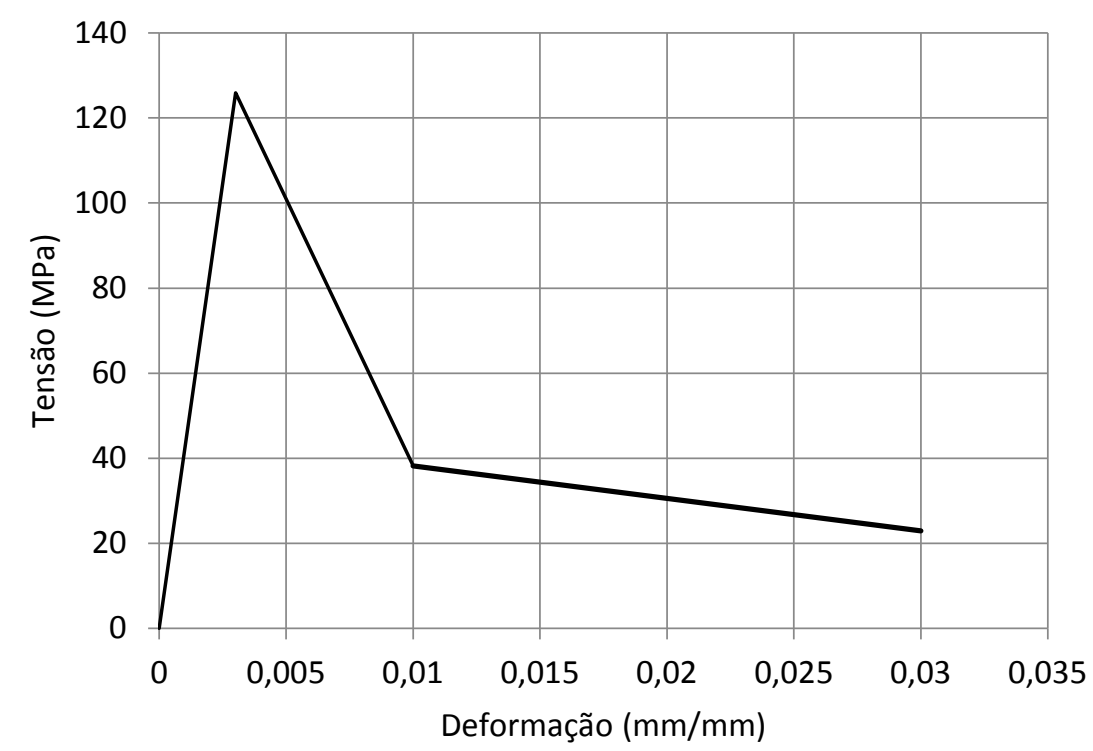

Figura 3.33 - Curva tensão-deformação do UHPFRC utilizada para a simulação numérica.

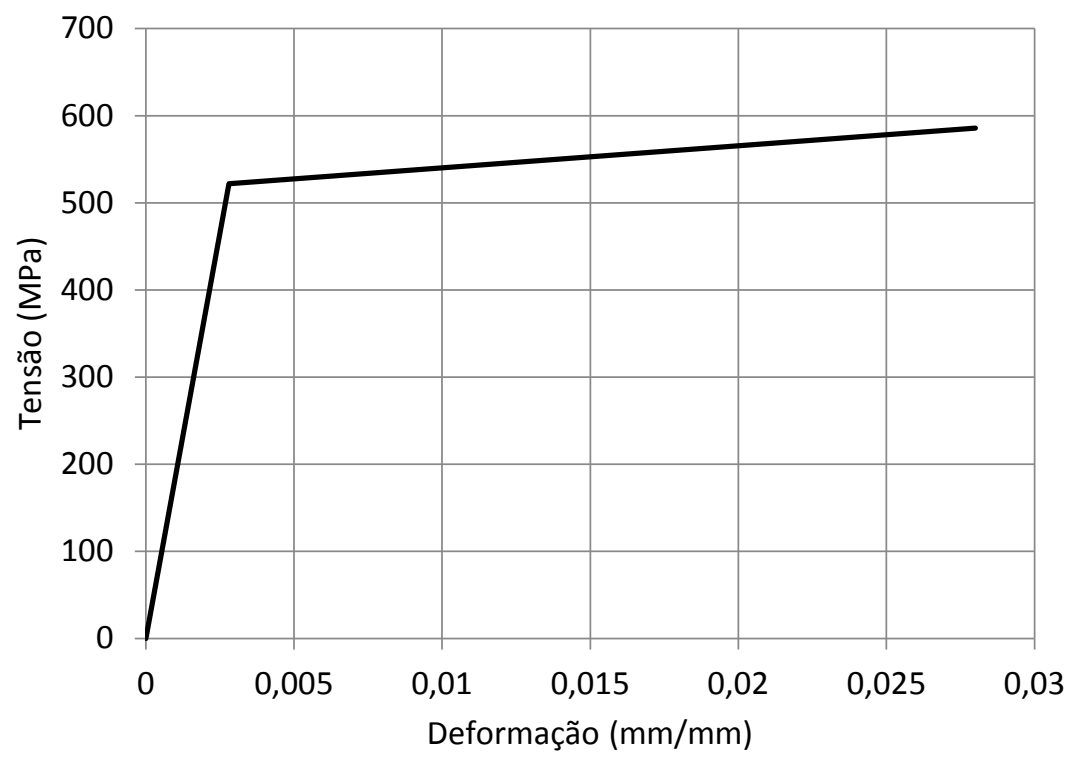

Figura 3.34 - Curva tensão-deformação do aço das armaduras longitudinais utilizada para a simulação numérica. 


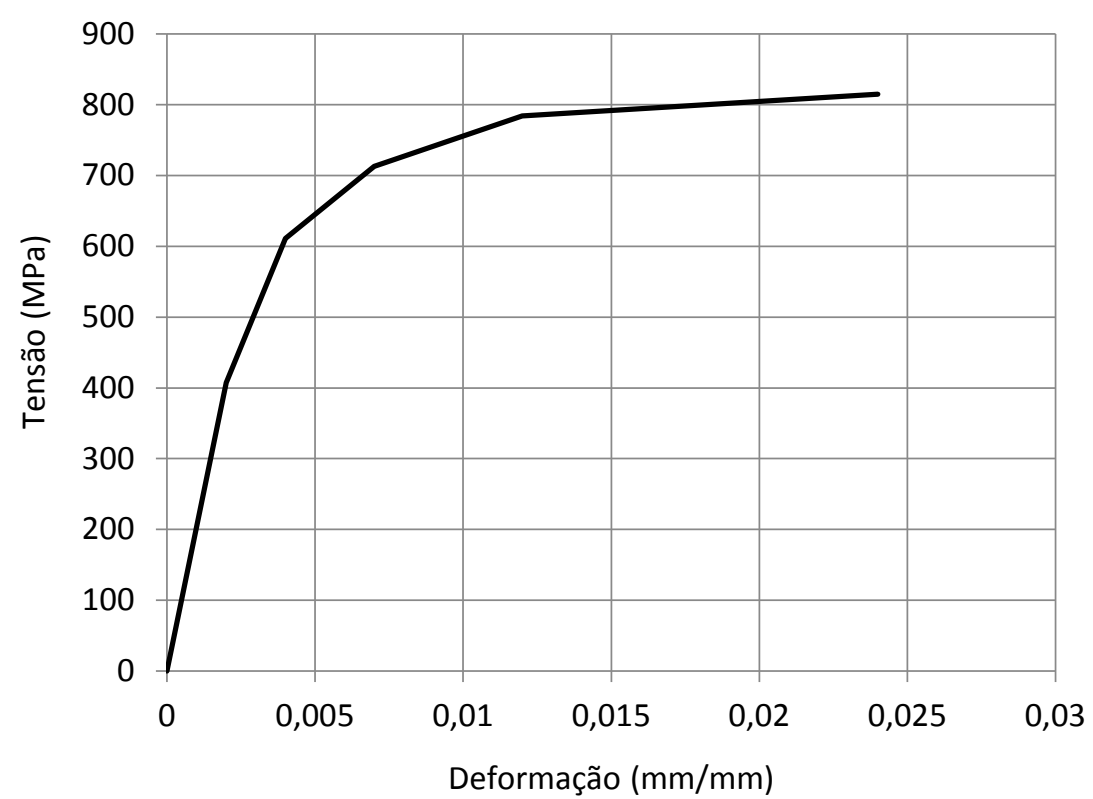

Figura 3.35 - Curva tensão-deformação do aço dos estribos utilizada para a simulação numérica.

A modelagem do comportamento à tração do concreto convencional e do UHPFRC foi feita considerando a energia de fratura. De acordo com Wille et al. (2014), a energia de fratura para o UHPFRC pode ser calculada segundo a quantidade de fibras metálicas, por meio da Equação 20, em que $G_{f}$ é a energia de fratura em N/m e $V_{f}$ é a porcentagem do volume de fibras na mistura.

$$
G_{f}=-1,4 \cdot V_{f}^{2}+13 \cdot V_{f} \quad(k N / m)
$$

Considerando que o UHPFRC utilizado na pesquisa continha $2 \%$ de fibras em volume, a energia de fratura calculada é $20,4 \mathrm{kN} / \mathrm{m}$, ou $20.400,00 \mathrm{~N} / \mathrm{m}$.

De acordo com a fib (2012), a energia de fratura para o concreto convencional pode ser calculada pela Equação 21 .

$$
G_{f}=73 \cdot f_{c m}^{0,18} \quad(N / m)
$$

Assim, como a resistência média $\left(f_{c m}\right)$ foi de 29,31 MPa, a energia de fratura para o concreto convencional é de 134,09 N/m.

O modelo escolhido para as simulações numéricas foi o "Concrete Damage Plasticity". Nesta pesquisa, as simulações foram realizadas considerando apenas a plasticidade do concreto. 
Os parâmetros de entrada do modelo "Concrete Damage Plasticity" tanto para o concreto convencional quanto para o UHPFRC estão apresentados na Tabela 3.12. Estes parâmetros são sugeridos pelo manual do programa ABAQUS.

Tabela 3.12 - Parâmetros de entrada do modelo "Concrete damage Plasticity" utilizados.

\begin{tabular}{|c|c|c|c|c|}
\hline \multicolumn{5}{|c|}{ Concrete DamagePlasticityModel } \\
\hline DilationAngle & Eccentricity & $\mathrm{fb}_{\mathrm{f}} / \mathrm{f} \mathrm{c}_{0}$ & $\mathrm{~K}$ & ViscosityParameter \\
\hline 40 & 0,1 & 1,66 & 0,66 & 0 \\
\hline
\end{tabular}

Para determinar a precisão dos resultados numéricos, foram realizadas duas simulações para o pilar C25F. Primeiramente com a malha adotada (35.600 elementos) na pesquisa e posteriormente com uma malha mais refinada (66.840 elementos), como mostra a Figura 3.36.
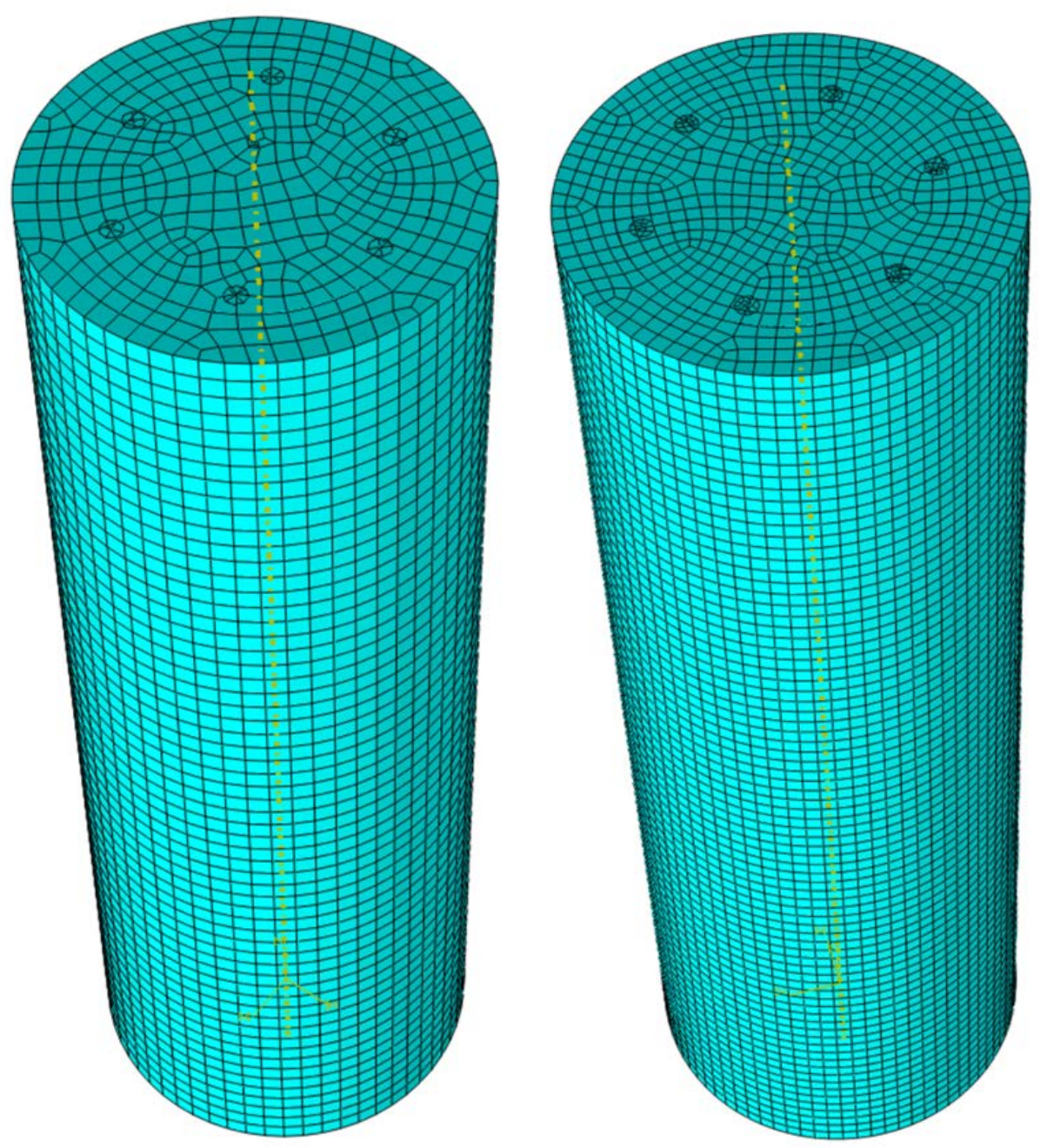

Figura 3.36 - Malha adotada na pesquisa e malha refinada, respectivamente. 
Os resultados das duas simulações são apresentados na Figura 3.37. Nota-se que os resultados são praticamente idênticos nas duas simulações. Como o tempo computacional da malha adotada foi muito menor, descartou-se a malha refinada.

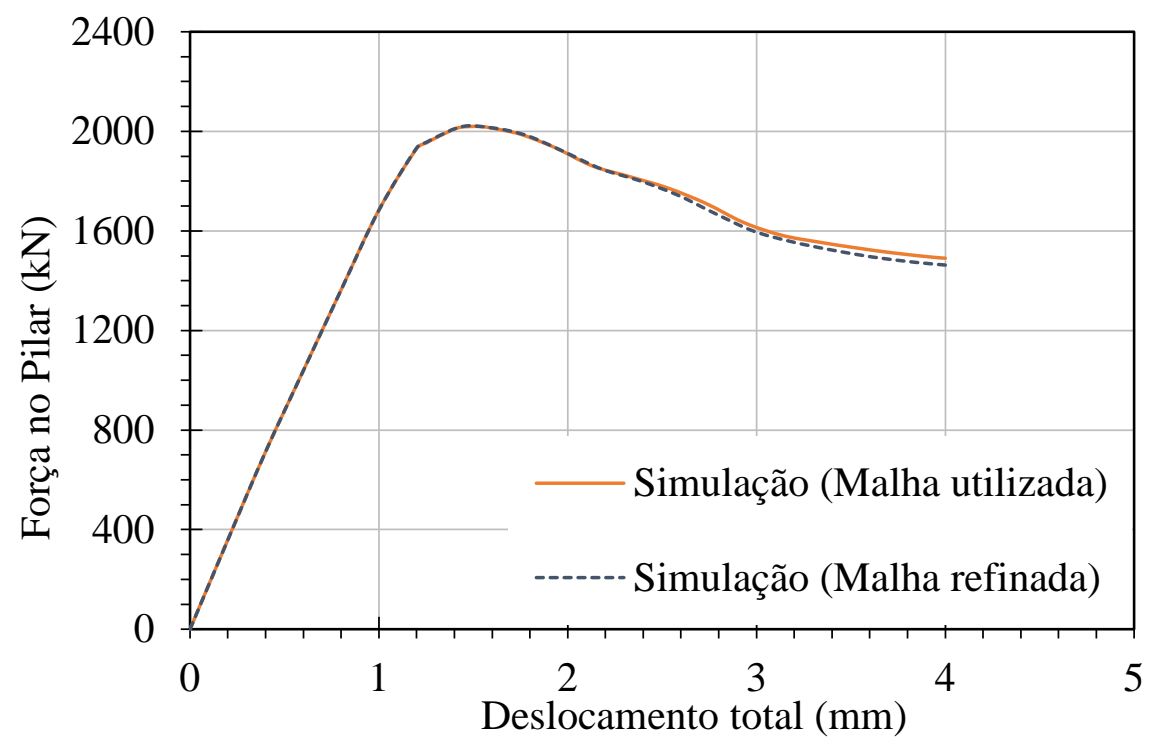

Figura 3.37 - Comparação entre a simulação utilizando a malha adotada na pesquisa e de uma malha mais refinada do pilar C25F. 


\section{RESULTADOS E DISCUSSÃO}

\subsection{ANÁLISE EXPERIMENTAL}

Neste capítulo são apresentados os resultados obtidos nos ensaios de compressão axial dos pilares. Primeiramente são apresentados os resultados referentes aos pilares circulares e em seguida dos pilares de seção transversal quadrada.

As curvas apresentadas neste capítulo são as curvas médias dos transdutores de deslocamento com leitura de prato a prato da máquina de ensaio, corrigidas conforme descrito no item 3.1.6.

\subsubsection{COMPORTAMENTO DOS PILARES CIRCULARES}

Para a análise dos resultados dos pilares de seção circular, são apresentados primeiramente os pilares reforçados com UHPC e posteriormente os pilares reforçados com UHPFRC.

Na Figura 4.1 são apresentadas as curvas força-deslocamento dos pilares de seção transversal circular reforçados com concreto de ultra-alto desempenho sem fibras (UHPC).

Observando-se a Figura 4.1, nota-se que o reforço com UHPC em pilares circulares só é viável com a aplicação de mecanismos auxiliares de reforço, como a manta de PRFC e os estribos adicionais. Caso contrário, a expansão do concreto convencional do pilar original acaba gerando tensões de tração na camisa de reforço, levando-a à ruptura frágil. Esta ruína da camisa de UHPC ocorre prematuramente fazendo com que não haja contribuição da região do cobrimento no ganho de resistência, por este fato, o comportamento do pilar reforçado fica comprometido. 


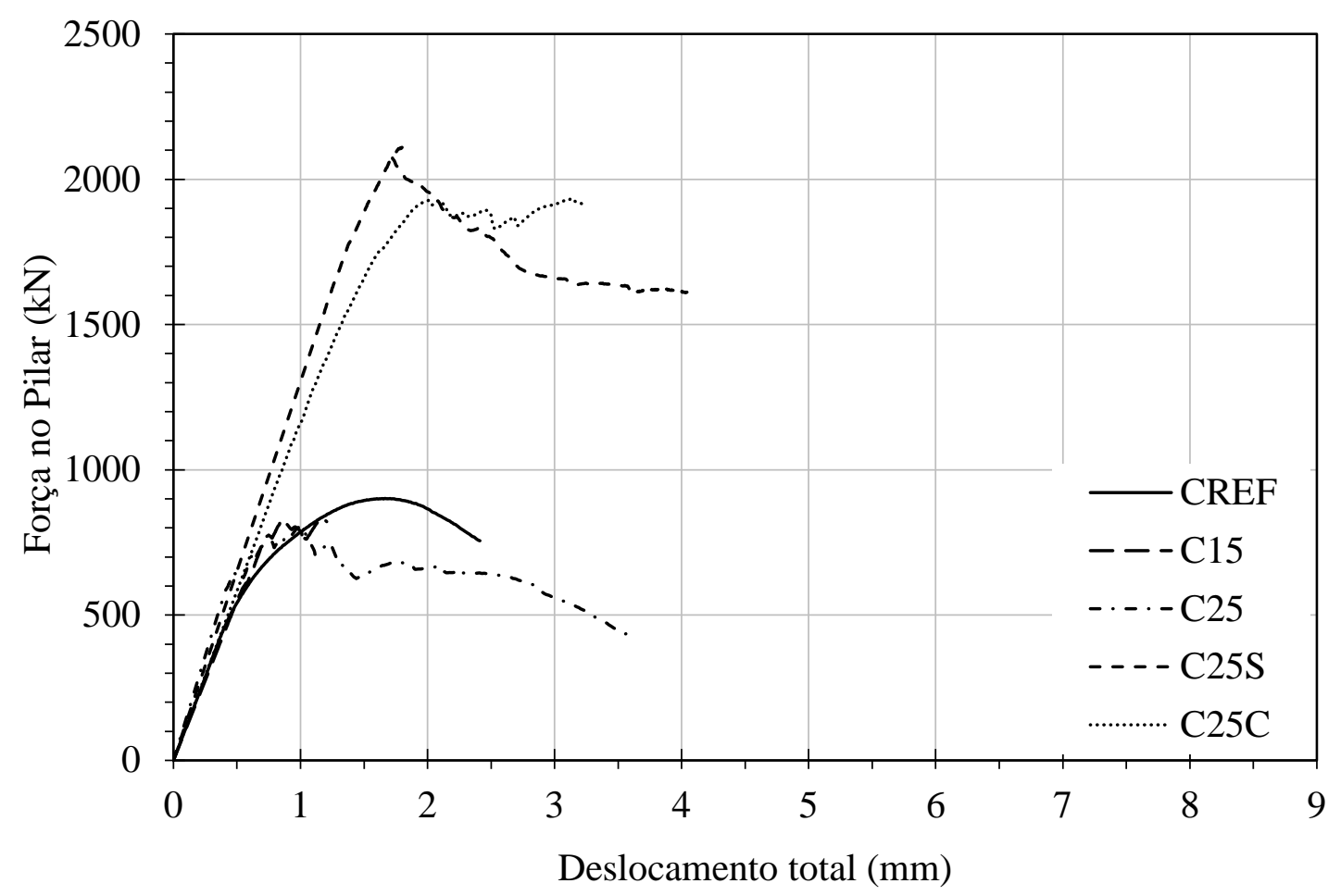

Figura 4.1 - Comparação dentre os diagramas dos pilares circulares reforçados com UHPC

Uma maneira de suprir a falta das fibras de aço no concreto de ultra-alto desempenho foi a utilização da manta de PRFC. Isso pode ser observado, comparando-se o pilar reforçado com camisa de 2,5 cm de UHPFRC (C25F) com o pilar reforçado com camisa de 2,5 cm de UHPC e manta de PRFC (C25C).

Observando-se a Figura 4.2 nota-se que os comportamentos dos pilares C25F e C25C são muito semelhantes. Também se observa que a adição da manta de PRFC num pilar com camisa de reforço de UHPC (C25) acarreta um aumento de resistência sem a perda de rigidez. Isto mostra que a adição da manta de PRFC absorveu as tensões de tração provocadas pela expansão do concreto do núcleo, assim como as fibras metálicas no pilar C25F. 


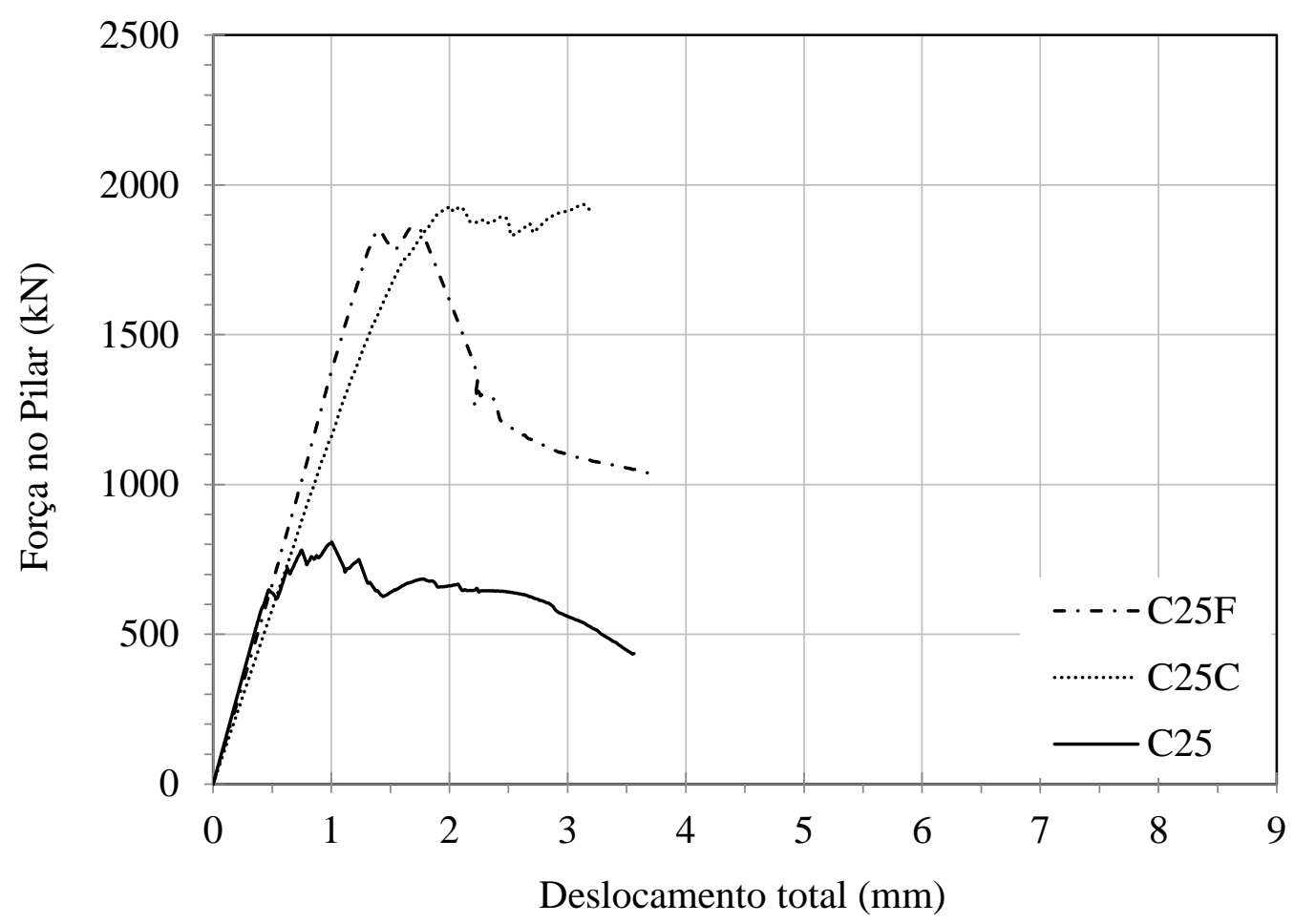

Figura 4.2 - Comparação entre os pilares C25F, C25C e C25.

Comportamento semelhante é observado no pilar reforçado com UHPC e armadura adicional, em que os estribos atuaram na falta das fibras metálicas no concreto, absorvendo as tensões de tração e conferindo maior resistência ao conjunto, como observado na Figura 4.3.

Neste caso, percebe-se um pequeno acréscimo de resistência do pilar C25S em relação ao pilar C25F. Isto se deve também ao acréscimo das armaduras longitudinais de reforço.

Portanto, nota-se que a utilização do UHPC como material de reforço em pilares circulares só é eficiente com a adição de elementos que absorvam as tensões de tração na camisa de reforço provenientes da expansão do concreto do núcleo. 


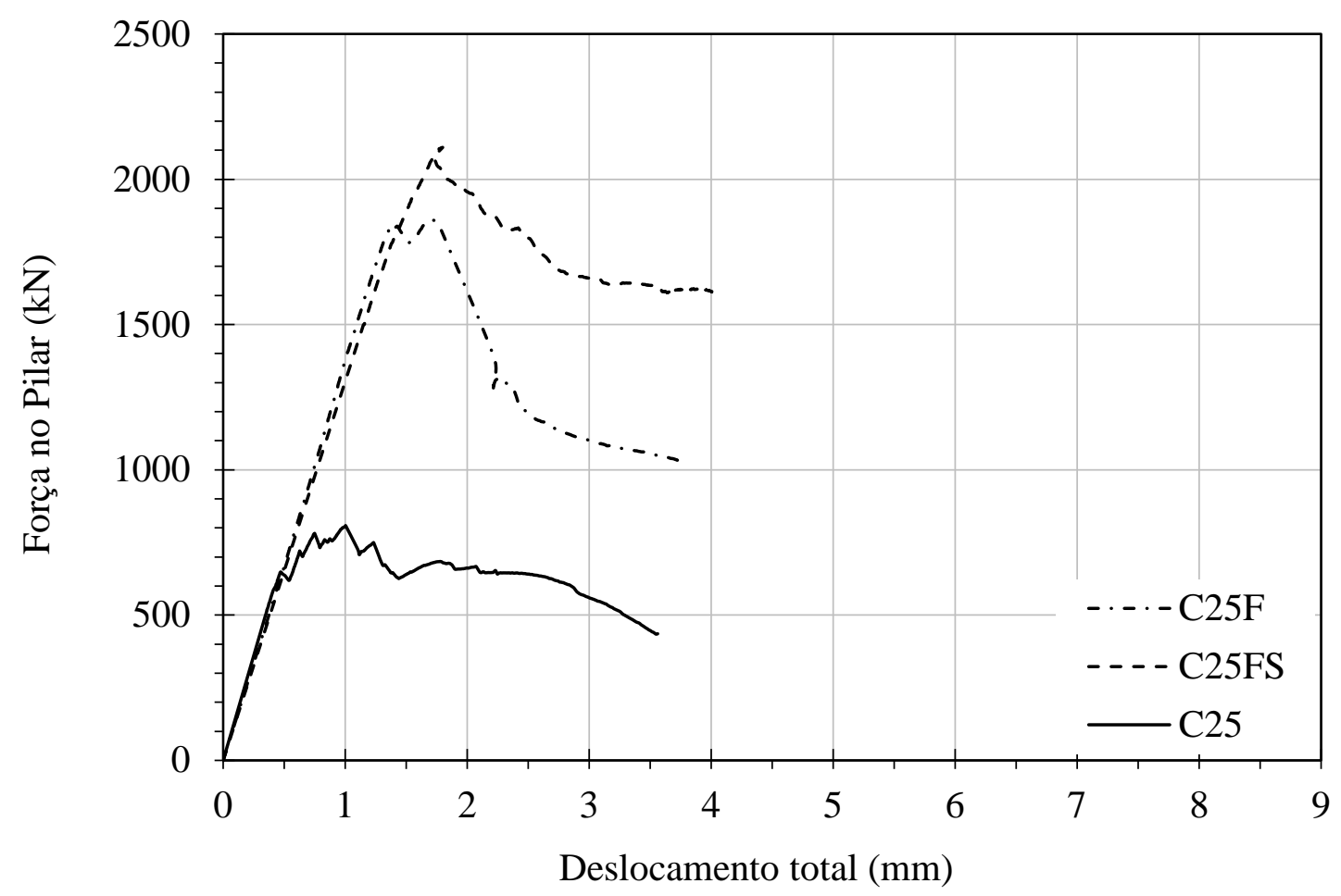

Figura 4.3 - Comparação entre os pilares C25, C25F e C25S.

Ao contrário do observado nos pilares com UHPC, na Figura 4.4, nota-se que nos casos em que há a camisa de UHPFRC sem dispositivos que geram confinamento (estribos e PFRC), o ganho de resistência é elevado. Isto é possível por causa da contribuição das fibras de aço na resistência e ductilidade na tração.

É interessante ressaltar que em todos os pilares reforçados com UHPFRC, não houve destacamento da camisa de reforço e apresentaram comportamento monolítico até a força última.

Outro fato que torna esta técnica de reforço extremamente interessante, é que as deformações últimas dos pilares reforçados são próximas à do pilar de referência. Mesmo em casos específicos, em que não é possível aumentar a intensidade de deformação no pilar reforçado, é possível a utilização desta técnica. 


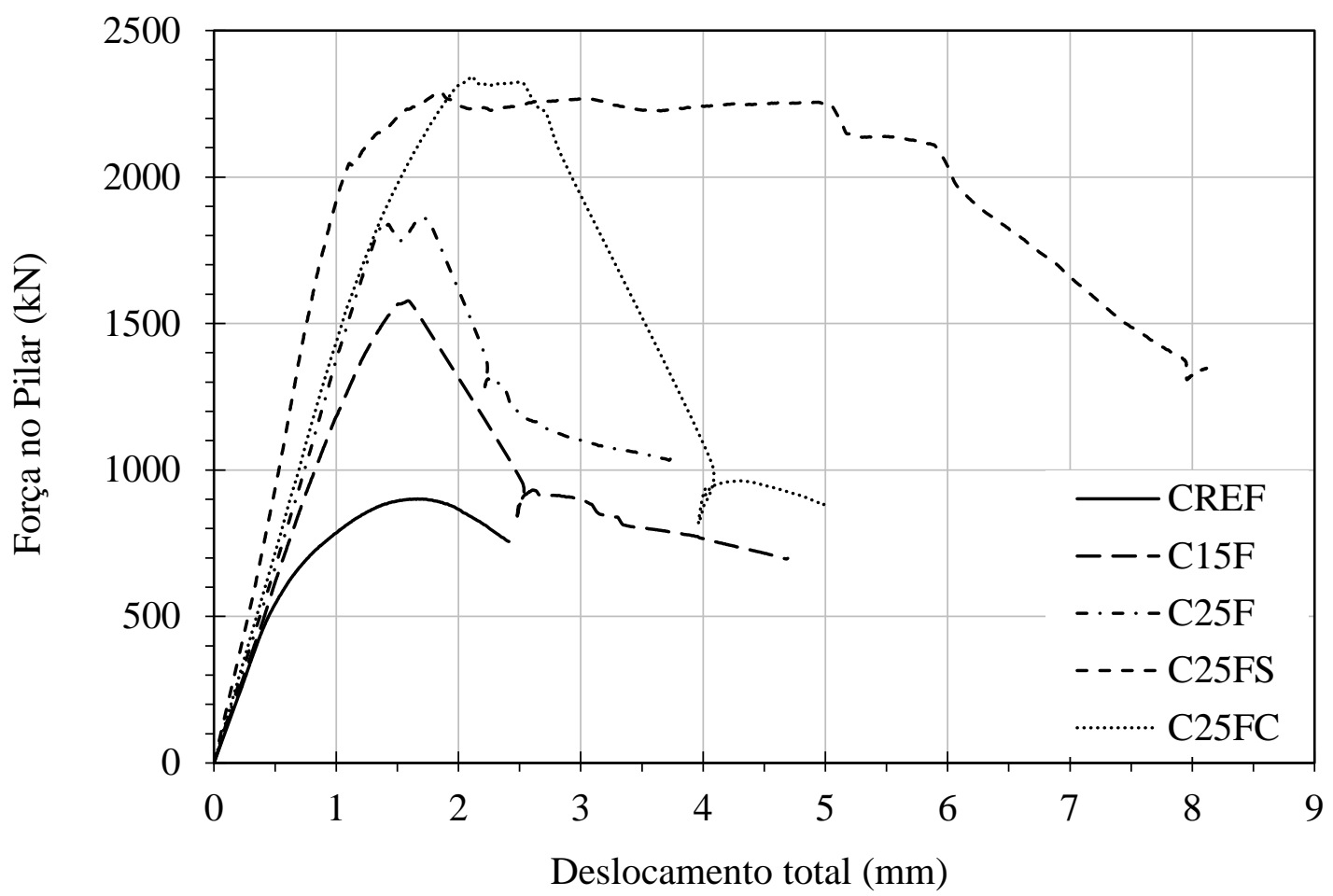

Figura 4.4 - Comparação dentre os diagramas dos pilares circulares reforçados com UHPFRC

Na Tabela 4.1, são mostradas as resistências dos pilares circulares reforçados com UHPC e UHPFRC, bem como as propriedades e o ganho de resistência de cada um deles comparando com o pilar original.

Ao analisar o ganho de resistência dos pilares reforçados, nota-se que o mesmo foi altíssimo, chegando a $160 \%$, lembrando-se, que não houve aumento de seção transversal, apenas substituição do cobrimento de concreto.

Tabela 4.1 - Ganho de resistência dos pilares reforçados de seção circular

\begin{tabular}{|l||c||c|c|c|c||c|c|c|c||}
\hline & CREF & C15 & C25 & C25S & C25C & C15F & C25F & C25FS & C25FC \\
\hline Resistência Máxima (kN) & 901,29 & 837,12 & 808,20 & 2109,56 & 1934,44 & 1577,34 & 1860,43 & 2291,77 & 2343,43 \\
\hline Espessura de UHPC (cm) & - & 1,5 & 2,5 & 2,5 & 2,5 & - & - & - & - \\
\hline Espessura de UHPFRC (cm) & - & - & - & - & - & 1,5 & 2,5 & 2,5 & 2,5 \\
\hline Armad. longitudinal adicional & - & - & - & $6 \phi 10 \mathrm{~mm}$ & - & - & - & $6 \phi 10 \mathrm{~mm}$ & - \\
\hline Armad. transversal adicional & - & - & - & $\begin{array}{c}\phi 5 \mathrm{~mm} \\
\mathrm{c} / 5 \mathrm{~cm}\end{array}$ & - & - & - & $\phi 5 \mathrm{~mm}$ & - \\
\hline Camadas de PRFC & - & - & - & - & 1 & - & - & - & 1 \\
\hline Ganho de Resistência (\%) & $\mathbf{0}$ & $\mathbf{- 7 , 1}$ & $\mathbf{- 1 0 , 3}$ & $\mathbf{1 3 4 , 1}$ & $\mathbf{1 1 4 , 6}$ & $\mathbf{7 5 , 0}$ & $\mathbf{1 0 6 , 4}$ & $\mathbf{1 5 4 , 3}$ & $\mathbf{1 6 0 , 0}$ \\
\hline
\end{tabular}

A seguir são feitos comentários sobre cada um dos pilares circulares, baseando-se nos ensaios experimentais. Outras observações são feitas durante a apresentação das simulações numéricas. 
O pilar circular com cobrimento de UHPFRC de 1,5 centímetro (C15F), apresenta seção transversal menor do que o pilar de referência, no entanto, alcançou um acréscimo de resistência de 75\% em relação ao pilar de referência (de 901,29 kN para 1.557,34 kN). Sua ruína foi dúctil e seu comportamento monolítico até a força última. Para determinar a contribuição de cada um dos materiais na resistência total foi necessário o uso de simulação numérica. Assim, os comentários a respeito da contribuição de cada material são feitos no item 4.2.

O pilar circular com cobrimento de UHPFRC de 2,5 centímetros (C25F), apresenta mesma seção do pilar de referência, ou seja, apenas foi realizada a substituição do cobrimento de concreto convencional pelo concreto de ultra-alto desempenho com fibras. Verificou-se neste caso, que apenas a substituição do cobrimento gerou um incremento de resistência de 106,4\% em comparação ao pilar de referência (de 901,29 kN para 1.860,43 kN). Como no pilar C15F, o comportamento entre o pilar original e a camisa de reforço também foi monolítico até a força última e a ruína foi dúctil por causa das fibras de aço.

No pilar com cobrimento de UHPFRC de 2,5 centímetros e reforço com armaduras longitudinais e transversais no interior do cobrimento (C25FS), foi verificado um acréscimo de resistência de 154,3\% (de 901,29 kN para 2.291,77 kN). Neste caso, também se constatou um comportamento monolítico sem destacamento da camisa de reforço e um comportamento muito mais dúctil que os demais pilares, por causa do confinamento provocado pelas armaduras transversais de reforço.

O pilar C25FC, é o pilar com 2,5 cm de cobrimento de UHPFRC, também envolto por uma camada de manta de PRFC. Neste caso se conseguiu o acréscimo máximo de resistência entre os pilares circulares, que foi de 160\% (de 901,29 kN para 2.343,43 kN). Esse acréscimo de resistência ocorreu em virtude do confinamento provocado pelo PRFC na camisa de UHPFRC, retardando sua ruína por tensões de tração. Isso pode ser notado pelo comportamento do diagrama força-deslocamento, que mantém a rigidez praticamente constante até a ruína, o que não ocorre em elementos que ganham resistência em face ao efeito de confinamento provocado por PRF, que por sua vez conseguem este acréscimo de capacidade resistente mediante à perda de rigidez.

Os Pilares C15 e C25, são pilares cujas substituições dos cobrimentos foram feitas por UHPC com espessura de 1,5 centímetro e 2,5 centímetros, respectivamente. Em ambos os casos, a ruína da camisa de reforço se deu prematuramente, por causa 
do comportamento frágil da camisa de reforço, que não suportou as tensões de tração oriundas da expansão do núcleo. Por causa da ruína prematura da camisa de reforço, as resistências dos pilares foram menores que a do pilar original. Assim, não se recomenda a utilização apenas do UHPC para o reforço de pilares circulares.

O pilar C25S, é o pilar com acréscimo de armadura no interior do cobrimento de 2,5 cm de UHPC. Ele teve um acréscimo de resistência de 134,1\%. Isso se deu tanto pelo acréscimo de armadura longitudinal quanto pelo confinamento provocado pelos estribos de reforço. Houve destacamento de forma repentina do cobrimento de UHPC das armaduras transversais de reforço, porém, por causa do confinamento provocado pelas armaduras transversais, o pilar reforçado não apresentou ruptura frágil.

O pilar C25C, é um pilar com 2,5 cm de cobrimento de UHPC envolto por uma camada de manta de PRFC. O acréscimo de resistência neste caso foi de 114,6\%. Este acréscimo foi possível graças ao efeito de confinamento provocado pela camisa de PRFC que retardou a ruína da camisa de UHPC por tensões de tração.

Com base na ruína brusca e prematura das camisas de UHPC que não possuíam nenhum tipo de confinamento e nas camisas de UHPFRC, que elevaram muito a capacidade resistente do pilar original, pode-se notar que a resistência à tração do concreto na direção transversal da camisa de reforço foi a responsável pelo sucesso do reforço.

A apresentação dos pilares circulares após a ruína é feita pela Figura 4.5. Nela são observadas as duas faces de cada pilar ensaiado. 


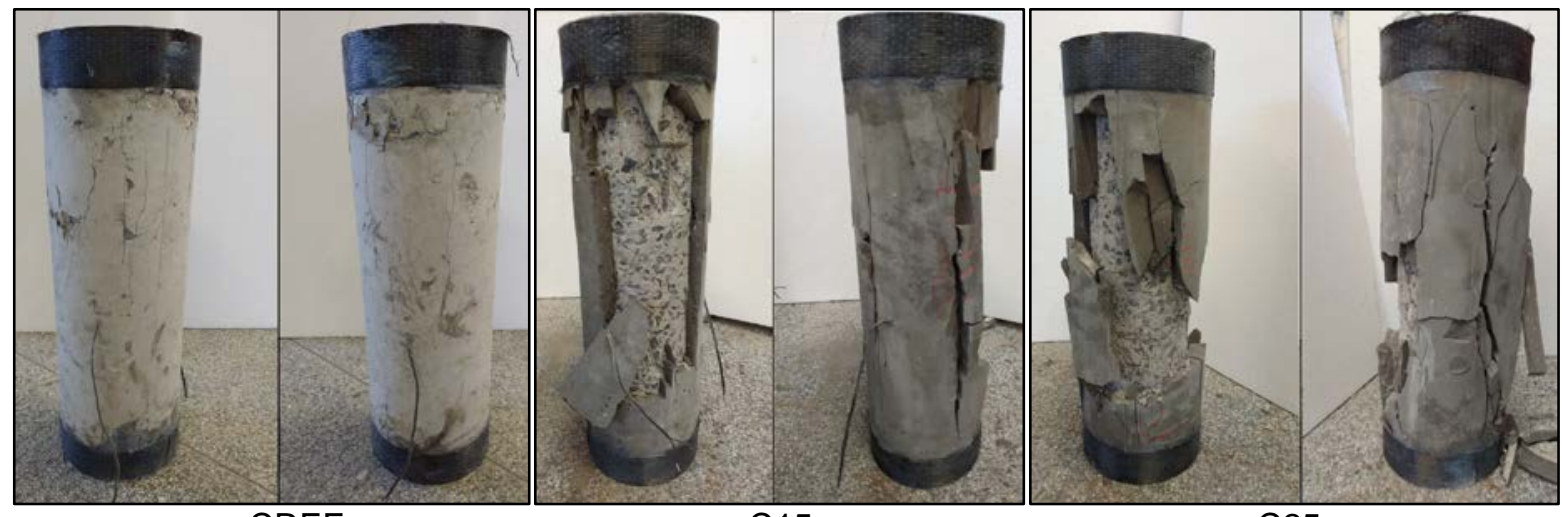

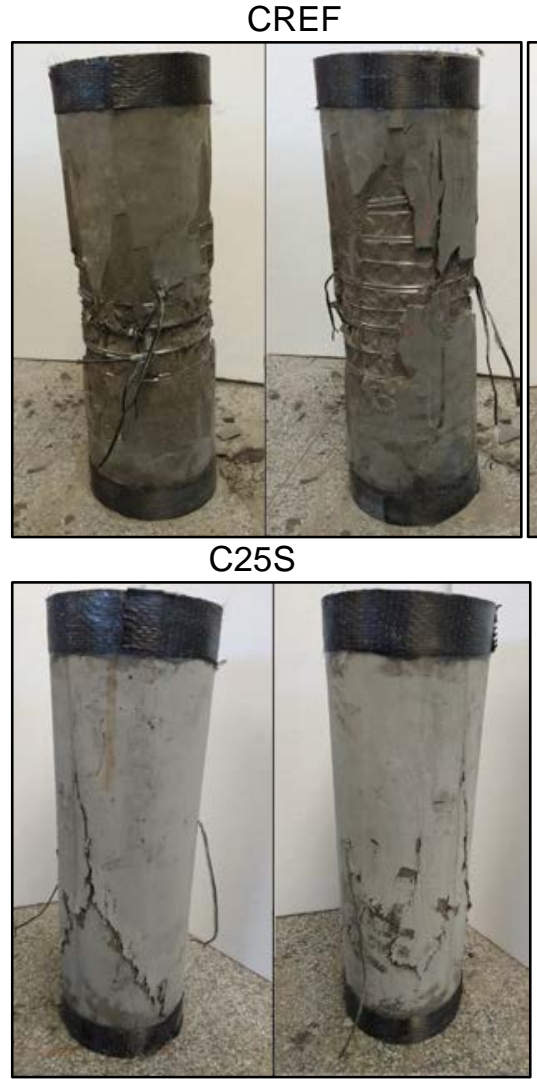

C25F

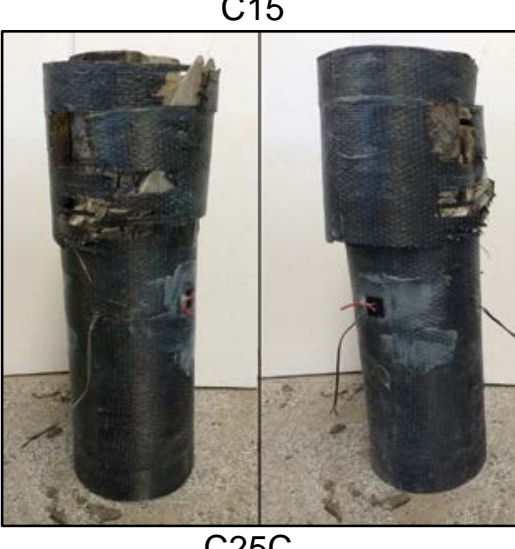

C25

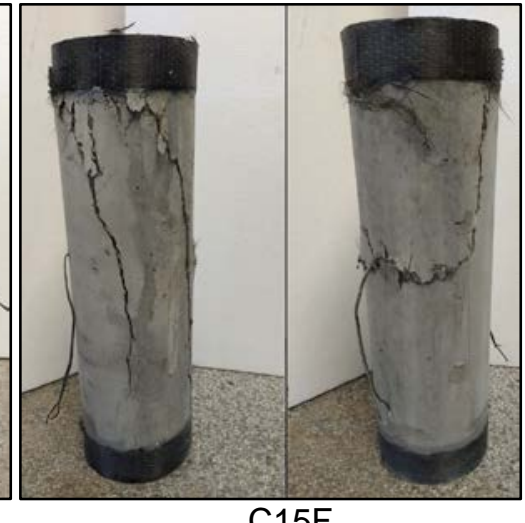

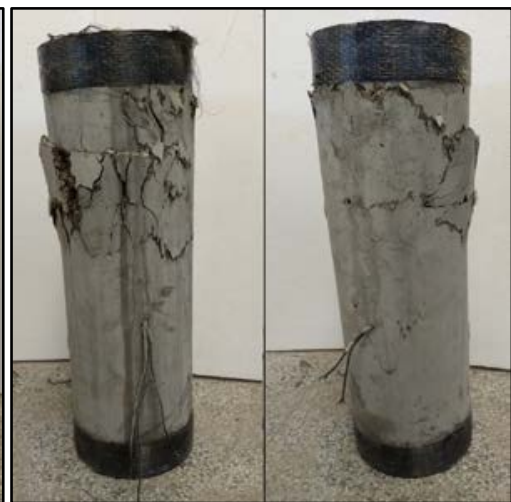

C25FS

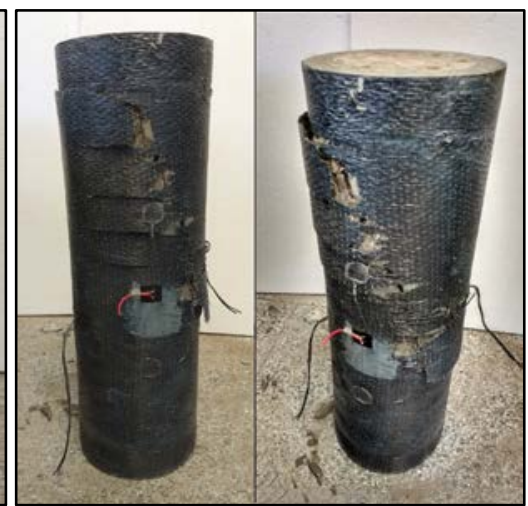

C25FC

Figura 4.5 - As duas faces dos pilares de seção circular após a ruína

\subsubsection{COMPORTAMENTO DOS PILARES QUADRADOS}

Na Figura 4.6 são apresentadas as curvas força-deslocamento dos pilares de seção transversal quadrada reforçados com concreto de ultra-alto desempenho sem fibras (UHPC). 


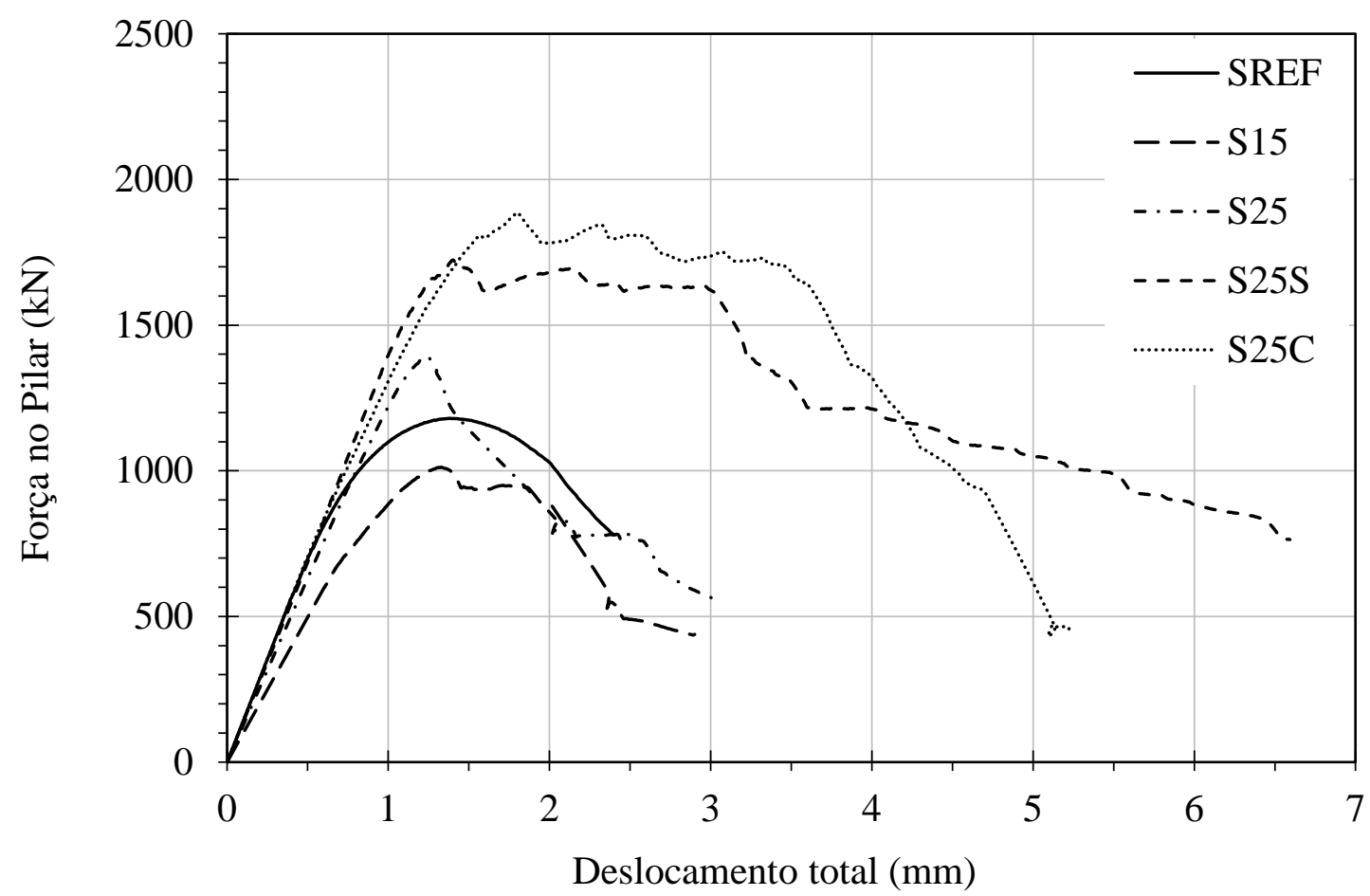

Figura 4.6 - Comparação dentre os diagramas dos pilares quadrados reforçados com UHPC

Analisando-se a Figura 4.6, pode-se observar que o ganho de resistência foi maior nos pilares S25S e S25C, justamente pelo confinamento gerado pela armadura adicional e pela manta de PRFC, porém, nota-se que o ganho de resistência não foi tão acentuado como nos pilares circulares com o mesmo sistema de reforço em virtude, principalmente, do pequeno confinamento do núcleo proporcionado pela seção quadrada. Porém, observa-se um pequeno acréscimo de resistência do pilar S25 em relação ao pilar de referência, o que não ocorreu nos pilares de seção circular.

O fato do pilar quadrado reforçado com UHPC (S25), apresentar resistência acima do pilar de referência (SREF), contrariamente ao observado nos pilares circulares, se deve à seção transversal do pilar em questão. Pelo fato da seção quadrada proporcionar menor confinamento que a seção circular, as tensões de tração na camisa de reforço provenientes da expansão do concreto do núcleo são menores, retardando a ruína prematura da camisa de reforço. Porém, este acréscimo de resistência ainda é muito baixo e a ruína continua sendo frágil.

Na Figura 4.7 são apresentadas as curvas força-deslocamento dos pilares de seção transversal circular reforçados com concreto de ultra-alto desempenho com fibras (UHPFRC). 
Observando-a, nota-se que as diferenças entre o comportamento do pilar com camisa de UHPFRC (S25F) e o comportamento dos pilares com reforço adicional (S25FS e S25FC) não foram tão acentuadas como nos pilares circulares. Isto se deve ao fato da seção do pilar interferir significativamente no confinamento gerado pelos estribos e pela camisa de PRFC.

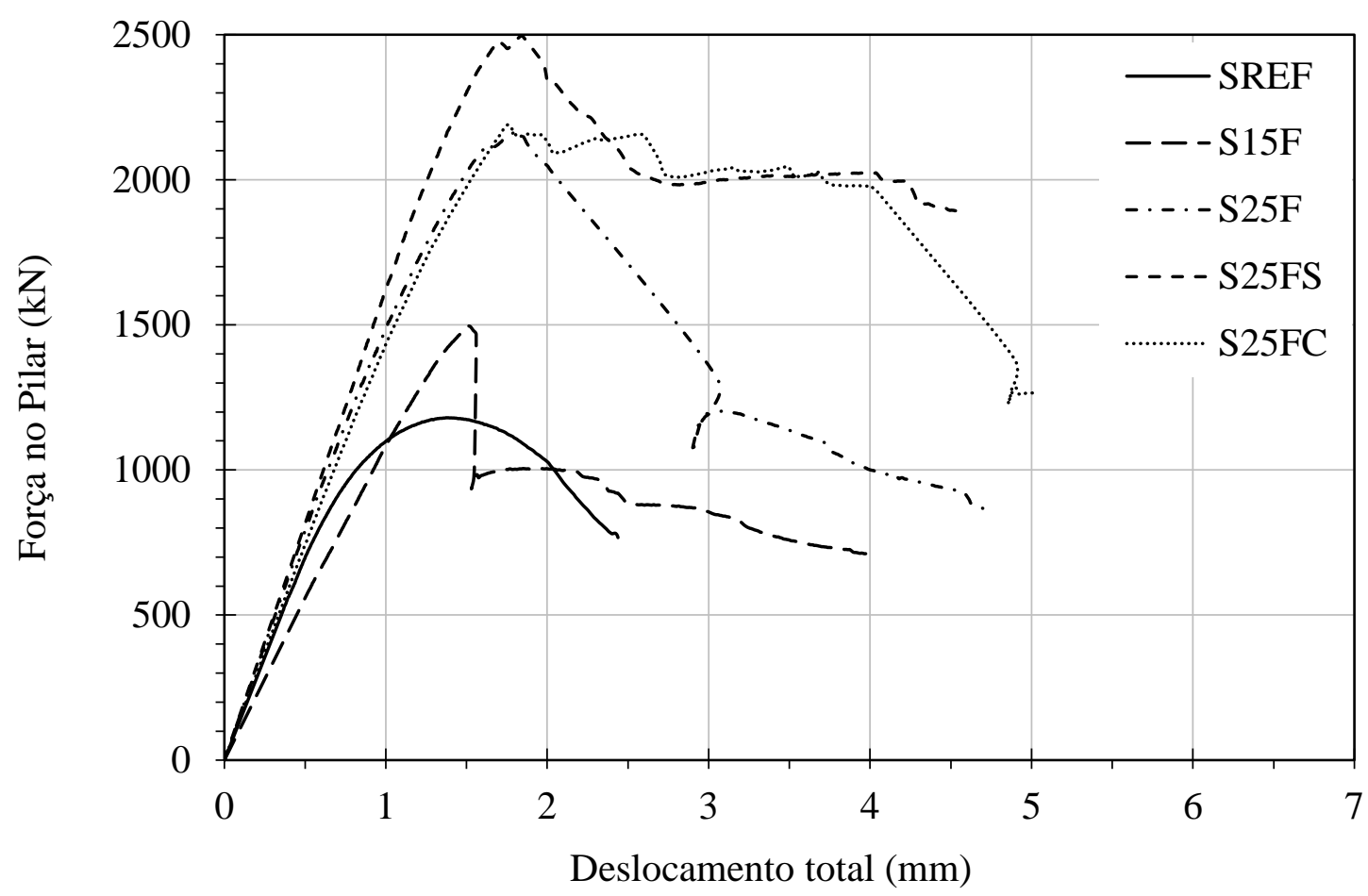

Figura 4.7 - Comparação dentre os diagramas dos pilares quadrados reforçados com UHPFRC

Como nos pilares circulares, os pilares quadrados reforçados também apresentaram deformações últimas próximas às do pilar de referência, tornando esta técnica de reforço adequada para elementos em que não pode se admitir grandes deformações adicionais.

Houve aumento de resistência na maioria dos pilares reforçados, porém, os incrementos não foram tão elevados quanto nos pilares circulares, como mostra a Tabela 4.2.

Observou-se também, que os pilares reforçados com UHPC sem nenhum dispositivo gerador de confinamento, sofreram ruína brusca da camisa de reforço e não obtiveram ganhos significativos de resistência, portanto, não são indicados para serem utilizados como reforço. Já os demais, tiveram resultados interessantes. 
Apesar do elevado incremento de resistência provocado pela adição da manta de PRFC (pilar S25C) e pela adição da armadura de reforço (pilar S25S), apenas a adição das fibras metálicas no concreto de reforço (pilar S25F) provocou um incremento de resistência maior (Figura 4.8). Isto mostra que a inserção das fibras metálicas no concreto de reforço é mais interessante que o uso de mecanismos para reforçar o UHPC (PRFC e armadura adicional), tornando o reforço mais barato e de fácil execução.

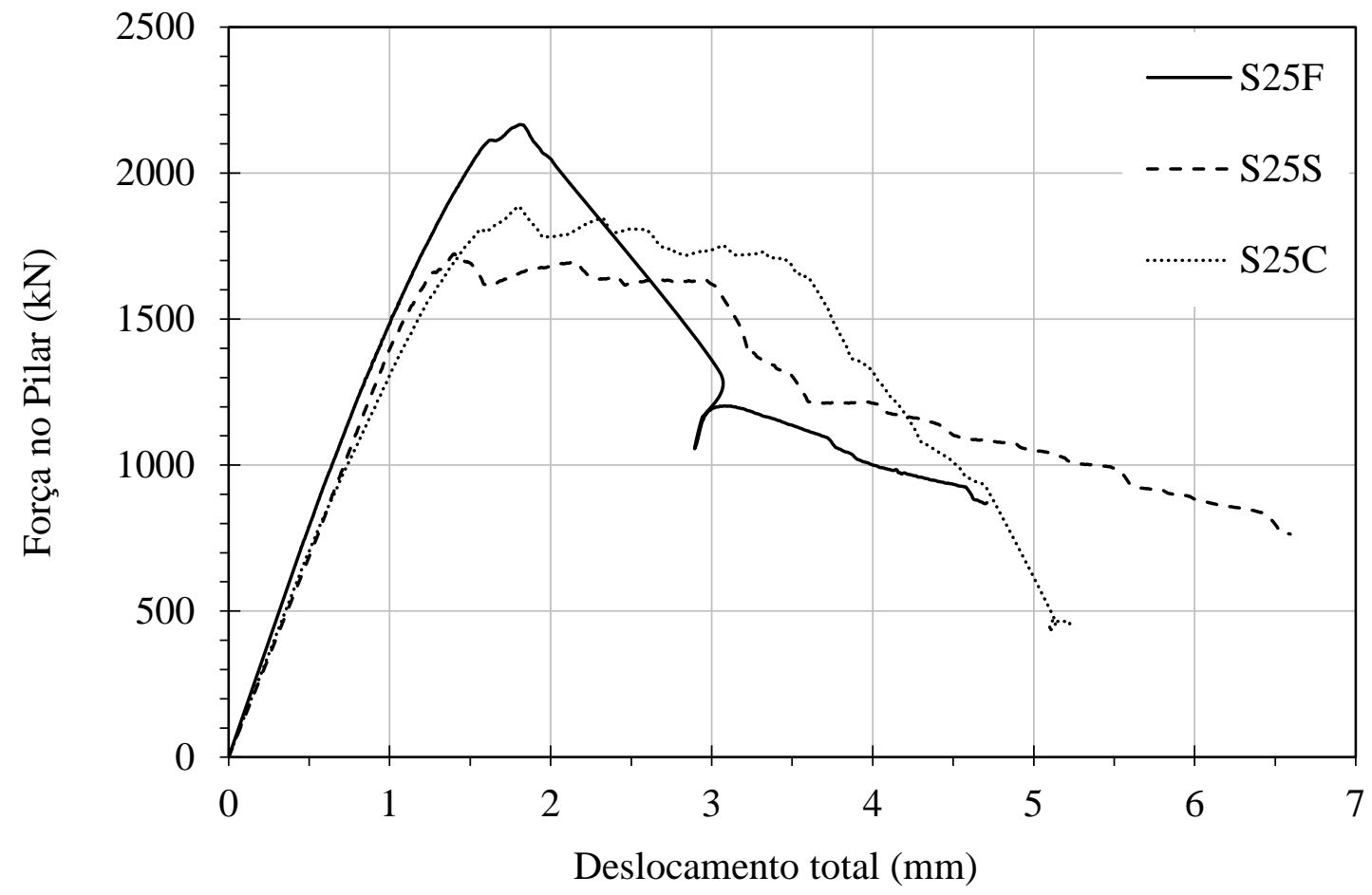

Figura 4.8 - Comparação entre os pilares S25F, S25S e S25C.

A Tabela 4.2 apresenta as propriedades de cada pilar, como espessura de reforço e composição do mesmo, bem como o percentual de ganho de resistência em relação ao pilar de referência.

Tabela 4.2 - Ganho de resistência dos pilares reforçados de seção quadrada

\begin{tabular}{|l||c||c|c|c|c||c|c|c|c|}
\hline & SREF & S15 & S25 & S25S & S25C & S15F & S25F & S25FS & S25FC \\
\hline Resistência Máxima (kN) & 1180,03 & 1012,39 & 1394,75 & 1723,69 & 1887,00 & 1496,77 & 2166,10 & 2498,70 & 2190,67 \\
\hline Espessura de UHPC (cm) & - & 1,5 & 2,5 & 2,5 & 2,5 & - & - & - & - \\
\hline Espessura de UHPFRC (cm) & - & - & - & - & - & 1,5 & 2,5 & 2,5 & 2,5 \\
\hline Armad. longitudinal adicional & - & - & - & $4 \phi 10 \mathrm{~mm}$ & - & - & - & $4 \phi 10 \mathrm{~mm}$ & - \\
\hline \multirow{2}{*}{ Armad. transversal adicional } & - & - & - & $\begin{array}{c}\phi 5 \mathrm{~mm} \\
\mathrm{c} / 5 \mathrm{~cm}\end{array}$ & - & - & - & $\phi 5 \mathrm{~mm}$ & - \\
\hline Camadas de PRFC & - & - & - & - & 1 & - & - & - & 1 \\
\hline Ganho de Resistência (\%) & $\mathbf{0}$ & $\mathbf{- 1 4 , 2}$ & $\mathbf{1 8 , 2}$ & $\mathbf{4 6 , 1}$ & $\mathbf{5 9 , 9}$ & $\mathbf{2 6 , 8}$ & $\mathbf{8 3 , 6}$ & $\mathbf{1 1 1 , 7}$ & $\mathbf{8 5 , 6}$ \\
\hline
\end{tabular}


A seguir são feitos comentários sobre cada um dos pilares quadrados, baseando-se nos ensaios experimentais. Outras observações são feitas durante a apresentação das simulações numéricas.

O pilar quadrado com cobrimento de UHPFRC de 1,5 centímetro (S15F) apresenta seção menor do que o pilar de referência, no entanto, alcançou um acréscimo de resistência de 26,8\% (de 1180,03 kN para 1.496,77 kN). Sua ruína não foi frágil e não houve destacamento da camisa de reforço.

O pilar circular com cobrimento de UHPFRC de 2,5 centímetros (S25F) possui a mesma seção do pilar de referência, ou seja, apenas foi realizada a substituição do cobrimento de concreto convencional pelo concreto de ultra-alto desempenho com fibras. Verificou-se neste caso, que apenas a substituição do cobrimento gerou um incremento de resistência de 83,6\% (de 1180,03 kN para 2.166,10 kN). Sua ruína também não foi frágil e não houve destacamento da camisa de reforço.

No pilar com cobrimento de UHPFRC de 2,5 centímetros e reforço com armaduras longitudinais e transversais no interior do cobrimento (S25FS), foi verificado um acréscimo de resistência de 111,7\% (de 1180,03 kN para 2.498.70 kN). Também se notou um comportamento monolítico sem destacamento da camisa de reforço.

O pilar S25FC, que possui 2,5 cm de cobrimento de UHPFRC e também reforço por uma camada de manta de PRFC alcançou um acréscimo de 85,6\% na resistência à compressão (de 1180,03 kN para 2.190,67 kN). Neste caso, pôde-se observar que não houve acréscimo significativo de resistência em relação ao pilar reforçado apenas com UHPFRC. Isto é compreensível, pois a seção quadrada proporciona um confinamento bem menor que a seção circular. Assim, não se observou grandes vantagens na utilização de uma camada de PRFC juntamente com a camada de UHPFRC em pilares quadrados para o acréscimo de resistência, já que o reforço sem PRFC se mostrou com a mesma efetividade.

Os Pilares S15 e S25, são pilares cujas substituições dos cobrimentos foram feitas por UHPC com espessura de 1,5 centímetro e 2,5 centímetros, respectivamente. Em ambos os casos, as resistências dos pilares foram próximas às do pilar original. Assim, não se observou vantagens com a utilização deste tipo de reforço.

O pilar S25S possui armadura de reforço no interior do cobrimento de 2,5 cm de UHPC. Ele teve um acréscimo de resistência de 46,1\%, muito menor que os 
$111,7 \%$ conseguido no pilar com UHPFRC. Neste caso, houve ruptura frágil do cobrimento de UHPC.

O pilar S25C possui 2,5 cm de cobrimento de UHPC envolto por uma camada de manta de PRFC. O acréscimo de resistência neste caso foi de 59,9\%. O incremento de resistência não foi maior pois a efetividade do confinamento em seções quadradas é menor que em seções circulares.

No caso dos pilares quadrados, a utilização do concreto de ultra-alto desempenho sem fibras (UHPC) não se mostrou vantajoso em nenhum dos casos se comparado com os pilares reforçados com UHPFRC. Assim, nota-se que em pilares com seções quadradas e, por conseguinte, retangulares (muito menor o confinamento), não é recomendável a utilização de concretos de ultra-alto desempenho sem fibras para o reforço.

A apresentação dos pilares quadrados após a ruína é feita por meio da Figura 4.9. Nela são observadas as rupturas frágeis das camisas de reforço de UHPC sem mecanismos de confinamento e da integridade da camisa de reforço com a utilização de UHPFRC.

\subsection{SIMULAÇÕES NUMÉRICAS COM O PROGRAMA ABAQUS}

Com a finalidade de entender melhor o comportamento dos reforços estudados e possibilitar o aproveitamento das análises para pilares com propriedades diferentes, foi utilizado o programa de elementos finitos ABAQUS.

Para averiguar se as simulações numéricas com o software ABAQUS representam adequadamente o comportamento dos pilares ensaiados, são apresentadas comparações entre as curvas experimentais determinadas por meio dos transdutores de deslocamentos e extensômetros e os dados das simulações numéricas.

As curvas experimentais utilizadas são as curvas apresentadas no item 4.1, cuja correção foi feita segundo o descrito no item 3.1.6.

Após a comparação entre os resultados experimentais e numéricos e as constatações sobre a forma de ruína de cada tipo de reforço, foi realizado um estudo paramétrico para verificar o acréscimo de resistência proporcionado pelo aumento da espessura da camada de reforço e pelo aumento das camadas de PRFC. 

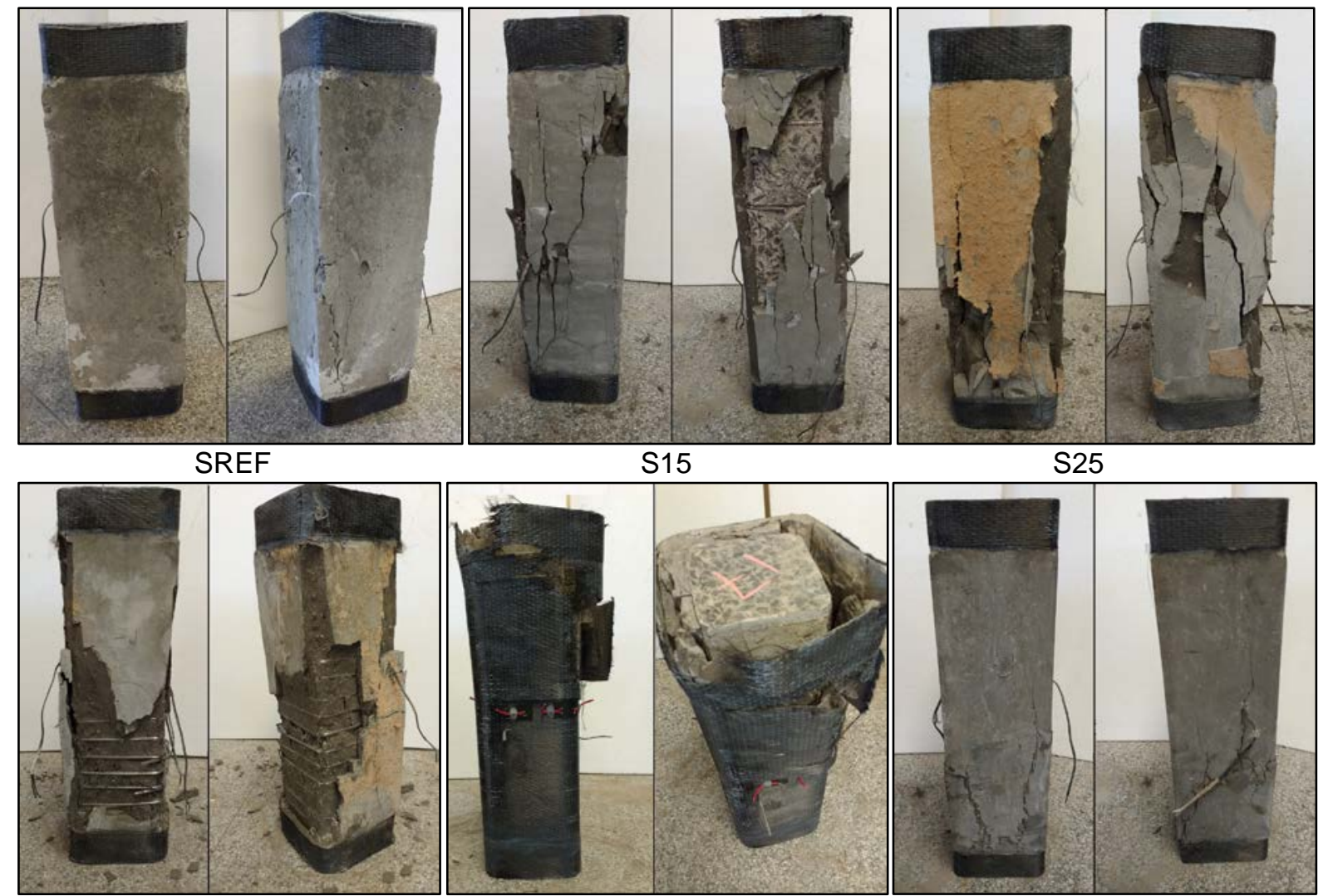

S25

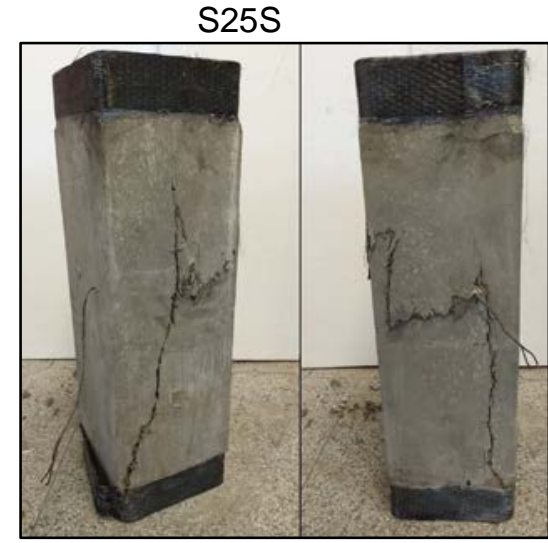

S25F
S25C

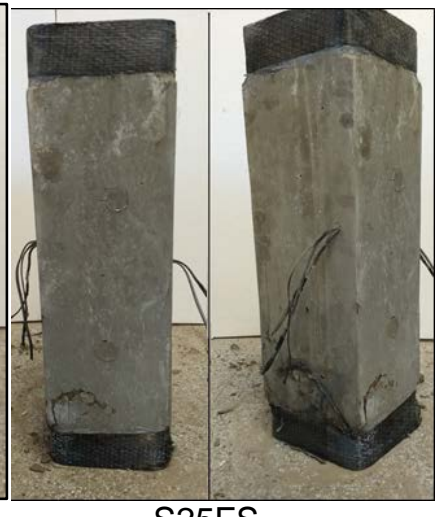

S25FS

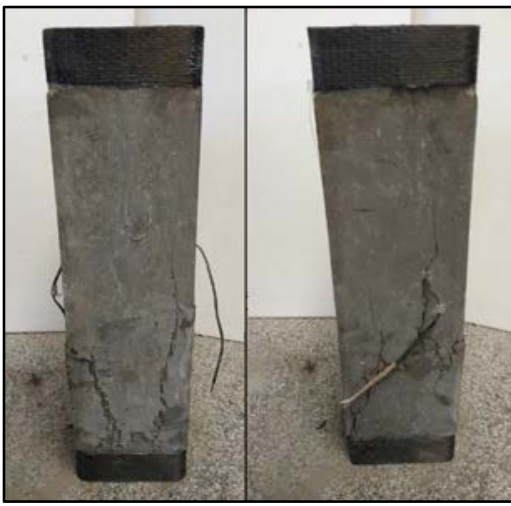

S15F

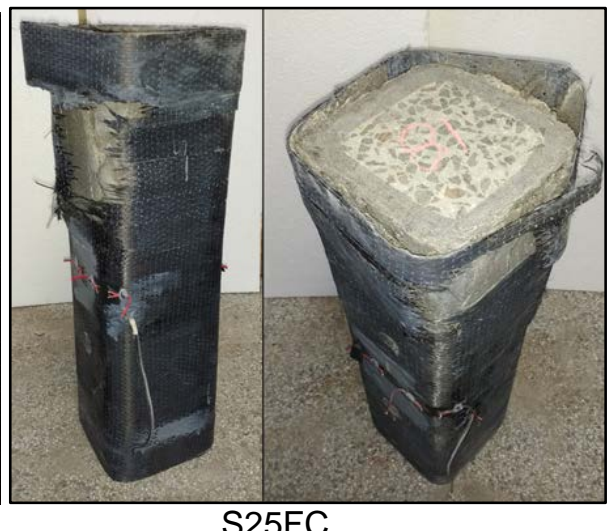

S25FC

Figura 4.9 - As duas faces dos pilares de seção quadrada após a ruína 


\subsubsection{PILARES CIRCULARES}

\subsubsection{Pilar circular de referência (CREF)}

O pilar CREF foi simulado com os dados experimentais médios coletados nos ensaios de caracterização dos materiais. A seguir são apresentadas as comparações entre as curvas experimentais e numéricas, a fim de comprovar a eficiência do modelo utilizado.

Na Figura 4.10 é apresentado o diagrama força-deslocamento do pilar ensaiado. Observando-se a figura, nota-se que a curva numérica tem as mesmas características da curva experimental.

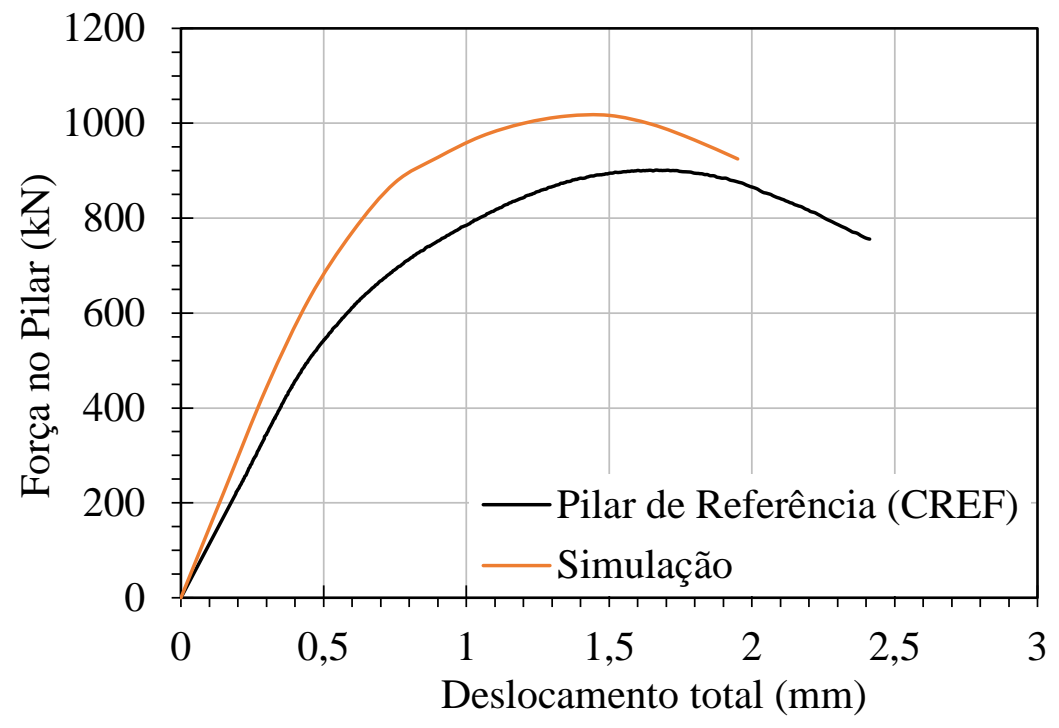

Figura 4.10 - Comparação entre o comportamento experimental e numérico do pilar CREF

Com relação às armaduras longitudinais, pode-se notar na Figura 4.11, que o comportamento da armadura longitudinal é descrito de forma satisfatória por meio da simulação numérica.

Como o comportamento numérico se aproxima do comportamento experimental, pode-se obter informações valiosas das simulações numéricas para o entendimento do mecanismo de ruína do pilar. 


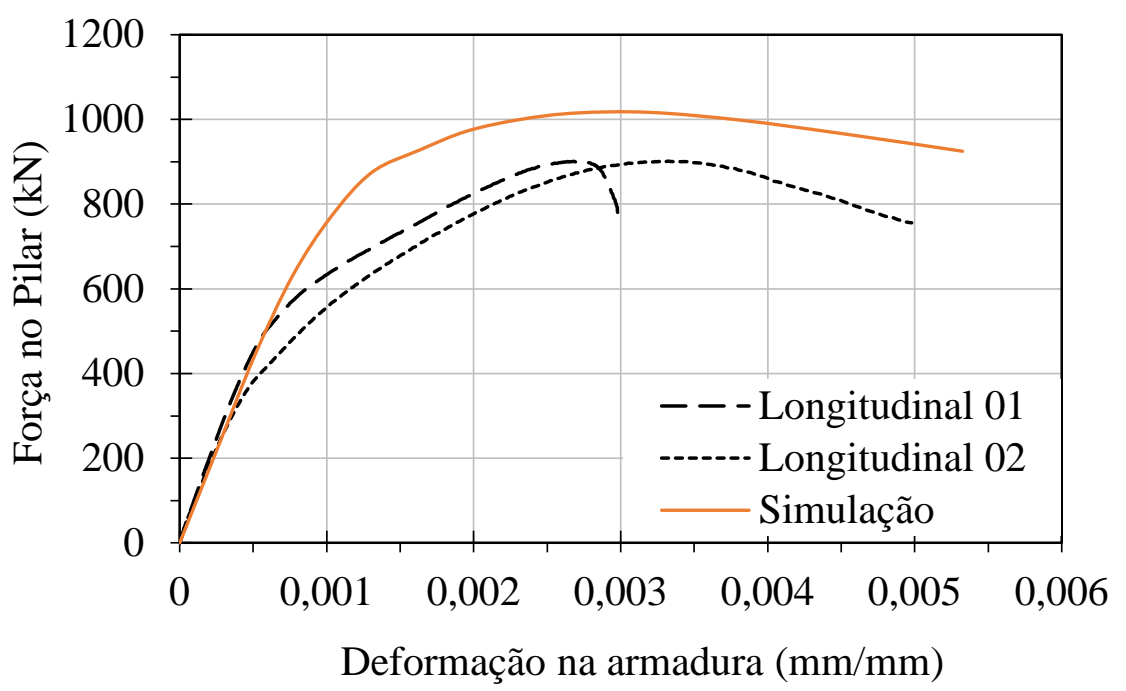

Figura 4.11 - Comparação entre o comportamento experimental e numérico das armaduras longitudinais do pilar CREF

Para a compreensão das tensões de compressão no concreto, no instante da ruína do pilar CREF, a Figura 4.12 apresenta as tensões no centro do pilar. Por meio dela pôde-se notar que excetuando-se principalmente as regiões das armaduras longitudinais, as tensões no concreto eram de aproximadamente $30 \mathrm{MPa}$, sendo que as maiores tensões de compressão se dão na região central por causa do confinamento provocado pelos estribos. É interessante notar que a resistência relativa ao concreto na força última se aproxima da resistência à compressão do corpo-deprova que foi de 29,31 MPa, mostrando pequeno confinamento do núcleo.

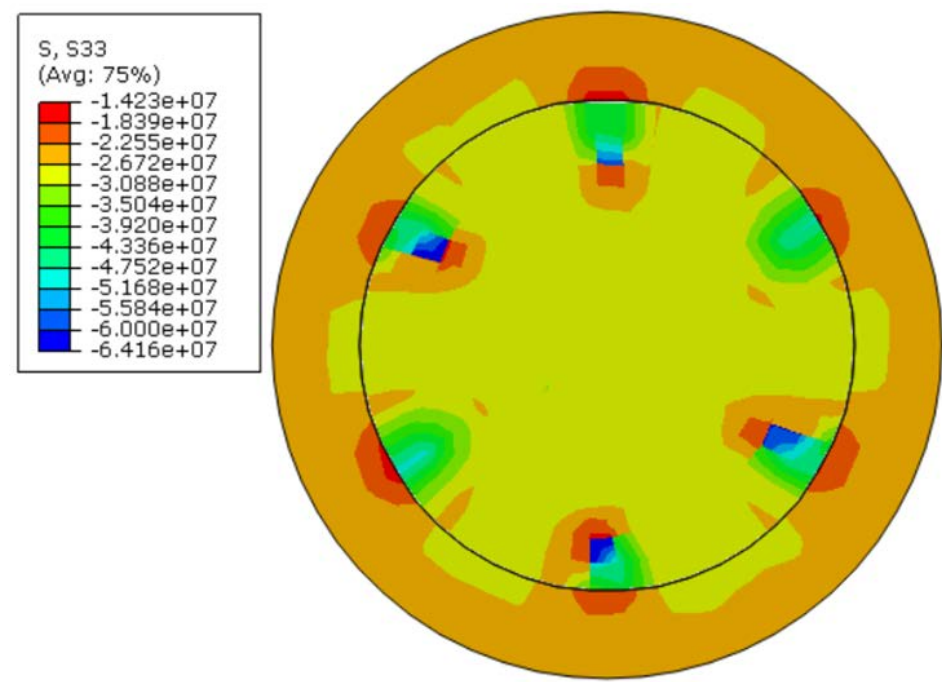

Figura 4.12 - Tensões de compressão no concreto referentes à resistência do pilar CREF

A constatação da pouca influência dos estribos do pilar original no ganho de resistência do núcleo, é uma informação importante para a previsão do 
comportamento dos pilares reforçados. Assim, verifica-se que a influência dos estribos do pilar original para o confinamento do núcleo é pequena.

\subsubsection{Pilar circular reforçado com camisa de 1,5 cm de UHPFRC (C15F)}

O pilar C15F também foi simulado com os dados experimentais médios coletados nos ensaios de caracterização dos materiais. A seguir são apresentadas as comparações entre as curvas experimentais e numéricas, a fim de comprovar a eficiência da análise.

Na Figura 4.13 é apresentado o diagrama força-deslocamento do pilar C15F. Observando-a, nota-se que a curva numérica também se assemelha à curva experimental.

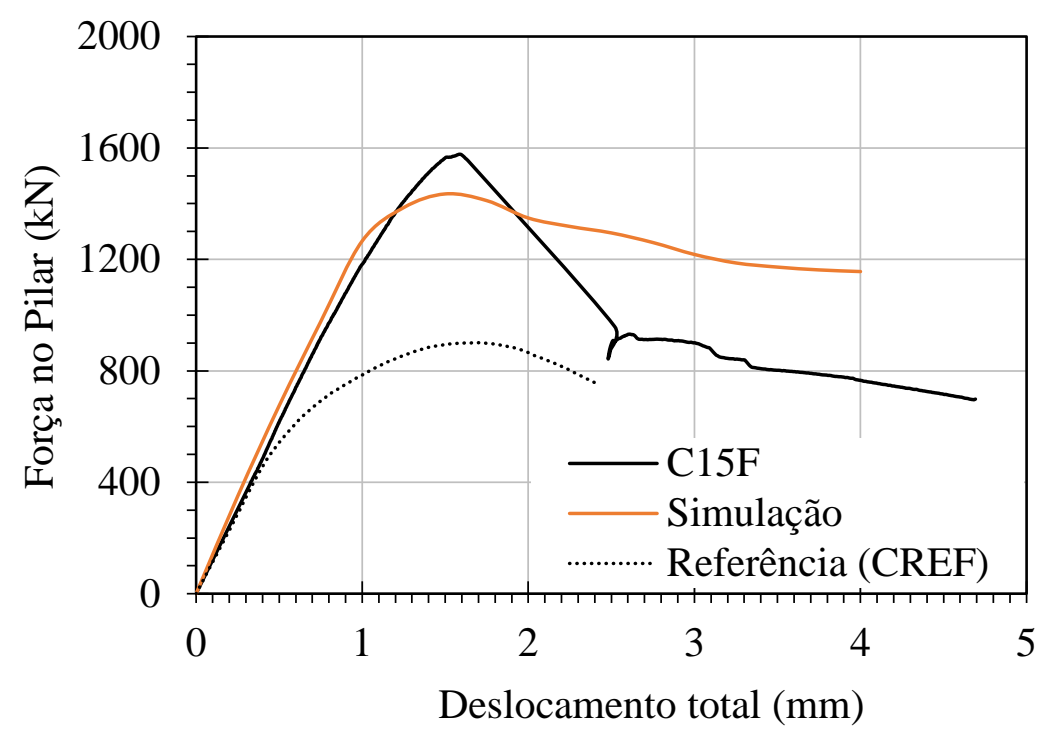

Figura 4.13 - Comparação entre o comportamento experimental e numérico do pilar C15F

Com relação às armaduras longitudinais, pode-se notar na Figura 4.14 que o comportamento numérico também se assemelha ao comportamento experimental.

Para a compreensão das tensões de compressão no concreto convencional e no UHPFRC, bem como das tensões de tração no UHPFRC, referentes à força última do pilar C15F, são apresentados os resultados da simulação numérica pelas Figuras 4.15 e 4.16. 


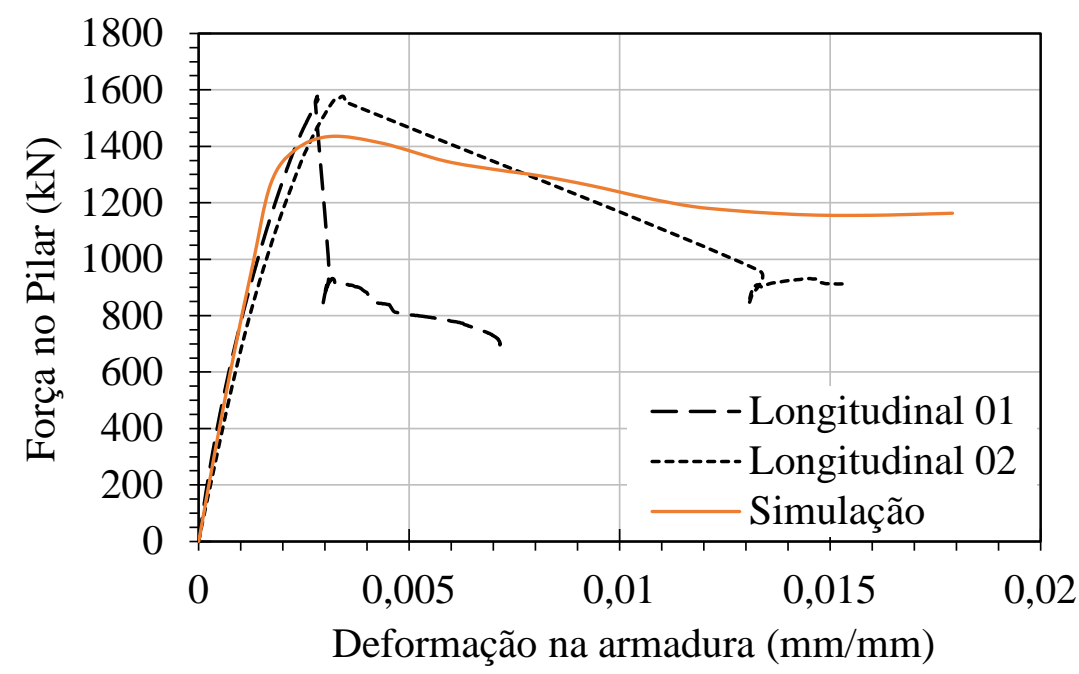

Figura 4.14 - Comparação entre o comportamento experimental e numérico das armaduras longitudinais do pilar C15F

A Figura 4.15 mostra as tensões de compressão axial no concreto convencional e na camisa de UHPFRC, na região central do pilar. Nela, pode-se notar que as tensões de compressão no concreto convencional relativa à força última no pilar, estava em torno de $40 \mathrm{MPa}$, bem acima da resistência à compressão do concreto convencional no ensaio de caracterização (29,3 MPa). Isto foi possível em virtude das tensões de confinamento geradas pela pequena camada de UHPFRC.

As tensões de compressão no UHPFRC relativas à força última no pilar, estavam em torno de $76 \mathrm{MPa}$, bem aquém da tensão verificada no ensaio de caracterização (125,9 MPa).
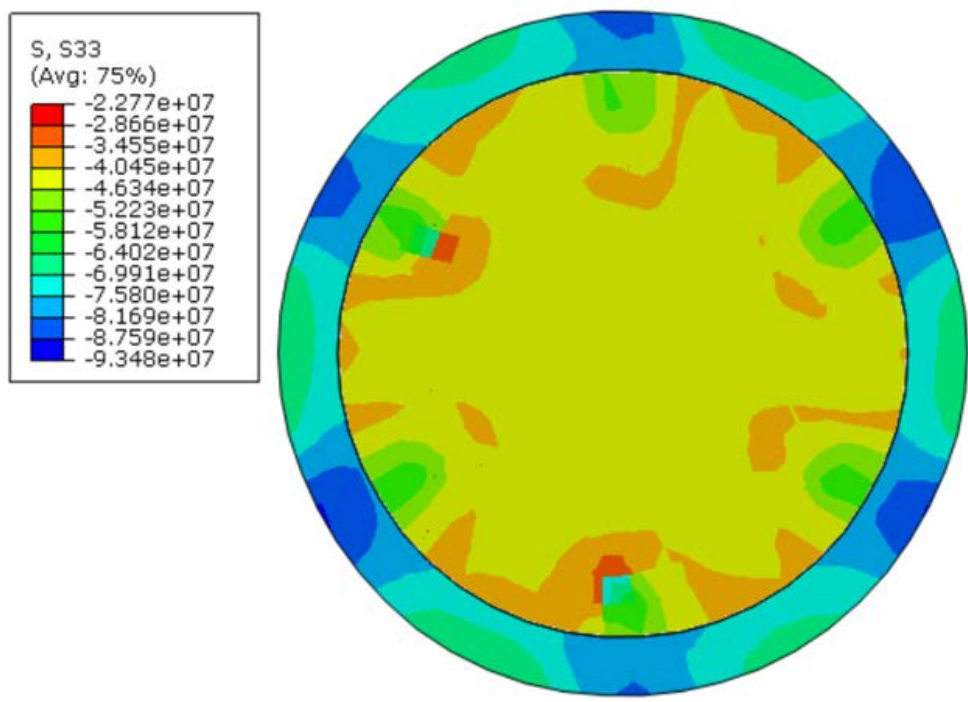

Figura 4.15 - Tensões de compressão no concreto convencional e no UHPFRC referentes à força última do pilar C15F 
As tensões de tração transversal no UHPFRC são apresentadas na Figura 4.16 por meio das tensões máximas principais. Nota-se que as tensões estavam em torno de $7 \mathrm{MPa}$ no instante da força última, muito aquém dos 17,09 MPa verificados no ensaio de tração.

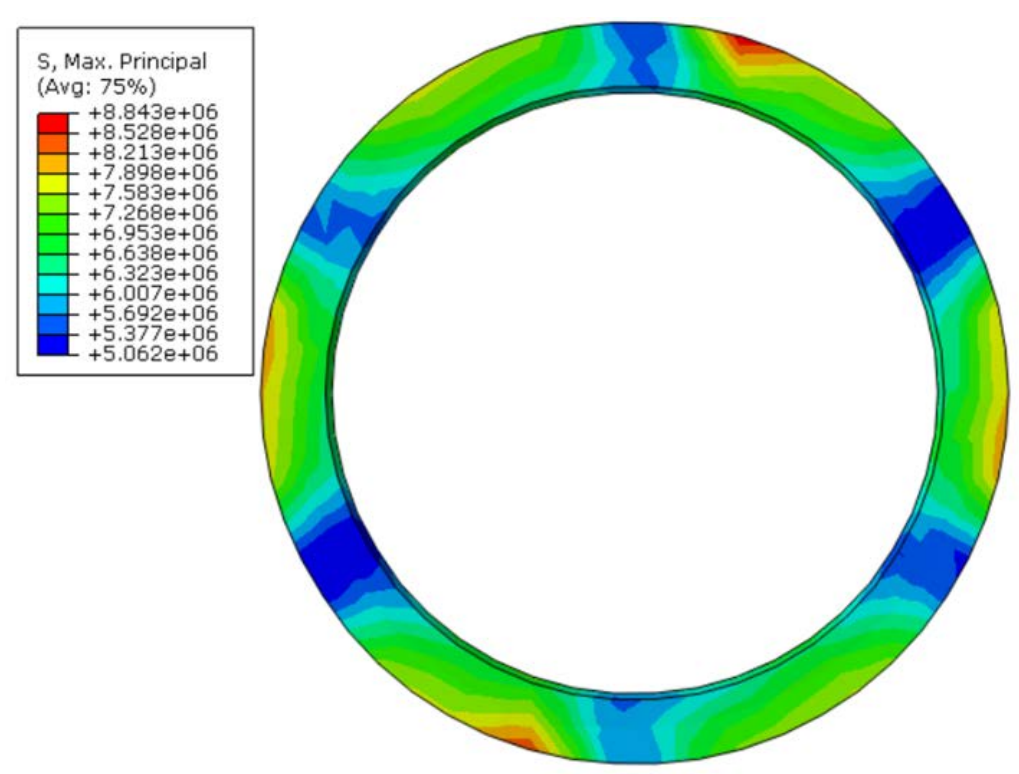

Figura 4.16 - Tensões máximas na região central do pilar C15F, referentes à força última

Considerando as informações acima, verifica-se que as tensões de tração e de compressão no UHPFRC não se aproximam das tensões de tração e compressão conseguidas nos ensaios de caracterização. Isto é facilmente explicado, pois os ensaios de caracterização são submetidos a estado uniaxial de tensão, enquanto o concreto em questão se apresenta sob o estado plano de tensões (se considerada a camisa de reforço como uma casca).

Assim, um critério de ruptura para estado plano de tensões pode ser utilizado para descrever a ruína da camisa. Dentre os critérios mais conhecidos, o que contempla tensões de tração diferentes das tensões de compressão, é o critério de ruptura de Mohr.

O critério de ruptura de Mohr estabelece que um estado de tensão seguro é representado por um círculo localizado inteiramente dentro da envoltória construída com os dados de ensaios, como mostrado na Figura 2.16. Uma aproximação dessa envoltória é a reta tangente construída apenas com os dados de compressão uniaxial e tração uniaxial como mostra a Figura 4.17.

Na Figura 4.17 é mostrado o critério de ruptura de Mohr, cujo valor de $76 \mathrm{MPa}$ de compressão é inserido, tendo como resultado o valor de 6,8 $\mathrm{MPa}$, valor muito 
próximo do calculado pela simulação numérica. Assim, pode-se considerar que o critério de Mohr representa adequadamente o comportamento de ruptura da camisa de reforço de UHPFRC.
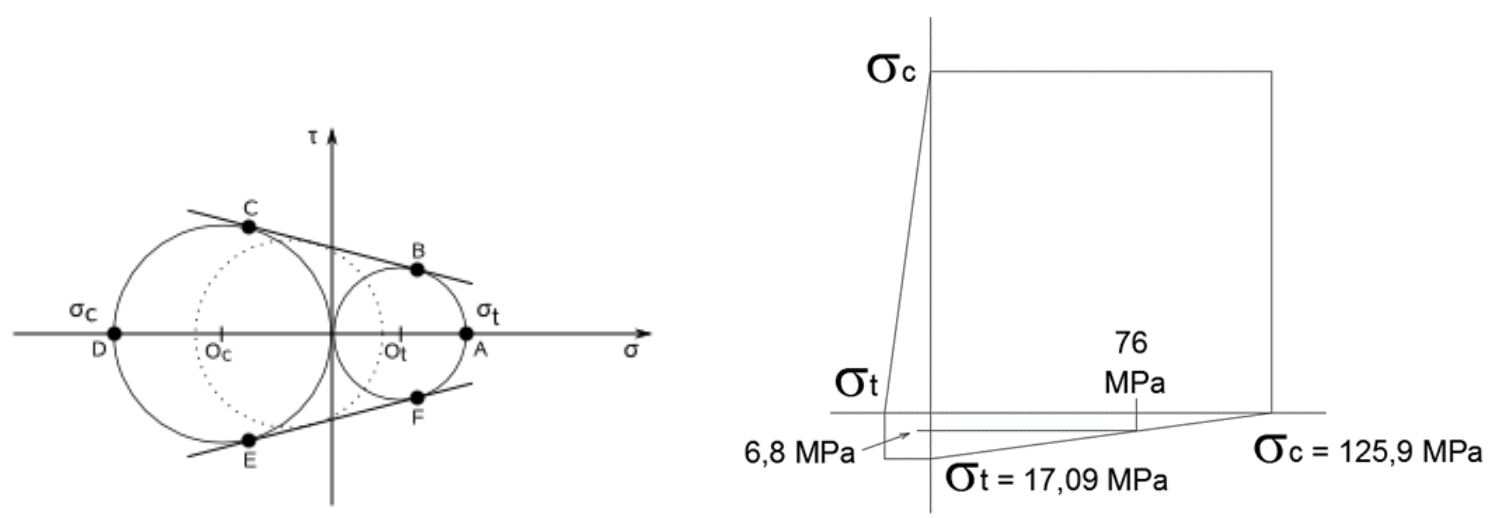

Figura 4.17 - Critério de ruptura de Mohr para a camisa de UHPFRC do pilar C15F

O mesmo critério é utilizado para a verificação da camisa de reforço do pilar C25F, para a confirmação da hipótese.

4.2.1.3 Pilar circular reforçado com camisa de 2,5 cm de UHPFRC (C25F)

O pilar C25F tem as mesmas propriedades do pilar C15F, porém com cobrimento de $2,5 \mathrm{~cm}$, o que conferiu maior resistência ao conjunto.

Na Figura 4.18 é apresentado o diagrama força-deslocamento do pilar C25F. Comparando-se as duas curvas, nota-se que a curva numérica deste pilar também se assemelha à curva experimental.

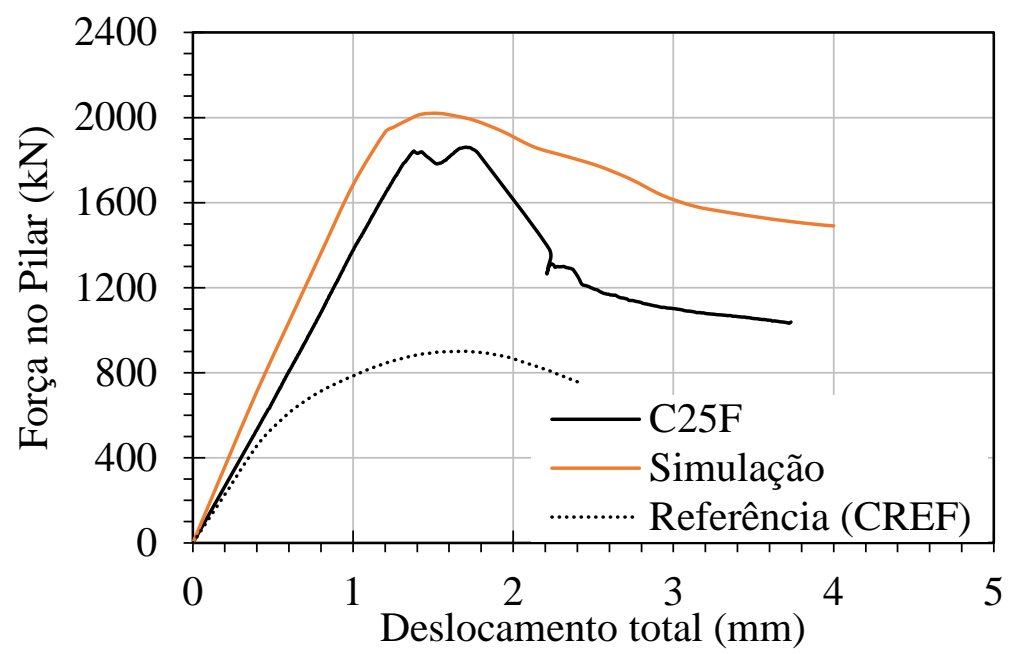

Figura 4.18 - Comparação entre o comportamento experimental e numérico do pilar C25F 
Com relação às armaduras longitudinais, observa-se na Figura 4.19 que o comportamento numérico também é próximo do experimental, mostrando a validade da análise.

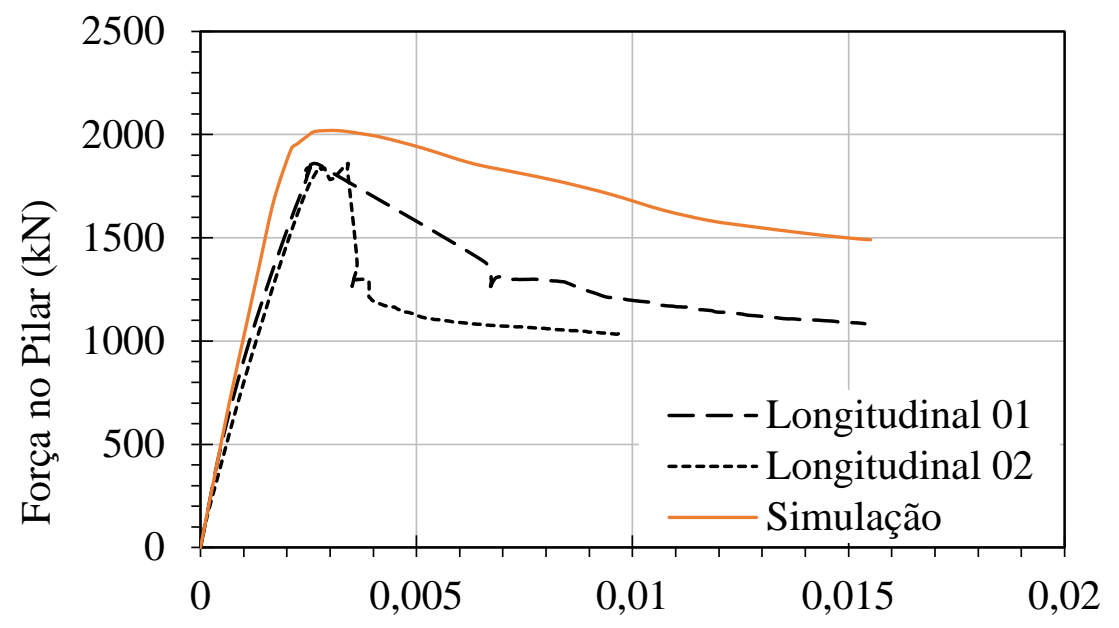

Deformação na armadura $(\mathrm{mm} / \mathrm{mm})$

Figura 4.19 - Comparação entre o comportamento experimental e numérico das armaduras longitudinais do pilar C25F

A Figura 4.20 mostra as tensões de compressão do concreto convencional e na camisa de UHPFRC no centro do pilar. Nela, pode-se notar que as maiores tensões de compressão no momento de força última no pilar estavam em torno de $45 \mathrm{MPa}$. Isto foi possível devido às tensões de confinamento provenientes da camisa de UHPFRC. As tensões de compressão no UHPFRC em virtude da força última no pilar, estavam em torno de $79 \mathrm{MPa}$.

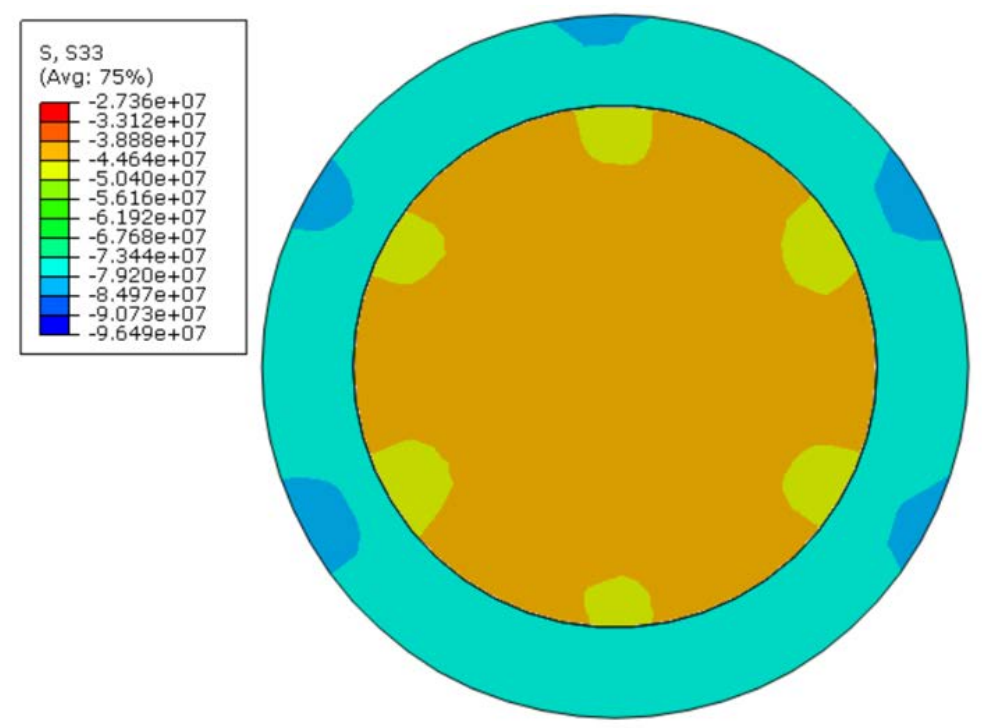

Figura 4.20 - Tensões de compressão no concreto convencional e no UHPFRC referentes à força última do pilar C25F 
As tensões de tração no UHPFRC são apresentadas na Figura 4.21 por meio das tensões máximas principais. Nota-se que as tensões variaram em torno de 6,4 MPa.

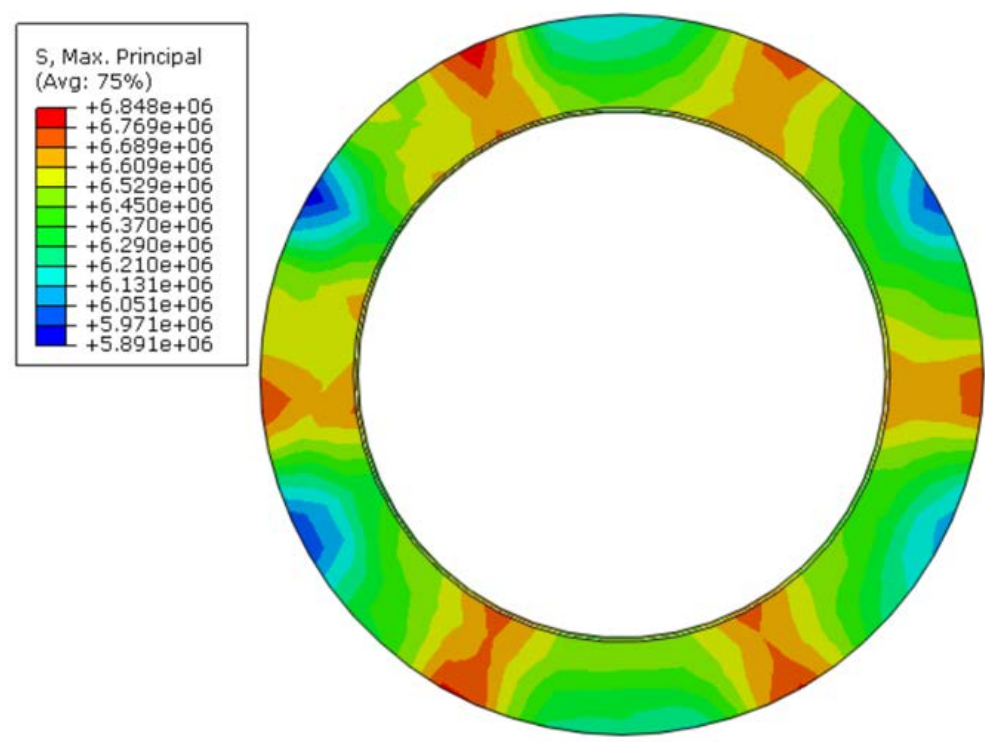

Figura 4.21 - Tensões de tração na camisa de UHPFRC referentes à força última do pilar $\mathrm{C} 25 \mathrm{~F}$

Como no pilar C15F, verifica-se que as tensões de tração e de compressão no UHPFRC não se aproximam das tensões de tração e compressão medidas nos ensaios de caracterização.

Assim, como no caso anterior, foi utilizado o critério de Mohr para verificar a forma de ruína. A Figura 4.22 mostra que este critério descreve satisfatoriamente a ruína da camisa de UHPFRC. No digrama foi inserida a tensão de compressão aproximada verificada na simulação numérica que foi em torno de 79 MPa e obtevese uma tensão de tração em torno de $6,4 \mathrm{MPa}$, o que foi verificado na simulação numérica.

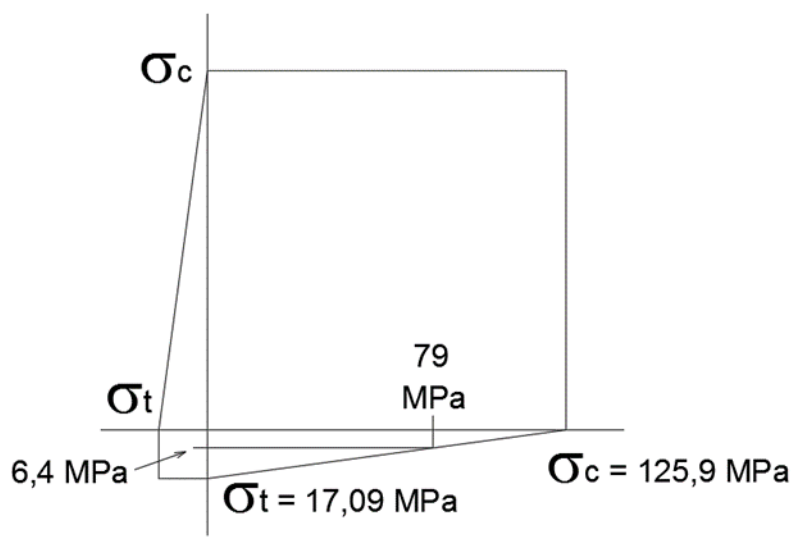

Figura 4.22 - Critério de ruptura de Mohr para a camisa de UHPFRC do pilar C25F 
Com base nos resultados obtidos nas simulações dos pilares C15F e C25F, é possível afirmar que o critério de Mohr descreve satisfatoriamente a ruína da camisa de UHPFRC.

4.2.1.4 Pilares reforçados com camisa de UHPFRC e armadura adicional (C25FS)

O pilar C25FS possui reforço de armaduras adicionais no interior da camisa de UHPFRC. Neste caso, obteve-se resultados numéricos muito coerentes em relação aos resultados experimentais na comparação das curvas força-deslocamento (Figura 4.23).

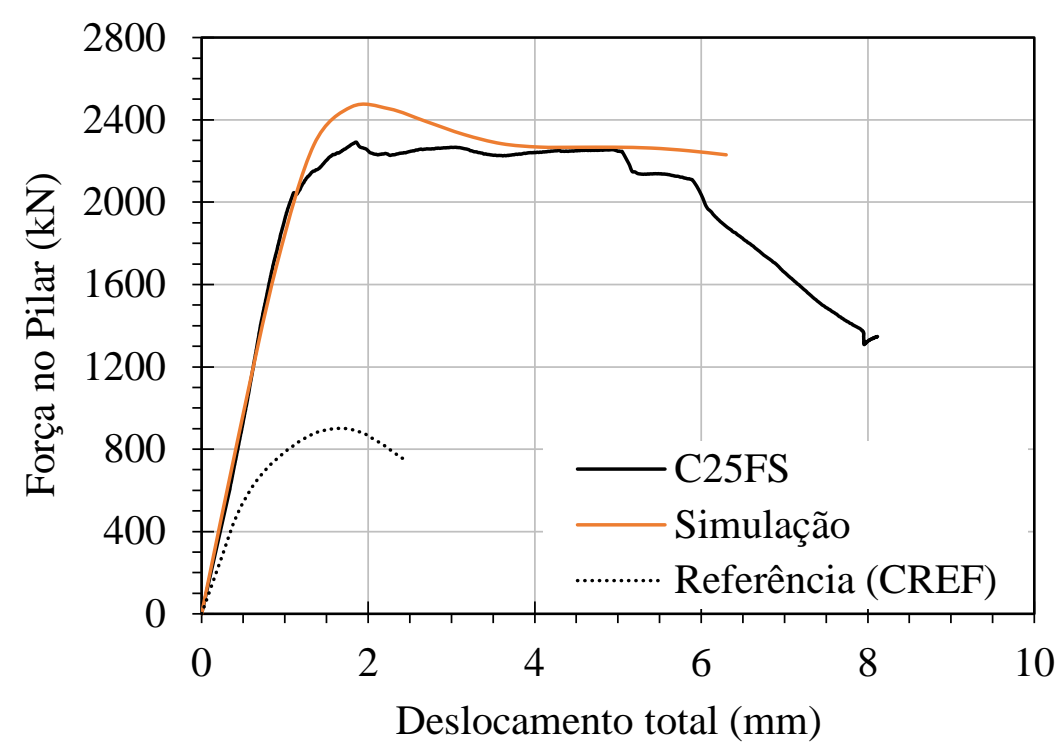

Figura 4.23 - Comparação entre o comportamento experimental e numérico do pilar C25FS

Com relação às curvas forca-deformação específica nas armaduras longitudinais (Figura 4.24) e às curvas forca-deformação específica nas armaduras transversais (Figura 4.25), o comportamento numérico obteve boa aproximação com relação ao comportamento experimental. 


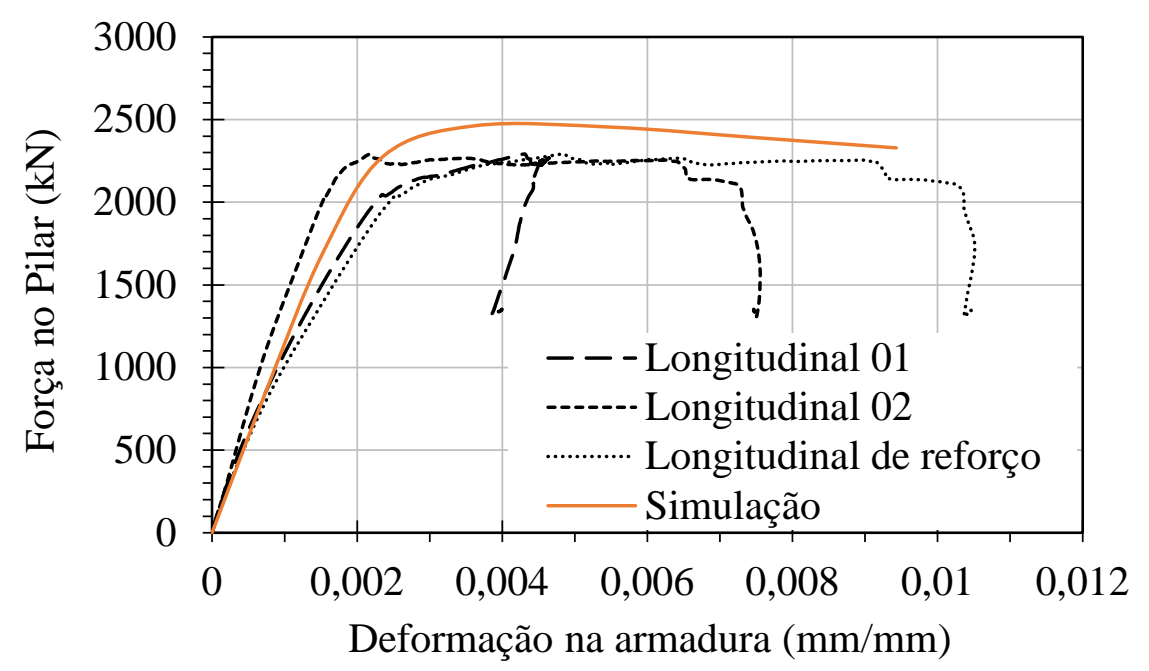

Figura 4.24 - Comparação entre o comportamento experimental e numérico das armaduras longitudinais do pilar C25FS

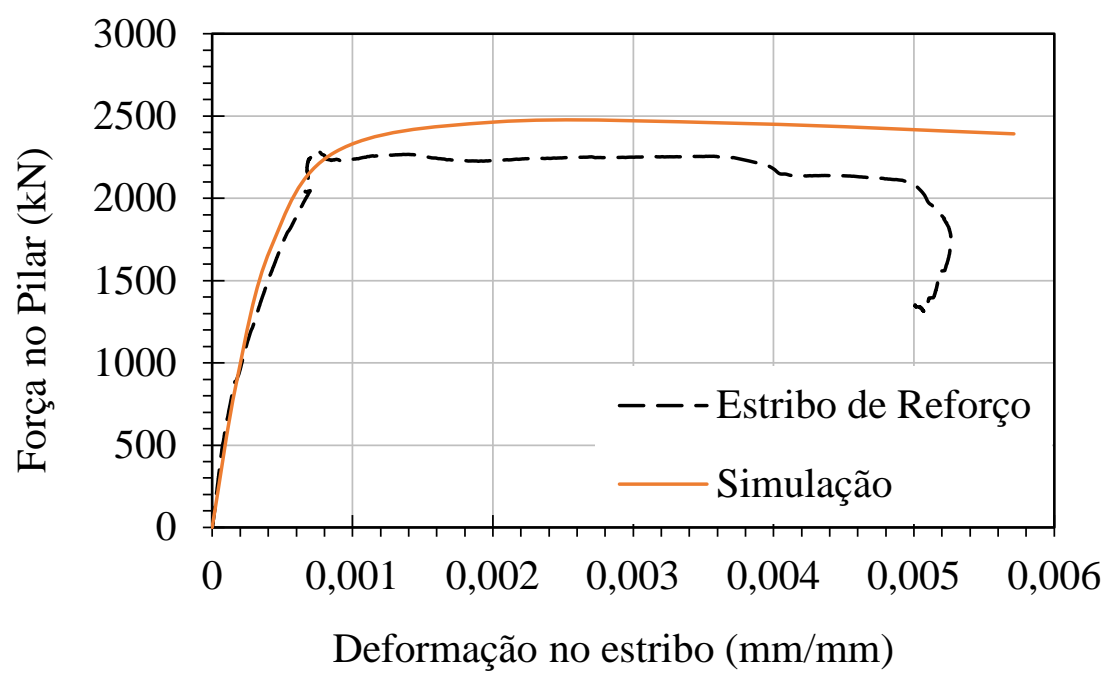

Figura 4.25 - Comparação entre o comportamento experimental e numérico dos estribos de reforço do pilar C25FS

Como os dados da simulação numérica demonstraram coerência em relação os dados experimentais, as tensões nos concretos são avaliadas a fim de se compreender o comportamento dos mesmos frente à ação da camisa de UHPFRC e das armaduras adicionais.

Por meio da simulação numérica do pilar em questão, notou-se que o concreto do núcleo apresentou tensões de compressão em torno de 53 MPa e o UHPFRC (da camisa de reforço) apresentou tensões de compressão em torno de 92 MPa (Figura 4.26).

Este acréscimo de resistência no concreto convencional e no UHPFRC em relação ao Pilar C25F foi possível em virtude da ação dos estribos da camisa de 
reforço que, por meio do confinamento do núcleo, reduziram a expansão do mesmo, conferindo maior resistência à camisa de UHPFRC.

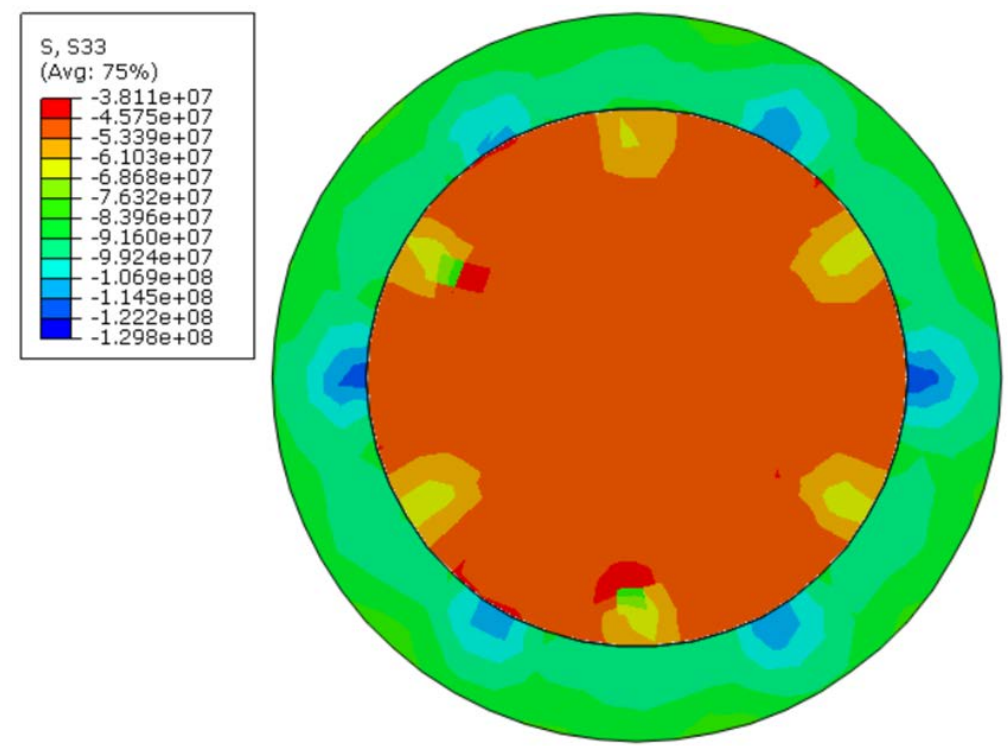

Figura 4.26 - Tensões de compressão no concreto convencional e no UHPFRC referentes à força última do pilar C25FS

Com relação às tensões de tração no UHPFRC, observou-se que elas estavam em torno de 4,2 MPa (Figura 4.27). Nota-se uma clara diminuição da intensidade das tensões de tração na camisa de UHPFRC em relação ao pilar C25F. Esta diminuição mostra a eficiência das armaduras de reforço em conter a expansão lateral do núcleo, preservando a camisa de UHPFRC.

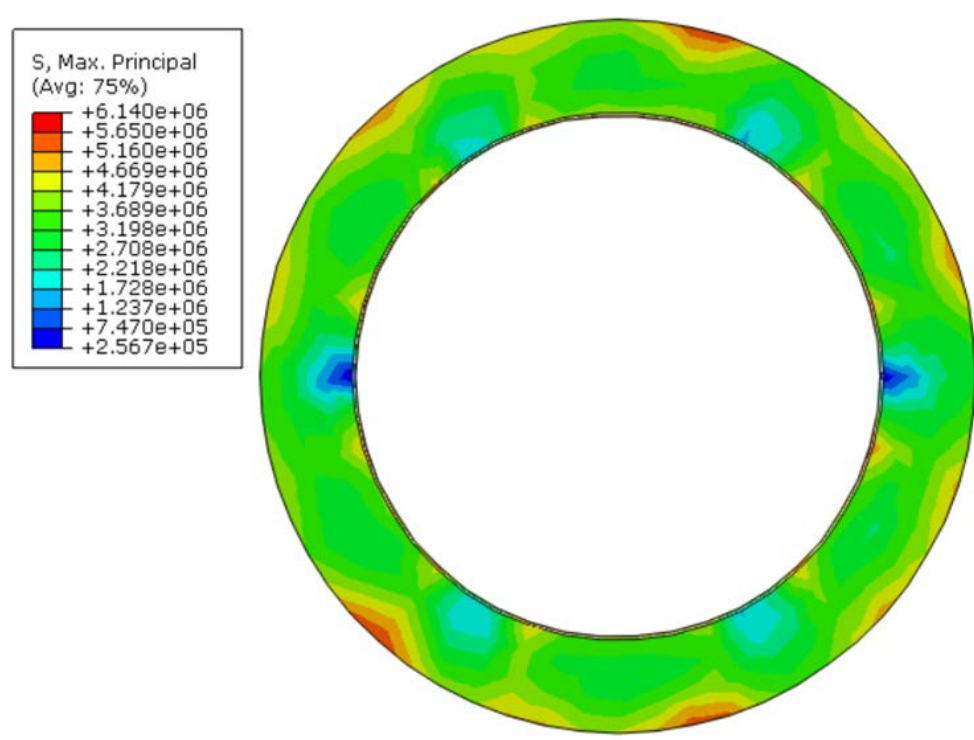

Figura 4.27 - Tensões de tração na camisa de UHPFRC referentes à força última do pilar C25FS 
Com a diminuição da expansão do núcleo, e, consequentemente a diminuição das tensões de tração na camisa de UHPFRC, a capacidade de suportar as tensões de compressão aumentou significativamente.

Para mostrar a validade do Critério de Mohr para este caso, inseriu-se a tensão aproximada de tração medida no UHPFRC e verificou-se que a tensão de compressão de ruína, estaria em torno de 95 MPa (Figura 4.28), o que realmente aconteceu, já que as tensões verificadas foram em torno de $92 \mathrm{MPa}$.

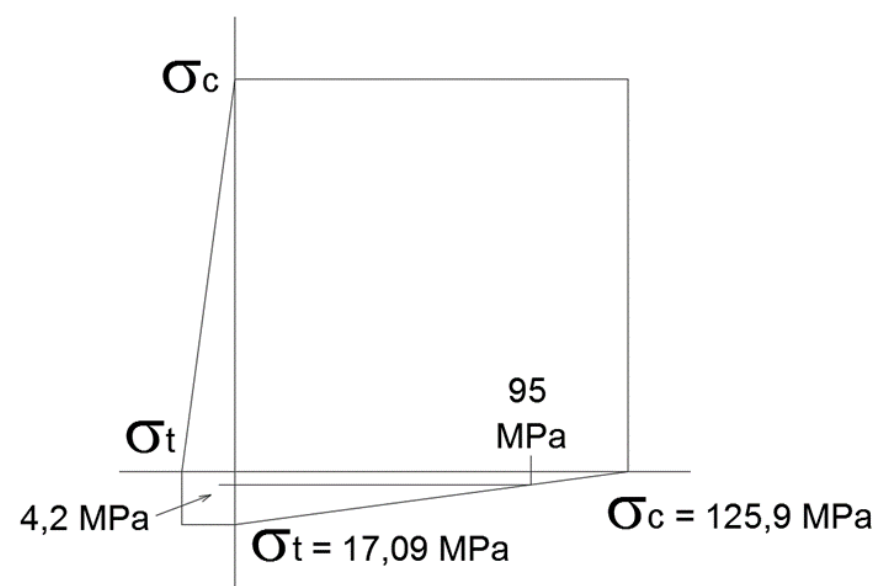

Figura 4.28 - Critério de ruptura de Mohr para a camisa de UHPFRC do pilar C25FS

É importante ressaltar que a execução deste tipo de reforço é muito mais complexa que a execução do reforço apenas com a camisa de UHPFRC (Pilares C15F e C25F).

\subsubsection{Pilares reforçados com camisa de UHPFRC e PRFC (C25FC)}

O pilar C25FC, com cobrimento de 2,5 cm de UHPFRC e 1 camada de PRFC, apresentou ruína com deformação menor no ensaio experimental do que na simulação numérica (Figura 4.30). Porém, a ruína prematura da camisa não interfere na resistência última do pilar e sim na ductilidade.

Assim, a simulação numérica descreve adequadamente o comportamento do pilar reforçado até a resistência última.

Uma hipótese para a ruína prematura é a localização das tensões de tração oriundas da ruptura da camisa de UHPFRC (Figura 4.29). Este fenômeno poderia ser atenuado com a utilização de mais camadas de PRFC. 


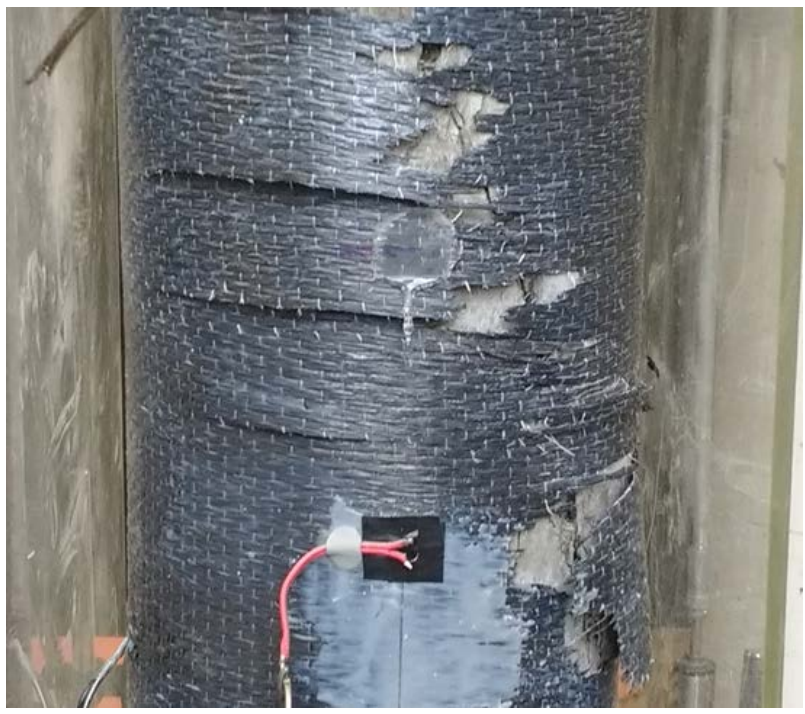

Figura 4.29 - Ruína do pilar C25FC

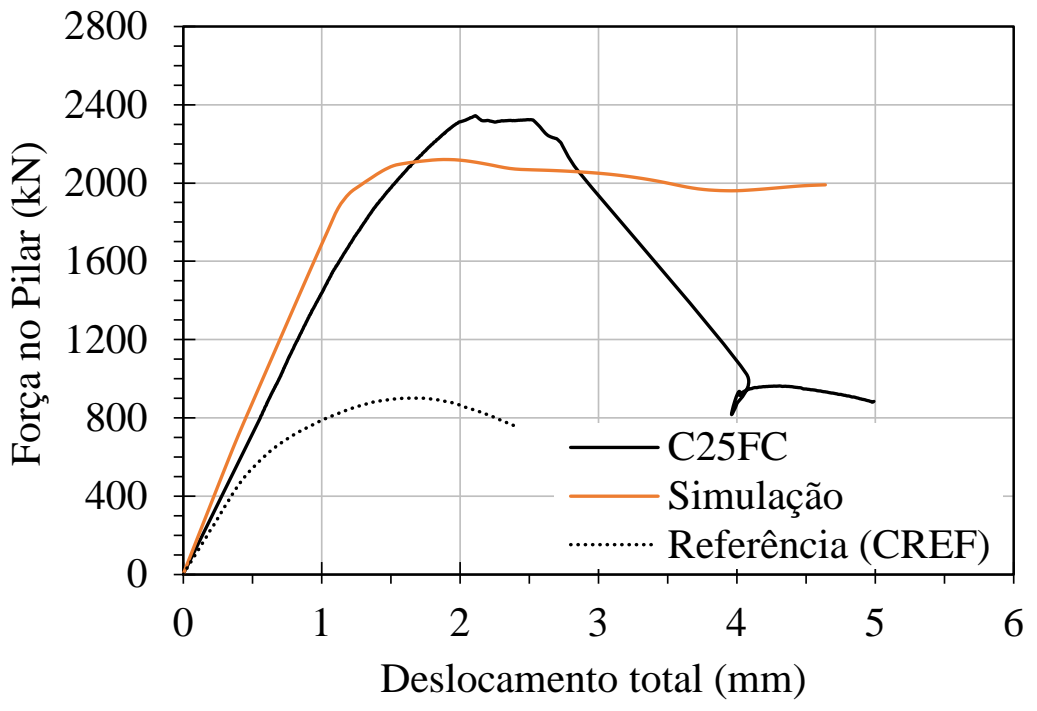

Figura 4.30 - Comparação entre o comportamento experimental e numérico do pilar C25FC

Pode-se observar na Figura 4.31, que o comportamento experimental das armaduras longitudinais também difere do comportamento numérico, por causa da ruptura prematura da camisa de reforço. 


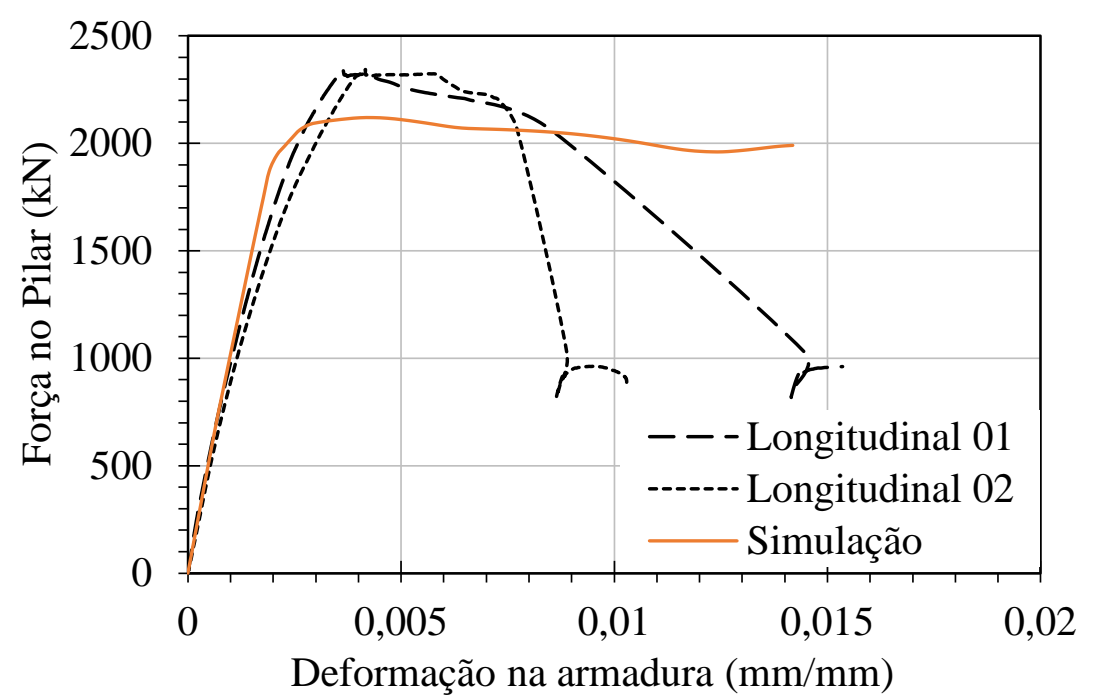

Figura 4.31 - Comparação entre o comportamento experimental e numérico das armaduras longitudinais do pilar C25FC

Pode-se notar por meio das curvas força-deformação mostradas na Figura 4.32, que a simulação numérica representa razoavelmente o comportamento experimental, principalmente até a força última.

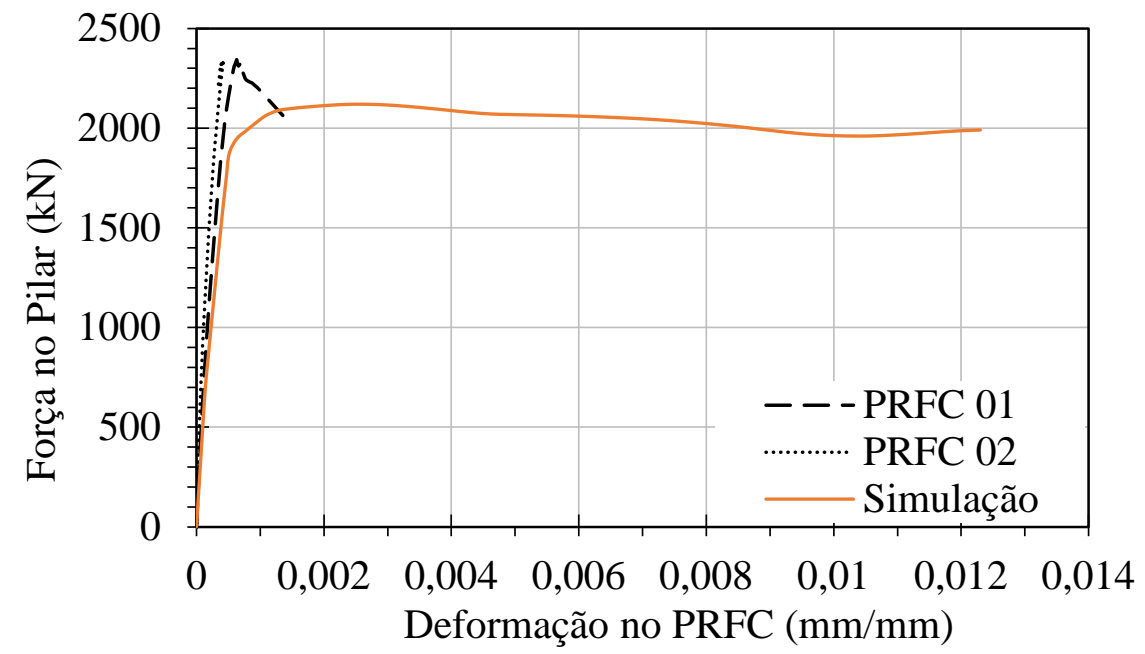

Figura 4.32 - Comparação entre o comportamento experimental e numérico da manta de PRFC do pilar C25FC

Para o entendimento do mecanismo de ruína do concreto convencional e do UHPFRC, são avaliadas as tensões de compressão nos concretos e as tensões de tração na camisa de UHPFRC.

Por meio da simulação numérica do pilar em questão, notou-se que o concreto do núcleo apresentou tensões de compressão em torno de 48 MPa e o UHPFRC (da 
camisa de reforço) apresentou tensões de compressão em torno de 87 MPa (Figura 4.33).

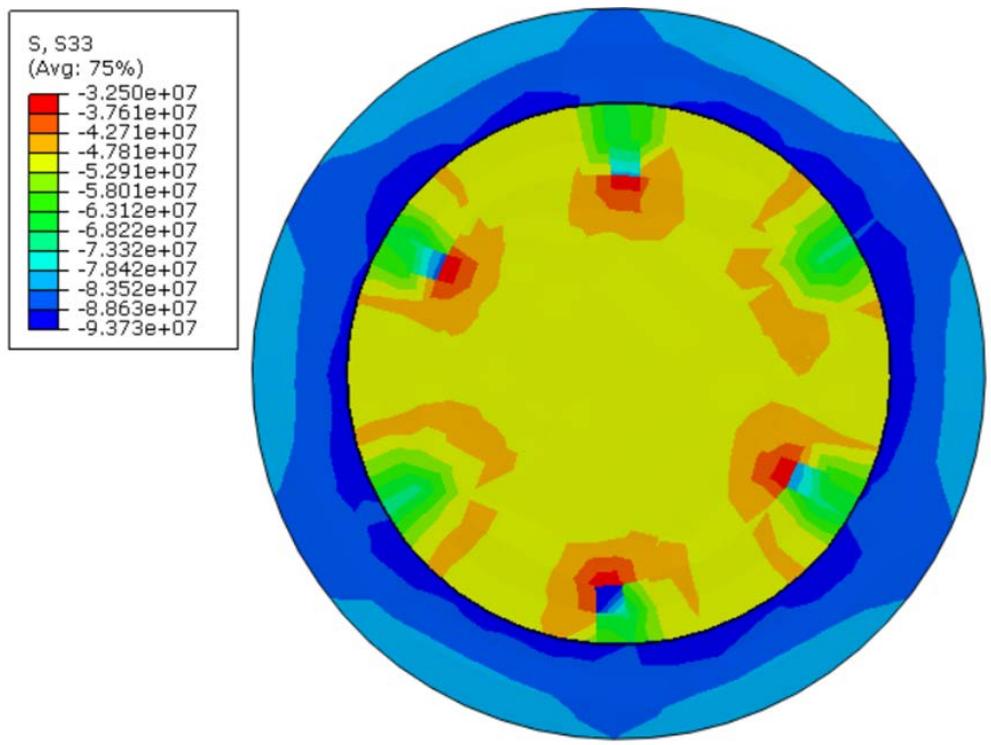

Figura 4.33 - Tensões de compressão no concreto convencional e no UHPFRC referentes à força última do pilar C25FC

Este acréscimo de resistência do concreto convencional e do UHPFRC em relação ao Pilar C25F foi possível por causa do confinamento provocado pela ação da camisa de PRFC.

Como mostrado na Figura 4.34, as tensões de tração na camisa de UHPFRC variaram em torno de 4,5 MPa. As maiores tensões de tração se concentraram junto à camisa de PRFC no momento da ruína.

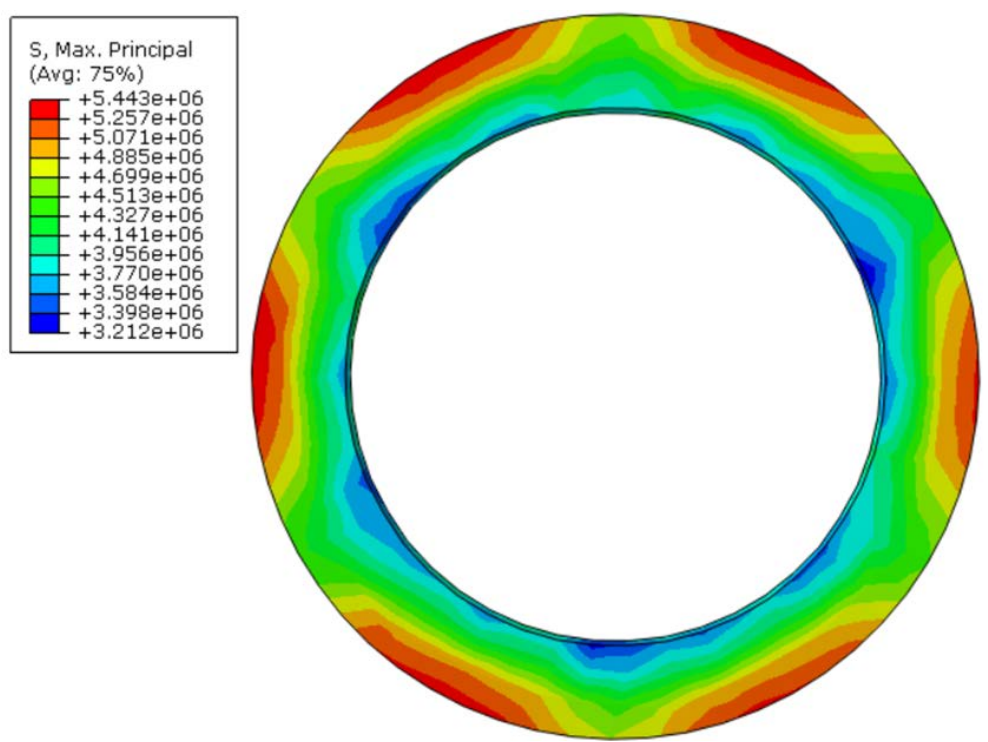

Figura 4.34 - Tensões de tração na camisa de UHPFRC referentes à força última do pilar $\mathrm{C} 25 \mathrm{FC}$ 
Foi interessante notar que antes da tensão última, mais especificamente próximo ao limite de proporcionalidade, ou seja, antes da acentuada perda de rigidez, as tensões de tração eram quase uniformes na camisa de UHPFRC (variaram basicamente entre 6,5 MPa e 7,2 MPa), e as tensões aumentavam do núcleo para as extremidades (Figura 4.35). Já as tensões de tração referentes à força última no pilar C25FC não foram uniformes (variaram basicamente entre 3,6 MPa a 5,4 MPa) e as tensões aumentavam das extremidades para o núcleo. Isto mostra que a camisa de PRFC começa a ser mobilizada efetivamente com a ruptura da camisa de UHPFRC.

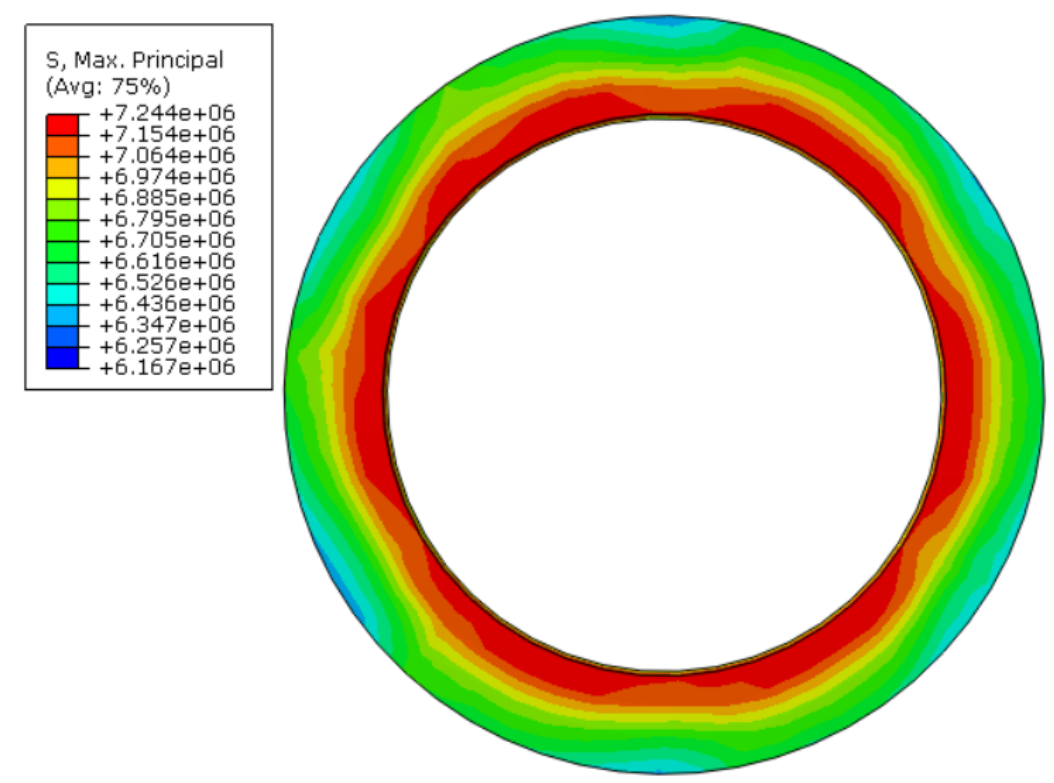

Figura 4.35 - Tensões de tração na camisa de UHPFRC referentes ao "limite de proporcionalidade" do pilar C25FC

Observando-se a Figura 4.36, nota-se que a contribuição da camisa de PRFC contribui pouco para o ganho de resistência e começa a atuar efetivamente após o início da ruptura da camisa de UHPFRC. 


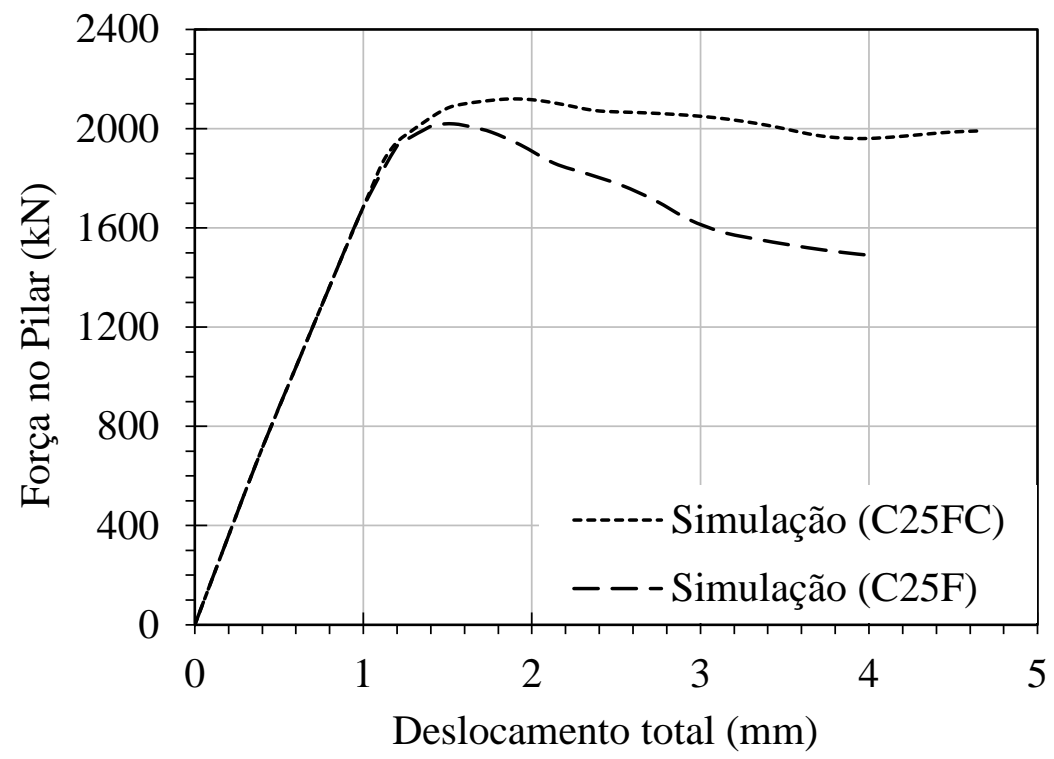

Figura 4.36 - Comparação entre as curvas numéricas dos pilares C25F e C25FC.

\subsubsection{COMPORTAMENTO DOS PILARES QUADRADOS}

O pilar SREF é o pilar quadrado de referência, cujo comportamento numérico e experimental pode ser observado na Figura 4.37.

Com relação às diferenças entre as duas curvas, nota-se que a curva numérica apresentou menor resistência, porém possui as mesmas características da curva experimental. É importante salientar que os dados utilizados para a simulação numérica são dados médios dos ensaios de caracterização, portanto, pequenas variações são esperadas entre estas curvas.

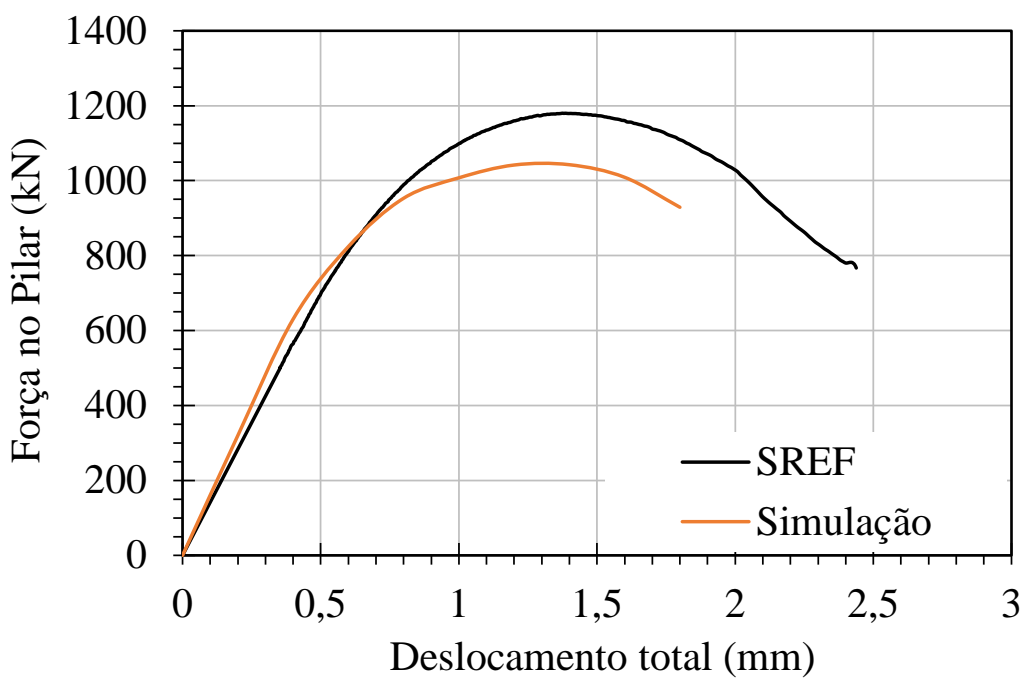

Figura 4.37 - Comparação entre o comportamento experimental e numérico do pilar SREF 
Com relação às armaduras longitudinais, o comportamento numérico também apresenta semelhanças ao comportamento experimental, como pode ser observado na Figura 4.38. Isto mostra que os dados fornecidos pela simulação numérica são confiáveis e podem ser utilizados para aumentar o universo de análise.

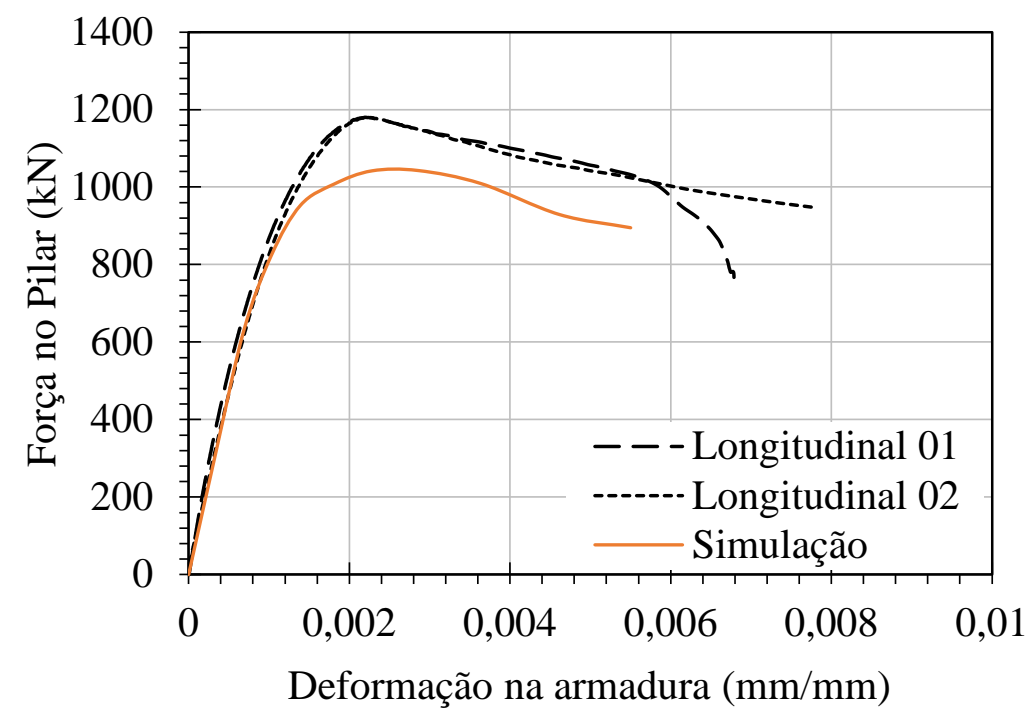

Figura 4.38 - Comparação entre o comportamento experimental e numérico das armaduras longitudinais do pilar SREF

As tensões de compressão no concreto convencional são mostradas na Figura 4.39. Observa-se que as tensões no concreto do núcleo são maiores por causa do confinamento provocado pelos estribos. É interessante notar que as tensões de compressão no concreto referente à força última ficou entre, aproximadamente 29 MPa no núcleo e $24 \mathrm{MPa}$ no cobrimento. Isto mostra que as tensões de compressão se aproximam da tensão média dos corpos-de-prova, que foi de 29,31 MPa. Isto mostra um confinamento provocado pelos estribos, porém com pequena intensidade.

A verificação do pequeno acréscimo de capacidade resistente do núcleo, provocado pelos estribos com espaçamento mínimo mostra a pouca influência dos estribos no confinamento do núcleo. 


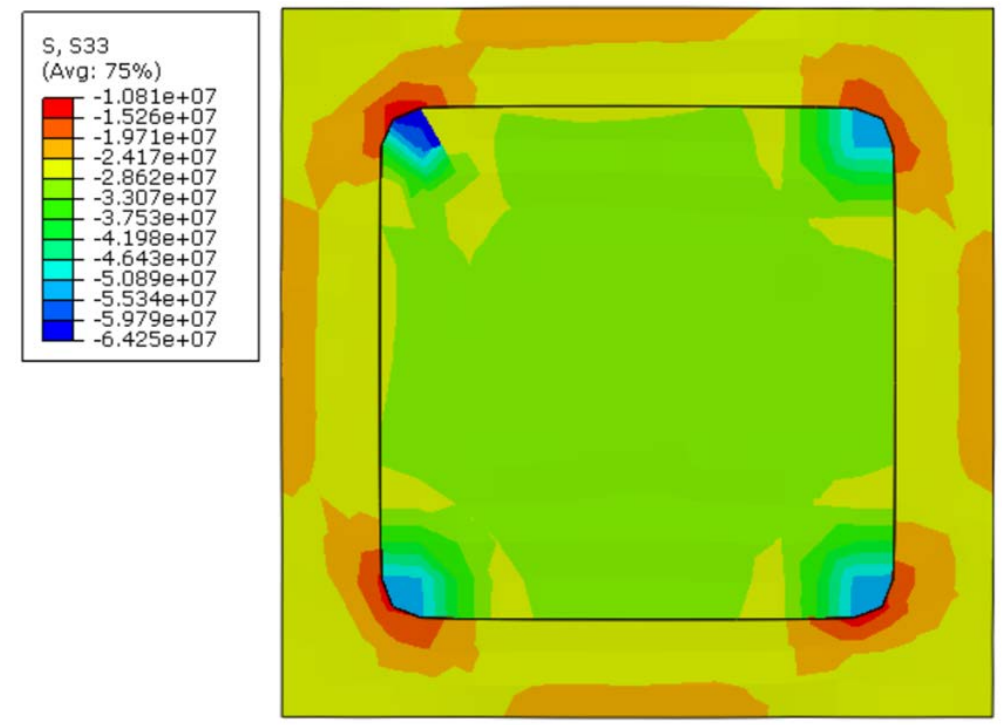

Figura 4.39 - Tensões de compressão no concreto convencional e no UHPFRC referentes à resistência última do pilar SREF

4.2.2.1 Pilar quadrado reforçado com camisa de 1,5 cm de UHPFRC (S15F)

Observando-se a Figura 4.40, pode-se observar que apesar da curva experimental apresentar uma queda brusca após a força última, causada pela ruína da camisa de UHPFRC, a curva numérica se assemelha à curva experimental, principalmente até a força última.

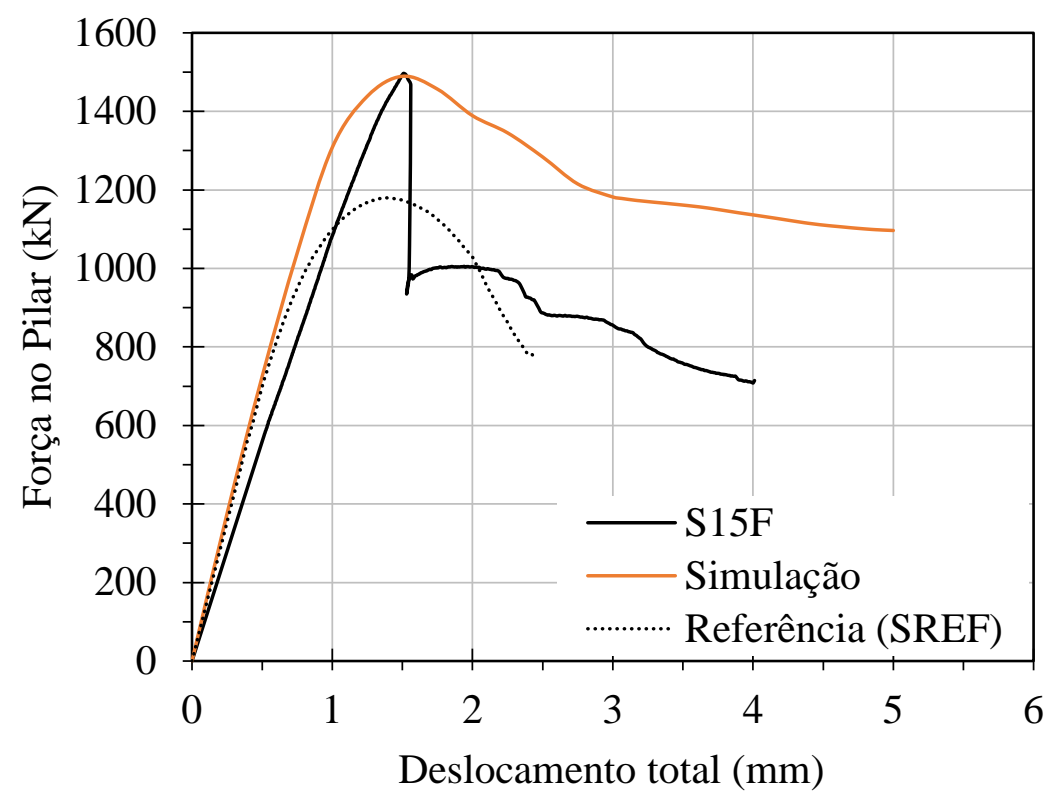

Figura 4.40 - Comparação entre o comportamento experimental e numérico do pilar S15F 
A ruína da camisa de reforço ocorreu próximo ao apoio (Figura 4.41), e a descontinuidade na geometria (os cantos foram arredondados para receber duas camadas de PRFC) pode ter contribuído para uma ruína prematura.

Mesmo com a ruína da camisa, as fibras ainda continuaram agindo, garantindo maior ductilidade ao pilar, se comparado ao pilar de referência.

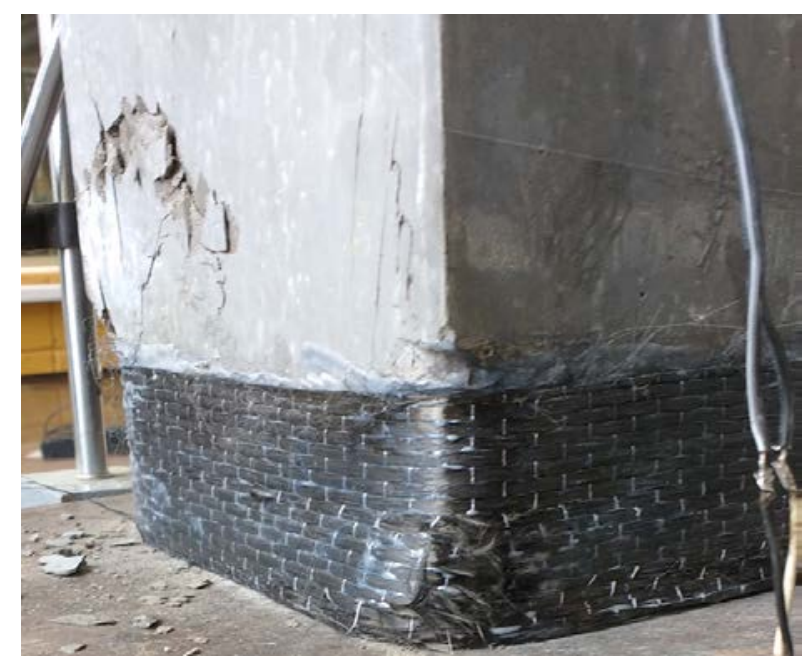

Figura 4.41 - Ruína do pilar S15F

Com relação às armaduras longitudinais, pode-se notar na Figura 4.42, que o comportamento numérico também se assemelha ao comportamento experimental, principalmente até a força última.

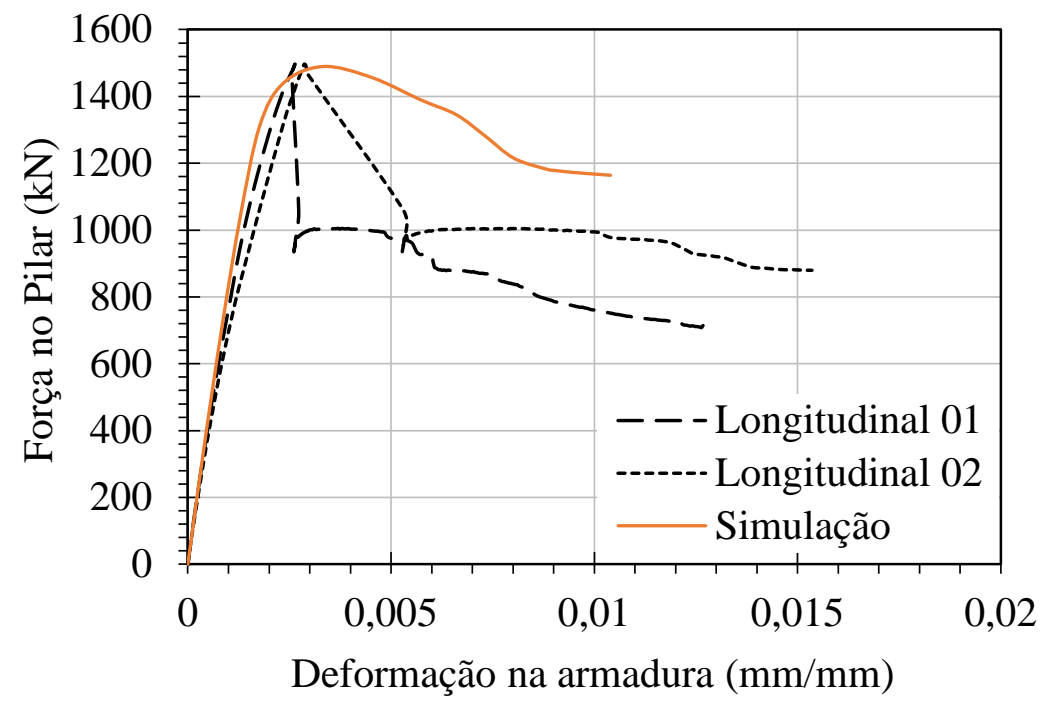

Figura 4.42 - Comparação entre o comportamento experimental e numérico das armaduras longitudinais do pilar S15F 
Como o comportamento do pilar S15F é descrito adequadamente, principalmente até a força última, são mostradas na Figura 4.43 as tensões de compressão, tanto no UHPFRC, quanto no concreto convencional.

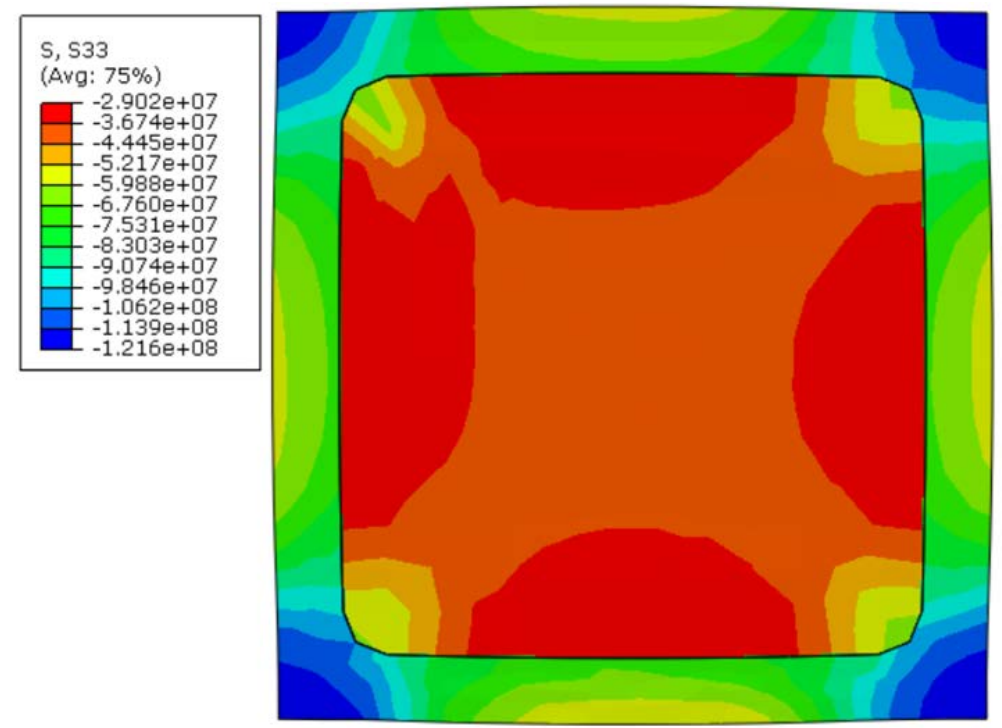

Figura 4.43 - Tensões de compressão no concreto convencional e no UHPFRC referentes à força última do pilar S15F

Nota-se, que as tensões de compressão no núcleo estavam em torno de 44 $\mathrm{MPa}$. Isto mostra que a pequena camada de UHPFRC $(1,5 \mathrm{~cm})$ conseguiu mobilizar pressões laterais suficientes para elevar a resistência do núcleo em cerca de 50\%.

Observando-se a Figura 4.43, nota-se que as tensões de compressão no UHPFRC não foram uniformes na seção e variaram entre $60 \mathrm{MPa}$ e $122 \mathrm{MPa}$ relativo à força última. As tensões de tração também não estavam uniformes na seção e variaram entre zero e $10 \mathrm{MPa}$, como mostra a Figura 4.44. 


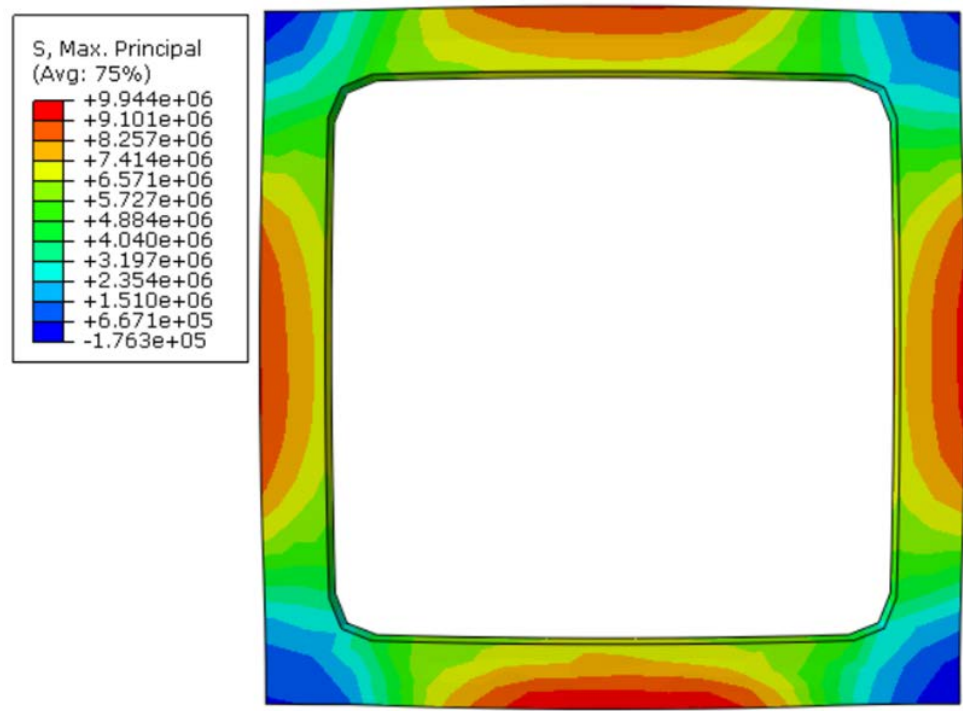

Figura 4.44 - Tensões de tração na camisa de UHPFRC referentes à força última do pilar S15F

Apesar do pilar S15F apresentar variações bem maiores de tensão ao longo de sua geometria que o pilar $\mathrm{C} 15 \mathrm{~F}$, os dois pilares mostraram comportamentos semelhantes (Figura 4.45). Isto mostra que a camisa de UHPFRC conseguiu confinar o núcleo do pilar de seção quadrada tanto quanto o pilar de seção circular. Será verificado no pilar S25F e na análise paramétrica se este fenômeno ocorre com espessuras maiores de UHPFRC.

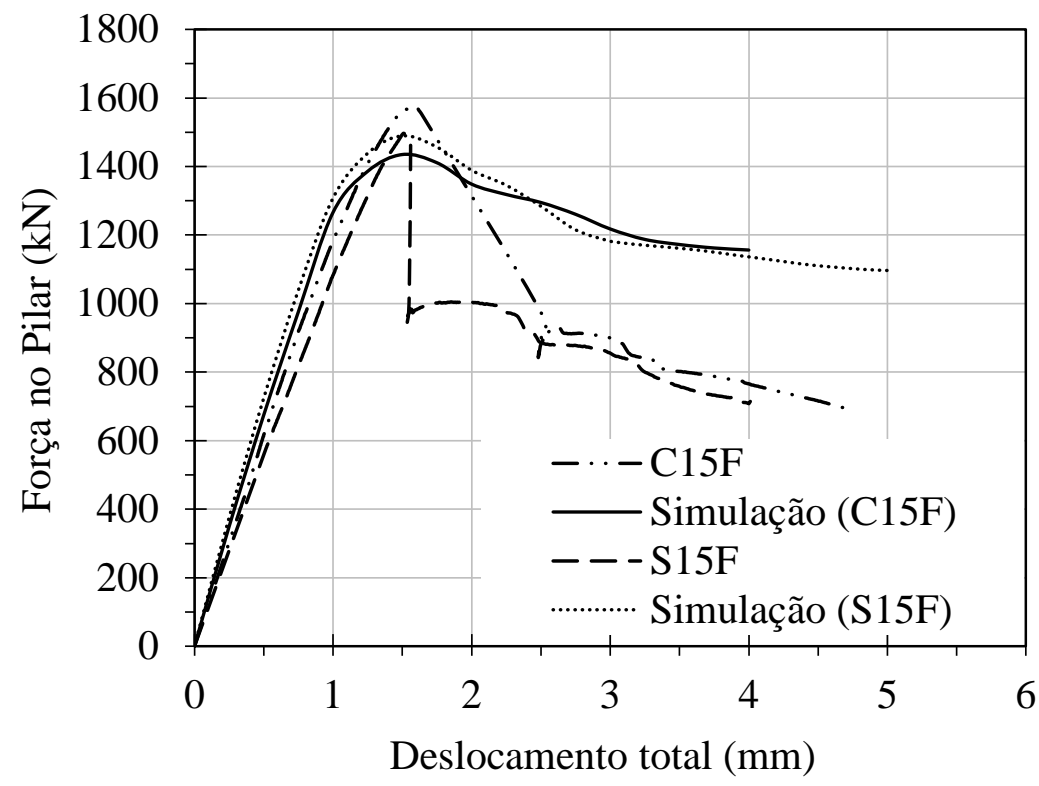

Figura 4.45 - Comparação entre os comportamentos dos pilares C15F e S15F 
4.2.2.2 Pilar quadrado reforçado com camisa de $2,5 \mathrm{~cm}$ de UHPFRC (S25F)

O pilar S25F apresentou comportamento numérico muito semelhante ao experimental, tanto na curva força-deslocamento do pilar reforçado (Figura 4.46), quanto na curva força-deformação específica das armaduras longitudinais (Figura 4.47).

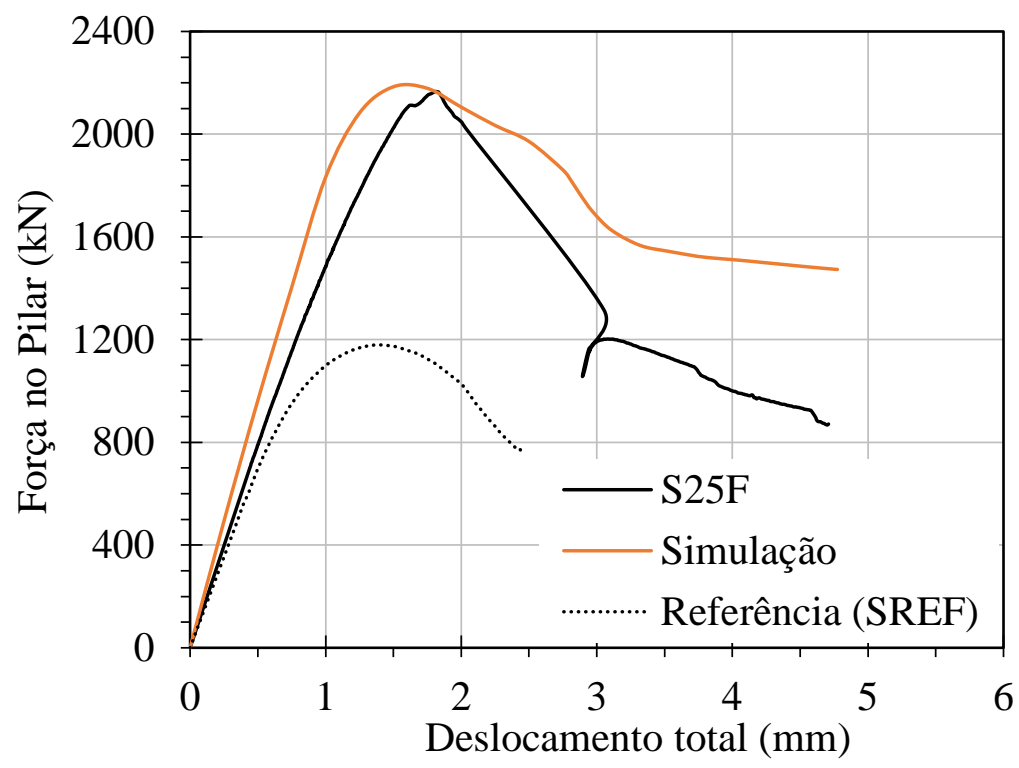

Figura 4.46 - Comparação entre o comportamento experimental e numérico do pilar S25F

Esta boa aproximação entre as curvas numéricas e experimentais mostram que a análise numérica é confiável e pode contribuir para o entendimento da contribuição de cada material na resistência do pilar S25F.

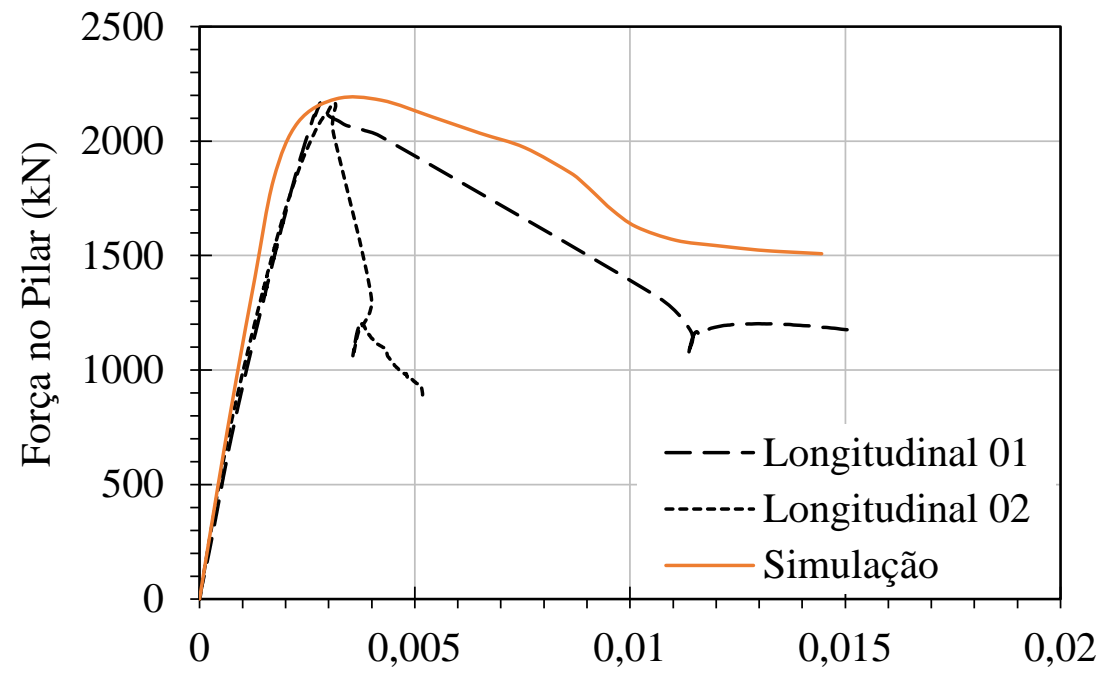

Deformação na armadura ( $\mathrm{mm} / \mathrm{mm})$ 
Figura 4.47 - Comparação entre o comportamento experimental e numérico das armaduras longitudinais do pilar S25F

As tensões de compressão no núcleo do pilar S25F referentes à força última estavam em torno de $49 \mathrm{MPa}$, como pode ser observado na Figura 4.48, mostrando que o aumento da espessura da camisa de UHPFRC contribui para o aumento das pressões laterais. As tensões de compressão no UHPFRC variaram entre $56 \mathrm{MPa}$ e $116 \mathrm{MPa}$, muito semelhante ao verificado no pilar S15F.

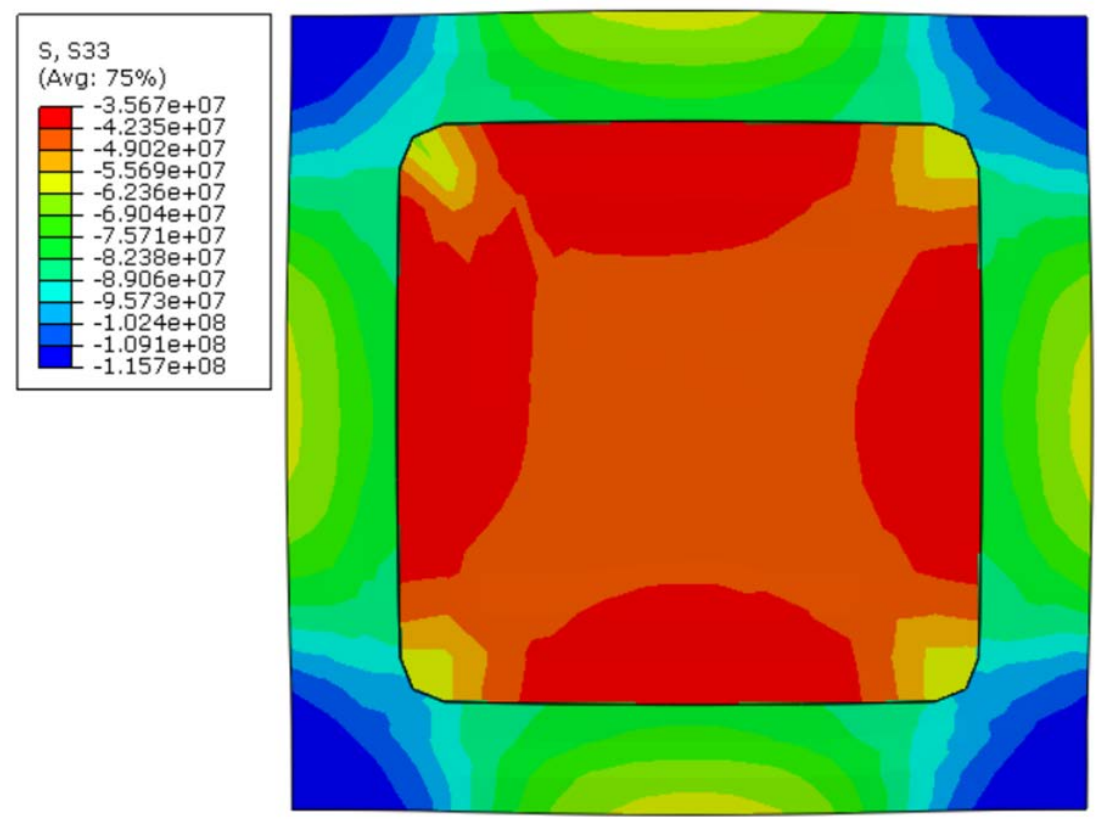

Figura 4.48 - Tensões de compressão no concreto convencional e no UHPFRC referentes à força última do pilar S25F

Com relação às tensões de tração no UHPFRC, observa-se por meio da Figura 4.49 que elas variaram entre aproximadamente zero e 9,1 MPa. 


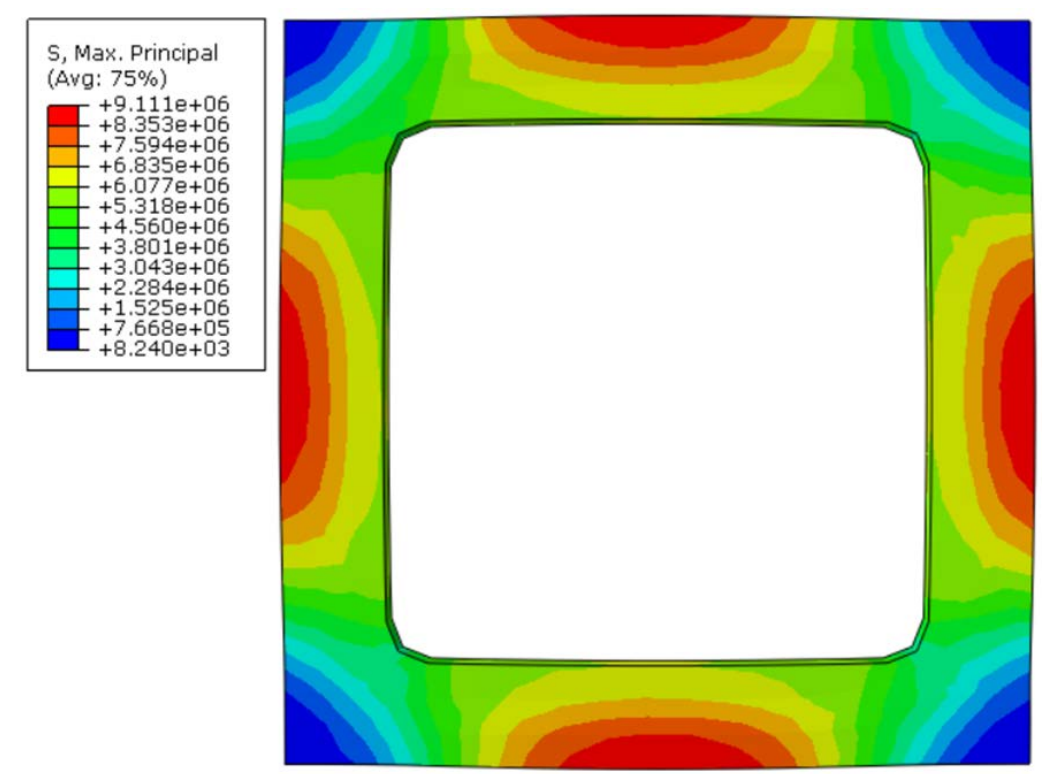

Figura 4.49 - Tensões de tração na camisa de UHPFRC referentes à força última do pilar S25F

Os pilares S25F e C25F também mostraram comportamentos semelhantes (Figura 4.50), porém a diferença de resistência foi maior neste caso. Isto pode ser explicado, pois ao comparar-se as áreas de UHPFRC em pilares circulares e quadrados, nota-se que quanto maior o aumento da espessura da camisa, maior a diferença entre as áreas, ou seja, neste caso a área de UHPFRC é maior no pilar quadrado, acarretando em uma resistência maior.

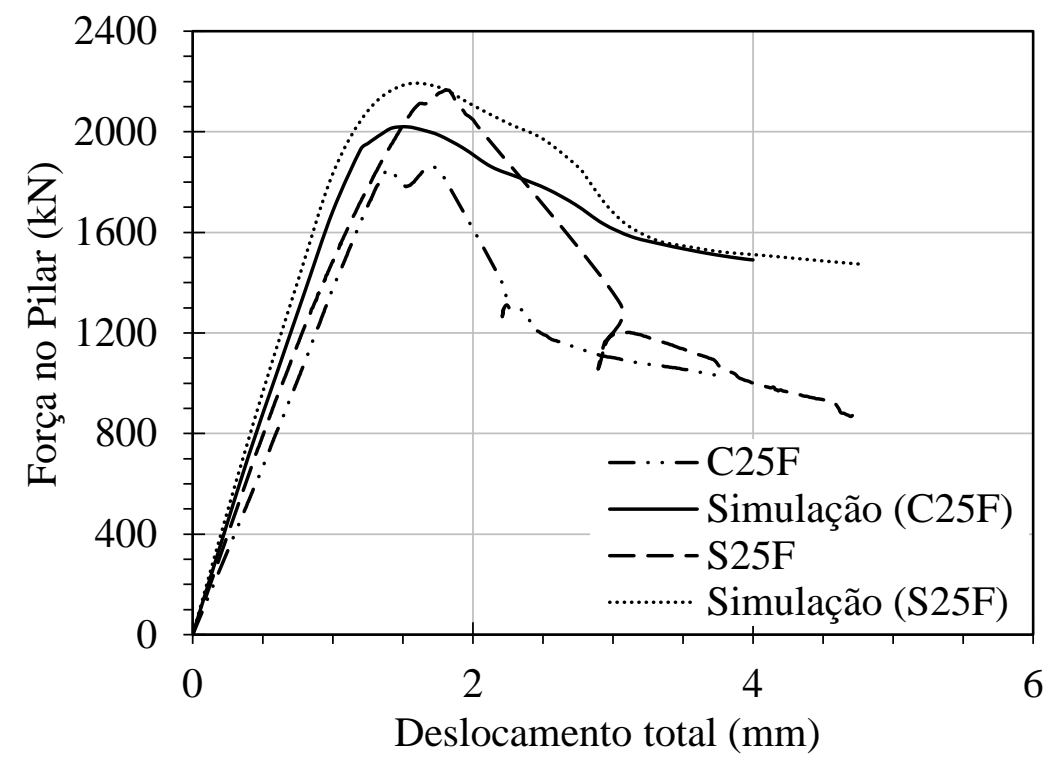

Figura 4.50 - Comparação entre os comportamentos dos pilares C25F e S25F 
$\mathrm{Na}$ apresentação da análise paramétrica é possível identificar melhor essa constatação.

4.2.2.3 Pilar quadrado reforçado com camisa de UHPFRC e armadura adicional (S25FS)

O pilar S25FS, é um pilar com reforço de quatro barras longitudinais de $10 \mathrm{~mm}$ e estribos de $5 \mathrm{~mm}$ a cada $5 \mathrm{~cm}$ no interiior da camisa de $2,5 \mathrm{~cm}$ de UHPFRC.

A comparação entre as deformações experimentais e numéricos no pilar S25FS pode ser observada na Figura 4.51. Nela, nota-se que o comportamento numérico se aproxima muito do comportamento experimental.

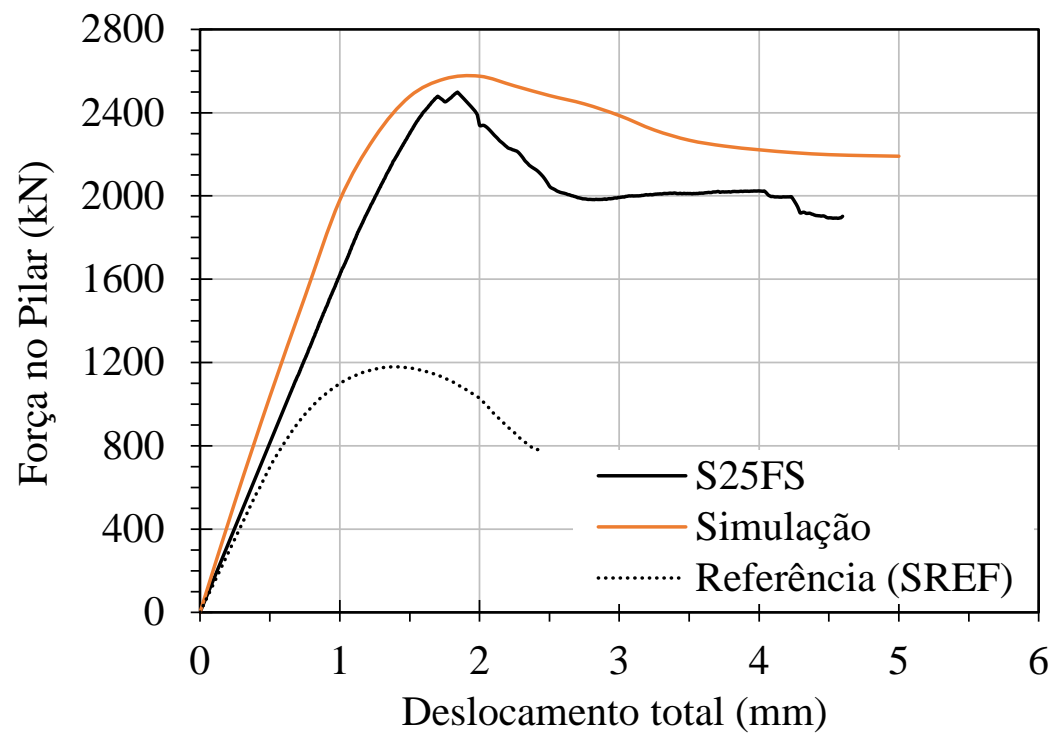

Figura 4.51 - Comparação entre o comportamento experimental e numérico do pilar S25FS

$\mathrm{Na}$ Figura 4.52, é apresentada a comparação entre as deformações experimentais e numéricas nas armaduras longitudinais. 


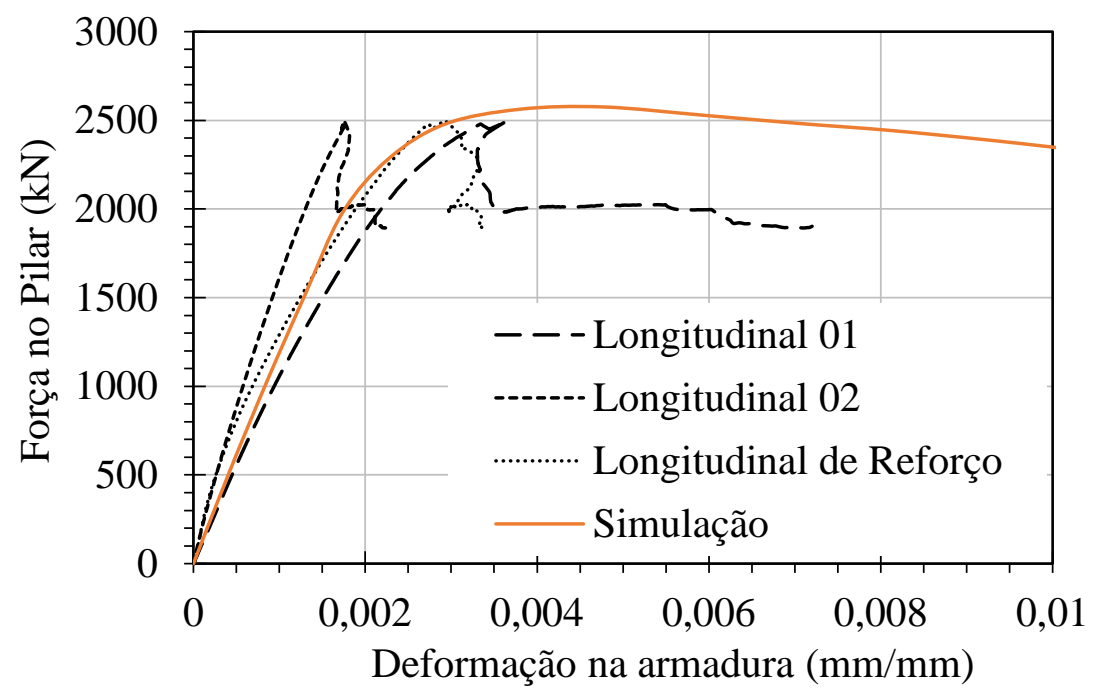

Figura 4.52 - Comparação entre o comportamento experimental e numérico das armaduras longitudinais do pilar S25FS

$\mathrm{Na}$ Figura 4.53, mostra-se a comparação das deformações numérica e experimentais nos estribos de reforço.

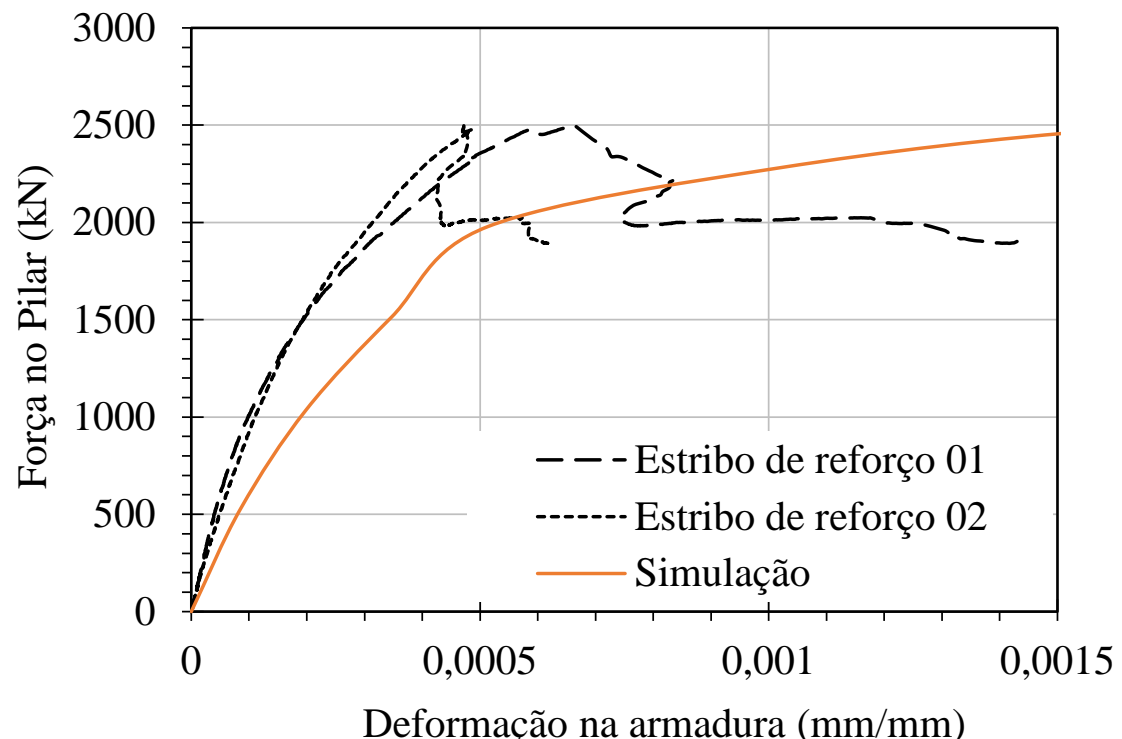

Figura 4.53 - Comparação entre o comportamento experimental e numérico dos estribos de reforço do pilar S25FS

Na simulação numérica, constatou-se que as tensões de compressão no núcleo do pilar S25FS estavam em torno de $51 \mathrm{MPa}$ e na camisa de UHPFRC em torno de $85 \mathrm{MPa}$ (Figura 4.55). É importante observar que os estribos de reforço aumentaram o confinamento do núcleo e com isso diminuíram a ação de expansão do núcleo sobre a camisa de UHPFRC, fazendo com que ambos os concretos suportassem maiores forças de compressão. 
Apesar da contribuição dos estribos para a contenção do núcleo, a execução desta técnica é muito mais complicada, que a substituição do cobrimento por UHPFRC, como no pilar S25F. Assim, como o acréscimo de resistência do pilar S25FS não é tão acentuado em relação ao pilar S25F, como mostrado na Figura 4.54, a técnica de reforço utilizada no pilar S25F se torna mais vantajosa pela sua simplicidade.

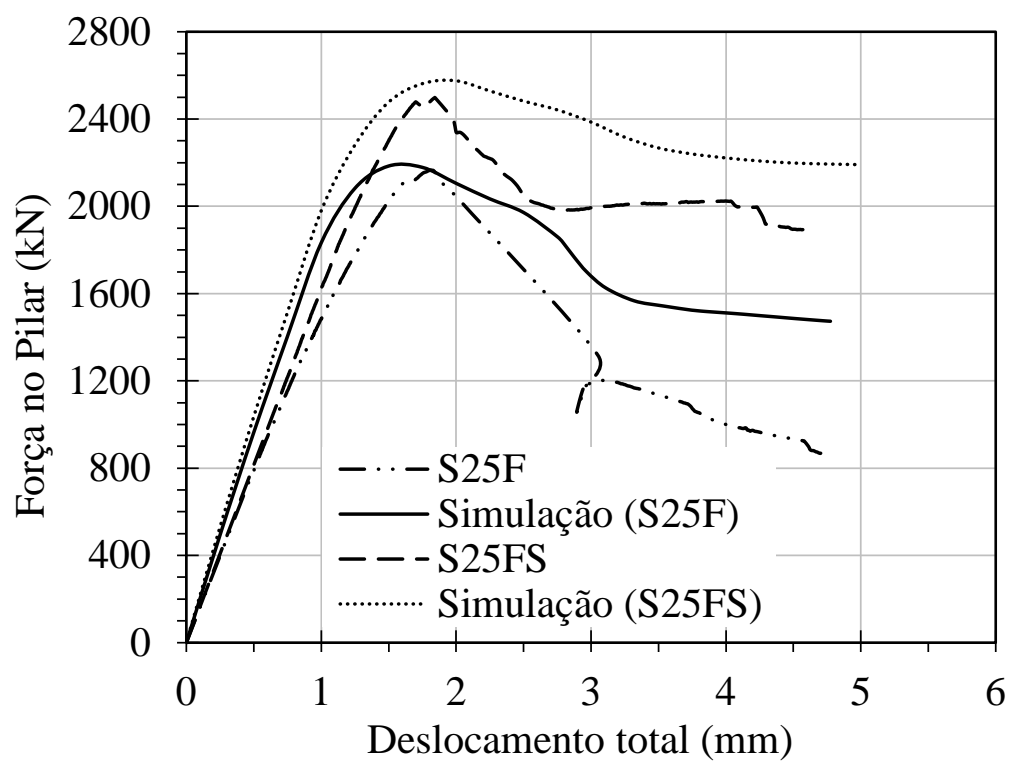

Figura 4.54 - Tensões de compressão no concreto convencional e no UHPFRC referentes à força última do pilar S25FS

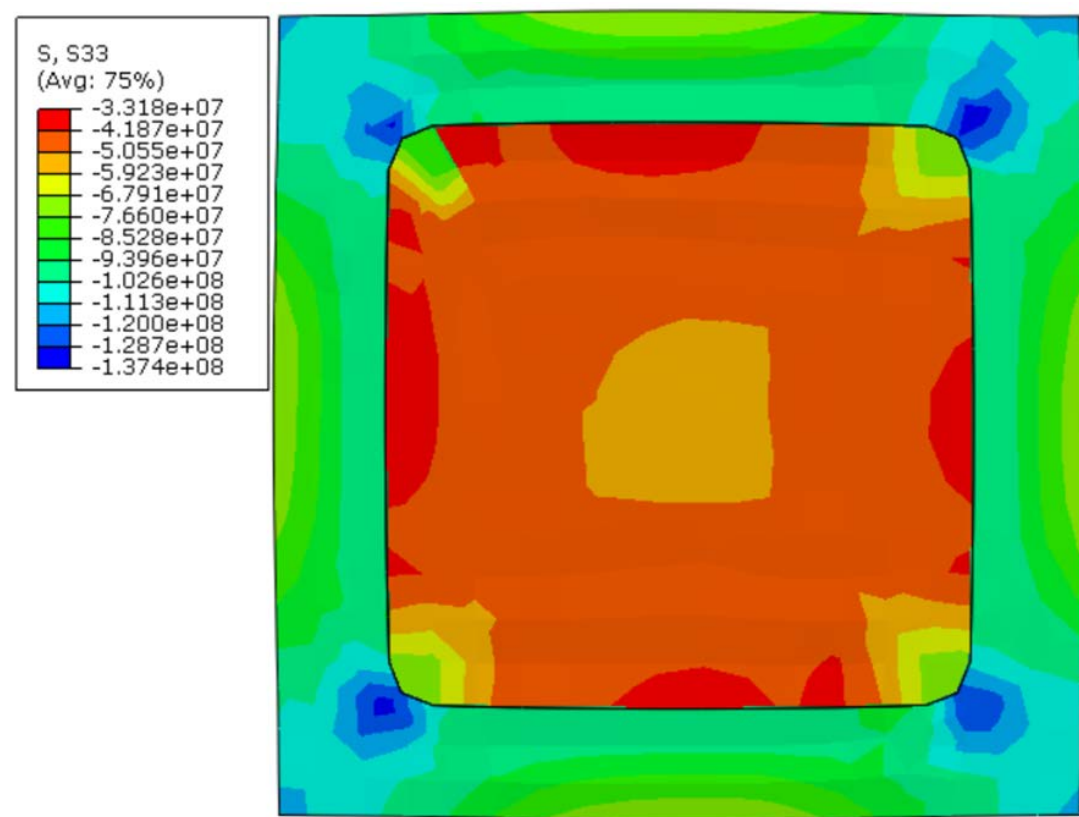

Figura 4.55 - Tensões de compressão no concreto convencional e no UHPFRC referentes à força última do pilar S25FS 
Com relação às tensões de tração no UHPFRC, observou-se na Figura 4.56, que elas estavam em torno de $3 \mathrm{MPa}$. Isso foi possível pois os estribos de reforço diminuíram a expansão do núcleo.

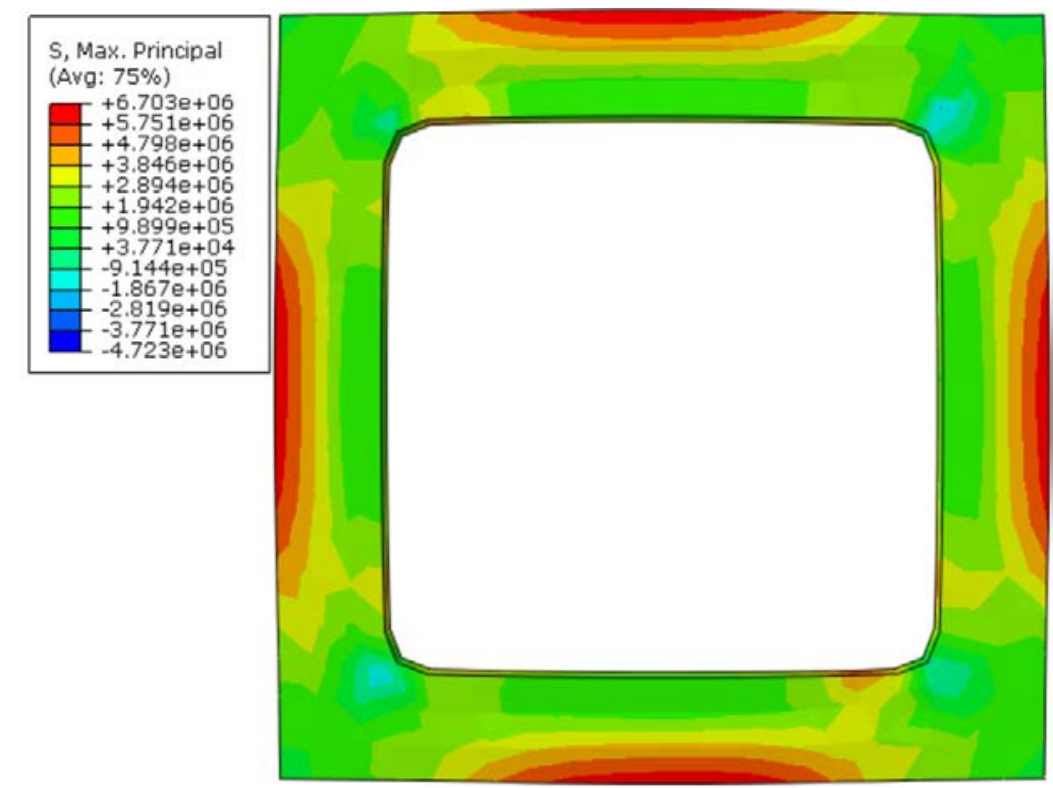

Figura 4.56 - Tensões de tração na camisa de UHPFRC referentes à força última do pilar S25FS

Assim, apesar da adição das armaduras garantir um aumento da capacidade resistente do pilar, a técnica que não utiliza estas armaduras se mostra mais vantajosa, pois consegue aumentar a capacidade resistente do pilar quase com a mesma intensidade e sua execução é muito mais simples.

\subsubsection{Pilares reforçados com camisa de UHPFRC e PRFC (S25FC)}

O pilar S25FC é um pilar cujo cobrimento de $2,5 \mathrm{~cm}$ foi substituído por UHPFRC e adicionada uma camada de PRFC.

Avaliando-se a Figura 4.57, observa-se que o diagrama força-deslocamento numérico é muito semelhante ao experimental. Analisando a Figura 4.58 constata-se que as curvas numéricas e experimentais relativas às deformações nas armaduras longitudinais também são muito semelhantes. 


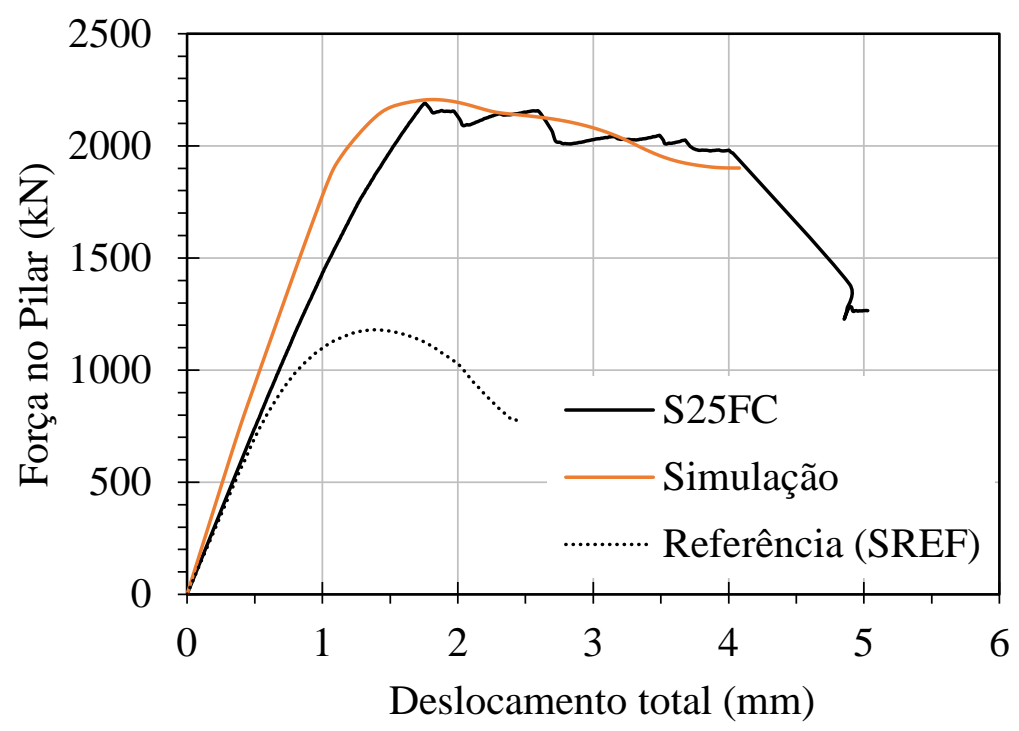

Figura 4.57 - Comparação entre o comportamento experimental e numérico do pilar S25FC

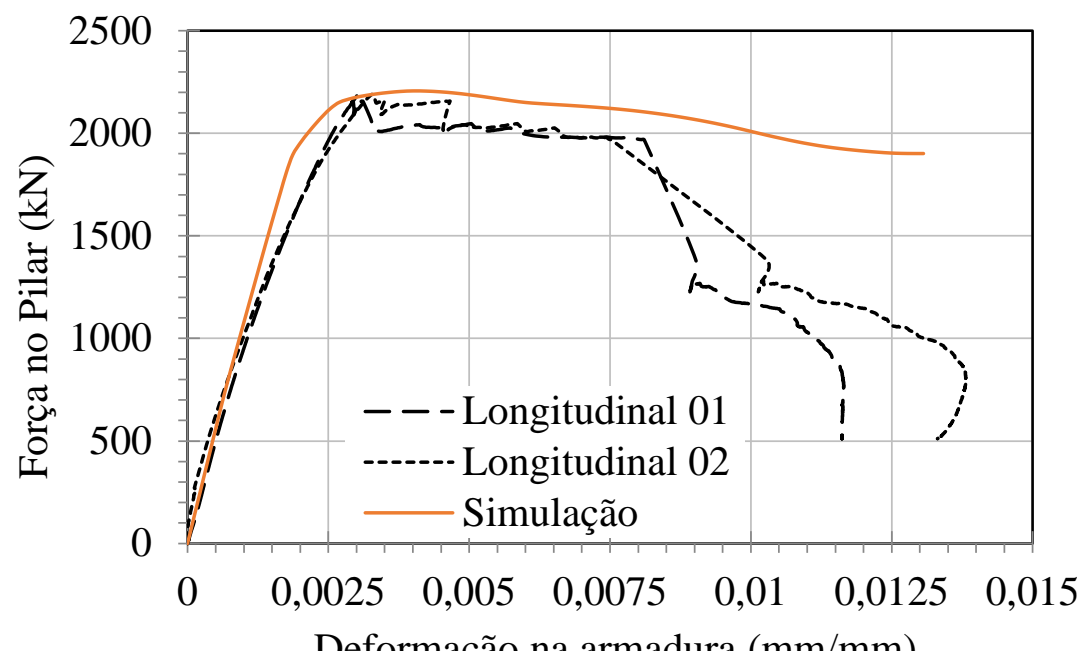

Figura 4.58 - Comparação entre o comportamento experimental e numérico das armaduras longitudinais do pilar S25FC

As curvas força-deformação lateral numéricas apresentadas na Figura 4.59, apresentam razoavelmente as curvas experimentais até a força última. 


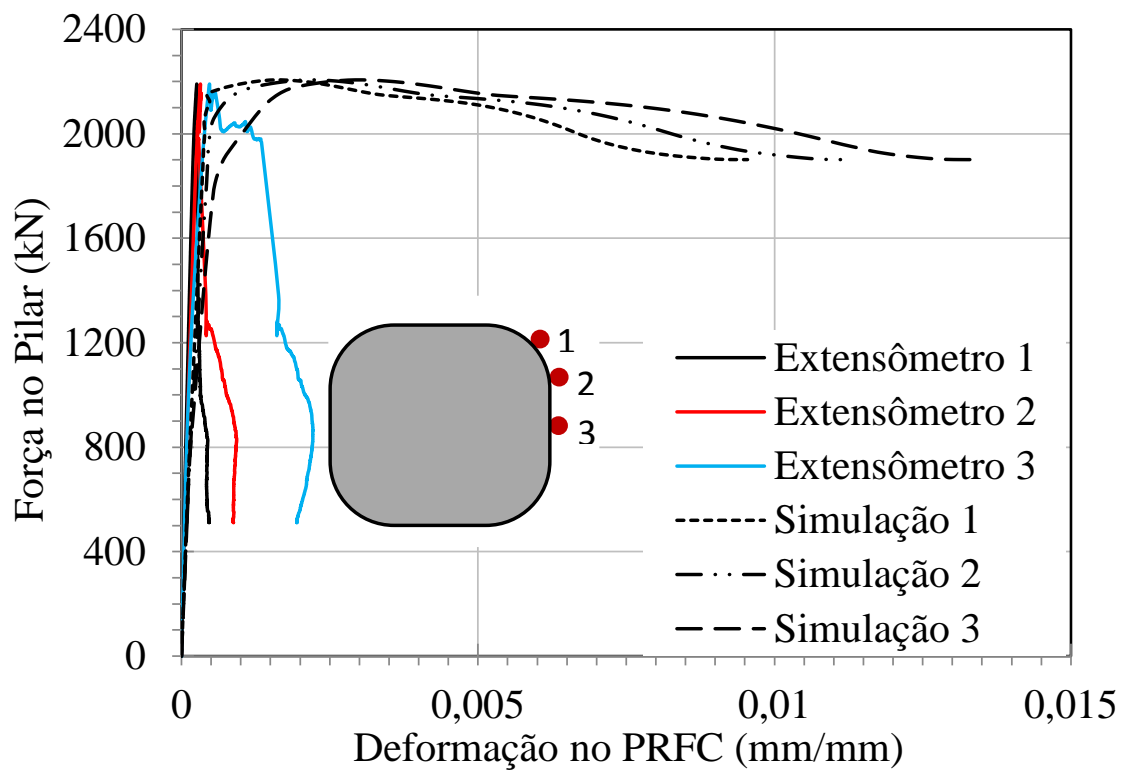

Figura 4.59 - Comparação entre o comportamento experimental e numérico da manta de PRFC do pilar S25FC

Para o entendimento do mecanismo de ruína do concreto convencional e do UHPFRC, são avaliadas as tensões de compressão nos concretos e as tensões de tração na camisa de UHPFRC.

Considerando a simulação numérica do pilar em questão, notou-se que o concreto do núcleo apresentou tensões de compressão em torno de $48 \mathrm{MPa}$ e o UHPFRC (da camisa de reforço) apresentou tensões de compressão em torno de 87 MPa (Figura 4.60).

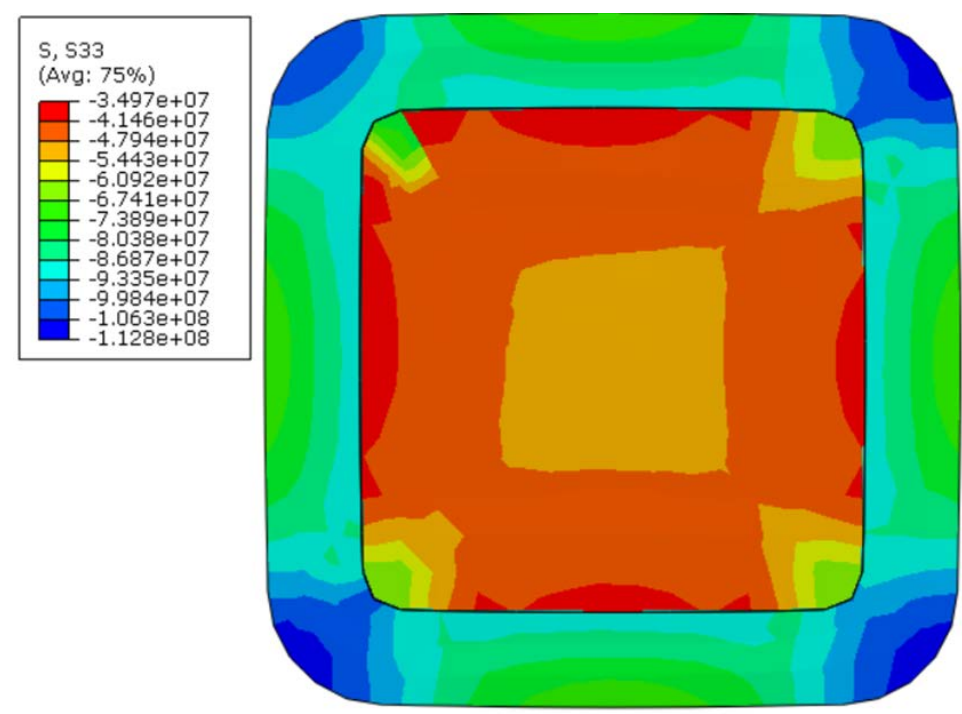

Figura 4.60 - Tensões de compressão no concreto convencional e no UHPFRC referentes à força última do pilar S25FC 
É interessante notar, que as tensões de compressão encontradas no pilar S25FC na força última, são praticamente iguais às encontradas no pilar circular C25F. Isto indica que as pressões laterais foram próximas nos dois casos.

Com relação às tensões de tração no UHPFRC, observa-se na Figura 4.61 que elas variaram entre $1 \mathrm{MPa}$ e $7 \mathrm{MPa}$.

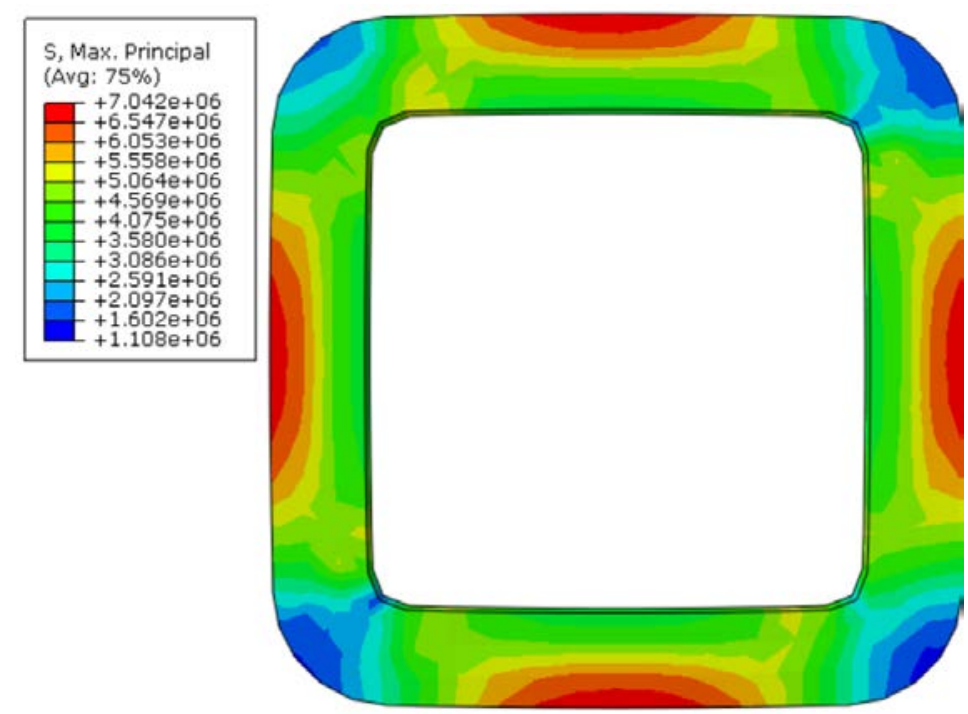

Figura 4.61 - Tensões de tração na camisa de UHPFRC referentes à força última do pilar S25FC

É importante notar que como no pilar S25FS, as tensões no UHPFRC e no concreto do núcleo por causa do efeito de confinamento proveniente da manta de PRF, porém, como no caso do pilar S25FS, o reforço com apenas a camada de UHPFRC se mostra mais vantajosa.

\subsubsection{ANÁLISE PARAMÉTRICA}

Durante a apresentação das simulações dos pilares circulares e quadrados, ficou clara a eficiência da camisa de UHPFRC para o aumento da resistência dos pilares reforçados. Ficou claro também, que a adição de armaduras adicionais e manta de PRFC contribuíram para um acréscimo de resistência e ductilidade.

$\mathrm{O}$ uso de armaduras adicionais mostrou-se pouco vantajoso pela dificuldade de se executar tal reforço em comparação com as outras duas propostas.

A adição de uma camada de PRFC também não se mostrou vantajosa devido aos bons resultados verificados na utilização apenas de UHPFRC, principalmente nos pilares quadrados, por isso, foi realizada uma análise paramétrica aumentando o 
número de camadas para avaliar a contribuição proporcionada por elas. Deve-se ponderar que as curvas apresentadas são apenas uma tendência dos resultados esperados, pois não há ensaios experimentais para confirmar tal comportamento.

Avaliando tanto a Figura 4.62, quanto a Figura 4.63, nota-se que a adição da manta de PRFC contribui para o aumento de resistência, porém com o aumento acentuado de deformações.

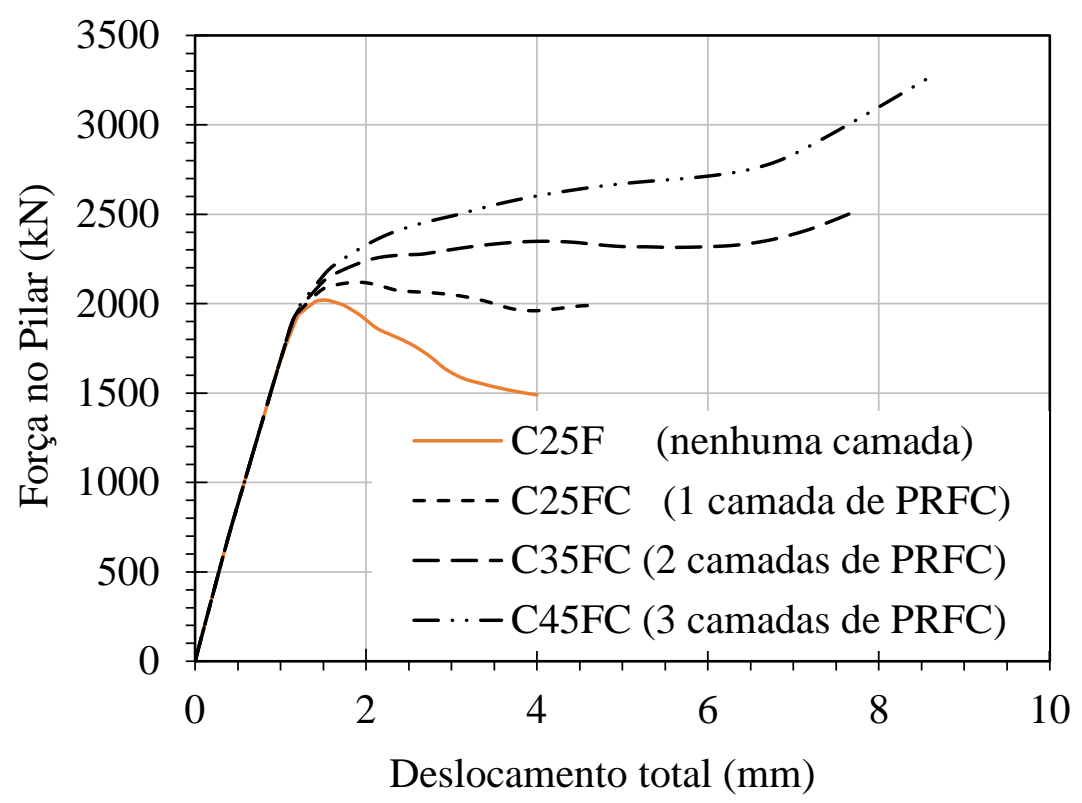

Figura 4.62 - Curvas numéricas para avaliação da influência do aumento de camadas de PRFC nos pilares circulares

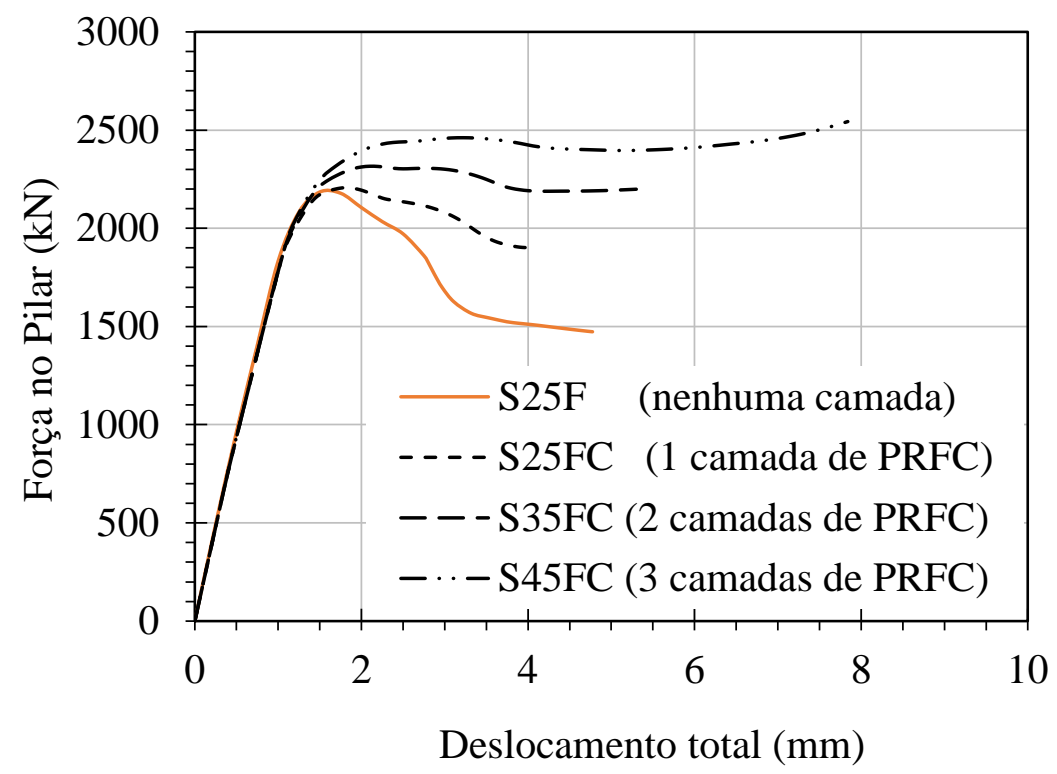

Figura 4.63 - Curvas numéricas para avaliação da influência do aumento de camadas de PRFC nos pilares quadrados 
A principal diferença entre o aumento das camadas nos pilares circulares e nos pilares quadrados, é que nos pilares circulares existe um maior ganho de resistência em virtude da influência da seção transversal.

Sendo assim, a adição de PRFC não contribui significativamente para o aumento de resistência sem um aumento considerável das deformações, e não há muitas vantagens que justifiquem o seu emprego junto ao UHPFRC, a não ser para a utilização em locais que demandem pilares com grande ductilidade.

Para uma melhor compreensão da influência da espessura da camisa de UHPFRC, foi realizada uma análise numérica considerando um aumento de $1 \mathrm{~cm}$ e 2 cm na espessura da camisa de reforço.

O pilar circular simulado com camisa de UHPFRC de $3,5 \mathrm{~cm}$ foi denominado C35FC e o pilar circular com camisa de $4,5 \mathrm{~cm}$ de espessura de C45FC.

A Figura 4.64 mostra o incremento de resistência causado pelo aumento da camisa de UHPFRC. Nela, pode-se observar que basicamente todos os pilares tiveram as forças últimas próximas a 1,5 cm de deslocamento, ou seja, a 2,5 \% de deformação específica, deformação esta, próxima ao verificado no pilar de referência.

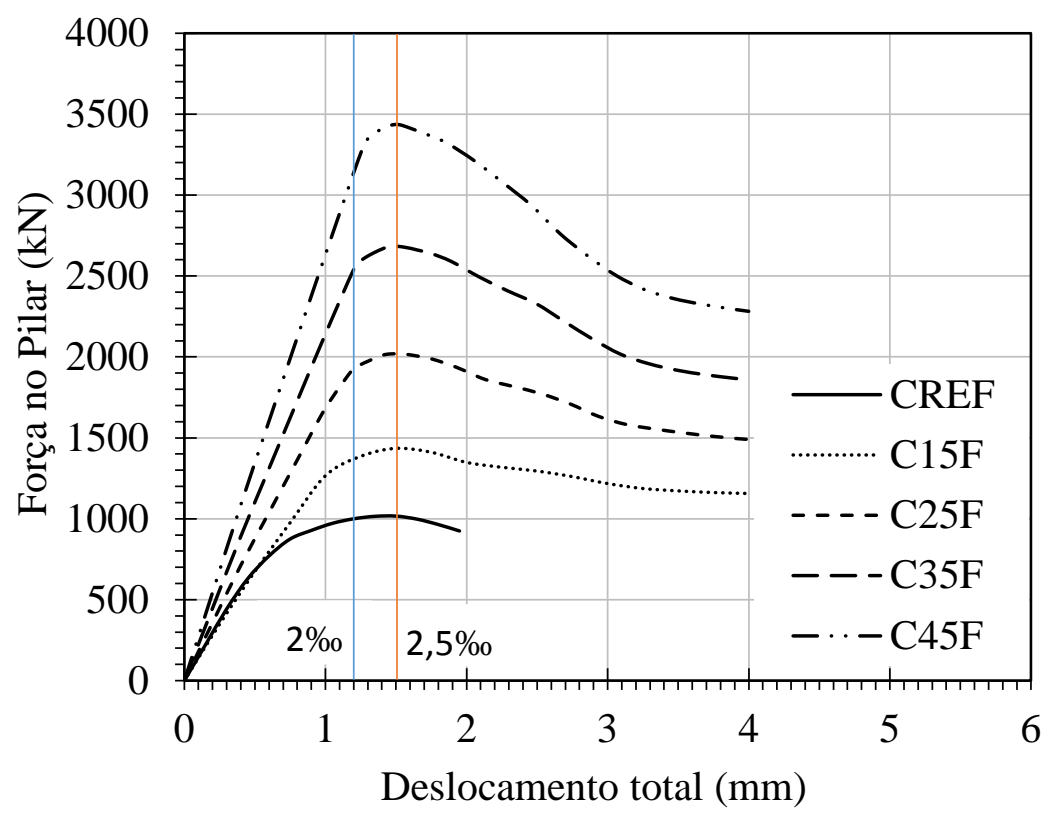

Figura 4.64 - Curvas numéricas para avaliação da influência do aumento de camadas de PRFC nos pilares quadrados

Apesar das deformações últimas estarem em torno de 2,5 \%o, as deformações últimas do concreto convencional não confinado no ensaio de caracterização, foram em torno de 2,0 \%. Nota-se na Figura 4.64, que, até um deslocamento de 1,2 cm, ou 
seja, até uma deformação de 2,0 \%o, os pilares com espessura de reforço acima de $2,5 \mathrm{~cm}$ não apresentaram perda de rigidez, ou seja, a perda de rigidez dos pilares reforçados acontece a partir de uma deformação em torno de 2,0 \%.

Como a ruína da camisa de UHPFRC ocorre principalmente pela ação da expansão do núcleo do pilar reforçado e o concreto comum apresenta expansão lateral acentuada a partir da deformação última, ou seja, em torno de 2,0 \%, a integridade do pilar reforçado é garantida para esta deformação.

Como mencionado no item anterior, o critério de Mohr representa de forma satisfatória a ruína do UHPFRC da camisa de reforço. Para tanto ele será utilizado para estimar as tensões de tração na camisa de UHPFRC referentes a uma deformação de 2,0 \%. Esta tensão de tração será utilizada para calcular a pressão lateral que atua no núcleo e assim calcular a resistência do concreto confinado.

A estimativa de resistência calculada neste trabalho se refere a resistência relativa a deformação de 2,0 \%, ou seja, enquanto o concreto do núcleo não apresenta expansão acentuada do núcleo. Esta é uma boa aproximação para se calcular a resistência desta técnica de reforço.

O cálculo da resistência aproximada dos pilares reforçados com UHPFRC (referentes à deformação de 2,0 \%), consiste em determinar no diagrama forçadeslocamento dos corpos-de-prova de UHPFRC, a tensão de compressão referente à deformação de 2,0 \%. De posse desta tensão de compressão, estima-se a tensão de tração por meio do critério de Mohr.

Após a determinação da tensão de tração, calcula-se a pressão lateral provocada pela camisa de UHPFRC, usando a Equação (2). Posteriormente, calculase também, a pressão lateral efetiva provocada pelos estribos e somam-se estas duas parcelas. De posse da pressão lateral total, utiliza-se a Equação (3) para a determinação da resistência do concreto do núcleo. Finalmente somam-se, as resistências do UHPFRC e das armaduras longitudinais referentes à deformação de 2,0 \% com a resistência do concreto confinado do núcleo.

A Tabela 4.3 mostra a comparação entre as resistências teóricas e numéricas referentes à deformação de 2,0 \% e as resistências numéricas e experimentais referentes à força última (cerca de 2,5\%). Nela pôde-se observar que a maior diferença entre as resistências teóricas e numéricas (referentes à deformação de 2,0 $\%$ ) foi de apenas $3,88 \%$. Isso mostra coerência do modelo teórico para o referido cálculo. 
Tabela 4.3 - Comparação entre as resistências teóricas, numéricas e experimentais dos pilares circulares reforçados com UHPFRC

\begin{tabular}{|l|c|c|c|c|}
\hline & C15F & C25F & CCF35 & CCF45 \\
\hline Força experimental última & 1577,34 & 1860,43 & - & - \\
\hline Força numérica última & 1434,99 & 2019,28 & 2685,36 & 3435,59 \\
\hline Força numérica referente a 2\%o & 1362,05 & 1930,85 & 2540,34 & 3138,39 \\
\hline Força teórica referente a 2\%o & 1383,63 & 1888,24 & 2441,78 & 3045,33 \\
\hline $\begin{array}{l}\text { Relação entre a força teórica e a } \\
\text { força numérica, referentes a 2\%o }\end{array}$ & $101,58 \%$ & $97,79 \%$ & $96,12 \%$ & $97,03 \%$ \\
\hline $\begin{array}{l}\text { Relação entre a força teórica (2\%o) } \\
\text { e a força numérica última }\end{array}$ & $96,42 \%$ & $93,51 \%$ & $90,93 \%$ & $88,64 \%$ \\
\hline
\end{tabular}

As curvas numéricas referentes às simulações dos pilares quadrados com camisa de UHPFRC podem ser observadas na Figura 4.65. As nomenclaturas dos pilares simulados com camisas de $3,5 \mathrm{~cm}$ e $4,5 \mathrm{~cm}$ de espessura de UHPFRC são S35F e S45F, respectivamente.

As resistências máximas, como nos pilares circulares, ocorrem próximo à deformação de 2,5 \%. Outra similaridade é a deformação de 2,0 \%o na qual se inicia a redução da rigidez. Como nos pilares circulares, são apresentados os procedimentos de cálculo para previsão da resistência referente à deformação de 2,0 $\%$.

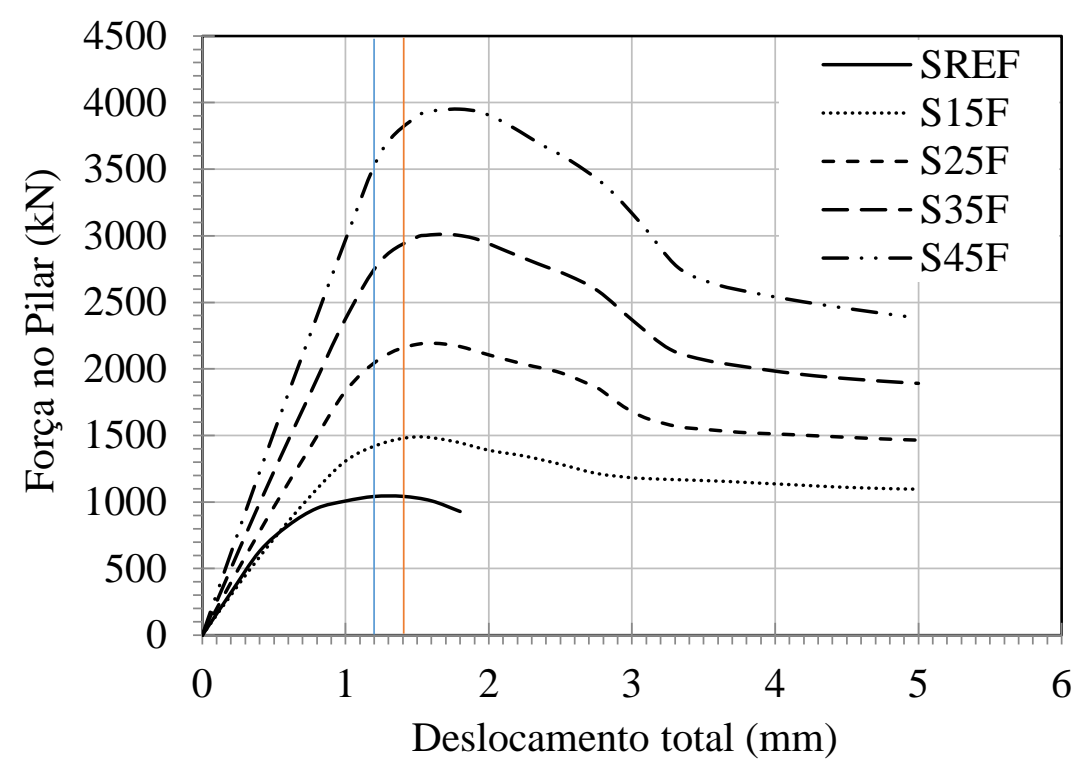

Figura 4.65 - Curvas numéricas para avaliação da influência do aumento da camada de UHPFRC nos pilares quadrados

Para o cálculo da resistência teórica dos pilares de seção quadrada reforçados com UHPFRC, considerou-se uma pressão uniforme em todo o pilar conforme modelo 
ilustrado na Figura 4.66. Para o cálculo das pressões laterais, considerou-se uma viga engastada dos dois lados com comprimento correspondente à dimensão do núcleo e espessura correspondente à espessura da camisa de UHPFRC. Escolheu-se o engastamento pela deformação da camisa de reforço, que ocorre como mostrado na Figura 4.66.
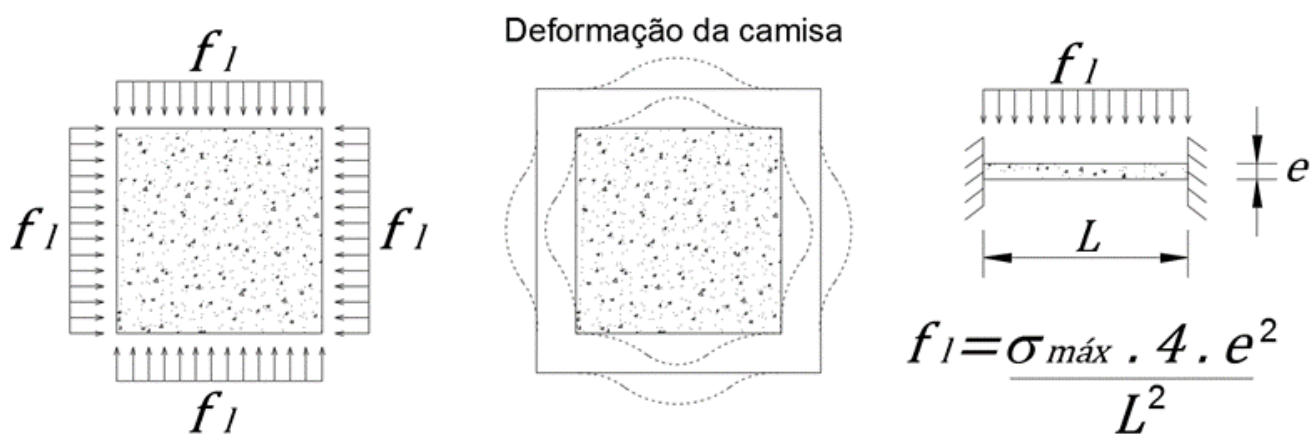

Figura 4.66 - Modelo proposto para o cálculo das pressões laterais nos pilares quadrados reforçados com UHPFRC

Observou-se que a tensão máxima de tração no momento da ruína foi em torno de $9 \mathrm{MPa}$ nas simulações de todos os pilares reforçados com UHPFRC. Assim, pôdese calcular a tensão máxima em uma viga engastada nas duas extremidades e determinar a pressão lateral que cada camisa exerce no núcleo.

De posse das pressões laterais calculadas com a tensão última de $9 \mathrm{MPa}$, calculou-se a resistência do concreto do núcleo confinado com a Equação (2). A resistência à compressão do UHPFRC foi considerada como nos pilares circulares, referente a uma deformação de 2,0 \%.

A Tabela 4.4 mostra a comparação entre as resistências teóricas e numéricas referentes à deformação de 2,0 \% e as resistências numéricas e experimentais referentes à força última (cerca de 2,5\%). Nela pôde-se observar que a maior diferença entre as resistências teóricas e numéricas (referentes à deformação de 2,0 \%) foi de apenas 1,91\%. Isso mostra a eficácia do modelo teórico.

Sugeriu-se adotar como referência de cálculo as resistências a 2,0 \% de deformação específica, pelo foco da pesquisa ser de reforço com camisas de pequena espessura, cuja ruína tem maior probabilidade de ocorrer após a deformação de 2,0 $\%$, por ser esta a deformação última do concreto convencional, e após esta deformação, a expansão do núcleo se torna muito mais acentuada podendo causar a ruína da camisa de reforço. 
Tabela 4.4 - Comparação entre as resistências teóricas, numéricas e experimentais dos pilares quadrados reforçados com UHPFRC

\begin{tabular}{|l|c|c|c|c|}
\hline & S15F & S25F & S35F & S45F \\
\hline Força experimental última & 1496,765 & 2166,097 & - & - \\
\hline Força numérica última & 1489,4 & 2184,73 & 3010,59 & 3950,96 \\
\hline Força numérica referente a 2\%o & 1412,448 & 2032,752 & 2728,862 & 3500,022 \\
\hline Força teórica referente a 2\%o & 1429,49 & 2070,69 & 2781,08 & 3559,98 \\
\hline $\begin{array}{l}\text { Relação entre a força teórica e a } \\
\text { força numérica referentes a 2\%o }\end{array}$ & $101,21 \%$ & $101,87 \%$ & $101,91 \%$ & $101,71 \%$ \\
\hline $\begin{array}{l}\text { Relação entre a força teórica } \\
(2 \% \text { ) e a força numérica última }\end{array}$ & $95,98 \%$ & $94,78 \%$ & $92,38 \%$ & $90,10 \%$ \\
\hline
\end{tabular}

É importante ressaltar que quanto maior a espessura da camisa de reforço, maior será a diferença entre a força referente à deformação de 2,0 \% e a força última do reforço. Porém esta é uma forma conservadora para o cálculo da resistência do pilar reforçado, já que após esta deformação a integridade da camisa de reforço não pode ser garantida. 


\section{CONCLUSÃO}

Atualmente, as técnicas de reforço de pilares ou alteram bruscamente as seções dos pilares, ou demandam elevadas deformações para o acréscimo de resistência ou são sensíveis aos agentes atmosféricos. Este trabalho apresenta uma nova técnica que não altera a geometria do pilar, apresenta deformação compatível com a do pilar não reforçado e utiliza material de maior durabilidade que o concreto convencional.

A presente pesquisa avaliou novas técnicas para reforço de pilares curtos com seções transversais circulares e quadradas, sujeitos a compressão centrada. Esses pilares foram reforçados com UHPC e UHPFRC e em alguns casos foram adicionados PRFC ou armadura adicional.

Buscou-se desenvolver um concreto de ultra-alto desempenho fluido o suficiente para concretagem de pequenas espessuras, avaliar a interação entre o concreto do núcleo e a camisa de reforço, verificar as intensidades de deformação dos pilares reforçados e avaliar a contribuição do pilar original.

Verificou-se que o traço proposto por Sobuz et al. (2016) para os concretos de ultra-alto desempenho, com a utilização de $9 \%$ de superplastificante, resultou em um concreto fluido que proporcionou a concretagem das camisas sem problemas, mesmo em espessuras menores que $1,5 \mathrm{~cm}$.

A resistência do pilar original é totalmente considerada em todos os casos, não só com a resistência original, mas com a resistência do concreto confinado.

Observou-se que o concreto de ultra-alto desempenho sem fibras (UHPC) apresenta ruína frágil e não é recomendado para a utilização em reforço de pilares, a não ser que seja acompanhado de elementos que produzam confinamento do concreto do núcleo.

Com relação ao UHPFRC, todos os pilares com este concreto apresentaram ganho de resistência e não houve destacamento da camisa de reforço em nenhum dos ensaios experimentais.

O reforço com UHPFRC se mostrou tão eficaz que até o pilar circular cujo cobrimento de 2,5 cm foi substituído por $1,5 \mathrm{~cm}$ de UHPFRC, ou seja, em que se reduziu a seção transversal, obteve-se acréscimo de resistência de $75 \%$. 
Observou-se que apenas a substituição do concreto do cobrimento por UHPFRC já confere um acréscimo elevado de resistência tanto em pilares de seção circular como em pilares de seção quadrada.

Por meio de simulações numéricas, notou-se que o aumento de pequenas espessuras no cobrimento, aumenta substancialmente a resistência dos pilares reforçados. Isso mostrou a eficiência do reforço com camisa de UHPFRC.

Analisando as simulações numéricas, constatou-se que a influência da manta de PRFC envolvendo a camisa de UHPFRC contribui principalmente para aumentar a ductilidade, e o ganho de resistência provocado pelo aumento das camadas só é possível mediante o acréscimo acentuado de deformações. Outra contribuição da manta de PRFC é impedir uma ruína prematura da camisa após a deformação última do concreto convencional não confinado (2\%).

$\mathrm{O}$ aumento de ductilidade provocado pelo aumento das camadas de PRFC pode ser interessante para locais sujeitos a sismos.

Com relação ao acréscimo de armaduras adicionais, observou-se que o aumento de resistência provocado pelo confinamento dos estribos é muito pequeno frente à dificuldade da execução do reforço, ou seja, é muito mais vantajoso, mesmo com um acréscimo menor de resistência, o uso apenas da camisa de UHPFRC.

Avaliando-se a técnica mais vantajosa, ou seja, a que substitui o cobrimento do pilar original por apenas uma camisa de UHPFRC, verifica-se que ela é mais simples que as técnicas tradicionais.

Finalmente conclui-se que, a melhor técnica estudada foi a de substituição do cobrimento apenas pela camisa de UHPFRC, por proporcionar elevado ganho de resistência, ser de fácil execução, apresentar deformações axiais similares às do pilar original e não alterar as condições geométricas do pilar.

São apresentadas a seguir algumas sugestões para trabalhos futuros a fim de dar continuidade ao tema estudado.
a) Análise experimental de pilares medianamente esbeltos e esbeltos reforçados com UHPFRC;
b) Análise experimental de pilares reforçados com UHPFRC submetidos a flexo- compressão;
c) Análise experimental de pilares retangulares reforçados com UHPFRC;
d) Análise de pilares reforçados com UHPFRC e PRFC mediante a ação de sismos.
e) Análise do reforço de pilares com UHPFRC em situação de incêndio. 


\section{REFERÊNCIAS BIBLIOGRÁFICAS}

ABDOLLAHI, B. et al. SIFCON strengthening of concrete cylinders in comparison with conventional GFRP confinement method. Construction and Building Materials, v. 36, p. 765-778, nov. 2012.

AMERICAN CONCRETE INSTITUTE (Org.). Guide for the Design and Construction of Externally Bonded FRP Systems for Strengthening Concrete Structures: ACl 440.2R- 08. Farmington Hills, 2008.

ASSOCIACAO BRASILEIRA DE NORMAS TECNICAS - ABNT - Projeto de estruturas de concreto - procedimento. NBR 6118, Rio de Janeiro, 2014.

ASSOCIACAO BRASILEIRA DE NORMAS TECNICAS - ABNT - Materiais metálicos - Ensaio de Tração Parte 1: Método de ensaio à temperatura ambiente. NBR 6892-1, Rio de Janeiro, 2013.

BRÜHWILER, Eugen; DENARIÉ, Emmanuel. Rehabilitation and Strengthening of Concrete Structures Using Ultra-High Performance Fibre Reinforced Concrete. Structural Engineering International, S. L., v. 23, n. 4, p.450-457, nov. 2013.

CARRAZEDO, Ricardo. Mecanismos De Confinamento e Suas Implicações no Reforço de Pilares de Concreto por Encamisamento com Compósito de Fibras de Carbono. 2002. 208 p. Dissertação (Mestrado) - Escola de Engenharia de São Carlos-universidade de São Paulo, São Carlos, SP, 2002.

CARRAZEDO, Ricardo. Mecanismos de confinamento em pilares de concreto encamisados com polímeros reforçados com fibras submetidos à flexocompressão. 2005. 267 p. Tese (Doutorado) - Escola de Engenharia de São Carlos - Universidade de São Paulo, São Carlos, SP, 2005.

FÉDERATION INTERNATIONALE DU BETÓN. FIB (Org.). Model Code 2010 - final draft, vol. 1, Bulletin 65, and vol. 2, Bulletin 66, Lausanne, Switzerland, 2012.

FÉDERATION INTERNATIONALE DU BETÓN. FIB (Org.). Externally bonded FRP reinforcement for RC structures: Bulletin 14. [S. L.], 2001.

DUCTAL. Structural Applications. Disponível em: <http://www.ductal.com/wps/portal/ductal/2-Structural>. Acesso em: 17 out. 2014.

EMPELMANN, M.; TEUTSH, M.; STEVEN, G. Improvement of the Post Fracture Behaviour of UHPC by Fibres. Second International Symposium on Ultra High Performance Concrete. Anais, 2008.

GRAYBEAL, Benjamin A.. Compressive Behavior of Ultra-High-Performance FiberReinforced Concrete. ACI Materials Journal, [s. L.], v. 104, n. 2, p.146-152, mar. 2007 
GUO, Y. H.; WANG, Z. Q. Research on Constitutive Law of UHPFRC Used in Numerical Simulation. Advanced Materials Research, v. 368-373, p. 1547-1550, out. 2011

HABEL, K.; GAUVREAU, P. Response of ultra-high performance fiber reinforced concrete (UHPFRC) to impact and static loading. Cement and Concrete Composites, v. 30, n. 10, p. 938-946, nov. 2008.

HASSAN, A. M. T.; JONES, S. W.; MAHMUD, G. H. Experimental test methods to determine the uniaxial tensile and compressive behaviour of ultra high performance fibre reinforced concrete (UHPFRC). Construction and Building Materials, v. 37, p. 874-882, dez. 2012.

HELENE, P. Manual de reparo, proteção e reforço de estruturas de concreto. São Paulo, 2003.

KANG, S.-T.; LEE, Y.; PARK, Y.-D.; KIM, J.-K. Tensile fracture properties of an Ultra High Performance Fiber Reinforced Concrete (UHPFRC) with steel fiber. Composite Structures, v. 92, n. 1, p. 61-71, jan. 2010.

LAM, L.; TENG, J. G. Design-oriented stress-strain model for FRP-confined concrete. Construction and Building Materials, v. 17, n. 67, p. 471-489, 1 fev. 2003.

MÁCA, P.; SOVJÁK, R.; VAVŘINÍK, T. Experimental Investigation of Mechanical Properties of UHPFRC. Procedia Engineering, v. 65, p. 14-19, jan. 2013.

MACHADO, A. P. Manual de reforço das estruturas de concreto armado com fibras de carbono. São Paulo: Viapol, 2010.

MAHMUD, G. H.; YANG, Z.; HASSAN, A. M. T. Experimental and numerical studies of size effects of Ultra High Performance Steel Fibre Reinforced Concrete (UHPFRC) beams. Construction and Building Materials, v. 48, p. 1027-1034, nov. 2013.

MAKITA, T.; BRÜHWILER, E. Tensile fatigue behaviour of Ultra-High Performance Fibre Reinforced Concrete combined with steel rebars (R-UHPFRC). International Journal of Fatigue, v. 59, p. 145-152, fev. 2014.

MEHTA, P. K.; MONTEIRO, P. J. M. Concreto: microestrutura, propriedades e materiais. 2a Edição. 2008.

NAAMAN, A. E. Toughness, ductility, surface energy and deflection-hardening FRC composites. Proceedings of the $\mathrm{JCl}$ international Workshop on Ductile Fiber Reinforced Cementitious Composites (DFRCC) - Application and Evaluation (DFRCC02). Anais. 2002

OLIVEIRA, D. S. de. Reforço de pilares de concreto armado de seção transversal retangular mobilizando efeitos de confinamento. 2017. 184 p. Tese (Doutorado) Escola de Engenharia de São Carlos - Universidade de São Paulo, São Carlos, SP, 2017. 
OZBAKKALOGLU, T.; LIM, J. C.; VINCENT, T. FRP-confined concrete in circular sections: Review and assessment of stress-strain models. Engineering Structures, v. 49, p. $1068-1088$, abr. 2013.

PARVIN, A.; BRIGHTON, D. FRP Composites Strengthening of Concrete Columns under Various Loading Conditions. Polymers, v. 6, n. 4, p. 1040-1056, 3 abr. 2014.

RIBEIRO, P. D. T. P. A Lenda do Reforço à Compressão de Pilares de Concreto Armado por encamisamento com Elementos Compósitos. Engenharia Estudo e Pesquisa, v. 10, n. 1, p. 46-53, 2010.

SAMAAN, M.; MIRMIRAN, A.; SHAHAWY, M. Model of concrete confined by fiber composites. Journal Structural Engineering. v. 124, n. 9, p. 1025-1031, 1998.

SHI, C. et al. A review on ultra high performance concrete : Part I. Raw materials and mixture design. CONSTRUCTION \& BUILDING MATERIALS, v. 101, n. November, p. 741-751, 2015.

SOBUZ, H. R. et al. Manufacturing ultra-high performance concrete utilising conventional materials and production methods. Construction and Building Materials, v. 111, p. 251-261, 2016.

SOUZA, V. C. M. DE; RIPPER, T. Patologia, recuperação e reforço de estruturas de concreto. [s.l: s.n.].

SUDANO, Alexandre Luis. Influência na forma da seção transversal no confinamento de pilares de concreto armado encamisados com PRFC (polímero reforçado com fibra de carbono). 2005. 147 p. Dissertação (Mestrado) - Curso de Engenharia de Estruturas, Departamento de Departamento de Estruturas, Universidade de São Paulo, São Carlos, 2005.

SUDANO, Alexandre Luis. Desenvolvimento de estratégias híbridas de reforço de pilares de concreto armado por encamisamento com compósitos de alto desempenho. 2010. 250 p. Tese (Doutorado) - Curso de Engenharia de Estruturas, Departamento de Departamento de Estruturas, Universidade de São Paulo, São Carlos, 2010.

TAKEUTI, A. R. Reforço de pilares de concreto armado por meio de encamisamento com concreto de alto desempenho. 1999. Dissertação (Mestrado) - Curso de Engenharia de Estruturas, Departamento de Departamento de Estruturas, Universidade de São Paulo, São Carlos, 1999.

TAKEUTI, A. R. Comportamento resistente imediato e ao longo do tempo de pilares reforçados por meio de encamisamento com concreto de alto desempenho. 2003. 266 p. Tese (Doutorado) - Curso de Engenharia de Estruturas, Departamento de Departamento de Estruturas, Universidade de São Paulo, São Carlos, 2003.

TAMUZS, V. et al. Behavior of concrete cylinders confined by a carbon composite. Mechanics of Composite Materials, v. 42, n. 4, p. 303-314, 2006. 
TAYEH, B. A. et al. Utilization of ultra-high performance fibre concrete (UHPFC) for rehabilitation a review. Procedia Engineering, v. 54, p. 525-538, jan. 2013.

TAYEH, B. A.; ABU BAKAR, B. H.; MEGAT JOHARI, M. A. Characterization of the interfacial bond between old concrete substrate and ultra high performance fiber concrete repair composite. Materials and Structures, v. 46, n. 5, p. 743-753, 5 out. 2012.

WANG, W. et al. Durability of an Ultra High Performance Fiber Reinforced Concrete (UHPFRC) under progressive aging. Cement and Concrete Research, v. 55, p. 113, jan. 2014.

WILLE, K.; EL-TAWIL, S.; NAAMAN, A. E. Cement \& Concrete Composites Properties of strain hardening ultra high performance fiber reinforced concrete (UHP-FRC) under direct tensile loading. Cement and Concrete Composites, v. 48, p. 53-66, 2014.

ZOHREVAND, Pedram; MIRMIRAN, Amir. Stress-Strain Model of Ultrahigh Performance Concrete Confined by Fiber-Reinforced Polymers. Journal of Materials in Civil Engineering, S. L., v. 25, n. 12, p.1822-1829, dez. 2013. 